\title{
FAK AND PYK2 ARE SPECIFICALLY ASSOCIATED WITH THE ACTIVATED PHAGOCYTIC RECEPTOR COMPLEXES FROM HUMAN U937 CELLS
}

\author{
by \\ Marwan G. AbidAlthagafi \\ B.Sc., University of Umm Al-Qura, 2008

\begin{abstract}
A thesis
presented to Ryerson University

in partial fulfillment of the

requirement for the degree of

Master of Science

in the program of Molecular Science
\end{abstract}

Toronto, Ontario, Canada, 2014

(C) Marwan G. AbidAlthagafi, 2014 


\section{AUTHORS'S DECLARATION}

I hereby declare that I am the sole author of this thesis.

I authorize Ryerson University to lend this thesis to other institutions or individuals for the purpose of scholarly research.

I further authorize Ryerson University to reproduce this thesis by photocopying or by

other means, in total or in part, at the request of other institutions or individuals for the purpose of scholarly research. 


\title{
ABSTRACT
}

\section{THE PRESENCE OF PROTEIN TYROSINE KINASES SPECIFICALLY ASSOCIATED WITH THE ACTIVATED PHAGOCYTIC RECEPTOR COMPLEXES FROM HUMAN U937}

\author{
Marwan G. Abid Althagafi \\ Master of Science, Molecular Science, Ryerson University 2014
}

The innate immune system is the first shield against foreign attack inside the human body, and it is usually carried out with phagocytosis. An essential macrophage cell surface protein is the $\mathrm{Fc}$ receptor which contributes to the engulfment of unknown antigens. One of the important members of $\mathrm{Fc}$ receptors is the gamma receptor that binds to the immunoglobulin G (IgG) ligand. Another key receptor in this study is the CD36 receptor, which plays a crucial role in the progression of atherosclerosis, the hardening of artieries, with its ligand oxidized low-density lipoprotein (OxLDL). In this report, protein tyrosine kinase enzymes have been detected in the involvement of receptor complexes with human U937 macrophages, specifically PTK2 and PTK2b genes. Protein tyrosine kinases were known to promote cell migration as a main player in intracellular signal transduction cascades in relation to extracellular stimuli. Cell surface proteins are essential for the immunization of various diseases; yet, the molecular machinery of surface receptors remains unclear. This research primarily examined the dynamic nature of protein tyrosine kinases in an ongoing investigation of macrophage cell surface receptors, particularly the role of $\mathrm{Fc} \gamma$ and CD36 receptors with their ligands $\operatorname{IgG}$ and oxLDL coated beads in phagocytosis. Our report demonstrates a novel role of PTK2 and PTK2b functions in relation to U937 CD36-mediated phagocytosis. The Phagocytic efficiency of U937 macrophages was analyzed using laser scanning confocal microscope after silencing the cells with siRNA followed by quantitative counting of phagocytosis. The PF drug FAK inhibitor was also introduced to compare the phagocytic efficiency of siRNA cells. 


\section{ACKNOWLEDGMENTS}

I highly acknowledge The Ministry of Higher Education in the Kingdom of Saudi Arabia through the Saudi Arabian Cultural Bureau (SACB) in Ottawa, Canada, for fully funding my project and my master's program at Ryerson University. I thank Dr. John G Marshall for giving me the opportunity to join the prestigious Molecular Science program at Ryerson University. And I am grateful to be under his supervision, support, and most of all giving me confidence throughout my master's - I will never forget all his valuable feedback in science and challenging life situations.

I thank my master's committee members Dr. Jeffrey Fillingham and Dr. Costin Antonescu for their continued support and guidance towards my master's thesis and the "Molecular Machines of the Cells" course. The most amazing gift I ever had was the excellent team I worked with in Marshall's lab. I thank Angelique Florentinus who always helped me to answer many critical questions regarding my experiments and especially with Mass Spectrometry troubleshooting. I would also like to thank my working lab members Wagday Samrgandi for his support, even after he left Canada, Pardis Pakshir, Jaimie Dufrense, Thanusi Thavarajah, Jeffery Howard and Peter Bowden for their continued help and support. Also I extend a special thank you to my friend Alejandro Saettone for his unconditional help and support in my project work.

I would like to give an endless thank you to my family for their remarkable support. My life and my existence indefinitely goes to my Mother Howayda Rezk for her prayers day and night for me to get through the hard times. A thank you of course my Father Ghazi Hassan AbidAlthagafi for his sincere and uncountable guidance, strength and encouragement for me to pursue my educational and life carrier. For that I could never return him such a favor. Also my deepest appreciation goes to my godfather Mohamed Sadek for his endless encouragement and patients for many hours whenever I asked a question to gain critical answers. In the end I would like to especially thank my brothers Tamer, Amer, Khaled and Rabea for their inspiration and support. 


\section{TABLE OF CONTENTS}

AUTHORS'S DECLARATION ................................................................................. II

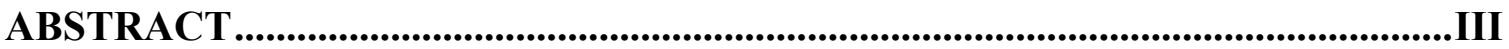

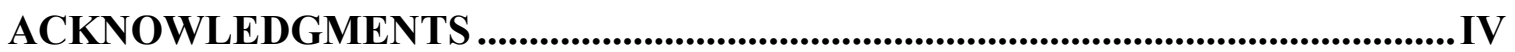

TABLE OF CONTENTS .......................................................................................... V

INDEX OF TABLES ….....................................................................................II

INDEX OF FIGURES .........................................................................................................

INDEX OF APPENDICES ....................................................................................................XI

LIST OF SELECTED ABBREVIATIONS .................................................................XIII

LIST OF SELECTED ABBREVIATIONS (CONTINUED)......................................XIV

1. INTRODUCTION ......................................................................................................... 1

1.1. Focal Adhesion Kinases................................................................................... 1

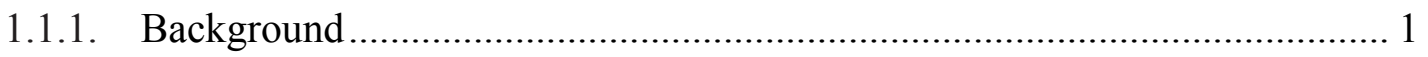

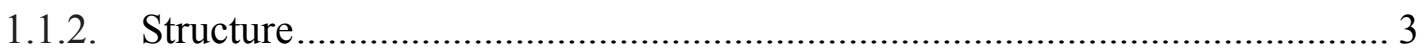

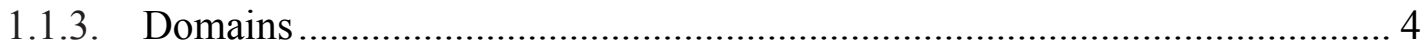

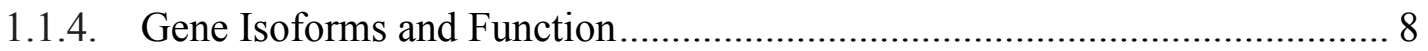

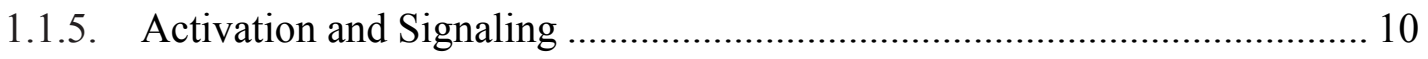

1.2. Atherosclerosis and Innate Immune Response ……………………………....... 14

1.3. Oxidized Low Density Lipoproteins.............................................................. 15

1.4. Macrophage Scavenger CD36 receptor ......................................................... 18

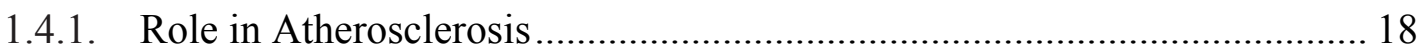

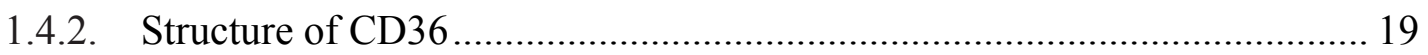

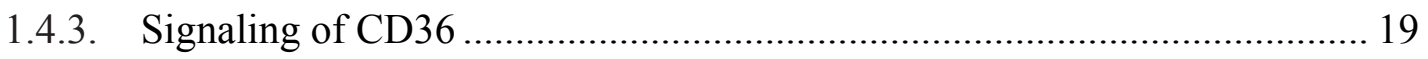

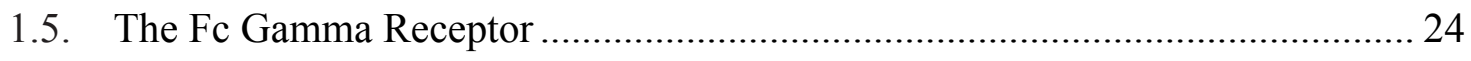


2. RATIONAL AND CENTRAL HYPOTHESIS ............................................ 28

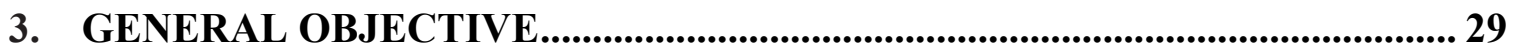

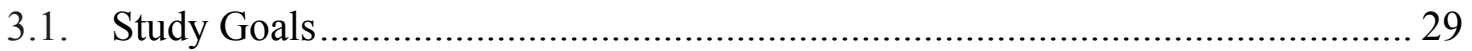

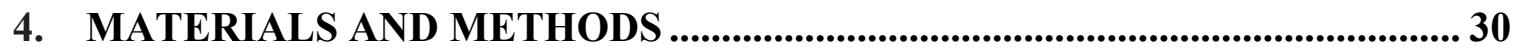

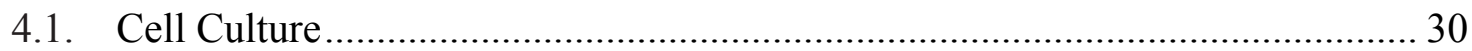

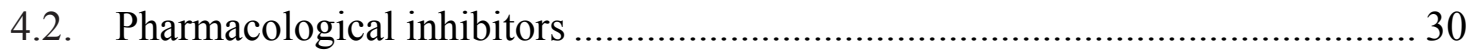

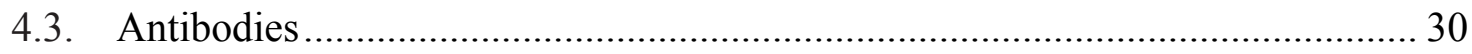

4.4. Oxidized Low Density Lipoprotein Preparation........................................... 30

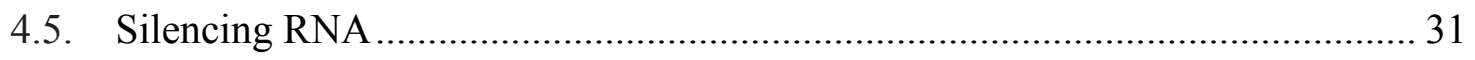

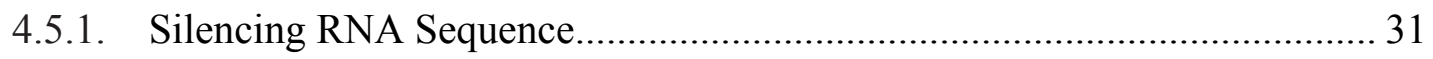

4.6. SEQUEST Association of Proteins Specific for Fc and CD36 Ligands............ 32

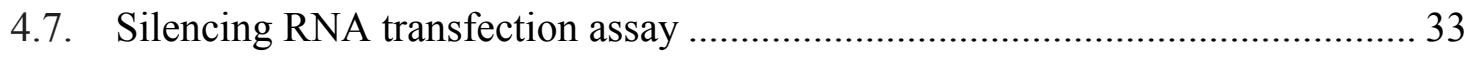

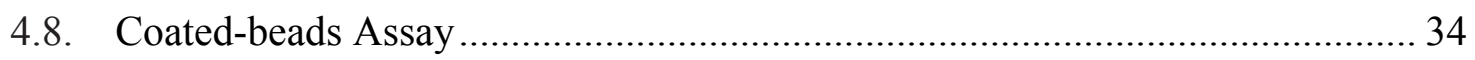

4.8.1. Ligand Coated-beads Preparation ........................................................ 34

4.8.2. Coated-beads Internalization Assay................................................ 34

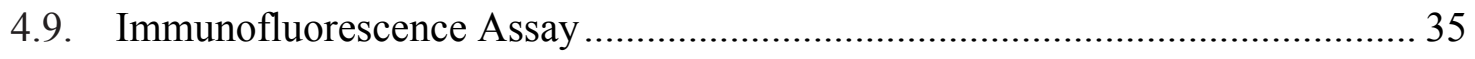

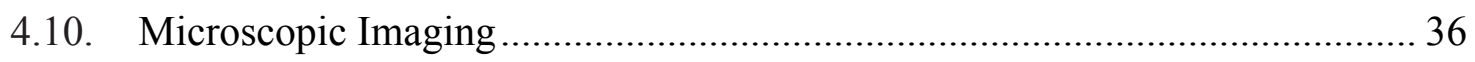

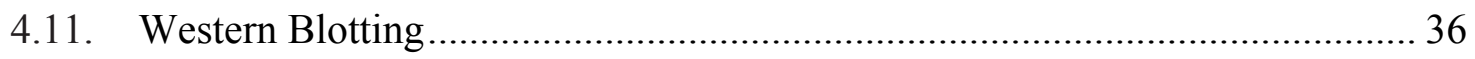

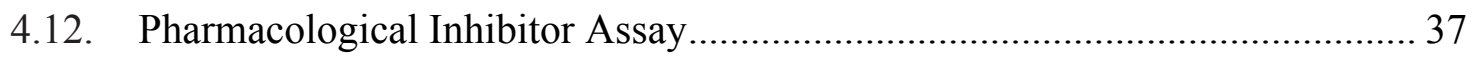

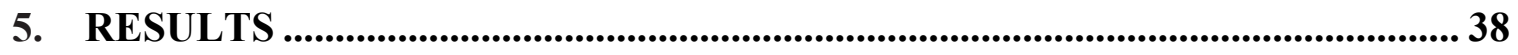

5.1. Mass Spectrometry Protein Tyrosine Kinases Detection ................................ 38

5.2. Phagocytosis Efficiency Assays in silenced RNA U937 cells ........................ 40

5.2.1. Beads Internalization in RPMI (10\%FBS) Media ................................... 40

5.2.2. Beads Internalization in RPMI Serum Free Media.................................. 44

5.2.3. Beads Internalization in HEPES Buffer.............................................. 46 


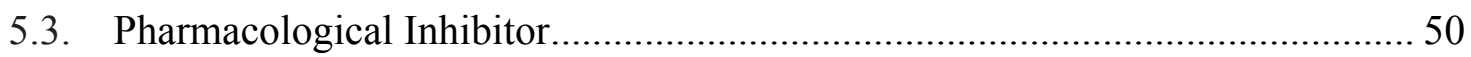

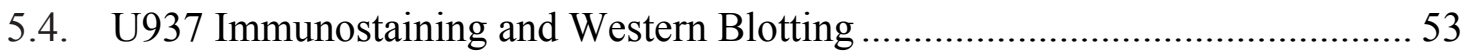

6. DISCUSSION ................................................................................................................... 58

6.1. Liquid Chromatography Mass Spectrometric Significance............................. 58

6.2. Role of Protein Tyrosine Kinases in U937 Phagocytosis ............................... 59

6.2.1. IgG-beads Association with PTKs in Phagocytosis ................................. 59

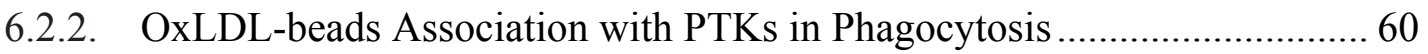

6.2.3. Immuno fluorescence/blotting and siRNA Knockdown Confirmation ..... 62

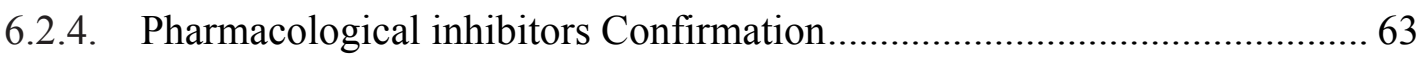

6.3. New information of Focal Adhesion Kinases Functions ................................... 64

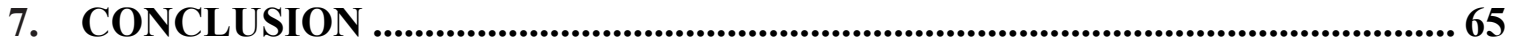

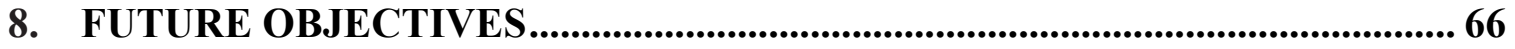

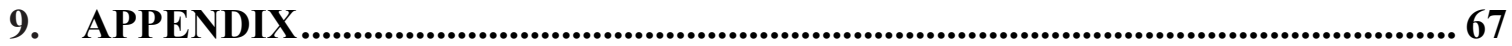

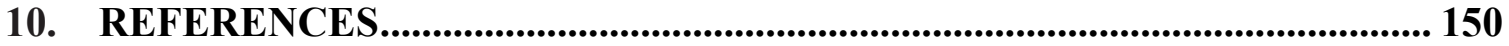




\section{INDEX OF TABLES}

Table 1. The protein tyrosine kinases peptide scores from mass spectrometry ........ 39

Table 2. Average internalized IgG beads in three independent experiments using

RPMI 10\% FBS supplemented media ........................................................................ 41

Table 3. Average internalized oxLDL beads in three independent experiments using

RPMI 10\% FBS supplemented media .................................................................... 43

Table 4. Average internalized oxLDL beads in three independent experiments using

serum free RPMI media. ........................................................................................ 46

Table 5. Average internalized oxLDL beads in three independent experiments using

HEPES buffer.

Table 6. Average internalized oxLDL beads in three independent experiments using

HEPES buffer with different concentrations of PF drug inhibitor......................... 51

Table 7. Average internalized IgG beads in two independent experiments using

RPMI 10\% FBS supplemented media with different concentrations of PF drug

inhibitor 


\section{INDEX OF FIGURES}

Figure 1. Focal adhesion kinases predicted protein domains site. (Obtained from Hall and Schaller, 2011).

Figure 2. Focal adhesion kinase $\mathrm{SH} 2$ and $\mathrm{SH} 3$ binding site. (Obtained from Hall and Schaller, 2011). 10

Figure 3. Focal adhesion kinase (FAK) domain schematic. (Obtained from Mitra et al., 2005). 12

Figure 4. Low-density lipoprotein structure. (Obtained from Badimón et al., 2009).

Figure 5. STRING 9.1 protein/protein interaction map of PTKs, Fc and scavenger receptors. Developed by Szklarczyk et al., 2011.

Figure 6. U937 average phagocytosis efficiency for IgG coated-beads internalization per cell in RPMI media supplemented with $10 \%$ FBS replicated three times. 40

Figure 7. U937 average phagocytosis efficiency for oxLDL coated-beads internalization per cell in RPMI media supplemented with 10\% FBS replicated three times. 42

Figure 8. U937 mean inside beads per cell for IgG and oxLDL beads. 44

Figure 9. U937 average phagocytosis efficiency of oxLDL-coated beads with RPMI serum free condition.

Figure 10. U937 average percentage of phagocytosis efficiency for oxLDL-coated beads in HEPES buffer.

Figure 11. U937 cells confocal microscope images of oxLDL-coated beads of silencing RNA targeted PTKs. 48

Figure 12. Comparison of U937 phagocytosis efficiency of RPMI (10\%FBS), RPMI serum free and HEPES buffer.

Figure 13. U937 cells treated PF 573228 (FAKs) drug inhibitor with oxLDL-coated beads in HEPES buffer. 50

Figure 14. U937 cells treated PF 573228 (FAKs) drug inhibitor with IgG-coated beads in HEPES buffer. 52

Figure 15. FAK and Pyk2 Immunoblotting of PMA-treated U937 cells. 53 
Figure 16. U937 cells immunofluorescence staining treated with oxLDL-coated beads, with monoclonal anti-Fak and polyclonal anti-Pyk2, permeablized with $0.1 \%$ Triton X-100. Row (A) FAK negative control and Pyk2 negative control. Row (B) FAK scrambled control and Pyk2 scrambled control. Row (C) FAK treated siRNA and Pyk2 treated siRNA. (C) FAK (Cy3 intensity variation). (D) Scrambled (No $2^{\text {ndry }}$ Cy5-conjugated Antibody)...................................................................................... 55 Figure 17. Regression analysis of Cy5 against Cy3 intensities for PTK2 (A) and PTK2b (B) siRNA-treated U937 cells. 


\section{INDEX OF APPENDICES}

Appendix A. Mass spectrometry PTKs detection peptides spectra. ........................... 67

Appendix B. Experimental design schematic including the goals in numbers.......... 69

Appendix C. STRING 9.1 protein/protein interaction of PTK2 and PTK2B

including Fc and CD36 receptors. Developed by Szklarczyk et al., 2011................. 70

Appendix D. SAS 9.3 program ANOVA analysis of the phagocytosis efficiency for

IgG beads first replicate in RPMI 10\%FBS media.

Appendix E. SAS 9.3 program ANOVA analysis of the phagocytosis efficiency for

IgG beads second replicate in RPMI 10\%FBS media............................................ 75

Appendix F. SAS 9.3 program ANOVA analysis of the phagocytosis efficiency for IgG beads third replicate in RPMI 10\%FBS media................................................... 79

Appendix G. SAS 9.3 program ANOVA analysis of the phagocytosis efficiency for oxLDL beads first replicate in RPMI 10\%FBS media.

Appendix H. SAS 9.3 program ANOVA analysis of the phagocytosis efficiency for oxLDL beads second replicate in RPMI 10\%FBS media.

Appendix I. SAS 9.3 program ANOVA analysis of the phagocytosis efficiency for oxLDL beads third replicate in RPMI 10\%FBS media.

Appendix J. SAS 9.3 program ANOVA analysis of the phagocytosis efficiency for oxLDL beads first replicate in RPMI serum free media. 94 Appendix K. SAS 9.3 program ANOVA analysis of the phagocytosis efficiency for oxLDL beads second replicate in RPMI serum free media.

Appendix L. SAS 9.3 program ANOVA analysis of the phagocytosis efficiency for oxLDL beads third replicate in RPMI serum free media.

Appendix M. SAS 9.3 program ANOVA analysis of the phagocytosis efficiency for oxLDL beads first replicate in HEPES buffer. 106

Appendix N. SAS 9.3 program ANOVA analysis of the phagocytosis efficiency for oxLDL beads second replicate in HEPES buffer.

Appendix O. SAS 9.3 program ANOVA analysis of the phagocytosis efficiency for oxLDL beads third replicate in HEPES buffer. 
Appendix P. SAS 9.3 program ANOVA analysis of PF 573228 treated cell by the phagocytosis efficiency for oxLDL beads first replicate in HEPES buffer.

Appendix Q. SAS 9.3 program ANOVA analysis of PF 573228 treated cell by the phagocytosis efficiency for oxLDL beads second replicate in HEPES buffer.

Appendix R. SAS 9.3 program ANOVA analysis of PF 573228 treated cell by the phagocytosis efficiency for oxLDL beads third replicate in HEPES buffer..... 126 Appendix S. SAS 9.3 program ANOVA analysis of PF 573228 treated cell by the phagocytosis efficiency for IgG beads first replicate in RPMI 10\% FBS media.... 130 Appendix T. SAS 9.3 program ANOVA analysis of PF 573228 treated cell by the phagocytosis efficiency for IgG beads second replicate in RPMI 10\% FBS media.134 Appendix U. SAS 9.3 program ANOVA analysis of PTK2 immunofluorescence Cy5 intensity of cells treated with oxLDL beads in HEPES buffer. 138 Appendix V.SAS 9.3 program regression analysis of PTK2 immunofluorescence Cy5 intensity verses Cy3 intensity.

Appendix W. SAS 9.3 program ANOVA analysis of PTK2B immunofluorescence Cy5 intensity of cells treated with oxLDL in HEPES buffer. Appendix X. SAS 9.3 program regression analysis of PTK2B immunofluorescence $\mathrm{Cy} 5$ intensity verses $\mathrm{Cy} 3$ intensity 147 


\section{LIST OF SELECTED ABBREVIATIONS}

ATP

ASAP1

ApoB100

CD36

$\mathrm{Cy}$

ESI

Erk

FAK

FAT

FBS

$\mathrm{Fc} \gamma \mathrm{R}$

FRNK

GSK3

Grb2

GRAF

Hef1

HEPES

$\operatorname{IgG}$

ITAM

Jak

Jnk

LARC

LOX-1

Lyn

LC

MAPK

MARCO

MS
Adenosine Tri-Phosphate

Arf-GAP with SH3 domain, ANK repeat and PH domain-containing protein 1

apolipoprotien B100

cluster of differentiation 36

cyanine

electrospray ionization

extracellular signal-related protein kinase

focal adhesion kinase

focal adhesion targeting domain

fetal bovine serum

fragment crystallizable $\gamma$ receptor

FAK-related nonkinase

glycogen synthase kinase 3

growth factor receptor bound protein 2

GTPase regulator associated with focal adhesion kinase haemagglutinin-esterase fusion glycoprotein

$\mathrm{N}$-2-hydroxyethylpiperazine-N-2-ethanesulfonic acid

immunoglobulin $\mathrm{G}$

immunoreceptor tyrosine-based activation motif

janus kinases

c-Jun N-terminal protein kinase

live-cell affinity receptor chromatography

lectin-type oxidized low-density lipoprotein receptor 1

V-yes-1 Yamaguchi sarcoma viral related oncogene homolog

liquid chromatography

mitogen activated protein kinase

macrophage receptor with collagenous structure

mass spectrometry 


\section{LIST OF SELECTED ABBREVIATIONS (CONTINUED)}

$\begin{array}{ll}\text { NADPH } & \text { nicotinamide adenine dinucleotide phosphate } \\ \text { NCBI } & \text { national center for biotechnology information } \\ \text { oxLDL } & \text { oxidized low-density lipoprotein } \\ \text { p130Cas } & \text { Crk-associated substrate p130 } \\ \text { PBS } & \text { phosphate buffered saline } \\ \text { PI3K } & \text { phosphoinositide 3-kinase } \\ \text { PKC } & \text { protein kinase C } \\ \text { PLC } & \text { phospholipase C } \\ \text { PLD } & \text { phospholipase D } \\ \text { PMA } & \text { phorbol 12-myristate 13-acetate } \\ \text { Pyk } & \text { proline-rich tyrosine kinase } \\ \text { PDGF } & \text { platelet-derived growth factor } \\ \text { PSGAP } & \text { pleckstrin homology and Src homology } 3 \text { domain containing } \\ \text { PH } & \text { rhoGAP protein } \\ \text { PTB } & \text { pleckstrin homology domain } \\ \text { SRA } & \text { phosphotyrosine binding domain } \\ \text { STAT } & \text { scavenger receptor A } \\ \text { Th1 } & \text { signal transducer and activator of transcription } \\ \text { Th2 } & \text { T helper cell 1 } \\ \text { THP-1 } & \text { T helper cell 2 } \\ \text { Rho GEF } & \text { Human acute monocytic leukemia cell line } \\ \text { ROS } & \text { rho guanine nucleotide exchange factor } \\ \text { RPMI } & \text { reactive oxygen species } \\ \text { SH2 } & \text { roswell park memorial institute } \\ \text { SHP-1 } & \text { Src Homology } 2 \\ \text { SFK } & \text { Src homology region 2 domain-containing phosphatase-1 } \\ \text { Syk } & \text { Src family kinase } \\ & \text { spleen tyrosine kinase } \\ \text { PHe } & \end{array}$




\section{INTRODUCTION}

\subsection{Focal Adhesion Kinases}

\subsubsection{Background}

In atherosclerosis (accumulation of lipids in the arterial intima) few studies have associated protein tyrosine kinases (PTKs) with cardiovascular disease. Tyrosine kinases are enzymes that are related to the protein kinase family and play an important role in various cellular functions (cell adhesion, signaling, etc). PTKs are found at the focal contacts that originate around the cell periphery of intracellular spaces (Sleg et al., 1999). PTKs have four gene isoforms with only two genes known to have a full-length structure including: PTK2 (or FAK) and PTK2b (or Pyk2). Recent review studies that have provided structural information about FAK and Pyk2 offer important insights into the function and molecular pathways of regulation; however, the key structural question as to how lipids bind to FAK domains (FERM domain) and the mechanism(s) involved remain unresolved (Hall and Schaller, 2011). To date, the known associations between protein kinases and Fc (fragment crystallizable) gamma receptor (receptor for immunoglobulin G) (Jankowski et al., 2008) and/or CD36 (receptor for lipid particles) receptor involves phagocytosis processes in immune cells such as macrophages (unpublished data). However, the machinery of FAK and Pyk2 activation remains unclear.

In 1992 Focal Adhesion Kinases (FAKs) were first identified as a substrate for the $\mathrm{v}$-Src oncogene as a result of oncogene transformation in fibroblasts associated with cancer (e.g., breast carcinoma) and/or cancer metastatic spread in the human body (Schaller et al., 1992; Weiner et al., 1993). FAKs are found in the majority of cell types and tissues from mammalian species to lower eukaryotic organisms, and FAKs are regulated by extracellular stimuli (for example integrin signaling) 
(Schaller et al., 1992; Hanks et al., 1992; Palmer et al., 1999; Fox et al., 1999). The presence of FAKs is implicated in various physiological disorders such as cardiovascular diseases, cancer progression and metastasis, and FAK have an important role during embryonic development (Vadali et al., 2007; Golubovskaya et al., 2009; Hall and Schaller, 2011). FAK is responsible for the communication between cells by regulation of cell attachment to focal adhesion sites leading to the initiation of traction force for cell migration (Schaller, 2010; Zheng et al., 2009). The assembly and disassembly of focal adhesions have a strong relationship to FAK activation and deactivation in various extra-intra cellular functions as seen in cancer metastasis (Schaller, 2010; Zheng et al., 2009). It has been suggested that FAK localization plays an important role in major structural changes seen in various studies on live cells (Cai et al., 2008; Papusheva et al., 2009). Thus, FAK is a core regulator of diverse cellular tasks regarding: cell signaling, survival, cycle, gene transcription, proliferation, migration, cytoskeleton remodeling, and microtubule formation (Schaller, 2010; Hall and Schaller, 2011).

Focal adhesions originate at the peripheral part of the intracellular space and near the intracellular matrix-integrin junctions that link together extracellular signaling and cytoskeletal proteins at the time of cell migration, spreading and adhesion (Ridley and Hall, 1992; Parsons, 2003; Taylor et al., 2001; Richardson et al., 1997). FAK is phosphorylated to regulate cell migration and adhesion in response to haptotactic, chemotactic and durotactic stimuli (Schaller, 2010; Zheng et al., 2009). Extracellular matrix stimuli and growth factors (such as epidermal growth factor (EGF) receptor) are responsible for the activation of FAKs, causing rapid tyrosine phosphorylation of FAK (Parsons, 2003). FAK has been implicated with respect to the regulation of Rho-family GTPases; thus, was linked to focal contact defects and microtubule polarization disruption via the loss of FAK expression (Ren et al., 2000). Regarding cell motility, Rho-family GTPases act as on/off switch within cells which controls actin cytoskeletal structure formation and dissociation (Ren et al., 2000). 
Pyk2 activation, Pyk2 being the other known isoform of FAKs, requires increased cytosolic calcium concentrations and was seen to localize less frequently to focal adhesions in various types of cells (Avraham et al., 2000). It has been suggested that Pyk2 participate in the signaling cascades for recruiting macrophages (Watson et al., 2001). The absence of Pyk2 showed impaired development of Bcells demonstrating the importance of protein kinases in various cell signaling events in relation to cellular stimuli (Guinamard et al., 2000). In addition unclear participation of Pyk2 with janus family kinases and Pyk2 activation through raised levels of calcium remains under investigation (Avraham et al., 2000; Benbernou et al., 2000).

\subsubsection{Structure}

FAK is located on chromosome 8 in the band 24 , with a size of $125 \mathrm{kDa}$ (Fiedorek and Kay, 1995; Agochiya et al., 1999). FAK consists of three main domains that are arranged linearly. At the band 4.1 in the N-terminus, FAK contains the FERM domain (erythrocyte band 4.1, Ezrin, Radixin, Moesin) followed by the kinase domain. At the C-terminus, the FERM and the kinase domains are separated by an uncategorized three proline-rich region (PRR) and the focal adhesion targeting (FAT) domain in the lateral C- terminal side (Girault et al., 1999; Sun et al., 2002; Hall and Schaller, 2011; Arold et al., 2002; Lietha et al., 2007). The structural features of the FERM, kinase and FAT domains are linked by flexible regions containing low-specificity motifs that allow connection with ligands (Arold, 2011). Interestingly, Pyk2 is $46 \%$ identical to FAK and $65 \%$ similar at the protein level, with the same structural characteristics and domain organization as FAK (Hall and Schaller, 2011) (Fig. 1). Pyk2 is located on chromosome 8 in the band 21, with a size of $116 \mathrm{kDa}$ (Herzog et al., 1996; Inazawa et al., 1996). 


\subsubsection{Domains}

\subsubsection{FERM Domain}

In early studies, FAK had been suggested to localize in the nucleus, yet, the role of the FERM domain has been the one that rests in the nucleus assessed more recently by (Lim et al., 2008). Pyk2 shares a similar FERM domain structure with 40\% FAK related structure (Lev et al., 1999). Within the FERM domain, there are F1, F2 and F3 subdomains (Fig. 1). F1 subdomain consists of a five-strand $\beta$ sheet topped by an $\alpha$-helix, and are found to play a role in structural modifications triggering interactions with other proteins (Ceccarelli et al., 2006).

F2 structure is entirely $\alpha$-helical with an acyl-CoA-binding protein related core, and it was suggested to participate in the autoinhibition conformation (Ceccarelli et al., 2006). Additionally, F2 subdomain conveys a significant function in FAK regulation processes, and is located on the top part of the F2 domain. Also, the F2 domain consists of KAKTLRK motif that is essential for FAK activation via FERM recruitment after the incitation of cell adhesion and growth factors stimulation (Fig. 1) (Cai et al., 2008; Papusheva et al., 2009; Chen and Chen, 2006; Dunty et al., 2004). Moreover, F2 is important for interactions with other cytoplasmic/membrane located ligands (Lim et al., 2008). The KAKTLRK motif is a key binding site for phosphatidylinositol (such as $\mathrm{PIP}_{2}$ ), and with the help of bisphosphorylated MET (receptor tyrosine kinase), ultimately leads to FAK activation (Chen and Chen, 2006). 


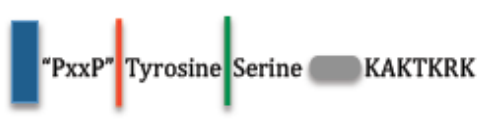

Figure 1. Focal adhesion kinases predicted protein domains site. (Obtained from Hall and Schaller, 2011).

In Figure 1, the kinase domain is localized between the $\mathrm{N}-\mathrm{C}$ terminal, focal adhesion targeting (FAT) domain is localized in the C-terminal, and the FERM (F1: Ezirn, F2: Radixin, F3: Moesin) domain is localized in the Nterminal. In the gray box the KAKTLRK sequence is located within the F2 domain top side. The blue indicated bands represent polyproline type II helical structure (PxxP motifs) (Hall and Schaller, 2011).

The F3 subdomain with its $\beta$ sandwich topped by the C-terminal $\alpha$-helix encompasses the pleckstrin homology (PH) domain containing a phospholipid-binding site and other domains such as an EVH1 (Ena/VASP homology) domain and a phosphotyrosine binding (PTB) domain (DiNitto and Lambright, 2006). In reports on cancer cells, p53 is known to interact with FAK directly in vitro and in vivo with FAK acting as a scaffold for p53 (Golubovskaya et al., 2008; Lim et al., 2008). In the case of Pyk2, a similar FERM domain shares a $12-15 \%$ sequence identity between FAK and other FAK family FERM domains (Girault et al., 1999). The autophosphorylation of Tyr397 is enhanced by a FERM/Kinase interaction, as well as the Src family kinases (SFKs) localization at focal contacts, growth factor receptor bound protein-7 Grb7, p85 (subunit of PI3K), p129 RasGAP, phospholipase C $\gamma$ (PLC $\gamma$ ), Shc adaptor protein (Fig. 3), and the suppressor of cytokine (SOCS) (Parsons, 2003; Schlaepfer et al., 2004; Hanks et al., 2003; Schaller, 2001). The FERM and kinase domain have a linker positioned in the center between both domains and contains the Tyr397 (SH2 site) and PxxP motif (SH3 site), 
an essential binding site for SFKs (Fig. 1) (Thomas et al., 1998). On the other hand, the binding of SFKs is achieved by Pyk2 phosphorylation sites, similar to those in FAK, with Tyr402 (SH2 site) (Avraham et al., 2000).

The FERM domain seems to regulate interactions of FAK with tyrosine kinases like ETK, the epidermal growth factor (EGF) receptor, the plateletderived growth factor (PDGF) receptor and ezrin (Fig. 3) (Sieg et al., 2000; Chen et al., 2001; Poullet et al., 2001).

\subsubsection{Kinase Domain.}

In FAK, The N-terminal site of the kinase domain contains a single $\alpha$-helix and a five-stranded $\beta$ sheet. However, the kinase domain C-terminal lobe is mainly an $\alpha$-helix, considering the kinase domain has a bi-lobed structure (Lietha et al., 2007). At the kinase domain, Pyk 2 have $60 \%$ similarities with FAK in proline-rich regions positions, and the exact same tyrosine phosphorylation sites (Tyr402, Tyr579, Tyr580 and Tyr881) to those of FAK phosphorylation sites (Tyr397, Tyr576, Tyr577 and Tyr925) (Hayashi et al., 2002).

The kinase domain has three possible identified conditions: Firstly a completely activated kinase domain conformation with full phosphorylation of the stimulated loop attached to a nonhydrolysable ATP analog; secondly, an inactive conformation of the kinase domain with an unphosphorylated stimulated loop and thirdly, the autoinhibition conformation of the kinase domain with an unphosphorylated loop attached to the FERM domain (Lietha et al., 2007; Nowakowski et al., 2002).

It is known that the phosphorylation of the kinase domain can be deactivated by a FIP200 (FAK family interacting protein) and through FIP200 interaction with the kinase and the FERM domains FAK is deactivated (Abbi et al., 
2002). However, the deactivation pathway of FAK via FIP200 is still unclear (Abbi et al., 2002).

The FAK kinase domain C-terminal $\alpha$-helix is located in the same site in the inactive and active conformations leading to the conclusion that the $\mathrm{C}$ terminal $\alpha$-helix is not a regulatory mode for FAK in the case of C-helix dislocation. The unphosphorylated kinase contains a disulfide bond between Cys456 and Cys459 in the N-terminal lobe. However, Pyk2 has a similar kinase domain with the exceptions being (1) the lack of a cysteine disulfide bond (Han et al., 2009) and (2) Pyk2 has Cys459 and Cys463 residues (Nowakowski et al., 2002).

\subsubsection{FAT Domain}

The focal adhesion targeting domain (FAT) has different binding partners that could change the scaffolding function of protein tyrosine kinases leading to activation of FAT or vise versa. The SH2 and SH3 domains are constituents of growth factor receptor bound protein 2 (Grb2) (Schlaepfer et al., 1994) (Fig. 3). To allow Grb2 binding to the FAT domain, SFKs (e.g., Src and Fyn) phosphorylation of Tyr925 located in the FAK loop enables the Grb2 SH2 domain binding (Schlaepfer et al., 1994; Arold et al., 2002). Also, Pyk2 has a similar binding process to that of the SH2 domain which involves the phosphorylation of Tyr402 and Tyr881 by binding of Grb2 and Src (Avraham et al., 2000).

The Grb2 binding site exists in the initial $\alpha$-helix of the FAT domain and allows for conformational changes and phosphorylation of the FAT domain as

a result of the growth factor receptor binding (Schlaepfer et al., 1994). The mitogen-activated protein kinase (MAPK) and RAS signaling pathways could be initiated by FAK, Grb2 interaction (promoted by integrin receptors) and paxillin dislocation from the FAT binding site allows for FAK to move and 
perform other activation functions (Schlaepfer et al., 1994). Also, Pyk2 allows for binding of paxillin at the FAT C-terminal domain (Hayashi et al., 2002). Phosphorylation of FAK at Tyr925 stimulates the recruitment of Grb2 and the dynamin complex in addition to regulating RAS/MAPK cascades. Through FAK release from focal contacts, the dislocation of paxillin from the FAT domain could also enhance FAK localization in other sites to manage other functions (Katz et al., 2003). Thus, the FAT complex with FAK is needed for microtubules stripping from focal contacts (Ezratty et al., 2005).

The FAT domain is suggested to localize Pyk2 when FAK is detached by the facilitation of integrins (e.g., $\beta_{1}$ integrin), which shows a different binding role of Pyk2 and FAK (Klingbeil et al., 2001). On one hand, the FAT domain binds to the integrin-associated protein talin distinctively while on the other hand Pyk2 binds to gesolin (integrin-associated protein) (Zheng et al., 1998; Wang et al., 2003). Thus, Pyk2 can be stimulated by integrins through SFKs activation (Sieg et al., 1998; Lakkakorpi et al., 2003).

\subsubsection{Gene Isoforms and Function}

Focal adhesion kinases, known as FAKs or the gene name protein tyrosine kinase 2 (PTK2) and closely related protein tyrosine kinase Pyk2 (also known as protein tyrosine kinase $2 \mathrm{~b}$ (PTK2b)), are non-receptor tyrosine kinases that possess distinct properties in addition to sharing functional and structural features (Hanks et al., 1992; Hall et al., 2011). There are four known isoforms for FAK but only the complete structures for PTK2 and PTK2b have been identified. FAK and Pyk2 have a closely similar sequence but Pyk2 upregulation is more limited compared to FAK (Lev et al., 1995; Avraham et al., 1995). The expression of Pyk2 is increased in brain cells and decreased in lung, kidney, liver and spleen cells (Avraham et al., 1995; Lev et al., 1995; Sasaki et al., 1995). 
Protein tyrosine kinases play a vital role in the accumulation of signaling complexes, as scaffolding proteins and in transmitting cellular signals via subsequent downstream phosphorylation cascades (Sieg 1999; Sieg et al., 2000; Hall and Schaller, 2011). The stimulation of cytokine and growth factor receptors prompt FAK activation as well as integrin signaling (Sieg et al., 2000; Dunty et al., 2004; Hall and Schaller, 2011). The pathway of Pyk2 activation by calcium is unclear (Avraham et al., 2000). Similarly, Pyk2 is stimulated by cytokines and growth factors, under amplified cytosolic calcium concentrations in response to ligands like platelet-derived growth factor (PDGF) or vasopressin (activates PLC), leading to stimulation of Pyk2. Thus, PTKs are affected by extracellular stimuli (Lev et al., 1995).

FAK deficient mice showed impaired ventricular septation, heart chambers and aortic arch formation, while the development of the nervous system in Xenopus laevis was also impaired with FAK deficiency (Doherty et al., 2010; Hakim et al., 2007; Forrest et al., 2009; DiMichele et al., 2009). FAK deficiency also caused defects in cellular proliferation, survival and migration, cardiomyocytes migration (Ward et al., 2007), differentiation of osteogenic cells (Wei et al., 2009), and nephron tubulogenesis in kidney (Guinamard et al., 2000). On the other hand, $p y k 2^{-/-}$exhibit significantly different roles. In mouse $p y k 2^{-/-}$knockouts were observed with normal fertility with no malformation, yet, the animals had observed defects in the immune system (low B cells) and humoral immune response. Furthermore, defective macrophages and osteoclasts in mice $p y k 2^{-/-}$ knockouts have been observed (Guinamard et al., 2000).

$\mathrm{Yu}$ et al. (2005) found that mice are more susceptible to obesity and insulin resistance when lacking $p y k 2$. In vivo studies on macrophage cells with $p y k 2^{-/-}$ mice have defects with cell motility and polarization as well as decreased diffusion of overall inflammatory stimuli (Okigaki et al., 2003). 


\subsubsection{Activation and Signaling}

The Rho GTPases family is a major stimulator for actin cytoskeleton polymerization, spreading and cell adhesion (Ridley, 2011). The downstream signaling of Rho GTPases is achieved in the presence of FAK, vinculin and paxillin (focal adhesion proteins) (Fig. 3), with known members of the integrin family ( $\beta 1, \beta 3)$ localized at focal contacts (Ridley, 2011). The knockdown of $\beta 1$ and/or $\beta 3$ integrin impaired the focal adhesion assembly and cell spreading on the ligand fibronectin (Costa et al., 2013).

Phosphorylation of FAK occurs at various locations and, unlike other kinases (active when phosphorylated at the kinase domain), kinase activation can only account for a small portion of overall FAK functions (Schaller et al., 1994; Calalb et al., 1995; Arold et al., 2001). A major autophosphorylation site located at Tyr397 and found between the kinase and FERM domains has a significant scaffolding role for the SH2 domain in relation to SFKs stimulation (Fig. 2). The interactions between the SH2 and SH3 domains, PRI motifs and p- Tyr397 are mainly activated by SFKs (Arold et al., 2001; Schaller et al., 1994). In the case of Pyk2, a major phosphorylation site includes Tyr402 and Tyr881 which have similar SH2 and SH3 domain activation pathways (Avraham et al., 2000).

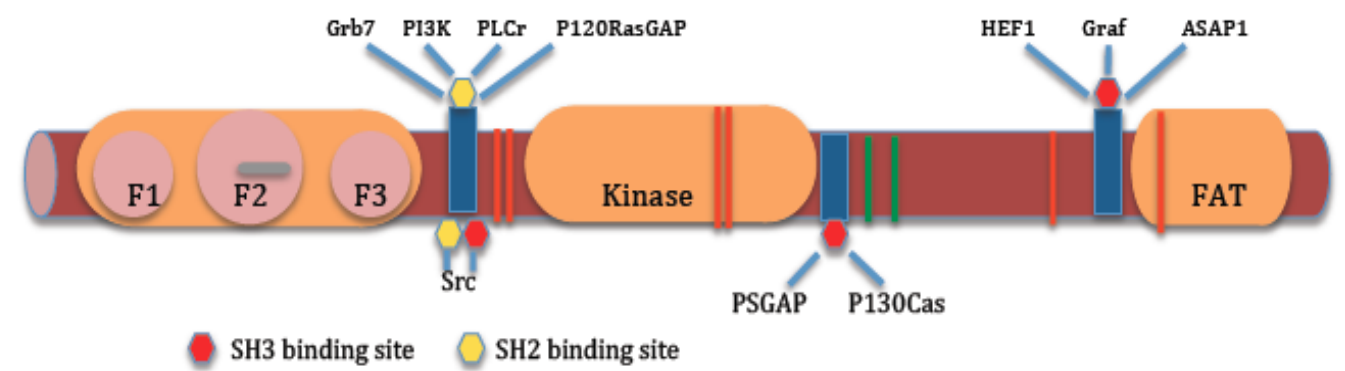

Figure 2. Focal adhesion kinase SH2 and SH3 binding site. (Obtained from Hall and Schaller, 2011). 
In figure 2, the position of proline-rich sites allows binding of $\mathrm{SH} 2$ and $\mathrm{SH} 3$ mediated scaffolding interactions with FAK. The yellow hexagons represent SH2 and the red hexagons represent $\mathrm{SH} 3$ activation factors which are recruited by SH2 and SH3 mediated binding.

The phosphorylation of serine sites occurs in Ser722 via PP1 phosphatase and glycogen synthase kinase 3 (GSK3) (Bianchi et al., 2005). Cyclin-dependent kinase 5 (Cdk5) is responsible for Ser732 phosphorylation (Xie and Tsai, 2004; Park et al., 2009). In addition, Ser722 and Ser 732 affect FAK catalytic activity by an undetermined pathway (Bianchi et al., 2005). Thus, there is a significant association of FAK serine phosphorylation in vivo, yet, the molecular machinery remains an open debate (Hall and Schaller, 2011).

FAK signaling and function in relation to cancer cell survival and motility have been succinctly reviewed (Zhao and Guan, 2009; Hanks et al., 2003). FAK phosphorylation sites were stimulated by SFKs, such as tyrosines 577, 576, 861, and 925 (Fig. 3); however, Pyk2 has identical FAK phosphorylation sites at the tyrosines 402, 579, 580, 881, and they were activated by SFKs (Calalb et al., 1995; Avraham et al., 2000). Both Tyr576 and Tyr577 are located in the kinase domain, noticeably in the activation site (Bianchi et al., 2005).

FAK-related nonkinase (FRNK) is located in the C-terminal in the noncatalytic domain of FAK and acts as a blocker for FAK by dislocating FAK from focal contacts and FRNK considered to be naturally occurring dominant-negative mutants (Richardson and Parsons, 1996; Gilmore and Romer, 1996). Accordingly, FRNK contains a proline-rich region at the C-terminal and also the FAT domain, and it is missing the FERM and kinase domains. As an important function, FRNK acts as a challenger to the focal adhesion site by pushing and suppressing away FAK binding seen in neonatal hearts (DiMichele et al., 2009; Gilmore and Romer, 1996). In the matter of the biological function and physiological regulation, it seems that FRNK has been extensively used to 
experimentally test for the role of FAK, and such a regulator was seen in heart growth. In addition, Pyk2 have similar FRNK mutants (DiMichele et al., 2009; Xiong et al., 1998).

In FAK, the processing of the $\mathrm{SH} 3$ domain-containing protein into a complex is accomplished by the scaffolding of proline-rich regions. By this mechanism, Src binding is granted via the activation of scaffolding protein partners like GRAF, GTPase activating proteins, ASAP1, Hef1 and p130cas, and PSGAP (Fig. 3) (Guan, 2010). In a recent study by Guan (2010), SH3 was extensively reviewed in regards to FAK function in downstream signaling and $\mathrm{SH} 3$ domain rests on proline-rich sites of FAK.

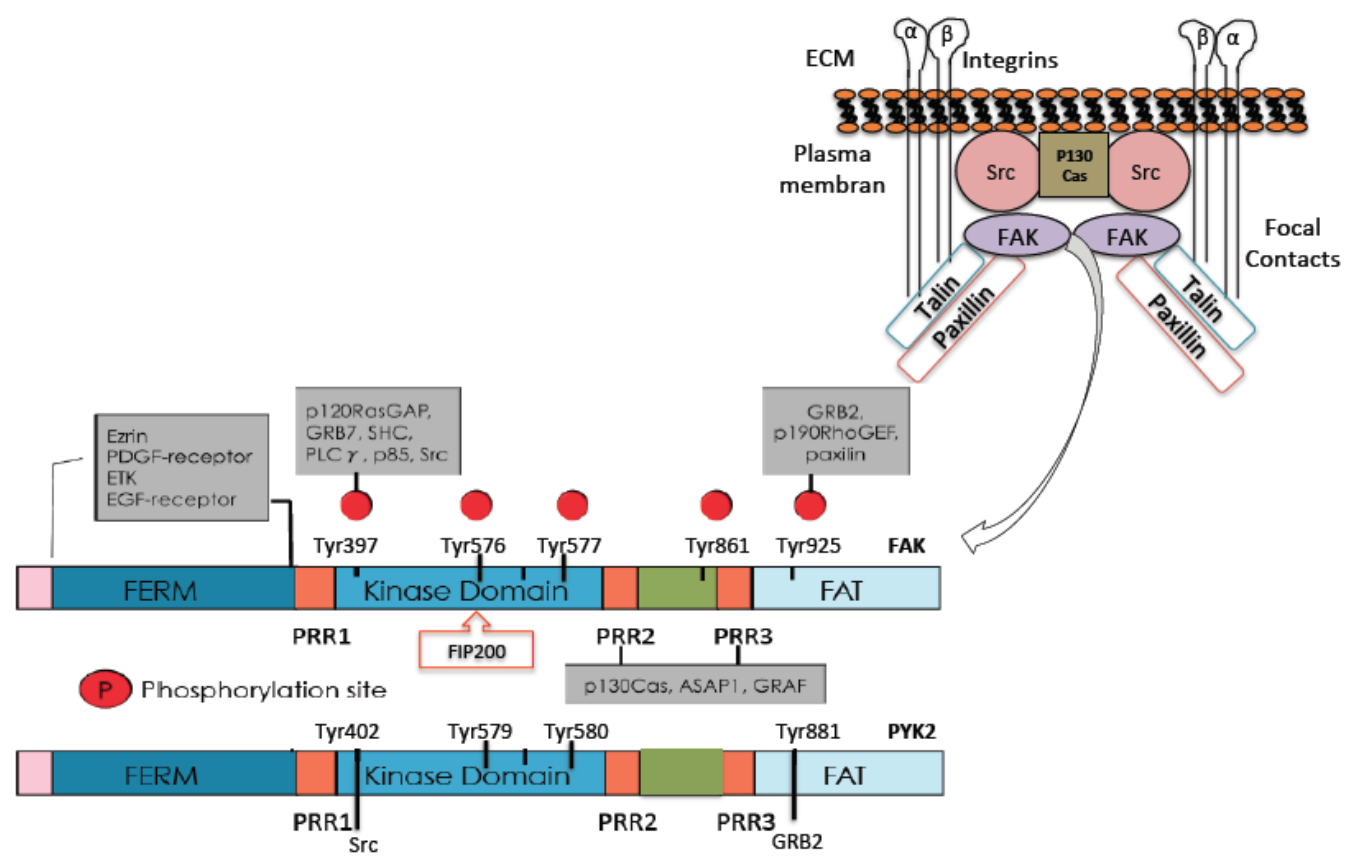

Figure 3. Focal adhesion kinase (FAK) domain schematic. (Obtained from Mitra et al., 2005).

In figure 3, the focal contacts show the integrins bound to cytoskeletal proteins like paxillin and talin recruiting FAK. The FERM domain allows interactions of FAK with the ETK, ezrin, the PDGF receptor and the EGF receptor. FAK contains three proline-rich regions (PRR), which bind to SH3 
domain-containing proteins such as the GTPase regulator associated with FAK (GRAF), p130Cas and the Arf-GTPase-activating protein ASAP1. The FAT domain links FAK to the activation of Rho GTPases by binding to p190 RhoGEF. There are several phosphorylation sites in FAK (e,g, Tyr397, 407, 576, 577, 861 and 925), and for Pyk2 (e.g., Tyr402, 579, 580, 881). Tyr397 phosphorylation creates an SH2 binding site for p120 RasGAP, the GRB7 receptor, the Shc adaptor protein, PLC $\gamma$, and p85 (a subunit of PI3K). Also, FAK Tyr925 and Ty397 phosphorylation as well as Tyr881 and Tyr402 phosphorylation for Pyk2 forms a binding site for Grb2 and Src respectively. For a maximal FAK catalytical activity phosphorylation of Tyr576 and Tyr577 in the kinase domain is required (Fig. 3) (Mitra et al., 2005). 


\subsection{Atherosclerosis and Innate Immune Response}

Although much research has been conducted to date, cardiovascular diseases are still the most common cause of heart disease in Western countries and becoming notable in underdeveloped countries (Alvarez-Llamas et al., 2008). A main player in the development of atherosclerosis disease is the immune system - specifically the innate immune response. In addition, the innate immune response can be the salvation of such a disease as well (Lundberg and Hansson, 2010).

The four main members of known lipoproteins synthesized in the liver are chylomicrons, low-density lipoproteins (LDL), very low-density lipoproteins (vLDL) and high-density lipoproteins (HDL), and these lipoproteins carry either dietary or endogenous lipids (Witztum and Steinberg, 1995). Chylomicrons are the first member of the lipoproteins that transport dietary lipids absorbed from the intestine to the liver. LDL (a phospholipid protein complex) carries cholesterol and triglycerides from the liver to peripheral tissues through the blood stream. A sufficient amount of plasma LDL can accumulate in the blood vessel arterial intima exposed to surface LDL receptor to be internalized by the immune cells (Witztum and Steinberg, 1995).

The atherogenic effect is a form of chronic inflammation caused by interactions with monocytes differentiated to macrophages, $\mathrm{T}$ cells, atrial wall receptors and lipoproteins such as LDLs. This inflammation can eventually lead to plaque formation. Plaque is mainly described as a buildup of lipids and immune compartments such as macrophages, mast cells and $\mathrm{T}$ cells, together with fibrous connective tissue containing collagen (Hansson et al., 2006).

The formation of plaque causes blockage of the arterial circulation and under high pressure may rupture and cause significant complications such as strokes and myocardial infarction (Navab et al., 1996; Epstein and Ross, 1999; Steinberg and Witztum, 1999). Plaque formation may also cause a narrowing of the lumen "stenosis" due to ischemic effects and to the neighboring tissue and necrotic cells 
surrounding the affected lesion (Hansson et al., 2006). In addition, rupturing of the plaque recruits coagulation factors and activates thrombosis. The thrombogenic cocktail (humoral coagulation and platelet aggregation) may give rise to thrombus formation leading to further complications such as myocardial and/or brain infarction (Hansson and Hermansson, 2011).

\subsection{Oxidized Low Density Lipoproteins}

Low-density lipoprotein has a hydrophilic complex of lipids and proteins, mostly apolipoprotien B100 (apoB100), along with a hydrophobic center holding cholesterol esters and triglycerides, with an LDL size of $\sim 20-25 \mathrm{~nm}$ (Fig. 4) (Badimón et al., 2009). Once LDL interacts with extracellular matrix components, lipoprotein modification starts by oxidation, nitration, glycation, and alkylation (Yamada et al., 1998, Zingg et al., 2000). Some of the LDL can escape across the subendothelial space through blood vessels where LDL is chemically modified by an oxidation reaction mediated by nitric oxide, myeloperoxide, free radicals and lipoxygenase (Leeuwenburgh et al., 1997; Hazen, 1997). In other cases, proteolytic and hydrolytic enzymes can also modify LDL thereby generating various forms of modified LDL (Oorni et al., 2000). This modification prevents LDL from being identified by LDL receptors which in turn attracts Class B scavenger CD36 to engulf oxidized LDL (oxLDL) via CD36-expressing macrophages (Yamada et al., 1998; Glass and Witztum, 2001).

OxLDL receptors can fall into one of the following classes: CD36, SR-AI and SRAII, and LOX-1 or CXCL16. Other receptors such as the low-density lipoprotein receptor related protein-1 (LRP-1) found in monocytes, platelets and smooth muscle cells (SMCs), have been shown to internalize LDL aggregates but not the native aggregates (Endemann et al., 1993; Ramprasad et al., 1995; Sawamura et al., 1997; Llorente-cortes et al., 2000). At the site of a lesion, vascular inflammation can be caused by oxLDL damage to the vascular smooth muscle cells and endothelial cells (Wiesner et al., 2010; Maskrey et al., 2011). The kinase activity of p21 (activated 
kinase 1) has been shown to relate to the penetrability of LDL via the endothelial wall and is thought to be mediated by Ser/Thr kinase Akt and protein kinase G (Orr et al., 2007; Fryer et al., 2006).

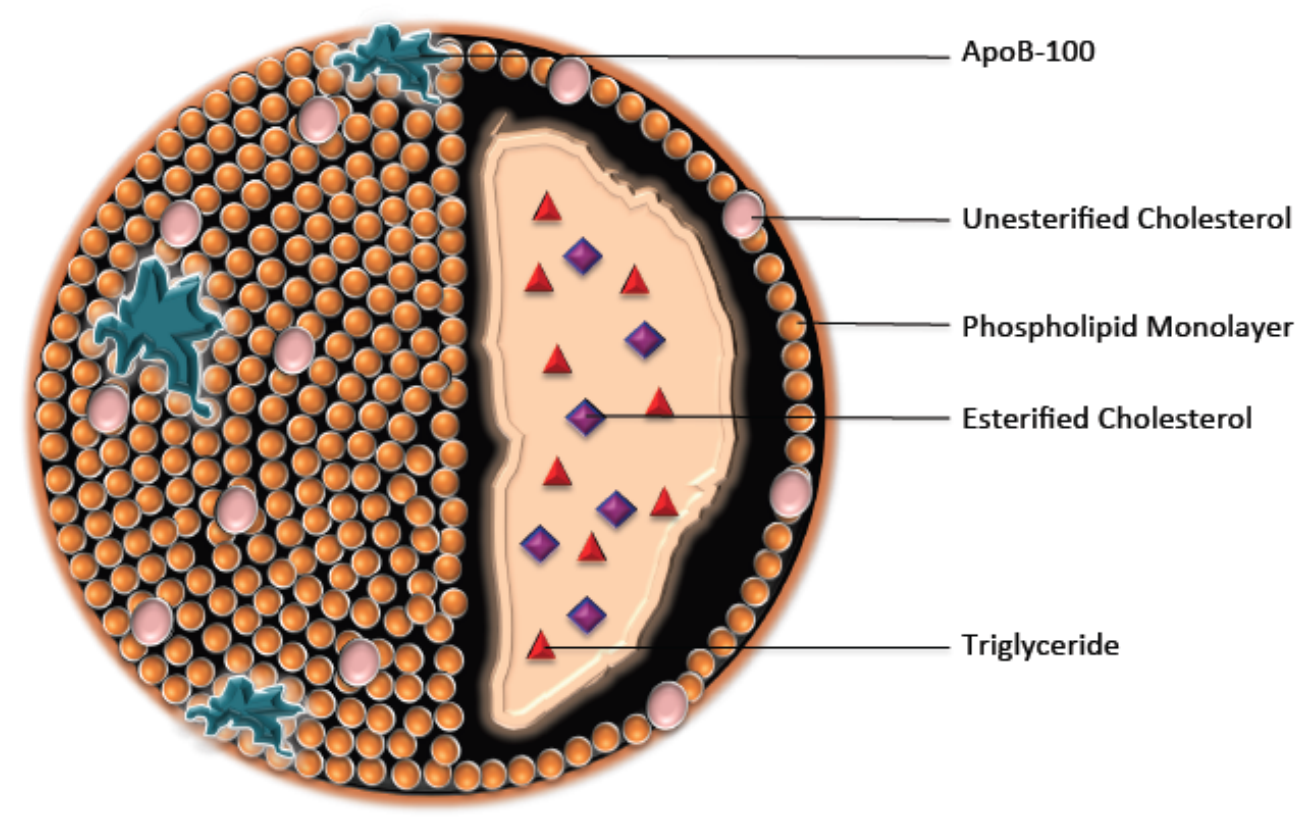

Figure 4. Low-density lipoprotein structure. (Obtained from Badimón et al., 2009).

Boullier et al. (2001) conducted an experiment between oxLDL phospholipids, the protein portion (apoB) and oxLDL itself, to observe the competition of those components with the CD36 binding site. Interestingly, high affinity binding was observed between the oxLDL phospholipids and apoB protein to the CD36 binding site compared to intact oxLDL (Boullier et al., 2001). oxLDL phospholipids and apoB protein could inhibit intact oxLDL binding to CD36 receptor by up to $80 \%$ (Terpstra et al., 1998).

A main cause for the development of atherosclerotic plaque is the formation of foam cells and fatty streaks stimulated by oxLDL positive chemotactic activity for monocytes differentiated to macrophages (Matsuura et al., 2008). More importantly, 
insufficient uptake of trapped oxLDL in the presence of foam cells can lead to apoptosis that causes the release of cytokines in addition to untreated oxLDL (Glass and Witztum, 2001).

The emission of reactive oxygen species (ROS) at lesion sites triggers additional oxidation of LDL and the release of cytokines stimulates T-cells such as Th1 and Th2 resulting in increased inflammation of the affected area(Hansson, 1997; Zingg et al., 2000; Glass and Witztum, 2001). A notable reduction of endothelial nitric oxide (NO) occurs in the presence of accumulated modified or native LDL due to stimulation of NO synthetase; however, NO degradation forms superoxide anions $\left(\mathrm{O}_{2}{ }^{-}\right)$radicals. This process can lead to the formation of cytotoxic peroxynitrite radicals through imbalanced $\mathrm{NO} /$ redox and $\mathrm{O}_{2}^{-}$formation that inhibits $\mathrm{NO}$ under the influence of protein nitrosylation (Pritchard et al., 1995; Liao et al., 1995; Vidal et al., 1998; Schmidt and Alp, 2007). The release of ROS can be associated with endothelial stress and dysfunction leading to the progression of the disease. 


\subsection{Macrophage Scavenger CD36 receptor}

\subsubsection{Role in Atherosclerosis}

To better understand the role of macrophages, researchers found a significant involvement of scavenger receptors, in regards to oxLDL removal and in mediating the cellular effect of oxidized lipoproteins. In addition, scavenger receptor function and gene expression in terms of their detailed regulatory mechanisms is still in intense debate. However, atherosclerosis dysregulatory mechanisms might be critically affected by the formation of foam cells. The knowledge of scavenger receptor function and gene expression could resolve and/or reduce the progression of atherosclerosis disease (Zingg et al., 2000).

Scavenger receptors have a multitude of functions due to their nonspecific binding of ligands. According to Yamada (1998), scavenger receptor genes can be divided into six classes as follows: (1) Class A encompasses MARCO and SRAI/II; (2) Class B involves SR-B1/CLA-1 (ligand for HDL) and CD36 (Fig. 5); (3) Class C in dSR-CI; (4) Class D involves CD68/Macrosialin; (5) Class E consists of LOX-1; (6) Class F includes SREC and other receptors such as SRPSOX, FEEL-1 and FEEL-2 found with macrophages and non-macrophges cells as well (Yamada et al., 1998; Platt et al., 1998; Krieger, 1997). In earlier reports, foam cell formation and lipid accumulation were mainly mediated by oxLDL receptors CD36 and SR-AI/II; however, CD68 and MARCO are less commonly involved in this role (Yoshida et al., 1998; Podrez et al., 2000).

The expression of CD36, SR-AI/II and SR-BI receptors are elevated at the site of the atherogenic effect and the receptors expressed for smooth muscles cells (SMCs) are LOX-1 and CD36 (Kataoka et al., 1999; Nakata et al., 1999; Gough et al., 1999; Ricciarelli et al., 2000). The oxLDL and acetylated LDL (acLDL) uptake is stimulated by lack ofdd SR-AI/II receptors with a 30\% and $80 \%$ decrease respectively, and thus, the oxLDL clearance is suggested by other 
scavenger receptors (Lougheed et al., 1997). Serum triacylglycerol, cholesterol and free fatty acids (non-esteried) have been shown to be elevated by a lacking of the CD36 receptor (Febbraio et al., 1999). The expression of scavenger receptors (triggered by modified lipoprotein) are initiated mainly in macrophages, kupffer cells (in the liver) and dendritic cells as specialized phagocytes. On the other hand, non-specialized phagocytes are known to be endothelial cells, neuronal cells, keratinocytes and aortic smooth muscle cells (Zingg et al., 2000).

\subsubsection{Structure of CD36}

The structure of CD36 is related to the class B scavenger receptor and was initially known as platelet glycoprotein III b/IV. It contains 472 amino acids and is $88 \mathrm{kDa}$ and highly $\mathrm{N}$-glycosylated. It falls in the band 11.2 of chromosome 7 with quite short sequences and has an extracellular domain with cytoplasmic and transmembrane domains. In other words, CD36 is highly hydrophilic with two hydrophobic domains in the plasma membrane and two cysteine residue sites for palmitoylation in each tail (Tao et al., 1996; Xiao Hua Yu, 2013). The CD36 receptor has a high attraction to oxLDL, binding between the amino acids 155 and 183 and other reported binding sites (amino acids 28-93 and/or 120-155) (Xiao Hua Yu 2013; Handberg et al., 2012). Studies have shown that some alleles of CD36 can be a risk factor for the initiation of atherosclerosis (591T allele) or can reduce the incidence of such a disease (573A allele) (Rac et al., 2012).

\subsubsection{Signaling of CD36}

In a study involving rats, CD36 showed a 16-carbon saturated fatty acid palmitate via thioester association to cysteine residues (Gao et al., 2012). However, alteration with the 14-carbon saturated fatty acid myristate seems to palmitate proteins at the cytoplasmic portion and not at the membrane site. In monocytes, increased CD36 expression is linked to palmitate via de novo ceramide production (Gao et al., 2012). Additionally, palmitoylated proteins are also 
engaged with the Src family nonreceptor protein tyrosine kinases, the $\alpha$-subunits of heterotrimeric $\mathrm{G}$ proteins and the $\mathrm{G}$ protein linked receptors (Sefton and Buss, 1987; Schlesinger et al., 1994; Milligan et al., 1995). Thus, attachment of palmitate to proteins could help in protein-protein and protein-lipid interactions and in protein-membrane interactions (Tao et al., 1996).

The highly elevated CD36 monocyte expression can be inhibited by atorvastatin treatment for patients who have developed with acute coronary disease (Piechota et al., 2012). The accumulation of macrophages (CD36) in the atrial intima exposed to fluid phase oxLDL is thought to activate FAK (Park et al., 2009). In a recent report, non-diabetic healthy individuals showed plasma CD36 associated with fatty liver, insulin resistance and atherosclerosis markers (Handberg et al., 2012).

In vivo studies involving mice have provided cases where atherosclerotic lesions with elevated aortic sinus due to foam cells were initiated by CD36 or SR-A lacking in apoE $^{--}$mice, even with noticeable peritoneal macrophage reduction (Moore et al., 2005). However, decreased CD36 expression in $\mathrm{apoE}^{--}$mice can be maintained with n-3 polyunsaturated fatty acids found in walnut and antioxidants (Nergiz-Unal et al., 2013). In other cases, postprandial hyperlipidemia can be reduced by anti-CD36 activity to avoid progression to atherosclerosis (Geloen et al., 2012). To reduce further damage to the arterial wall due to apoptotic formation in relation to oxLDL accumulation, antioxidants such as resveratrol and vitamins $\mathrm{C}$ and $\mathrm{E}$ have been suggested (Sugawa et al., 1997; Draczynska-Lusiak et al., 1998).

Various reports on clinical trials associate atherosclerosis progression with CD36deficient patients (Yuasa-Kawase et al., 2012) and thus more investigations are needed to determine the role of CD36/oxLDL. In human platelets, integrins like $\alpha \operatorname{IIb} \beta 3$ and $\alpha 6 \beta 1$ and tetraspanin CD9 are known to associate with macrophage CD36 (Thorne et al., 2000; Miao et al., 2001). 
Upregulation of CD36 involved with modified LDLs and peroxisome proliferator activated the receptor- $\gamma$ (PPAR- $\gamma$ ) ligand (Okazaki et al., 2008; Chiurchiu et al., 2011; Yang et al., 2011; Granados-Principal et al., 2012). Depending on different cell type expression, signaling of CD36 seems to recruit different kinases (Prieto et al., 1994). In particular, participation of focal adhesion kinases and Rho GEFs, which signals CD36 to perform degradation, active migration internalization and binding regulation (Prieto et al., 1994). CD36 can be reduced considerably with treatment by tumor necrosis factor $\alpha$ (TNF- $\alpha$ ) and interferon $\gamma$ combined (Chu et al., 2013). FAK activates actin polymerization and is thought to have an impact on macrophage aggregation and foam cell formation in the arterial intima (Park et al., 2009).

In other studies, cytoskeleton formation was stimulated by CD36 signaling to activate the phosphorylation cascade in order to polymerize actin via the scaffolding protein paxillin, FAK, Pyk2, Fyn and p130Cas (Stuart et al., 2007; Park et al., 2009) (Fig. 1). In earlier studies, upon exposure to oxLDL in the presence of CD36 in atrial intima, phosphorylation in the Vav family members of guanine nucleotide exchange factor is stimulated, and in the case with Vav deletion, then observed decline of foam cell formation and oxLDL uptake (Rahaman et al., 2006; Prieto et al., 1994). Additionally, lower CD36 expression can be achieved by inhibition of the c-Jun/activator protein (AP-1) using kaempferol inhibitor (Li et al., 2013). According to Bochem et al. (2013) an essential protein $\mathrm{ABCA1}$ (a member of $\mathrm{ABC}$ gene transporters superfamily) influences the reduction of foam cell formation in atherosclerosis since ABCA1 is a main HDL lipoprotein. Absence of proatherogenic lipoproteins can play a role since the lack of ABCA1 in mice along with SR-BI showed low levels of foam cell buildup and decreased cholesterol levels with no sign of atherogenic effect (Zhao et al., 2011). The involvement of CD36 in C32 melanoma cells is linked to tetraspanin CD51 and integrins like $\alpha 3 \beta 1$ and $\alpha 6 \beta 1$ (Thorne et al., 2000; Miao et al., 2001). 
Febbraio et al. (2000) found that CD36 apo E-null mice decreased the calculated surface area of aorta lesion by more than $76 \%$, and apo E-double null mice presented lower levels in weight gain, cholesterol and triacylglycerol ( $\mathrm{Su}$ et al., 2005). Studies on different species of rodents and rats were unsatisfactory regarding inhibited SR-BI (Demetz et al., 2012). The study by Demetz et al. (2012) implied that atherosclerotic rats treated with silencing RNA targeted to SR-BI resulted in a reduction in atherosclerotic lesions compared to control rodents.

Activation of FAK can be established through CD36 stimulation of free radical release via NADPH oxidase in the presence of oxLDL due to the down-regulation of SHP-1 (Park et al., 2009). Phospholipase C (PLC) is stimulated via tyrosine kinase phosphorylation because of its presence on the platelet lipid portion along with CD36; however, little evidence exists for a straight linkage concerning CD36 and PLC (Gousset et al., 2004). Another protein tyrosine kinase family like Lyn, Fyn and Yes might contribute in CD36 signaling activated by ligand binding in platelet (Huang et al., 1991).

Other known CD36 up regulators found with interleukin 4 (IL-4) and macrophage colony stimulating factor, and IL-4 are thought to activate 12/15-lipoxigenase expression and peroxisome proliferator-activated receptor gamma (PPAR $\gamma$ ) (Yesner et al., 1996; Li et al., 2009; Hashizume and Mihara, 2012; Zhao et al., 2012). The SR-BI expression can be stimulated by the transcriptional factor PPAR $\gamma$ in a PPAR $\gamma / \mathrm{LXR} \alpha$-dependent pathway via a resveratrol (Res) supplement (Yang et al., 2011). The engulfment of oxLDL can be enhanced by the elevated expression of CD36 via PPAR $\gamma$ combined with the retinoid X receptor (RXR) pathway (Rahaman et al., 2006). The down regulation of PPAR $\gamma$ can be triggered by mulberry leaf polyphenol extract (MLPE) leading to macrophage SR-A reduction (Yang et al., 2011). Thus, Res and MLPE can play a role in the regulation of oxLDL uptake through up and down CD36 expression. Decreased 
CD36 expression seen in THP-1 magrophages might be linked to the stimulation of TGF- $\beta_{1,2}$ that triggers mitogen-activated protein kinase (MAP kinases) and in turn deactivates PPAR- $\gamma$ (Han et al., 2000).

In Mycobacterium tuberculosis, phospholipase D (PLD) activation has been linked to the bacteria by their macrophage-mediated phagocytosis, regulated partially by CD36, and negative straight connection of PLD with CD36 (Kusner et al., 1996).

Increased production of hydrogen peroxide $\left(\mathrm{H}_{2} \mathrm{O}_{2}\right)$ in platelets and monocytes was seen in cases were activation of TNF- $\alpha$ occurred due to the stimulation of nuclear factor kappa-light-chain-enhancer of activated B cells (NF-кB) when monoclonal antibodies were cross-linked with CD36 (Aiken et al., 1990; Lipsky et al., 1997). OxLDL-coated surfaces were thought to influence macrophages releasing triple times the amount of $\mathrm{H}_{2} \mathrm{O}_{2}$ compared to uncoated oxLDL particles (Maxeiner et al., 1998).

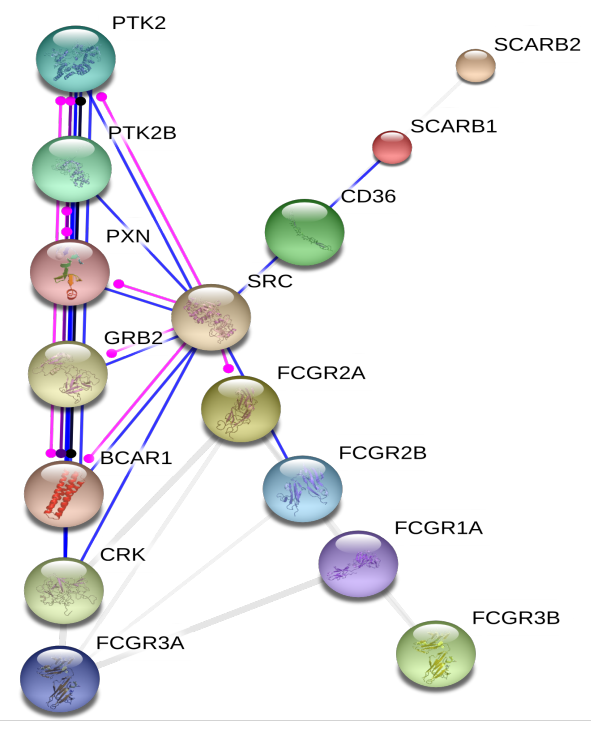

Figure 5. STRING 9.1 protein/protein interaction map of PTKs, Fe and scavenger receptors. Developed by Szklarczyk et al., 2011. 


\subsection{The Fc Gamma Receptor}

The immune system is stimulated by foreign antigens and is carried out by the innate and the adaptive immune divisions. Fe receptors adopt antibodies that are generated by innate immune cells and these cells are directed by an adaptive immune system that shows a tight connection between both parts of the immune system (Cheeseman, 2006). The $\mathrm{Fc}$ gamma receptor $(\mathrm{Fc} \gamma \mathrm{R})$ is usually activated by its ligand immunoglobulin $\mathrm{G}$ ( $\operatorname{IgG}$ ) coating foreign particles through binding to the fragment crystal $(\mathrm{Fc})$ region of $\mathrm{IgG}$ in a process known as phagocytosis (Jankowski et al., 2008; Cheeseman, 2006). The Fc $\gamma \mathrm{R}$ family is comprised of three main classes: (1) Fc $\gamma$ RI and Fc $\gamma$ RIII (activators); (2) Fc $\gamma$ RII (inhibitor) and (3) low affinity Fc $\gamma$ R subclasses such as Fc $\gamma$ RIIA, Fc $\gamma$ RIIB, Fc $\gamma$ RIIC, Fc $\gamma$ RIIIA, and Fc $\gamma$ RIIIB (Fig 5) (Van Lent et al., 2001; Takai, 2002).

Jankowski (2008) successfully captured activated Fc- $\gamma$ receptors directly from the surface of live cells using the IgG ligand. Human Fc $\gamma$ Rs are leukocytic surface glycoproteins with different affinities for IgG (Jankowski et al., 2008). The novel technique to isolate FcRs and their immune complexes is known as live-cell affinity receptor chromatography (LARC). Following the isolation of FcRs using mass spectrometry, protein peptides scores were correlated to proteins and captured from receptor complexes (Jankowski et al., 2008). FcyRs are incorporated in the phagocytosis of antigens coated with IgG, cytokine generation, removal of immune complexes and other immune tasks (Ravetch and Bolland, 2001).

Following IgG ligand binding, Fc $\gamma$ Rs are activated and phosphorylated at the tyrosine based stimulation motifs. Activation of $\mathrm{F} c \gamma$ Rs promotes phosphorylation and recruits proteins like Syk and Src family kinases, protein kinase C (PKC), Rho-family GTPases, diacylglycerol (DAG), phosphoinositide 3-kinase (PI3K), phosphatidylinositol 4,5-bisphosphate ( $\left.\mathrm{PIP}_{2}\right)$ and phosphatidylinositol $(3,4,5)$ trisphosphate ( $\left.\mathrm{PIP}_{3}\right)$ (Araki, 1996; Botelho et al., 2000; Larsen et al., 2002; Swanson 
and Hoppe, 2004; Nimmerjahn and Ravetch, 2006). Activation of the actin cytoskeleton is also implied with FcR binding to ligands and elements to the actin cytoskeleton remodeling are poorly illustrated (Kodama et al., 2004; Marshall et al., 2001). In human macrophages, FAK phosphorylation was suggested to link with Fc $\gamma$ receptor- mediated phagocytosis (Greenberg et al., 1994).

Upon Fc receptor activation, SFKs are phosphorylated on the immunoreceptor tyrosine-based activation motifs (ITAMs). ITAM motifs are suggested to phosphorylate two tyrosines which on the other hand stimulate Syk family kinases via the binding to two Src homology 2 (SH2) domains in Src and Syk (Underhill and Goodridge, 2007). ITAMs are also involved with FcyRIIA and FcyRIIIB (Hogarth, 2002). In humans FcyRIIIB expressed in neutrophils is anchored with glycosylphosphatidyl inositol (GPI). In murine, FcyRIIA is connected with a single polypeptide ITAM (Hogarth, 2002). Thus, at the genetic level human and murine ITAM motifs show a dissimilar relation to Fc receptors (Hogarth, 2002).

In earlier studies the formation of phagosome vacuoles was activated through the initiation of phosphorylation cascades that controls actin polymerization, membrane remodeling, ROS generation and other processes (Aderem and Underhill, 1999; Etienne-Manneville and Hall, 2002). In vitro studies show that ITAM motif-related FcyRs are also connected to the ROS released from neutrophils during activation (Underhill and Goodridge, 2007; Tsuboi et al., 2008). The stimulation of calciumdependent Pyk2 seems to depend on ITAMs through the regulation of the cytokine receptor Jak-Signal transducer and the activator of transcription (Jak-STAT) pathway with interferon (Ivashkiv, 2009; Dhodapkar et al., 2007). A recent study shows a strong relation of CD36 with FcyR when activated (Heit et al., 2013). Using an immunoprecipitation technique, Heit et al (2013) found that upon CD36 activation, Tetraspanins (CD9 and CD81) and integrins ( $\beta 1$ and $\beta 2)$ were involved and known to interact with ITAM motifs in relation to FcyR intercellular portion. In addition, Src and Syk activation was reported when CD36 was coupled to ITAMs leading to the internalization of CD36-related ligands (Heit et al., 2013). 
In mice macrophages FcyRIIA related ITAM activation had demonstrated a role in autoimmune diseases (such as arthritis) (Tsuboi et al., 2008). In contrast, in vivo FcyRIIIB showed no sign of toxicity other than a build-up in the affected tissue (Tsuboi et al., 2008). A report in murine macrophages observed no elevation of p125Fak phosphorylation in a phagocytic Fc $\gamma \mathrm{R}$-dependent manner (Pan et al., 1999).

Phagocytosis in human neutrophils was observed with the stimulation of kinases such as mitogen-activated protein kinase (MEK1 or MAP2K1) cross-linked with FcyR (Karimi and Lennartz, 1998; Mansfield et al., 2000). Other proteins like phospholipase D (PLD) and phospholipase A2 ( $\left.\mathrm{PLA}_{2}\right)$ are stimulated during FcyRmediated phagocytosis in human macrophages and were thought to increase phagocytosis signals connected to the regulation of leukotrienes generation (Lennartz et al., 1997; Kusner et al., 1999; Mancuso et al., 2001).

The Rac member of Rho-family GTPase and members of the Vav family of nucleotide exchange factors (GEFs) are part of the immune complexes that show involvement with Fc receptors (Cox et al., 1997; Massol et al., 1998; Castellano et al., 2000; Garcia-Garcia and Rosales, 2002). Rac is thought to be a major cytoskeletal shape-remodeling player (Patel et al., 2002). It has been concluded that members of Vav also play an activation sequence scenario in FcyR. The Vav dominant negative mutant studies showed impaired macrophage engulfment of IgG-coated particles at the time of phagocytosis (Patel et al., 2002).

In Zhang et al. (2010) the main focus was on applying different IgG densities on coated particles. Low IgG-density coated particles were less efficiently engulfed by phagocytic cells with reduced concentrations of $3^{\prime}$ phosphoinositides ( $\left.3^{\prime} \mathrm{PI}\right)$ and insignificant concentrations of PKCe being observed. On the other hand, high IgGdensity coated particles showed increased levels of $\mathrm{Fc} \gamma \mathrm{R}$ presenting, suggesting a role of $\mathrm{PIP}_{3}$-drived 3'PI in phagocytosis (Zhang et al., 2010). The stimulation of PKC and 
PLC proteins is by PI3K activation that plays a role in phagocytosis initiation (Larsen et al., 2000; Melendez et al., 1999; Greenberg and Grinstein, 2002).

Lee et al. (2007) found a relation of adaptor molecule Crk and a dedicator of cytokinesis (Dock180) to phagocytosis when knockdown with silencing RNA occurred. The Crk silenced protein altered the engulfment of IgG-coated particles in RAW264.7 macrophages cells (Lee et al., 2007). Giodini et al. (2009) conducted an experiment with a non-typical phagocytic $293 \mathrm{~T}$ cell line and demonstrated that, in the cross-presentation of FcyRIIA, a remarkable influence on the phagocytic efficiency of IgG-coated partials occurred. Thus, Fcy receptors are a key player in phagocytosis and in internalization of particles. 


\section{RATIONAL AND CENTRAL HYPOTHESIS}

Proteomic studies have been dedicated to plasma biomarkers advances. Key efforts have focused towards this purpose, while currently other proteomic methodologies still represent a minor proportion of the existing atherosclerosis studies. One of the more recent methods to identify protein receptor complexes has been used by Marshall's group which involves liquid chromatography and tandem mass spectrometry (LC-MS/MS) to quantify the isolated proteins by their peptide fragments ionized in an electrospray ionization (ESI) mode (Jankowski et al., 2008).

An assumption of this study is that if focal adhesion kinases (FAKs) or protein tyrosine kinases were involved in cell immune response communication processes, then FAKs are more likely to be identified in relation to receptor complexes by mass spectrometry. Silencing RNA, confocal microscopy and immunofluorescence techniques were introduced to FAKs in order to confirm the LARC data obtained by LC-MS/MS, as well as to study FAKs regulatory role in IgG and oxLDL mediated phagocytosis. A quantitative analysis of phagocytosis and FAKs localization after siRNA knockdown will also strengthen the hypothesis of FAKs association with phagocytosis. Knowledge about the complex links between ligand binding, FAK interaction and localization will provide an understanding in regards to FAK role in current immune diseases. 


\section{GENERAL OBJECTIVE}

The objective of this study was to determine the presence of protein tyrosine kinases specifically associated with the activated phagocytic receptor complexes in human U937 macrophages.

\subsection{Study Goals}

The goals of this study were as Follows:

1. Confirm protein tyrosine kinases presence in U937 cells detected by Mass Spectrometry.

2. Compare and calculate the phagocytosis efficiency of IgG and oxLDL coated beads assays in U937-treated siRNA (PTK2 \& PTK2b) cells.

3. Inhibit PTKs (FAKs) using pharmacological inhibitors.

4. Confirm the knockdown and show the localization of PTK2 (FAK) and PTK2b (Pyk2) in U937 cells by Immunostaining and confirm the presence of PTK2 and PTK2b by Western Blotting (Appendix. B). 


\section{MATERIALS AND METHODS}

\subsection{Cell Culture}

Macrophage human U937 cells purchased from American Type culture Collections (ATCC, Manassas, VA, USA), were incubated with RPMI 1640 medium with Lglutamine (Mediatech, Manassas, VA, USA) at $37^{\circ} \mathrm{C}$ with $5 \% \mathrm{CO}_{2}$ enriched with 10\% fetal bovine serum (FBS) (Invitrogen, Carlsbad, CA, USA).

\subsection{Pharmacological inhibitors}

PF 573228 (FAKs inhibitor) was obtained from Sigma Aldrich (St. Louis, MO, USA). The PF drug inhibitor was used to compare the phagocytic inhibition with PTK2 and PTK2b silencing RNA knockdown experiments.

\subsection{Antibodies}

Monoclonal anti-FAK (clone 4.47) and polyclonal anti-Pyk2 were purchased from Upstate-Millipore (Billerica, MA, USA). Secondary antibodies were obtained from Jackson ImmunoResearch (West Grove, PA, USA). Polyclonal rabbit anti-Cu ${ }^{2+}$ oxidized human lipoprotein antibody was obtained from Calbiochem (La Jolla, CA, USA). Alexa Fluor 488 Phalloidin was purchased from Invitrogen.

\subsection{Oxidized Low Density Lipoprotein Preparation}

Human plasma (EDTA-treated) was ultracentrifuged in a TLA110 rotor (Beckman Coulter) at $100000 \mathrm{rpm}$ at $4^{\circ} \mathrm{C}$ for 1 hour, to extract the low-density lipoprotein band using $\mathrm{KBr}$ to achieve a density of $1.30 \mathrm{~g} / \mathrm{ml}$ and layered with $\mathrm{NaCl} 1.006 \mathrm{~g} / \mathrm{ml}$. The band was collected in a dialysis cassette "slide-A-Lyzer dialysis cassette" (Thermo 
Scientific, USA), and was dialyzed extensively overnight in PBS including $0.5 \mathrm{mM}$ EDTA. LDL was then oxidized with $5 \mu \mathrm{M} \mathrm{CuSO}_{4}$ in $37^{\circ} \mathrm{C}$ for 18 hours in dark. The oxidation of LDL was terminated with a fresh PBS containing $40 \mu \mathrm{M}$ butylated hydroxytoluene and $0.3 \mathrm{mM}$ EDTA. The termination of oxidation was carried out for $\sim 6 \mathrm{~h}$ at $4^{\circ} \mathrm{C}$ in dark. After termination, oxLDL was dialyzed extensively at $4^{\circ} \mathrm{C}$ in dark for $24 \mathrm{~h}$. The oxLDL was then collected in eppendorf tubes and stored at $4{ }^{\circ} \mathrm{C}$ in dark (Shen et al., 2008).

\subsection{Silencing RNA}

Silencing RNA cy3-tagged for PTK2 and PTK2b was obtained from Sigma Aldrich (St. Louis, MO, USA). The knockdown of PTK2 and PTK2b with siRNA was established to evaluate the phagocytic efficiency of macrophage cells against coated microbeads and to compare with PF drug inhibitor experiments.

\subsubsection{Silencing RNA Sequence}

\subsubsection{PTK2 Sequence (FAK)}

1) 5, [Cy3]rGUrAUUrGrGrArCrCUrGrCrGrArGrGrGrATT 3 ' 5' UrCrCrCUrCrGrCrArGrGUrCrCrArAUrArCTT 3'

2) 5' [Cy3]rCrGrArAUrGrAUrArArGrGUrGUrArCrGrATT 3' 5' UrCrGUrArCrArCrCUUrAUrCrAUUrCrGTT 3'

\subsubsection{PTK2b Sequence (Pyk2)}

1) 5' [Cy3]rCUrGrAUrGrArCrCUrGrGUrGUrArCrCUTT 3 ' 5' rArGrGUrArCrArCrCrArGrGUrCrAUrCrArGTT 3'

2) 5' [Cy3]rCrArCrAUrGrArArGUrCrCrGrAUrGrArGrATT 3' 5' UrCUrCrAUrCrGrGrArCUUrCrAUrGUrGTT 3' 


\subsection{SEQUEST Association of Proteins Specific for Fc and CD36 Ligands}

Marshall's lab identified protein receptor complexes in relation to U937 macrophages via the LARC protocol using liquid chromatography-electrospray ionization and tandem mass spectrometry (LC-ESI-MS/MS) (unpublished data). The LARC protocol was performed by Dr. John G. Marshall using sucrose gradient to isolate the beads after U937 cells were French pressed and using a step gradient of $\mathrm{NaCl}$ to isolate the complex, and digest the proteins in the $\mathrm{NaCl}$ fractions with trypsin before injecting to the MS. The proteins ionized and recorded by full MS were followed by matching the protein peptide sequences via SEQUEST algorithm to a non-redundant library of protein peptides. On the side, beads were incubated with growth media or crude cell lysates, and were used as a control to compare with proteins associated with LARC. To avoid false positive results, controls were injected alongside LARC samples to account for non-specific binding of proteins to naked beads incubated with crude lysate and/or growth culture medium. Following the identification of LARC proteins, silencing RNA, drug inhibitors assays and immunofluorescence staining were visualized via the confocal microscopy to quantify phagocytosis efficiency, and were applied to verify and confirm the functional role of proteins directly associated with U937 macrophages receptor mediated phagocytosis. 


\subsection{Silencing RNA transfection assay}

U937 cells were cultured in a $75 \mathrm{~cm}^{2}$ culture flask for 72 hours to reach a confluency of $60-80 \%$, cells were then centrifuged for 4 min at $3500 \mathrm{rpm}$, and fresh RPMI media enriched with $10 \%$ FBS was added. Cover slips $(2.5 \mathrm{~cm})$ were placed in 6-well culture plate, followed by adding 3-6 drops of the $60-80 \%$ confluent cells in wells containing phorbol 12-myristate 13-acetate (PMA) to differentiate the cells (Georgetown, ON) with a final concentration of $100 \mathrm{nM} /$ well. The PMA treated cells were incubated in $37^{\circ} \mathrm{C}\left(5 \% \mathrm{CO}_{2}\right)$ for 72 hours.

After 72 hours of incubation, cells treated with PMA were washed three times with fresh media. Cells were then transfected with siRNA (short interfering doublestranded RNA) (look for sequence above), using the transfection reagent XtremeGENE (Roche, Indianapolis, IN, USA). The controls used for the transfection experiment were scrambled siRNA to serve as a negative control. Non-treated cells served as a positive control. The scrambled siRNA was used as a control and was mixed with the X-tremeGENE reagent. Both siRNA and the transfection reagent were diluted with serum free (SF) RPMI media prior to mixing. Similarly, the siRNAs for PTKs were diluted with SF media before mixing with SF diluted X-tremeGENE solution. The master mix of the X-tremeGENE solution containing siRNA for each condition was incubated for $20 \mathrm{~min}$. The master mix was then added to the cells and incubated for 72 hours. 


\subsection{Coated-beads Assay}

\subsubsection{Ligand Coated-beads Preparation}

Polystyrene micro-beads were purchased from Bangs Laboratories Inc. (Fisher, IN, USA), and were used to prepare IgG and oxLDL coated-beads. The microbeads stock contains $10 \%(\mathrm{v} / \mathrm{v})$ suspension $\sim 2.185-\mathrm{E} 10 / \mathrm{ml}$ and a size of $2 \mu \mathrm{m}$. From the beads stock, $1.5 \mu 1$ was added to $500 \mu 1$ phosphate-buffered saline solution (PBS) containing $3 \mu \mathrm{l}$ of $1 \mathrm{mg} / \mathrm{ml} \mathrm{IgG} \mathrm{stock,} \mathrm{and} 4 \mu \mathrm{l}$ of oxLDL stock against $1.5 \mu \mathrm{l}$ of beads/well in $500 \mu \mathrm{lBS}$. Both of the prepared ligands were incubated for $30 \mathrm{~min}$ in a Ferris-wheel. After incubating for $30 \mathrm{~min}$, ligand coated-beads were centrifuged (micro-centrifuge) at 12 000-14 $000 \mathrm{rpm}$ and washed four times to clear nonattached ligands. A final volume of $100 \mu \mathrm{PBS}$ was added to the pelleted coated-beads.

\subsubsection{Coated-beads Internalization Assay}

Following cell transfection a IgG coated-beads internalization assay was performed in a media condition consisting of RPMI media supplemented with $10 \%$ FBS. The oxLDL coated-beads internalization assay was performed in three different conditions as follows: (1) RPMI with 10\% FBS; (2), serum free RPMI and (3) HEPES buffer. Both the IgG and oxLDL beads internalization assays were incubated with cover slips for 2 hours.

After the cells were transfected with the siRNA for 72 hours, fresh medium was added to the wells. The prepared IgG and oxLDL beads were dispersed to the wells and incubated for 2 hours at $37^{\circ} \mathrm{C}$ and $5 \% \mathrm{CO}_{2}$. Washing of the cover slips was followed with ice-cold PBS terminating phagocytosis beads internalization assay. Cells were then fixed by appling 4\% paraformaldehyde for $20 \mathrm{~min}$ in a rocker shaker. The fixation process was terminated by adding $5 \%$ glycine 
prepared in PBS for $5 \mathrm{~min}$ and washed three times. Cover slips were incubated with blocking solution containing 1\% donkey serum and 5\% skim milk prepared in PBS for $30 \mathrm{~min}$. After blocking, cover slips containing IgG coated-beads were labeled with cy5-conjugated donkey anti-human antibody (1:10 000) for $30 \mathrm{~min}$ incubated in the dark. For cover slips containing oxLDL coated-beads, primary rabbit anti- $\mathrm{Cu}^{2+}$ human lipoprotein antibody (1:25) was incubated for 30-45 min. Following cover slips incubation with the primary antibody, secondary cy5conjugated donkey anti-rabbit antibody (1:10 000) was added for $30 \mathrm{~min}$ in the dark. Thereafter, cover slips for both treatments were washed five times with PBS and mounted with Dako medium (Dako, Carpentaria, CA, USA). The laser confocal microscope was used for imaging of the prepared slides.

\subsection{Immunofluorescence Assay}

The staining for permeablized cells was performed in order to verify the localization of FAK and Pyk2 knockdown by siRNA experiments. The antibodies for FAK (monoclonal) and Pyk2 (polyclonal) were used for cell staining to a new set of 6-well plates containing siRNA U937 cells seeded on coverslips with only HEPES buffer treated with oxLDL beads for 2 hours. The siRNA treatments were as follows: scrambled control; scrambled with only secondary antibody control; no siRNA treatment control; PTK2 siRNA and PTK2b siRNA.

As mentioned above, siRNA treated U937 cells on cover slips were incubated with oxLDL beads for 2 hours followed by ice-cold washing and fixing for 20 min with $4 \%$ paraformaldehyde and termination of fixing with 5\% glycine for $5 \mathrm{~min}$. Blocking solution was added for $30 \mathrm{~min}$ with either $1 \%$ donkey or $1 \%$ goat serum depending on the different antibody clones and suitable secondary Cy5-conjugated (donkey antimouse or goat anti-rabbit) antibody. Cells then underwent permeabilization with the addition of $0.1 \%$ Triton X-100 for 30 min. The primary antibody for FAK and Pyk2 was then added to the cover slips in a dilution of 1.5:25 for 1 hour. The secondary antibody was added in 1:5000 dilution for 1 hour. As mentioned above for one of the 
controls, the secondary antibody was added without the primary antibody. Cover slips were then washed three times and a final staining step was performed by adding phalloidin green color for $45 \mathrm{~min}$ to 1 hour. Cover slips were then mounted to microscopic slides for imaging by laser confocal microscopy (Zeiss LSM 510 Meta).

\subsection{Microscopic Imaging}

Images of the microscopic slides prepared for cells binding to IgG or oxLDL beads and cells immunostaining of FAK and Pyk2 were captured by a Zeiss LSM 510 Meta scanning confocal microscope containing Ar 488-nm, He/Ne 543-nm and He/Ne 633$\mathrm{nm}$ lasers. The images were reviewed using Zeiss LSM Image Browser and the Image $\mathrm{J}$ program to count the number of beads for single cells and the intensity of protein localization. The total number of beads was subtracted from the outside number of beads giving the number of engulfed beads per cell using Microsoft (MS) Excel ${ }^{\circledR}$. The number of engulfed beads were divided by the total number of beads to determine phagocytic efficiency for an average of a 100-cell count per treatment. Average cell intensity values for protein localization in negative treatments were compared with protein localization in knockdown treatments. A one-way ANOVA was used to determine phagocytic efficiency and protein localization intensity for U937-treated cells.

\subsection{Western Blotting}

U937 cells were seeded into a $75 \mathrm{~cm}^{2}$ flask treated with $100 \mathrm{nM}$ PMA in RPMI media enriched with $10 \%$ FBS for 72 hours. The cells were washed three times with PBS and scraped. The scraped cells were then collected and added to $400 \mu \mathrm{L} 2 \times$ sodium dodecyl sulphate polyacrylamide gel electrophoresis (SDS-PAGE) tricine sample buffer and warmed to $65^{\circ} \mathrm{C}$ for $10 \mathrm{~min}$. The protein concentration was assessed by the Dumbroff Dotblot protein assay. The SDS tricine samples were then centrifuged for 10-30 sec to pellet DNA before loading the samples. Samples were then loaded to the 
wells of 9\% SDS-PAGE with a total protein concentration of $30 \mathrm{mg}$ per well and left for 1:30 hours in 125 V. Colored ladder PiNK plus Prestained Protein (FroggaBio, ON, Canada) was loaded as a control. The gel protein bands were transferred to a polyvinylidene fluoride membrane (PVDF) (Millipore, Billerica, MA, USA). The PVDF membrane was then blocked with 5\% skim milk, $0.1 \%$ Tween and either $1 \%$ goat or donkey serum in PBS for 30 min. The antibodies for FAK and Pyk2 were then added in 1:100 and 1:1000 concentrations respectively. Next, peroxidase conjugated goat anti-mouse or donkey anti-rabbit secondary antibody were added at a 1:10 000 concentration. The enhanced chemiluminescece (ECL) solution containing $0.125 \mathrm{mM}$ luminol, 0.1 M Tris/ $\mathrm{HCl} \mathrm{pH}$ 8.8, $7.7 \mathrm{mM} \mathrm{H}_{2} \mathrm{O}_{2}$ and $2 \mathrm{mM}$ 4-iodopheylboronic acid was used to enhance protein bands. Images for protein bands were taken by BIORAD ChemiDoc XRS.

\subsection{Pharmacological Inhibitor Assay}

Human U937 cells were added in 6-well containing coved slips $(2.5 \mathrm{~cm})$ treated with $100 \mathrm{nM}$ PMA in growth media for 72 hours. Cover slips were washed three times with PBS and fresh media was added. PF 573228 FAKs drug inhibitor stock was resuspended in DMSO and added to the wells for 1 hour with concentrations ranging from $0.1-10 \mu \mathrm{M}$ and a final concentration of DMSO containing $\mathrm{PF}$ of $<0.1 \%$ per well. OxLDL or IgG coated beads were then added for 2 hours directly after drug treatment. Cover slips were washed with ice-cold PBS and fixed with 4\% paraformaldehyde for $20 \mathrm{~min}$. Fixation was the terminated with 5\% glycine for $5 \mathrm{~min}$ and blocking with $1 \%$ donkey serum plus 5\% skim milk powder in PBS for $30 \mathrm{~min}$. For oxLDL, primary rabbit anti-oxLDL antibody (1:25) was added for 30-45 min. Beads were then stained with either secondary cy5-conjugated donkey anti-human or donkey anti-rabbit antibody (1:10 000) for $30 \mathrm{~min}$ in the dark. Cover slips were washed five times with PBS and mounted with Dako medium. 


\section{RESULTS}

\subsection{Mass Spectrometry Protein Tyrosine Kinases Detection}

The LARC experiment was performed for capturing proteins attached to the ligands IgG and oxLDL mediated phagocytosis in U937 macrophages by Dr. John G. Marshall (unpublished data). The proteins detected by LARC were manually reviewed in order to choose the most suspected proteins involved in phagocytosis. Protein tyrosine kinases were among other kinases in the MS list of detected proteins with considerable numbers of peptide scores in correlation to the parent proteins matched by the SEQUEST library database adopted from mass spectrometry. Specific gene isoforms for PTKs including PTK2 and PTK2b were chosen from the list of tyrosine kinases to be further investigated by independent analytical methods as mentioned above.

The LARC protocol was used to identify the proteins interacting with the Fc and CD36 receptor complexes in U937 macrophages. The presence of PTKs in ligand receptor complexes was first suggested by the mass spectrometric data in correlation to PTKs peptide fragments (Table. 1) (Appendix. A). The calculated number of peptide scores for PTK2 and PTK2b are shown in Table 1 with different treatments and controls. The treatments used in Table 1 were as follows: (1) LARC-IgG; (2) LARC-IgG-control; (3) LARC-IgG-Media-beads; (4) LARC-oxLDL; (5) LARCoxLDL-control; (6) LARC-oxLDL-Media-beads; (7), LARC-AntiCD36-IgA; (8) LARC-AntiCD36-IgA-control and (9) LARC-Uncoated-beads-Extract. The LARCIgG and LARC-oxLDL in Table 1 represents the peptide scores of PTK2 and PTK2b identified by the mass spectrometry reverse phase column in which IgG or oxLDL beads were incubated with live U937 cells. The controls for LARC-IgG and LARCoxLDL were accomplished by incubating each of the $\operatorname{IgG}$ and oxLDL beads with crude homogenates from U937 cells and, in most of the cases, the controls show lower PTKs peptide scores indicating a unique detection of PTKs and thus 
eliminating false positive results (Table 1). The LARC-IgG-Media-beads and LARCoxLDL-Media-beads columns represent PTKs peptide scores derived from the media used to incubate IgG or oxLDL beads with U937 cells. The column with LARCUncoated-beads-Extract represents peptide scores when naked-beads were mixed with crude homogenates of cells. The LARC-AntiCD36-IgA shows the relationship between PTKs and the CD36 receptor when IgA coated-beads were incubated with live U937 cells. However, lower protein hits was seen in the LARC-AntiCD36-IgAcontrol. Thereafter, protein tyrosine kinases were selected depending on the highest scores of LARC IgG and oxLDL in live cells, as mentioned above, in comparison to their controls.

Table 1. The protein tyrosine kinases peptide scores from mass spectrometry.

\begin{tabular}{|c|c|c|c|c|c|c|c|c|c|}
\hline $\begin{array}{c}\text { Gene } \\
\text { symbol }\end{array}$ & $\begin{array}{c}\text { LARC } \\
\text { IgG }\end{array}$ & $\begin{array}{c}\text { LARC } \\
\text { IgG } \\
\text { Control }\end{array}$ & $\begin{array}{c}\text { LARC } \\
\text { IgG } \\
\text { Media } \\
\text { Beads }\end{array}$ & $\begin{array}{l}\text { LARC } \\
\text { oxLDL }\end{array}$ & $\begin{array}{c}\text { LARC } \\
\text { oxLDL } \\
\text { Control }\end{array}$ & $\begin{array}{c}\text { LARC } \\
\text { oxLDL } \\
\text { Media } \\
\text { beads }\end{array}$ & $\begin{array}{c}\text { LARC } \\
\text { AntiCD36- } \\
\text { IgA }\end{array}$ & $\begin{array}{c}\text { LARC } \\
\text { AntiCD36- } \\
\text { IgA } \\
\text { Control }\end{array}$ & $\begin{array}{c}\text { LARC } \\
\text { Uncoated } \\
\text { Beads } \\
\text { Extract }\end{array}$ \\
\hline PTK2 & 118 & 94 & 13 & 446 & 403 & 4 & 291 & 237 & 140 \\
\hline PTK2 & 113 & 89 & 10 & 439 & 342 & 2 & 282 & 240 & 184 \\
\hline PTK2 & 124 & 90 & 13 & 430 & 397 & 4 & 289 & 234 & 134 \\
\hline PTK2B & 71 & 58 & 1 & 229 & 132 & 0 & 187 & 105 & 58 \\
\hline PTK2B & 112 & 99 & 6 & 405 & 233 & 1 & 312 & 232 & 132 \\
\hline PTK2B & 162 & 184 & 6 & 649 & 415 & 1 & 497 & 411 & 222 \\
\hline
\end{tabular}




\subsection{Phagocytosis Efficiency Assays in silenced RNA U937 cells}

In order to determine whether PTKs are truly involved in phagocytosis, the cells were treated with either an siRNA directed at PTKs or a scrambled siRNA. Beads internalized by cells were then counted.

\subsubsection{Beads Internalization in RPMI (10\%FBS) Media}

\subsubsection{IgG Coated-beads}

The IgG coated microspheres were incubated for 2 hours with PMA treated U937 cells after siRNA knockdown. An initial manual count of 150 cells per treatment for scrambled control, no treatment, PTK2 siRNA, PTK2b siRNA, and an extra treatment of both PTK2 and PTK2b silenced U937 in one well (see Fig. 6). The Experiment was replicated three times (Appendix. D-F).

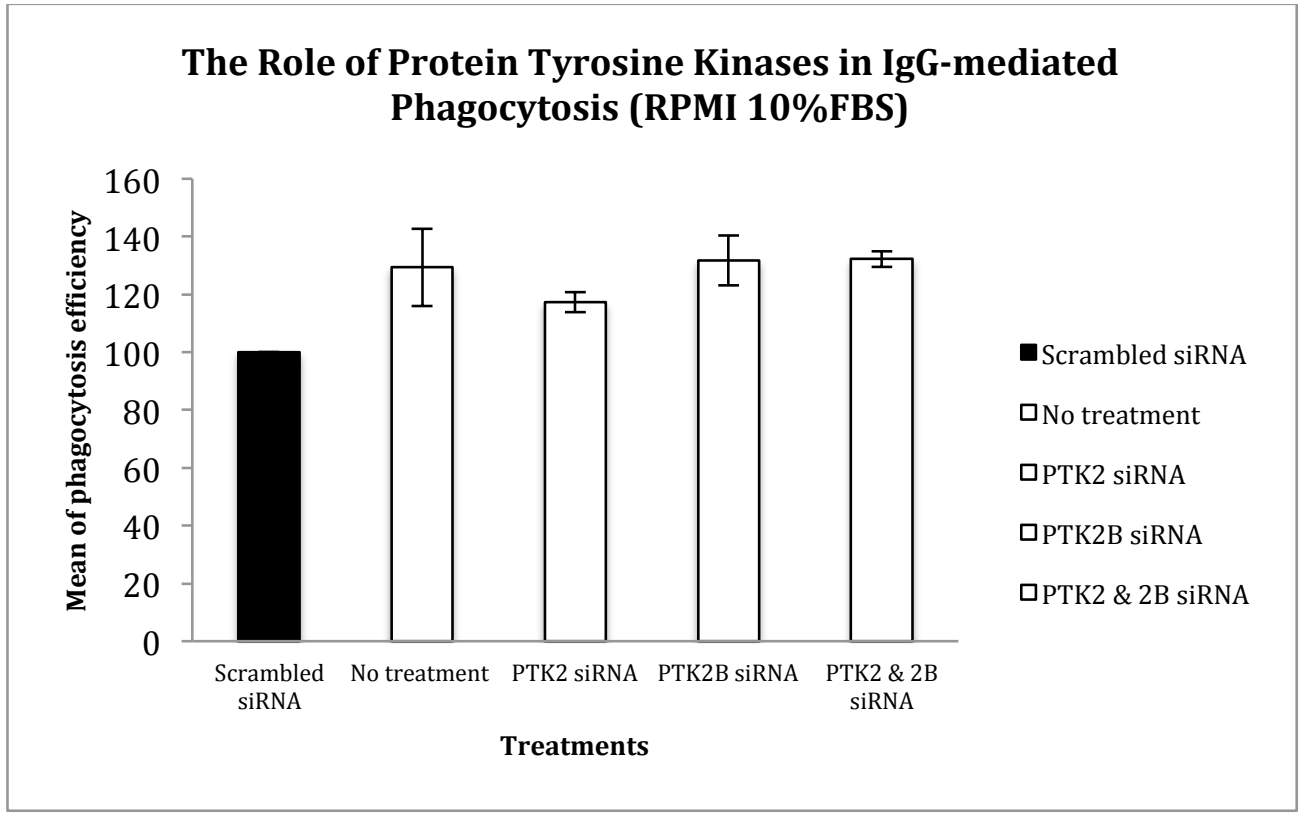

Figure 6. U937 average phagocytosis efficiency for IgG coated-beads internalization per cell in RPMI media supplemented with 10\% FBS replicated three times. 
U937 Cells were seeded to a 6-well plate and treated with PMA (100 nM) for 72 hours. SiRNAs were added for scrambled control, PTK2, PTK2b and both (PTK2 \& 2B) treatments for 72 hours. Non-treated cells were left as a positive control. Human IgG-coated beads were then incubated with siRNA-treated and non-treated U937 cells for 2 hours. Cells were then fixed, blocked, tagged with Cy5-cojugated donkey anti-human IgG antibody and then mounted to microscopic slides to be imaged using confocal microscopy. The LSM images of cells were processed and counted using the Image $\mathbf{J}$ program. The total number of beads was subtracted from the outside (Cy5 tagged) beads in order to get the total number of engulfed beads per cells, using Excel software. The average phagocytosis efficiency was then calculated by the total number of beads and divided by the number of engulfed beads per cell. The following treatments were counted for 150 cells per treatment and the experiment was replicated in three independent days. Table 2 shows the average number of IgG beads internalized in U937 cells.

Table 2. Average internalized IgG beads in three independent experiments using RPMI 10\% FBS supplemented media.

Treatment

Three Replicates

\begin{tabular}{l|ccc|} 
& Average & St-Dev & St-Error \\
Scrambled & 9.33 & 3.53 & 1.76 \\
Negative & 12.56 & 3.80 & 1.90 \\
PTK2 siRNA & 9.88 & 2.44 & 1.22 \\
PTK2b siRNA & 12.32 & 4.62 & 2.31 \\
Both siRNA & 6.86 & 3.16 & 1.58 \\
\cline { 2 - 4 } & & &
\end{tabular}




\subsubsection{OxLDL Coated-Beads}

Figure 7 shows the phagocytic internalization of PMA-treated U937 cells incubated with oxLDL-coated microspheres for 2 hours prior to siRNA treatment. As mentioned in the IgG internalization assay, similar media condition (RPMI 10\%FBS) was applied for oxLDL beads including treatments of scrambled control, no treatment, PTK2 siRNA, PTK2b siRNA, and both PTK2 and PTK2b silenced U937 in one well. 150 cells per treatment were counted for three independent experiments (see Fig. 7) (Appendix. G-I).

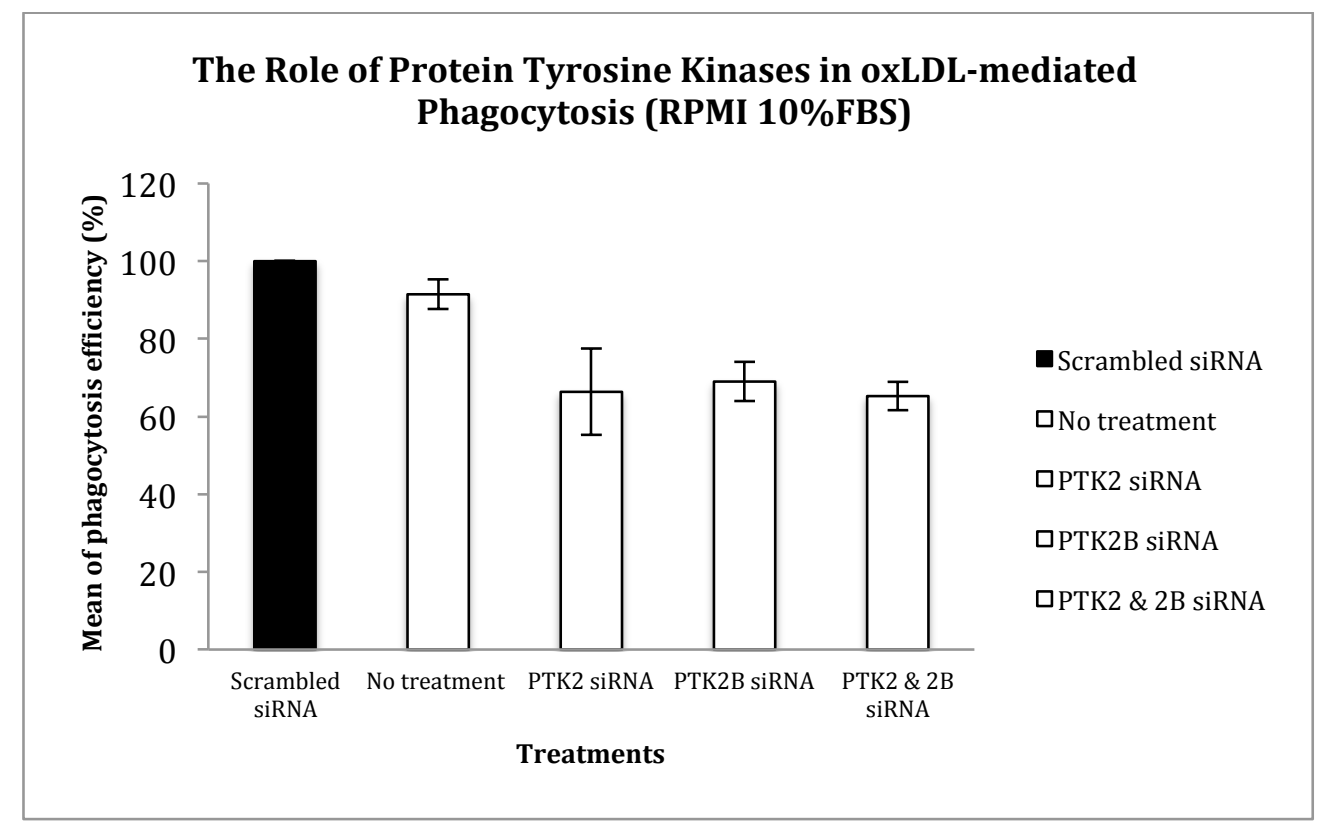

Figure 7. U937 average phagocytosis efficiency for oxLDL coated-beads internalization per cell in RPMI media supplemented with $10 \%$ FBS replicated three times.

In the Figure 7, U937 Cells were treated with PMA (100 nM) for three days. Scrambled siRNA and non-treated cells served as the controls of this condition, and siRNA for PTK2, PTK2b and both (PTK2 \& 2B) treatments were the tested samples. Cells were transfected with siRNA and left for 72 hours. Plasma OxLDL-coated beads were incubated with all treatments for 2 hours. Cells were then fixed, blocked and incubated with rabbit anti-oxLDL 
primary antibody. OxLDL beads were tagged with Cy5-cojugated donkey anti-rabbit oxLDL antibody. Cover slips containing cells were washed and mounted to slides to be imaged by confocal microscopy. Using Image $J$ and Excel programs, total number of beads was counted and subtracted from the outside beads in order to get the total number of engulfed beads per cells. The mean phagocytic efficiency was calculated as mentioned in Figure 5 with the same number of total cell count in triplicate experiments. Table 3 shows the average number of oxLDL beads internalized in U937 cells.

\section{Table 3. Average internalized oxLDL beads in three independent experiments using RPMI 10\% FBS supplemented media.}

Treatment

Scrambled

Negative

PTK2 siRNA

PTK2b siRNA

Both siRNA

Three Replicates

\begin{tabular}{|ccc|}
\hline Average & St-Dev & St-Error \\
7.76 & 2.06 & 1.18 \\
7.02 & 1.45 & 0.83 \\
5.25 & 1.98 & 1.14 \\
5.32 & 1.63 & 0.94 \\
5.13 & 1.80 & 1.04 \\
\hline
\end{tabular}

Figure 8 provides a comparison between the average IgG and oxLDL beads internalization efficiency of U937 macrophages in RPMI media supplemented with $10 \%$ FBS. Appendix D-I shows the statistical validity of the above mentioned conditions. 


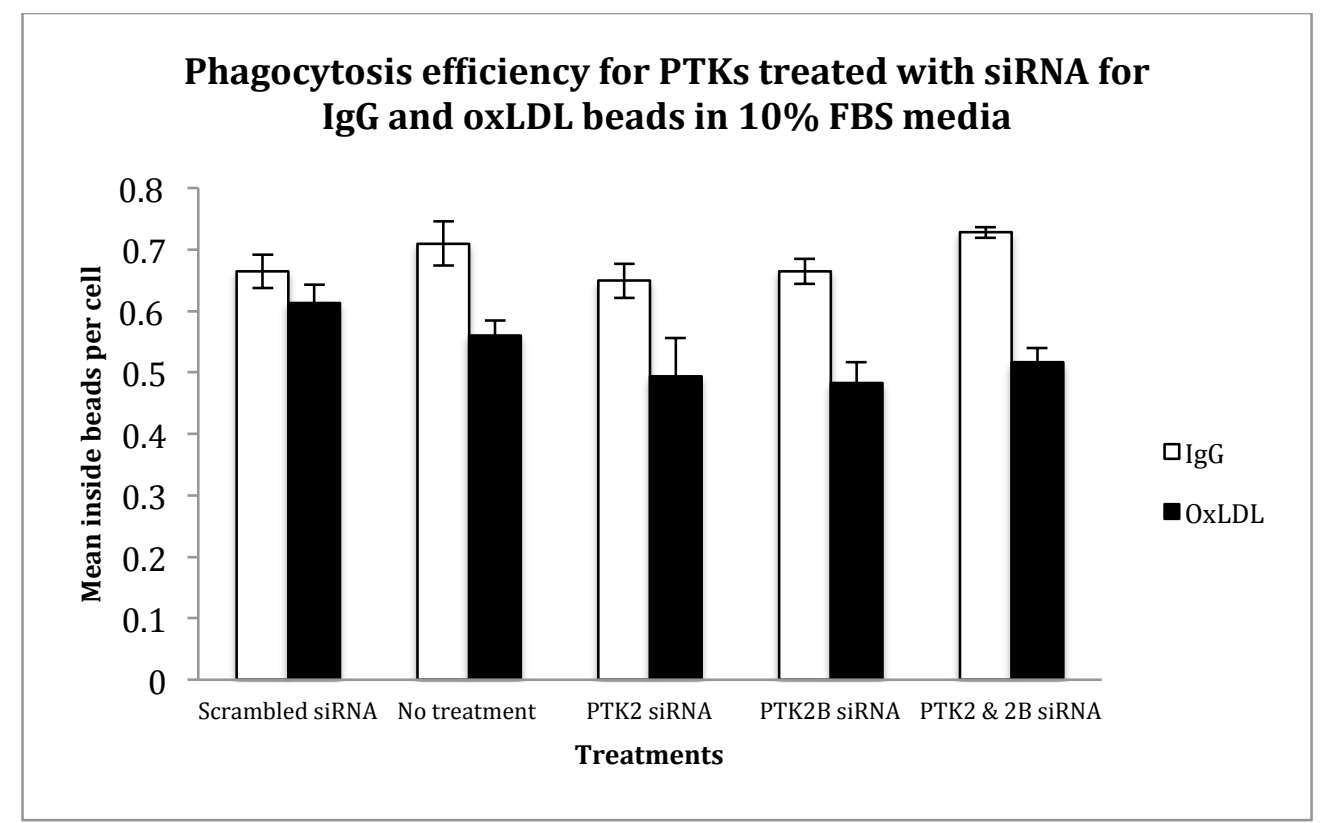

Figure 8. U937 mean inside beads per cell for IgG and oxLDL beads.

U937 cells were seeded to 6-well plate and differentiated using PMA (100 $\mathrm{nM}$ ) for 72 hours. Cells were transfected for 72 hours with siRNA treatments, and non treated control was also included. Followed by incubation of IgGcoated or oxLDL-coated beads for 2 hours. Cells were fixed, blocked, stained with conjugated-Cy5 donkey anti-human (IgG beads) or anti-rabbit (oxLDL beads, antibody tagged rabbit anti-oxLDL) antibody. The cover slips were then mounted on microscopic slides and imaged via laser confocal microscope. Efficiency of beads internalization was counted and calculated using Image $\mathrm{J}$ and excel software. The phagocytosis efficiency experiments were performed in triplicates with 150 cells count per treatment.

\subsubsection{Beads Internalization in RPMI Serum Free Media}

Figure 8 shows phagocytosis of oxLDL coated beads in PMA-treated U937 cells incubated for 2 hours in RPMI serum free. The treatments used in this condition including: scrambled control, no treatment, PTK2 siRNA, PTK2b siRNA, and both (PTK2 \& PTK2b) silenced cells. 150 cells per treatment were counted for three independent experiments (see Fig. 9) (Appendix. J-L). 


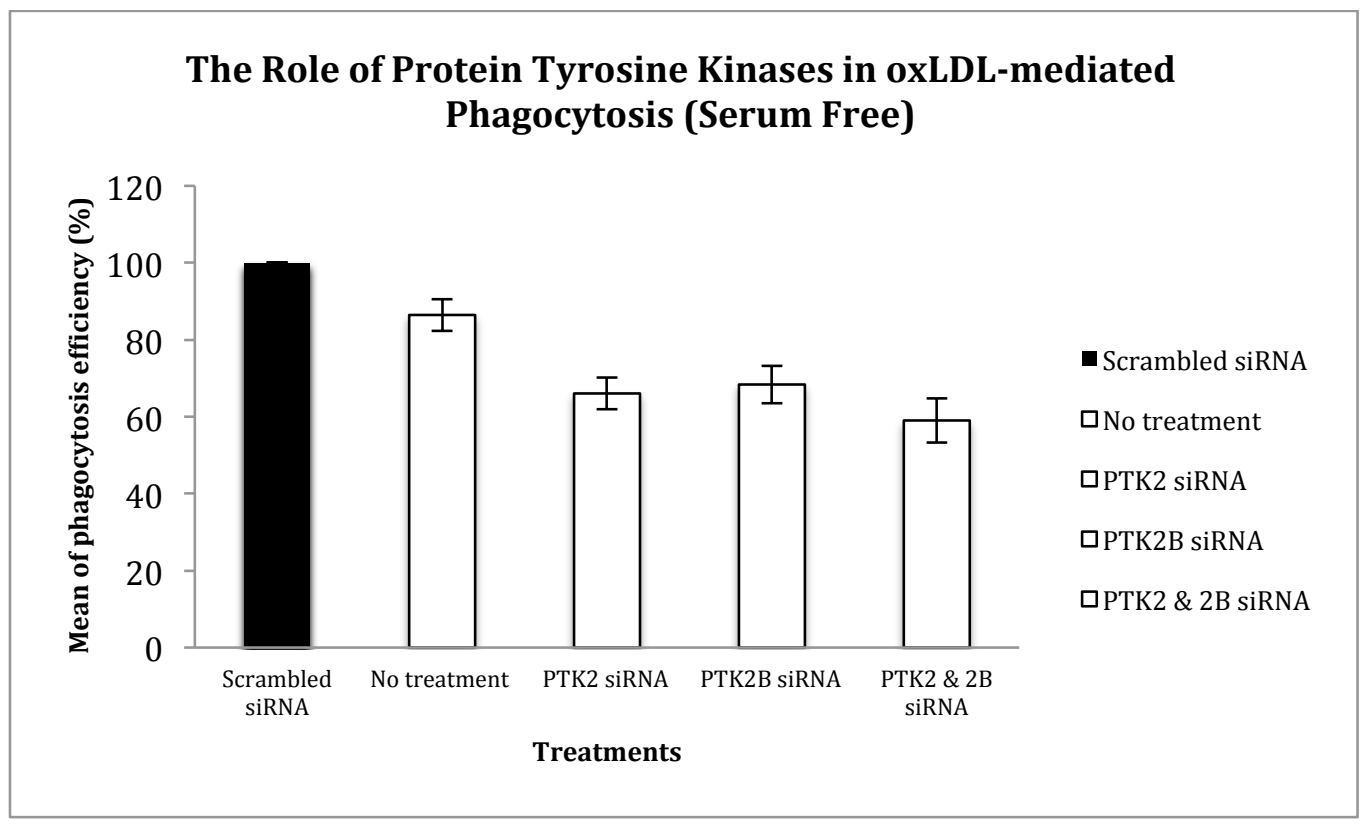

Figure 9. U937 average phagocytosis efficiency of oxLDL-coated beads with RPMI serum free condition.

Figure 9 shows the mean phagocytic internalization of oxLDL-coated microspheres by U937-treated cells with PMA (100 nM) in serum free RPMI media. Cells were then silenced in the above mentioned conditions for 72 hours. OxLDL-coated beads were incubated with all treatments for 2 hours. Followed by fixing, blocking and incubating the cells with rabbit anti-oxLDL primary antibody. OxLDL beads were then stained with Cy5-cojugated donkey anti-rabbit oxLDL antibody. Cells were mounted on microscopic slides to be imaged by confocal microscopy. Using image $\mathrm{J}$ and MS Excel programs, the mean of phagocytic efficiency was calculated as mentioned in other conditions with 150 cell count in triplicate experiments (Appendix. J-L). Table 4 shows the average number of oxLDL beads internalized in U937 cells. 
Table 4. Average internalized oxLDL beads in three independent experiments using serum free RPMI media.

Treatment

Three Replicates

\begin{tabular}{l|ccc|}
\cline { 2 - 4 } & Average & St-Dev & St-Error \\
Scrambled & 8.93 & 1.32 & 0.76 \\
Negative & 7.92 & 0.06 & 0.038 \\
PTK2 siRNA & 4.09 & 0.70 & 0.40 \\
PTK2b siRNA & 3.99 & 0.78 & 0.45 \\
Both siRNA & 3.20 & 0.51 & 0.29 \\
\hline
\end{tabular}

\subsubsection{Beads Internalization in HEPES Buffer}

Figure 10 shows U937 phagocytic internalization of oxLDL-coated beads incubated for 2 hours with HEPES buffer of cells-treated PMA. The treatments used were similar to the above mentioned conditions. Three independent experiments were performed with 150 cell count per treatment (see Fig. 10) (Appendix. M-O).

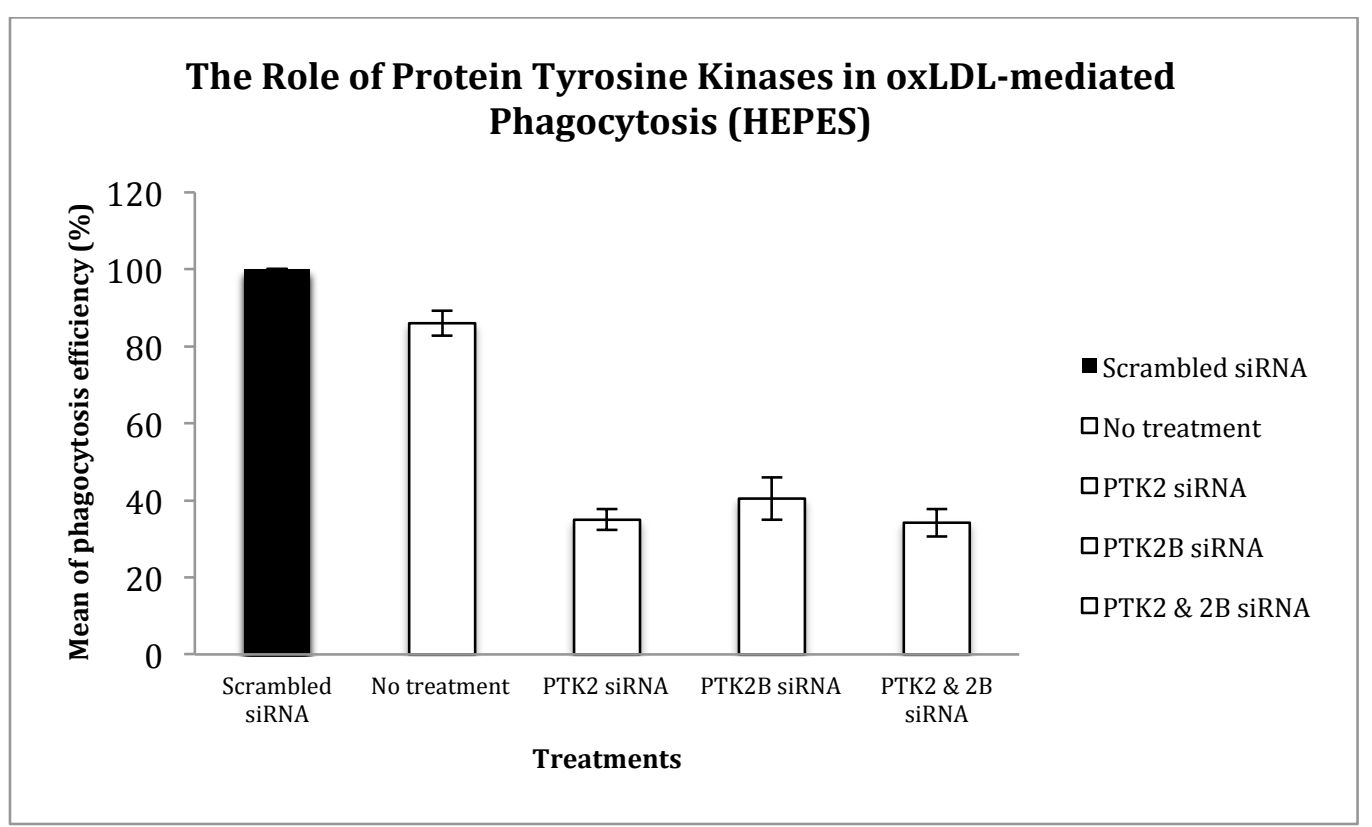


Figure 10. U937 average percentage of phagocytosis efficiency for oxLDLcoated beads in HEPES buffer.

In Figure 10, U937 cells are shown with the mean of phagocytic internalization of oxLDL-coated beads treated with PMA in HEPES buffer. As mentioned for the other media conditions, cells with different siRNA treatments were silenced for 72 hours. OxLDL beads were then incubated with the cells for 2 hours followed by, fixing, blocking and incubating the cells with rabbit anti-oxLDL primary antibody. OxLDL beads were then stained with Cy5-cojugated donkey anti-rabbit oxLDL antibody. Cells were mounted to microscopic slides to be imaged by the confocal microscope. Using image $\mathrm{J}$ and MS Excel programs the mean phagocytic efficiency was calculated as mentioned in other conditions with 150 cell count in triplicate experiments (Appendix. M-O). Table 5 shows the average number of oxLDL beads internalized in U937 cells.

Table 5. Average internalized oxLDL beads in three independent experiments using HEPES buffer.

Treatment

Three Replicates

\begin{tabular}{l|ccc|}
\cline { 2 - 4 } & Average & St-Dev & St-Error \\
Scrambled & 7.57 & 0.44 & 0.25 \\
Negative & 7.67 & 0.62 & 0.35 \\
PTK2 siRNA & 2.51 & 0.20 & 0.12 \\
PTK2b siRNA & 2.43 & 0.59 & 0.34 \\
Both siRNA & 2.36 & 1.059 & 0.61 \\
\hline
\end{tabular}



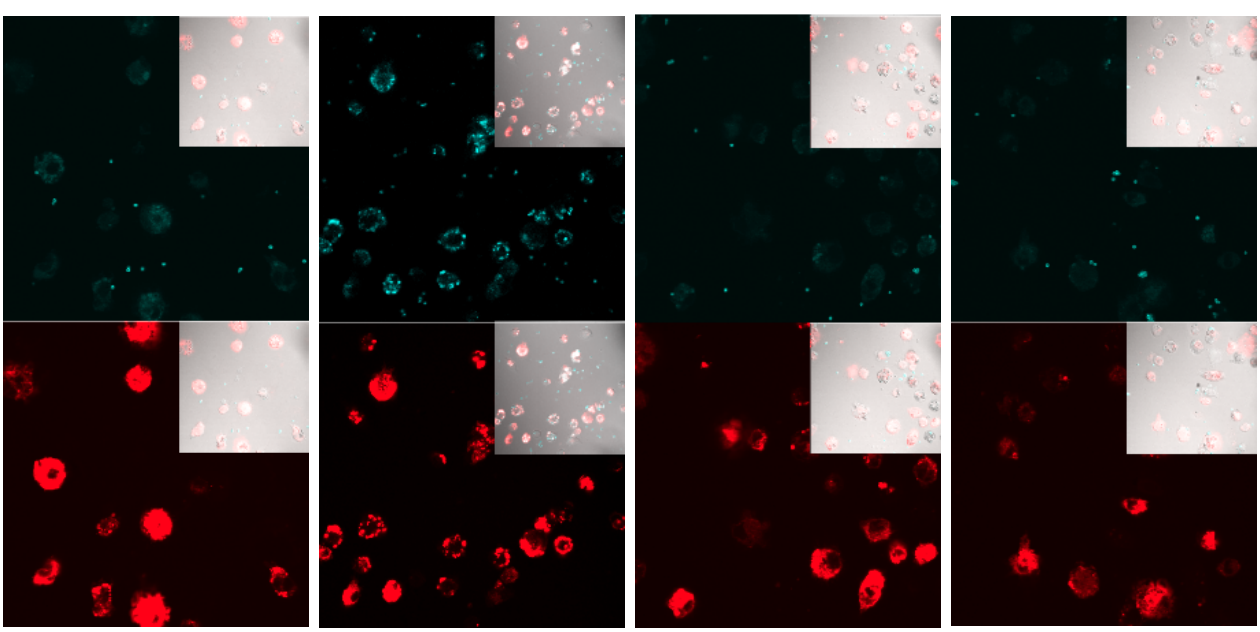

No treatment

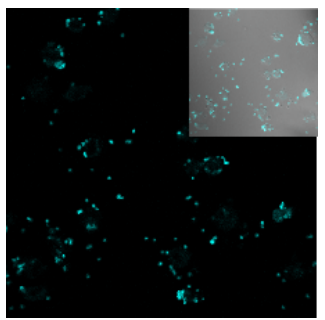

Figure 11. U937 cells confocal microscope images of oxLDL-coated beads of silencing RNA targeted PTKs.

Cells were incubated for three days in media treated PMA (100 nM). Cy3 tagged siRNA transfection for 72 hours was followed for each of the treatments including: scrambled control, PTK2, PTK2b and both (PTK \& PTK2b), and non treated cells were used as a positive control. OxLDL was then added to the cells for 2 hours. Followed by fixing and blocking the cells. The coated beads were incubated with rabbit anti-oxLDL antibody and secondary Cy5-cojugated donkey anti-rabbit antibody was then added. The red (Cy3) channel is for siRNA, and the blue (Cy5) channel is for the outside beads.

Figure 12 shows a comparison of U937 average phagocytic efficiency of oxLDLcoated beads in all three media conditions including: RPMI 10\%FBS, RPMI serum free and HEPES buffer. 


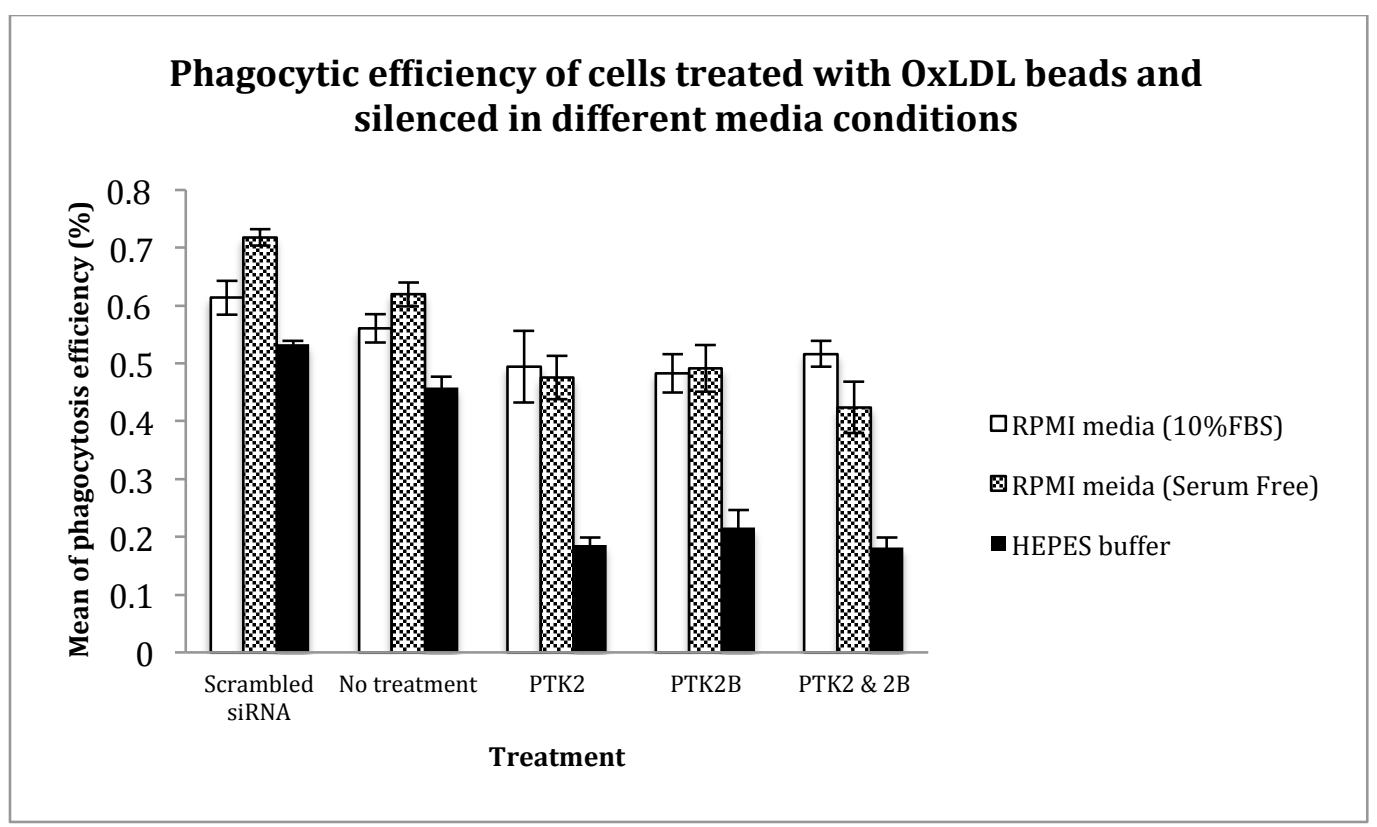

Figure 12. Comparison of U937 phagocytosis efficiency of RPMI (10\%FBS), RPMI serum free and HEPES buffer. 


\subsection{Pharmacological Inhibitor}

U937 cells were treated with PMA for 72 hours and PF drug inhibitor for FAKs (PTKs) was added to the cells with different concentrations in HEPES buffer for $1 \mathrm{~h}$ prior to beads incubation. OxLDL or IgG coated beads were then incubated for 2 hours. Quantitative cell count with Image J software determined the phagocytic efficiency of beads internalized. Drug treatment was performed in three independent experiments for oxLDL beads (Fig. 13) and two independent experiments for IgG beads (Fig. 14).

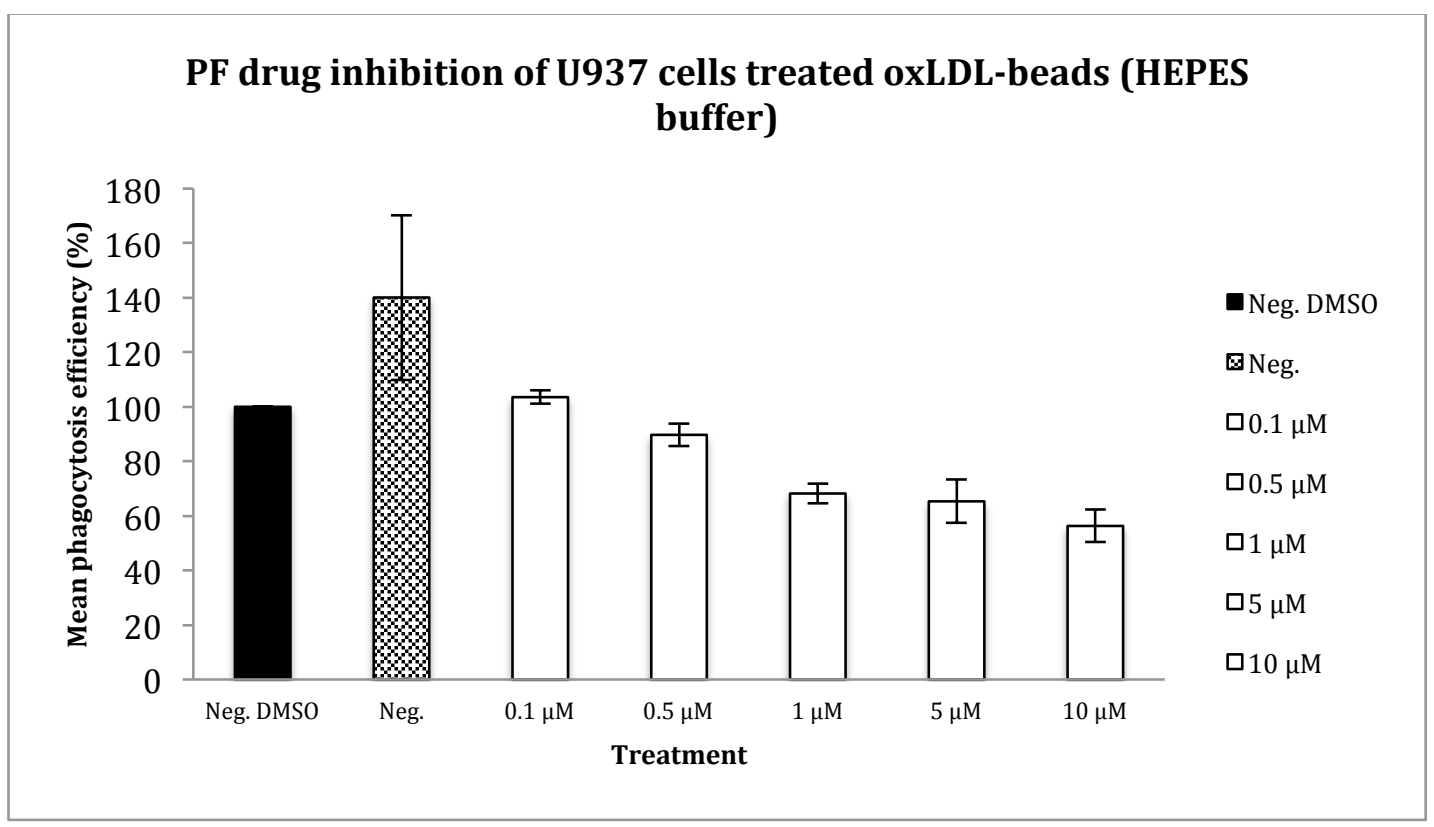

Figure 13. U937 cells treated PF 573228 (FAKs) drug inhibitor with oxLDLcoated beads in HEPES buffer.

Figure 13 shows U937 cells differentiated using $100 \mathrm{nM}$ PMA concentration for 72 hours. Cells were then incubated for 1 hour with PF 573228 in HEPES buffer. The treatments used were negative control, negative DMSO ( $0.1 \%$ final concentration) and PF dilutions of $0.1,0.5,1,5$ and $10 \mu \mathrm{M}$ amounts. The oxLDL beads were then incubated for 2 hours. Cells were then fixed and blocked with donkey serum plus skim milk. Primary rabbit anti-oxLDL antibody was added and cells were tagged with $2^{\text {ndry }}$ Cy5-conjugated donkey anti-rabbit antibody. Cells were then mounted and 
captured using confocal microscopy. Image J program was used to count the cells (25 cells/treatment) and by dividing the number of inside beads by the total number of beads phagocytosis efficiency was determined for three independent experiments (Appendix. P-R). Table 6 shows the average number of oxLDL beads internalized in U937 cells.

Table 6. Average internalized oxLDL beads in three independent experiments using HEPES buffer with different concentrations of PF drug inhibitor.

Treatment

Three Replicates

\begin{tabular}{l|ccc|}
\cline { 2 - 4 } Neg. DMSO & Average & St-Dev & St-Error \\
Neg. & 8.16 & 0.64 & 0.37 \\
$10 \mu \mathrm{M}$ & 7.46 & 0.8 & 0.46 \\
$5 \mu \mathrm{M}$ & 3.04 & 0.2 & 0.12 \\
$1 \mu \mathrm{M}$ & 3.92 & 0.55 & 0.32 \\
$0.5 \mu \mathrm{M}$ & 5.05 & 0.6 & 0.35 \\
$0.1 \mu \mathrm{M}$ & 5.57 & 0.97 & 0.56 \\
& 6.61 & 0.43 & 0.25 \\
\hline
\end{tabular}

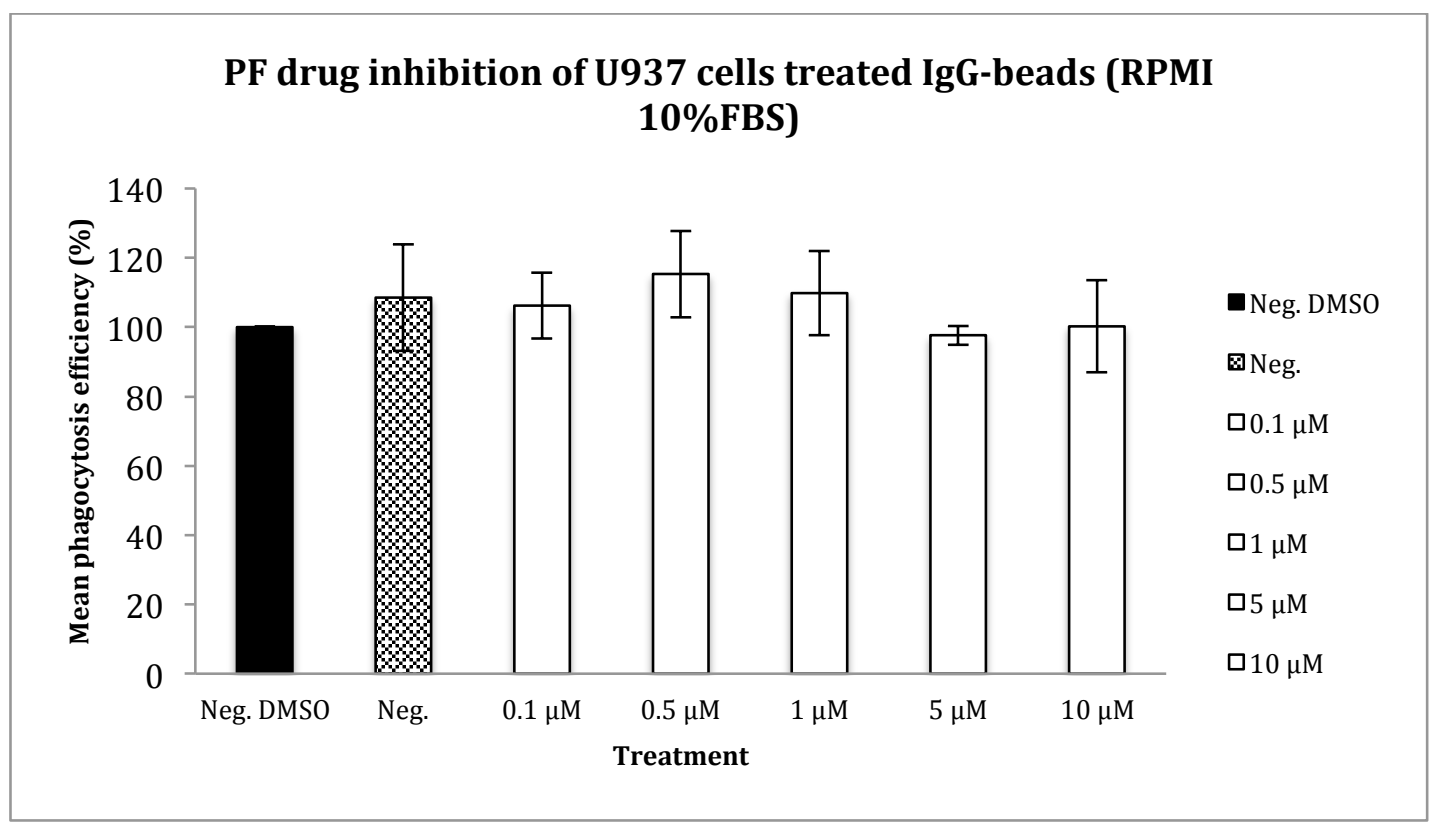


Figure 14. U937 cells treated PF 573228 (FAKs) drug inhibitor with IgG-coated beads in HEPES buffer.

Figure 14 shows U937 cells incubated with 100 nM PMA for three days. Cells were treated with PF 573228 in RPMI 10\% FBS media for 1 hour. Negative treatment and negative DMSO (0.1\% final concentration) were used as a control. PF dilutions of $0.1,0.5,1,5$ and $10 \mu \mathrm{M}$ amounts were added to different wells. IgG-coated beads were then incubated for 2 hours and then fixed and blocked with donkey serum and skim milk. Cells were stained with $2^{\text {ndry }}$ Cy5-conjugated donkey anti-human antibody. The cover slips were then mounted onto microscopic slides and imaged using confocal microscopy. Cells were counted with Image J program (25 cells/treatment) and phagocytosis efficiency was calculated by dividing the number of inside beads by the total number of beads. Two independent experiments were performed (Appendix. S \& T). Table 7 shows the average number of IgG beads internalized in U937 cells.

Table 7. Average internalized IgG beads in two independent experiments using RPMI 10\% FBS supplemented media with different concentrations of PF drug inhibitor.

Treatment Two Replicates

\begin{tabular}{l|ccc|} 
& Average & St-Dev & St-Error \\
Neg. DMSO & 11.96 & 4.35 & 3.08 \\
Neg. & 10.32 & 0.39 & 0.28 \\
$10 \mu \mathrm{M}$ & 12.56 & 3.16 & 2.24 \\
$5 \mu \mathrm{M}$ & 11.12 & 1.018 & 0.72 \\
$1 \mu \mathrm{M}$ & 11.4 & 0.84 & 0.6 \\
$0.5 \mu \mathrm{M}$ & 12.24 & 2.03 & 1.44 \\
$0.1 \mu \mathrm{M}$ & 14.5 & 1.159 & 0.82 \\
\hline
\end{tabular}




\subsection{U937 Immunostaining and Western Blotting}

PMA treated U937 cells were permeablized and treated with antibodies against FAK (PTK2) and Pyk2 (PTK2b). The staining of the cells was performed in order to visually identify the localization of PTK2 and PTK2b and to determine the intensity of the proteins in silenced RNA cells (Fig. 16). A one-way ANOVA was used to compare the overall Cy5 (blue channel) intensity for the negative treatments and Cy5 intensity for the PTK2 and PTK2b siRNA treatments (Appendix. U \& W). A regression analysis was also performed to identify the relation of Cy5 intensity against $\mathrm{Cy} 3$ (red channel) intensity in order to report variations in knockdown treatments against protein localization intensity for PTK2 and PTK2b (Appendix. V $\& \mathrm{X})$.

Western blots were performed in order to identify the presence of PTK2 and PTK2b in bands $\sim 125 \mathrm{KDa}$ and $\sim 116 \mathrm{KDa}$, respectively. Similar to immunostaining antibodies, monoclonal anti-Fak (1:100) and polyclonal anti-Pyk2 (1:1000) antibodies were used on SDS-PAGE containing differentiated cell lysate samples (Fig. 15).

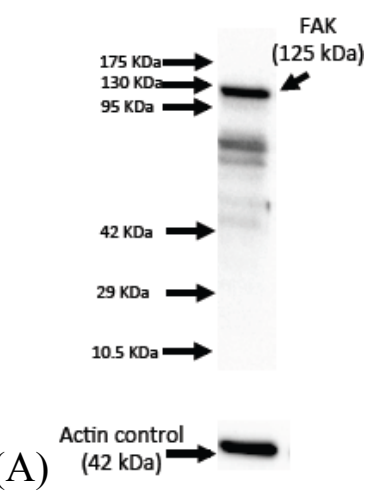

(A) $\stackrel{\text { Actin control }}{(42 \mathrm{kDa})}$

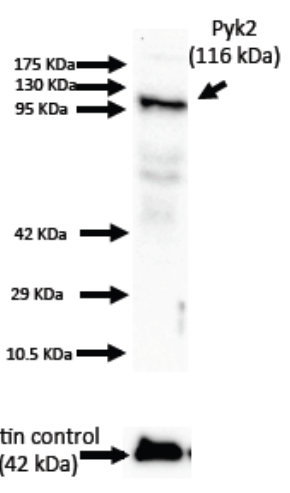

\section{Figure 15. FAK and Pyk2 Immunoblotting of PMA-treated U937 cells.}

U937 Cells were differentiated in $100 \mathrm{nM}$ PMA for 72 hours and followed by the addition of lysate to $2 \times$ SDS Tricine sample buffer. Lysate was added to wells and resolved in 9\% SDS-PAGE. Bands were transferred onto polyvinyl difluoride membrane and blocked with $1 \%$ goat serum plus 5\% skim milk for 30 min and tagged 
with primary mouse anti-Fak (1:100) (A) or rabbit anti-Pyk2 (1:1000) (B) antibody for $30 \mathrm{~min}$ followed by the addition of peroxidise-conjugated anti-mouse or antirabbit secondary antibody. PVDF membranes were then developed by enhanced chemiluminescence. Mild antibody stripping of the same membranes used was performed for 2 hours at room temperature. Followed by blocking, incubating with primary anti- $\beta$ actin antibody, and $2^{\text {ndry }}$ HRP-conjugated antibody. Membranes were then developed by ECL solution. 
FAK Negative Control

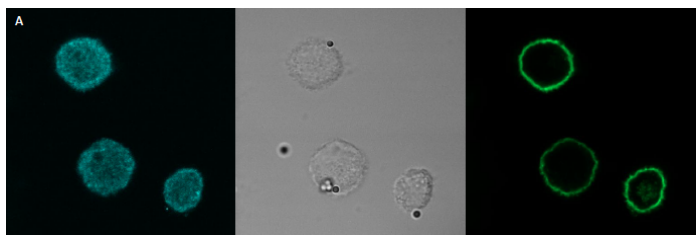

FAK Scrambled Control

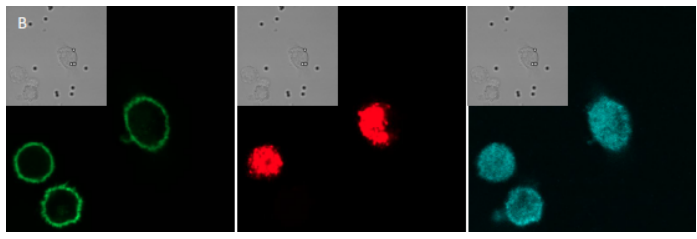

FAK treated siRNA

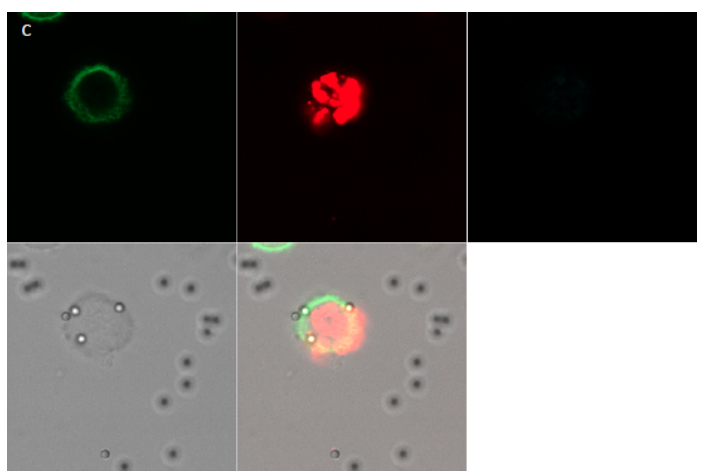

FAK (Cy3 intensity variation)

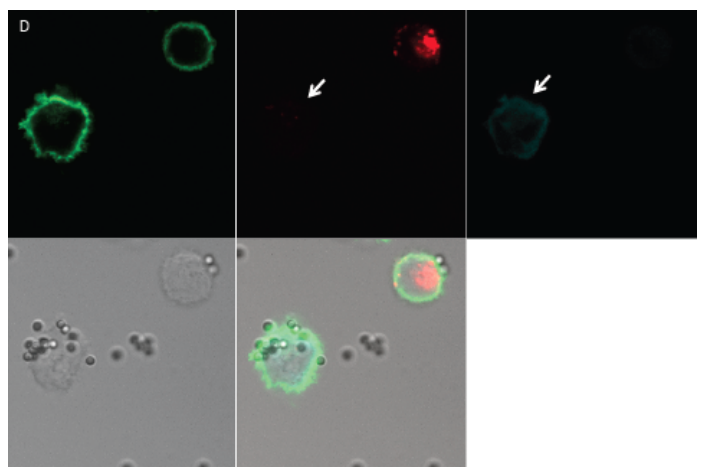

Pyk2 Negative Control

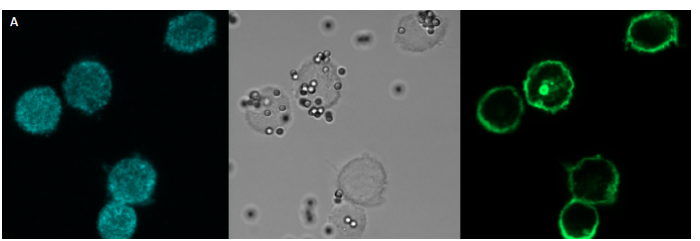

Pyk2 Scrambled Control

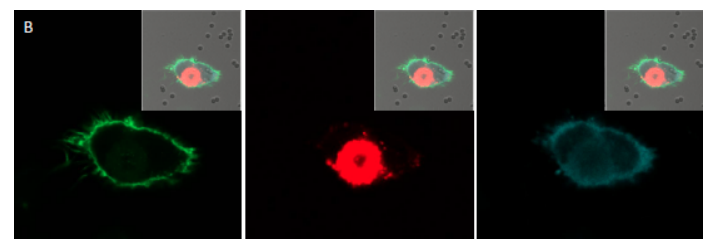

Pyk2 treated siRNA

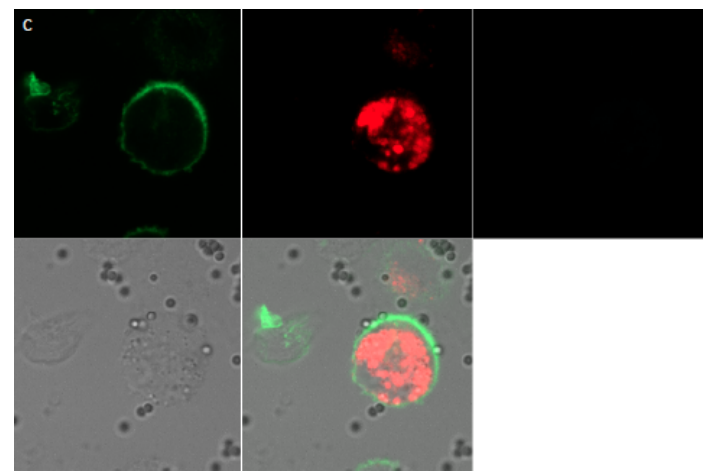

Scrambled (No $2^{\text {ndry }}$ Cy5-conjugated Antibody)

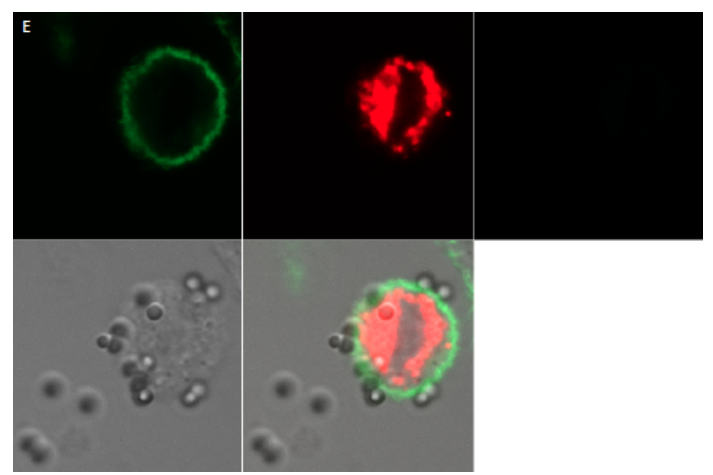

Figure 16. U937 cells immunofluorescence staining treated with oxLDL-coated beads, with monoclonal anti-Fak and polyclonal anti-Pyk2, permeablized with 0.1\% Triton X-100. Row (A) FAK negative control and Pyk2 negative control. Row (B) FAK scrambled control and Pyk2 scrambled control. Row (C) FAK treated siRNA and Pyk2 treated siRNA. (C) FAK (Cy3 intensity variation). (D) Scrambled (No $2^{\text {ndry }}$ Cy5-conjugated Antibody). 
In the confocal images presented in Figure 16, row A shows U937 cells subjected to the negative non-silenced treatments incubated with oxLDL-coated beads, permeablized with primary mouse anti-Fak or rabbit anti-Pyk2 antibodies, incubated with secondary Cy5-cojugated donkey anti-mouse or goat anti-rabbit antibodies (blue channel). phalloidin (green channel) was then added to show live cells actin ring. Row B shows U937 cells scrambled control incubated with siRNA and challenged with oxLDL beads, permeablized with anti-Fak or anti-Pyk2 and stained with $2^{\text {ndry }} \mathrm{Cy} 5$ antibody and phalloidin. Row C shows U937 cells treated with FAK (PTK2) or Pyk2 (PTK2b) siRNAs and with oxLDL beads, permeablized with anti-Fak or anti-Pyk 2 and with oxLDL beads, tagged with $2^{\text {ndry }}$ Cy5 antibody and phalloidin. Image D shows U937 cells treated with FAK siRNAs, permeablized with anti-Fak tagged with $2^{\text {ndry }} \mathrm{Cy} 5$ antibody (in this image variation of Cy5 versus Cy3 intensities is shown. Image (E) shows U937 cells treated with scrambled siRNA control and with oxLDL beads, and only stained with $2^{\text {ndry }}$ Cy5 antibody and phalloidin.

Three days PMA-treated U937 cells were incubated with siRNA for 72 hours, and were then treated with oxLDL-coated beads for 2 hours in HEPES buffer. Permeablized U937 cells treatments were as follows: negative control, scrambled control (1), scrambled control (2) with only $2^{\text {ndry }}$ antibody, PTK siRNA and PTK2b siRNA. Cells were then fixed and blocked with 5\% skim milk containing 1\% donkey or goat serum in PBS. Cell permeabilization was then performed by adding $0.1 \%$ Triton X-100 for $30 \mathrm{~min}$. The primary mouse anti-FAK or rabbit anti-Pyk2 antibodies were then added to the cover slips for 1 hour except for the scrambled control (2). The secondary Cy5-cojugated donkey anti-mouse or goat anti-rabbit antibodies were added in 1:5000-1:10 000 concentration for 1 hour followed by the addition of phalloidin which served as a control to show live cells with an actin ring. Cells were washed five times and mounted onto microscopic slides to be imaged by the confocal microscope. Image $\mathrm{J}$ software was used to quantify the intensities of Cy5 and Cy3. 100 cells per negative control were assessed against 
100 cells per PTK2 siRNA, and 140 cells per negative control were tested against 200 cells of PTK2b siRNA for only one independent experiment (Appendix. U-X). 


\section{DISCUSSION}

\subsection{Liquid Chromatography Mass Spectrometric Significance}

Over the last decade proteomic studies have been evolving and have provided data resulting in more complicated hypothesis and theories of protein existence and interpretation in human body. Liquid chromatography mass spectrometry is considered to be one of the more sensitive techniques that can detect attomolar amounts by their Mass to Charge $(\mathrm{m} / \mathrm{z})$ ratio. Proteomic studies were introduced to LC-MS and have shown great promise since MS can ionize and detect down to three peptides from the parent protein by quadrupole mass analyzer with electrospray ionization to form a fragment ion spectra (Aebersold and Goodlett, 2001).

This study was solely dependent on the initial interpretations of protein receptor complexes successfully captured by live cell affinity receptor chromatography (LARC) protocol and analyzed by LC-ESI-MS/MS. Protein tyrosine kinases were one of many protein kinases that were detected by LARC via MS in U937-mediated phagocytosis. The peptide scores relevant to PTKs were associated to their abundance in immune complexes. LARC control treatments for non-specific interaction provided by the media or uncoated beads extracts assessed the presence of PTK2 and PTK2b in relation to ligand mediated phagocytosis. The controls for non-specific protein binding, such as naked beads incubated with crude homogenate, had a lower peptide scores for PTKs compared to LARC (such as LARC-oxLDL) samples and are thus mandatory to avoid or reduce any false positive results accounted for PTKs (Table 1). We were able to successfully confirm the validity and specificity of mass spectrometric PTK interpretations via independent analytical proteomics techniques. Thus, protein tyrosine kinases can significantly influence the phagocytic functions of immune U937 macrophages cells; therefore, mass spectrometry is considered to be a reliable method for detecting proteins and their correlated peptides among the wide scale of proteomic techniques. 


\subsection{Role of Protein Tyrosine Kinases in U937 Phagocytosis}

The phagocytosis efficiency experiments indicated by siRNA transfection, immunostaining and pharmacological inhibitors assays were implemented to confirm the presence of protein tyrosine kinases and to support LARC-mass spectrometric interpretations.

\subsubsection{IgG-beads Association with PTKs in Phagocytosis}

The Fc gamma receptor $(\mathrm{Fc} \gamma \mathrm{R})$ is triggered by immunoglobulin $\mathrm{G}(\mathrm{IgG})$ ligand covering antigen particles via binding to the $\mathrm{Fc}$ portion of $\mathrm{IgG}$, a process referred to as phagocytosis (Jankowski et al., 2008; Cheeseman, 2006). Our results on PTK2, PTK2b, and both (PTK2 \& PTK2b) siRNA knockdown in relation to the Fc gamma receptor and its ligand $\operatorname{IgG}$ did not show any significant effect on phagocytosis efficiency of U937 macrophages ( $p>0.05$ ) (Appendix. D-E). The IgG-coated beads were only incubated with U937 in one media condition of RPMI supplemented with 10\% FBS for 2 hours (Fig. 5). Greenberg et al. (1994) suggested that in human macrophages FAK phosphorylation was thought to connect with Fc $\gamma$ Rs-mediated phagocytosis. However, in a later study by Pan et al. (1999) FcyR-mediated phagocytosis showed no increase of p125Fak phosphorylation in mice macrophages. The activation of Pyk2 via the cytokine receptor Jak-STAT mechanism in the presence of interferon appears to be dependent on ITAMs stimulation (Ivashkiv, 2009; Dhodapkar et al., 2007). Different subgroups of FcyRs such as FcyRIIA exhibited a function in autoimmune diseases when activated by ITAMs and others like FcyRIIIB demonstrated some accumulation in the affected tissue with no toxic effect in in vivo mice macrophages reports (Tsuboi et al., 2008). Our mass spectrometric data (Table 1) showed lower PTK2 and PTK2b peptides scores with the Fc $\gamma \mathrm{R} / \mathrm{IgG}$ complex than with the CD36/oxLDL complex. Thus, PTK2 and PTK2B could have a different role in cellular functions rather than in FcyRs-induced phagocytosis in U937 macrophages. 


\subsubsection{OxLDL-beads Association with PTKs in Phagocytosis}

The mass spectrometric data demonstrated a strong involvement of protein tyrosine kinases (PTK2 and PTK2b) with the CD36 scavenger receptor, specifically, in the presence of oxLDL coated particles, which was an objective of this study. The mechanism for triggering the CD36 receptor is usually activated by oxLDL-coated antigens and, in the absence of CD36 receptor, a notable increase of serum cholesterol and other free fatty acids (Febbraio et al., 1999). Other studies show that in the absence of macrophage SR-AI/II, an $80 \%$ reduction of acetylated LDL clearance, in contrast to a $30 \%$ reduction of oxLDL uptake by this receptor indicating a different scavenger receptor (such as CD36) is likely to be responsible for oxLDL uptake (Lougheed et al., 1997). Clinical trials indicated an association of atherogenic development and progression in CD36 depleted patients (Yuasa-Kawase et al., 2012). Thus, investigations are needed for the CD36 receptor and its ligand partner oxLDL in atherosclerosis diseases.

In our study, human U937 cells were incubated with oxLDL beads in three media conditions including: RPMI enriched with 10\%FBS, RPMI serum free, and HEPES buffer, to observe and manage the best possible phagocytic inhibition. The initial observation for cellular phagocytic capability was with $10 \%$ FBS media incubated with either IgG or oxLDL coated beads for 2 hours. We found that with IgG beads, challenged macrophages where the siRNA was knockdown using siRNA directed at PTK2, PTK2b, and both siRNA had no significant reduction in phagocytosis efficiency (Appendix. G-I). In contrast, a significant phagocytic efficiency effect was seen in U937 challenged with oxLDL beads in media condition including RPMI 10\%FBS ( $\mathrm{F}=8.51, \mathrm{p}<0.05$ ), RPMI serum free ( $\mathrm{F}=34.38, \mathrm{p}<0.0001)$, and HEPES buffer $(\mathrm{F}=101.67, \mathrm{p}<0.0001)$ in all PTKs siRNA conditions. Thus, PTK2 and PTK2b both play a role in phagocytosis in human U937 cells-treated oxLDL-coated beads. 
In recent studies the stimulation of FAK has been correlated with ROS production through NADPH oxidase by down regulation of oxidative SHP-1 in a CD36/oxLDL dependent manner (Park et al., 2009). FAK activation is also connected to CD36 build up in the atrial intima in the presence of oxLDL in the fluid phase (Park et al., 2009). Another way of FAK phosphorylation is suggested by Src family kinases (such as Lyn) at the time of CD36 signaling and with src homology 2-containing phosphotyrosine phosphatase (SHP-2) inhibition (Silverstein et al., 2010). FAK can also bind directly to Lyn (Mlinaric-Rascan and Yamamoto, 2001), and CD36 at the C-terminal making strong binding connection with FAK recognized by peptide affinity chromatography (Thorne et al., 2006). continuous activation of FAK is caused by a cocktail effect of free radicals and SHP-2 inactivation when oxLDL is present leading to an unbalanced or loss of actin regulation of cellular functions (Silverstein and Febbraio, 2010). The main players in actin polymerization through known scaffolding proteins includes paxillin, FAK, Pyk2, Fyn and p130Cas, and they were suggested to be activated by CD36 signaling cascades (Stuart et al., 2007; Park et al., 2009). Thus, PTK2 and PTK2b can play a role in phagocytosis induced by oxLDL particles as mentioned in this study involving human U937 and other murine macrophage studies. 


\subsubsection{Immuno fluorescence/blotting and siRNA Knockdown Confirmation}

The immunofluorescent staining of U937 cells and western blotting assays successfully confirmed the localization of PTK2 and PTK2b when introduced to oxLDL beads (Fig. $14 \& 15$ ). The permeablized cytosolic staining of the cells and intensity quantification provided the ability of this system to calculate the abundance of PTKs silenced or non-silenced with RNA (Appendix. U-X). Overall localization of PTK2 and PTK2b is clearly concentrated in the peripheral part of the cytosol indicating its presence at the focal contacts and near actin site (see image). Our report shows a significant effect of siRNA on PTK2 ( $\mathrm{F}=26.46$, p $<0.0001)$ and PTK2b (F=44.98, $\mathrm{p}<0.0001)$ localization against negative treatments with ANOVA analysis (Appendix. U \& W). A regression test was performed with $\mathrm{Cy} 5$ intensity against $\mathrm{Cy} 3$ intensity for silenced

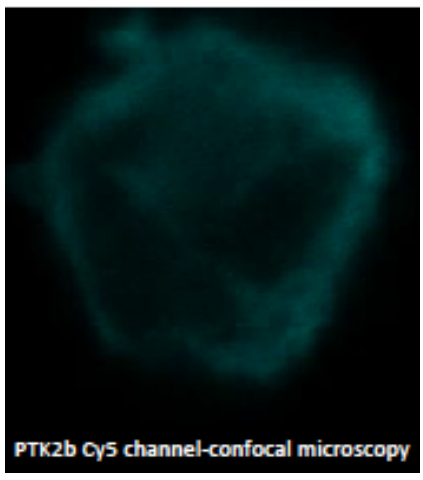
PTK2 ( $F=103.38, p<0.0001)$ and silenced PTK2b ( $F=74.88, p<0.0001)$ (Fig. 17) (Appendix. V \& X).

A successful western blotting was carried out to confirm the protein bands for PTK2 or FAK (125 kDa) and PTK2b or Pyk2 (116 kDa) (Fig. 15), using PMAtreated U937 cell lysate. 

A) PTK2
B) PTK2B
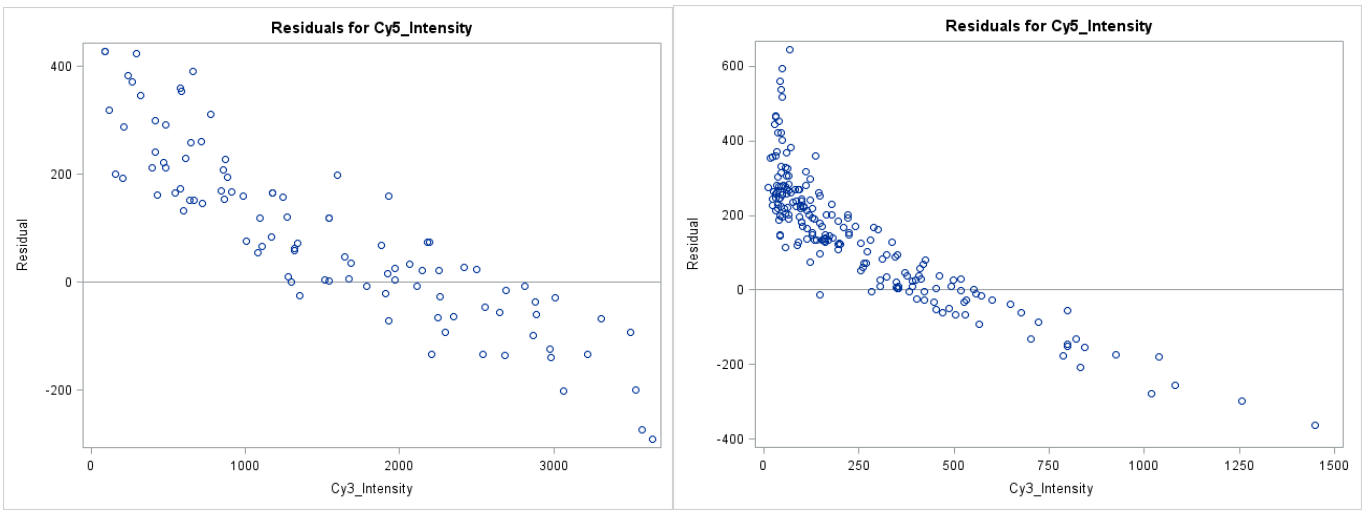

Figure 17. Regression analysis of Cy5 against Cy3 intensities for PTK2 (A) and PTK2b (B) siRNA-treated U937 cells.

The total cell intensity count for PTK2 was 100 cells and PTK2b 200 cells (Appendix. V \& X).

\subsubsection{Pharmacological inhibitors Confirmation}

This study utilized a diverse experimental procedure by using the known nonspecific FAK drug inhibitor PF 573228 to further confirm the role of PTKs in phagocytosis and to validate drug inhibition techniques. We used IgG-coated beads in U937 cells (10\% FBS media) treated with PF 573228 in different concentrations. Our results using this procedure showed no sign of phagocytic efficiency effect of IgG-coated beads internalization (Appendix. $S$ \& $T$ ). However, the other scenario performed with oxLDL beads (HEPES buffer) and treated with PF drug including concentrations of $0.1,0.5,1,5,10 \mu \mathrm{M}$, and only 5 $\mu \mathrm{M}$ and $10 \mu \mathrm{M}$ concentrations significantly impaired phagocytosis beads internalization $(\mathrm{F}=11.56, \mathrm{p}<0.0001)$ (Appendix. P-R).

Recent studies have showed no significant effect of PF 573228 treatment with 1 $\mu \mathrm{M}$ concentration on either oxLDL or IgG coated beads for U937 phagocytosis (unpublished data). Other studies found that by using the PF 573228 FAK drug 
inhibitor, human platelet cytosolic calcium levels were inhibited and indirectly inhibited FAK. Furthermore, FAK phosphorylation was directly blocked using 1 $\mu \mathrm{M}$ of PF concentration leading to PAK and Akt inhibition (Jones et al., 2009). Lafrenaye and Fuss (2010) observed that PF-treated oligodendrocytes ( $\mathrm{PF}=100$ $\mathrm{nM}$ ) blocked FAK autophosphorylation with no sign of cell survival defects. However, our results of macrophages U937-treated PF FAK inhibitor showed an effect of phagocytosis efficiency using 5 and $10 \mu \mathrm{M}$ drug concentrations with oxLDL-coated beads (Fig. 13).

\subsection{New information of Focal Adhesion Kinases Functions}

The initial data for PTK2 and PTK2b isoforms obtained from the mass spectrometry provided a correlation of the suggested tyrosine kinases in the process of phagocytosis of oxLDL beads. At the molecular level our results showed that protein tyrosine kinases are released from macrophage U937 cells. In the literature different human macrophage cell lines demonstrated FAK or Pyk2 signaling in the CD36 receptor in relation to phagocytosis (Greenberg et al., 1994; Febbraio et al., 1999; Watson et al., 2001; Guinamard et al., 2000; Park et al., 2009). Nevertheless, our findings reveal a novel association of PTK2 and PTK2b secreted from human macrophage U937 cells. The preliminary results of PTKs connection with receptor complexes by mass spectrometry were confirmed by independant analytical methods. Thus the results from this study support the hypothesis of PTKs function and signaling in phagocytosis as well as in the atherosclerosis progression. As a result, the presence of protein tyrosine kinases in human macrophages could provide a clear understanding of the cellular adhesion and focal contact mechanisms in relation to phagocytosis of oxLDL beads and the CD36 signaling pathway. However, an investigation on PTK uncharacterized domains dynamic activation processes could support our findings. 


\section{CONCLUSION}

Despite the current advances in FAKs structural, signaling and therapeutics development, the full interpretation of FAKs structure remains under investigation. Indeed, other FAK isoforms are also not fully recognized from a structural point of view. Our findings revealed a puzzling function of FAKs where they play a role in macrophage phagocytosis in human immune cells. The overall confirmation tests for PTK2 and PTK2b were performed in various cell stress conditions including siRNA PTKs knockdown, PTKs immunofluorescence localization and drug inhibition analysis. This report demonstrates possible ways of quantifying the effect of IgG beads and oxLDL beads in phagocytosis at the time of PTK2 and PTK2b inhibition and successful reduction of phagocytosis efficiency of the U937 cell line under different treatment conditions. Protein tyrosine kinases including PTK2 and PTK2b were inactivated by short interfering RNA plus known drug inhibitors with viable overall cell functions. The inactivation of PTK2 and PTK2b successfully decreased the ability of U937 cells to engulf oxLDL-coated beads in relation to CD36 receptor macrophage-mediated phagocytosis. Our novel interpretations of PTK2 and PTK2b knockdown inhibition of oxLDL beads uptake by their CD36 receptor could undermine PTKs insignificant role in activated Fc $\gamma \mathrm{R}$ and their ligand IgG. This novel insight obtained as a result of this study could reveal some of the important answers in FAKs biological functions in the human body, especially in regards to the innate immune response found with atherosclerosis disease. Yet, FAKs structural solutions and knowledge of FAK other isoforms could facilitate the current dilemma of their explicit functions in vivo and in vitro under the molecular level in relation to phagocytosis of oxLDL in atherosclerosis. 


\section{FUTURE OBJECTIVES}

Future studies on the presence of PTK2 and PTK2b in receptor complexes can be tested with dominant negative mutants to further confirm the results obtained by this study. Furthermore, structural knowledge of the uncharacterized proline-rich sites for FAK could provide our study more confidence of domains signaling role and in lipids binding to FAK FERM domain. Finally, the identification of other FAK isoforms with their fulllength structure could demonstrate how the protein kinase family functions and their involvement in phagocytosis. 


\section{APPENDIX}

\section{Appendix A. Mass spectrometry PTKs detection peptides spectra.}

Capture of PTK2 by a tandem mass ESI-MS/MS $(\mathrm{m} / \mathrm{z})$ using reverse phase column. The spectra showing MS/MS fragment $\mathrm{MH}+2159.322 \mathrm{Da}$ with peptide sequence of EIEMAQKLLNSDLGELINK. PTK2 is found with Anti CD36IgAtreatment.

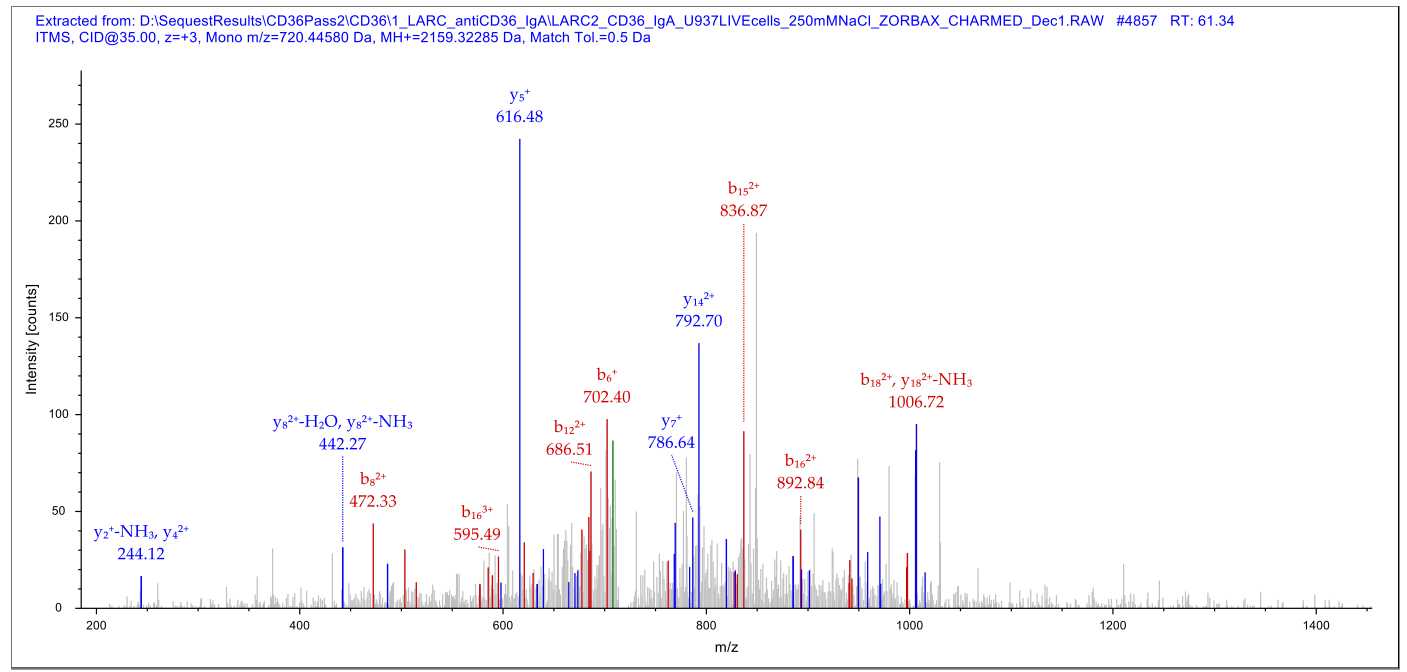

Capture of PTK2 by a tandem mass ESI-MS/MS $(\mathrm{m} / \mathrm{z})$ using reverse phase column. The spectra showing MS/MS fragment $\mathrm{MH}+1398.587 \mathrm{Da}$ with a peptide sequence of NLLDVIDQARLK. PTK2 is found with LARC oxLDL treatment.

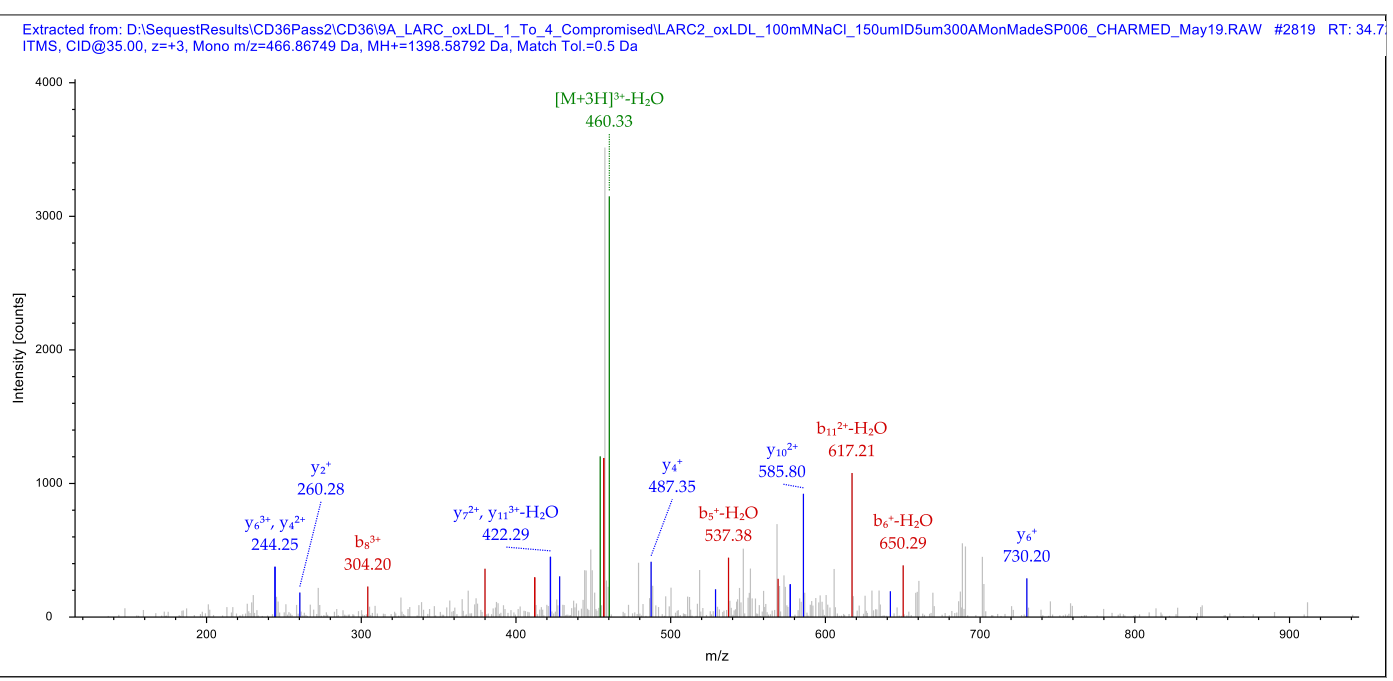


Capture of PTK2b by a tandem mass ESI-MS/MS $(\mathrm{m} / \mathrm{z})$ using reverse phase column. The spectra showing MS/MS fragment MH+2222.316 Da with a peptide sequence of YASKVSEGMALQLGCLELRR. PTK2 is found with LARC oxLDL treatment.

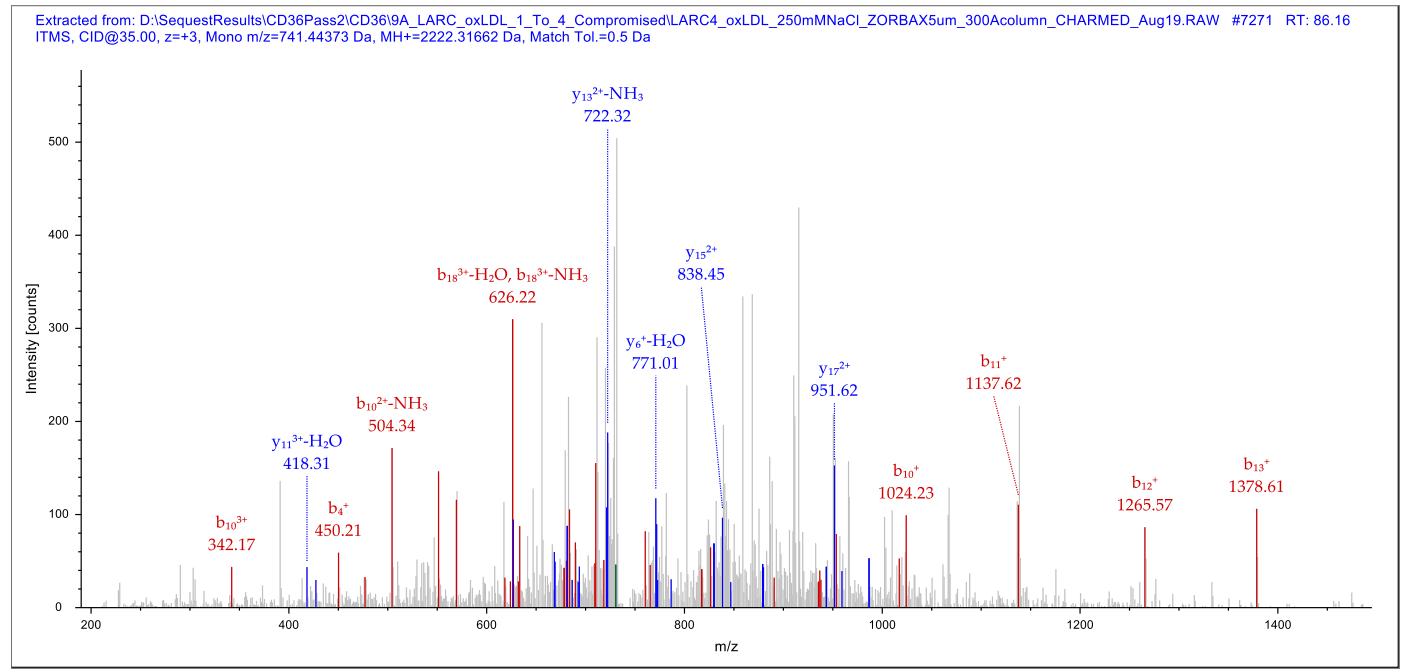




\section{Appendix B. Experimental design schematic including the goals in}

\section{numbers.}

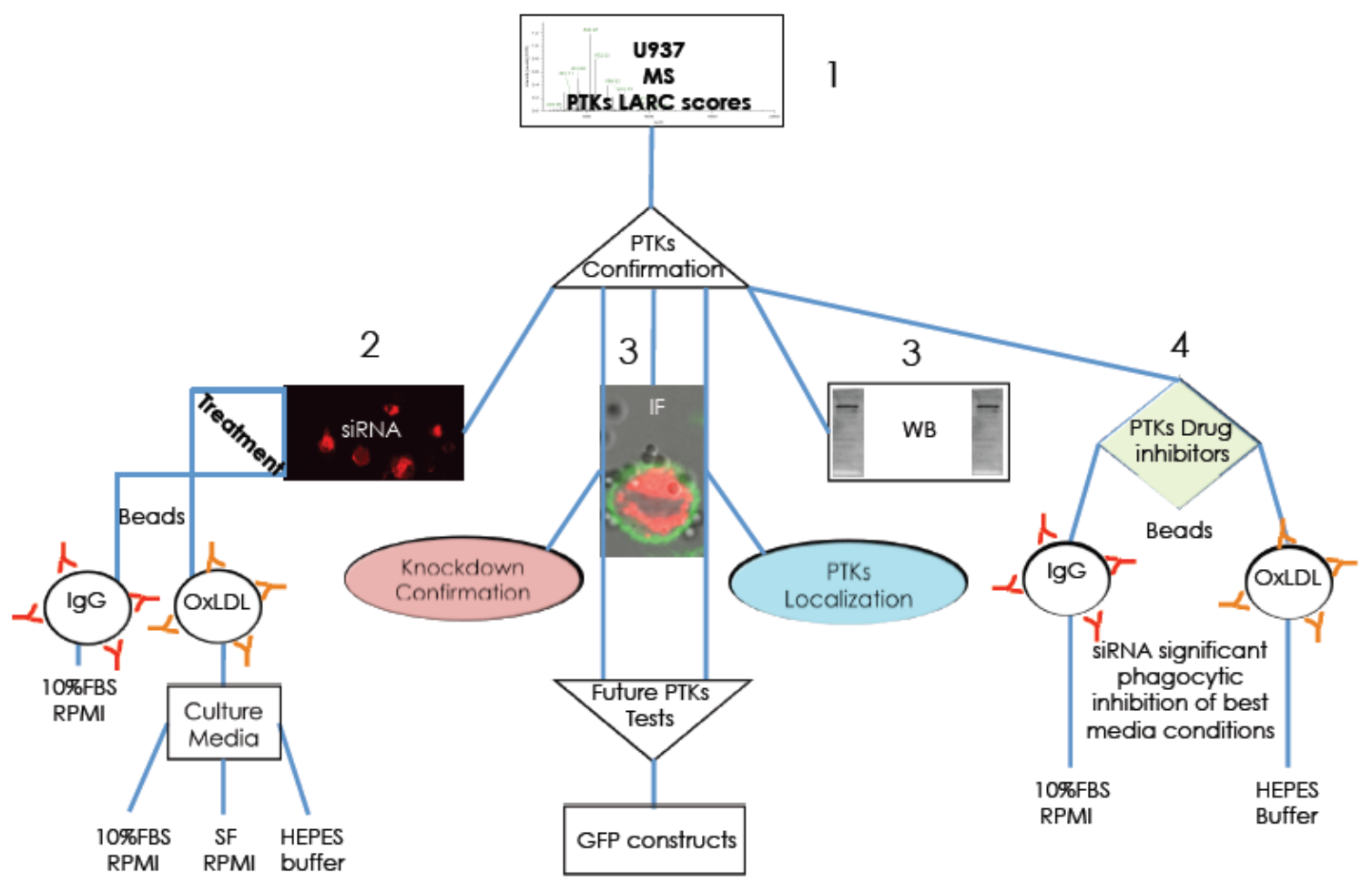




\section{Appendix C. STRING 9.1 protein/protein interaction of PTK2 and}

PTK2B including Fc and CD36 receptors. Developed by Szklarczyk et al., 2011.

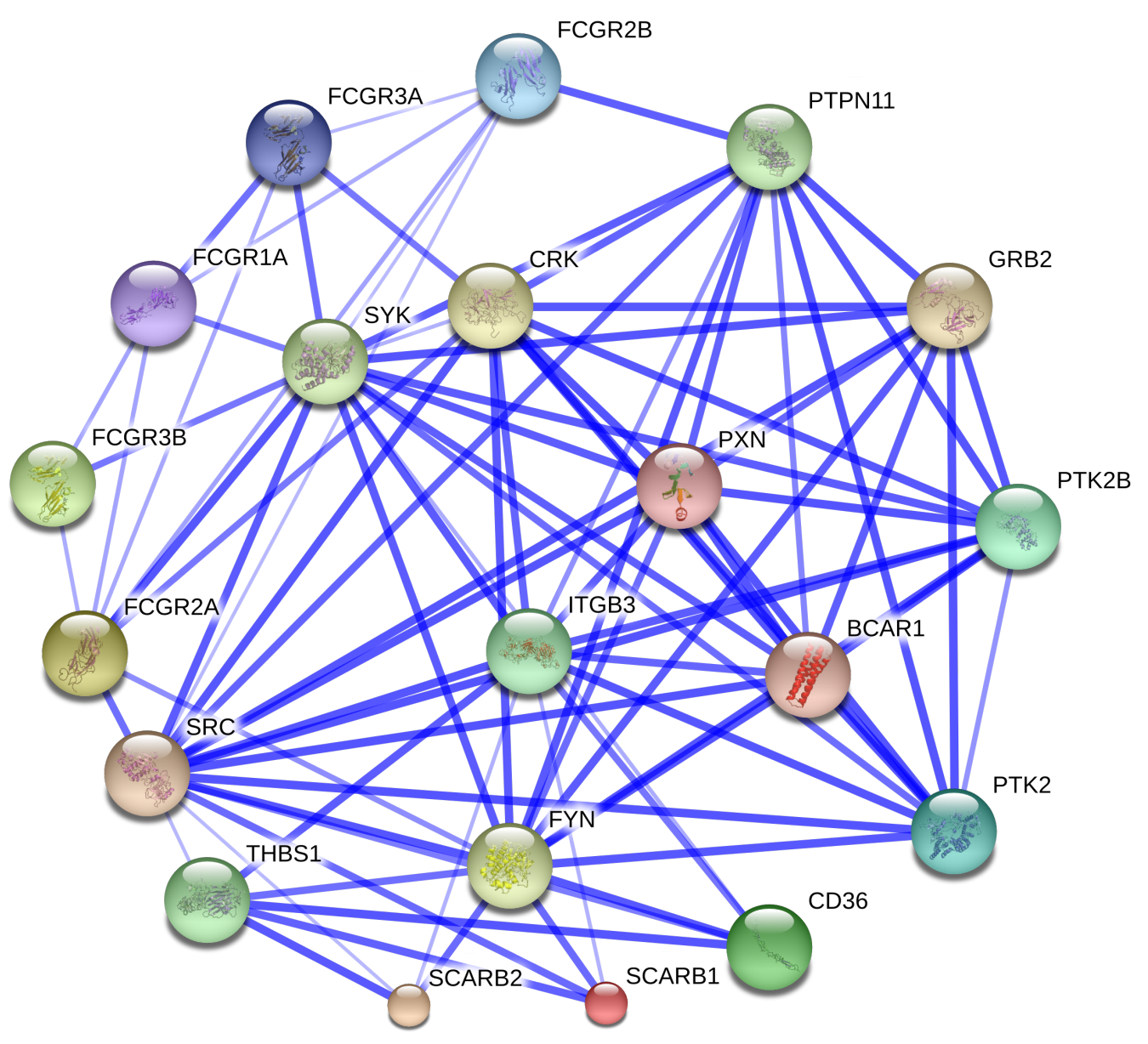




\section{Appendix D. SAS 9.3 program ANOVA analysis of the phagocytosis efficiency for IgG beads first replicate in RPMI 10\%FBS media.}

The SAS System

The GLM Procedure

\section{Class Level Information}

Class Levels Values

Treatment $\quad 5$ Both Neg PTK2 PTK2B scrambled

Number of Observations Read 1499

Number of Observations Used 1499

The GLM Procedure

Dependent Variable: Phagocytosis_Efficiency_U937

$\begin{array}{lrrrrr}\text { Source } & \text { DF } & \text { Sum of Squares } & \text { Mean Square } & \text { F Value } & \text { Pr }>\text { F } \\ \text { Model } & 4 & 3.5679410 & 0.8919853 & 8.76<.0001 \\ \text { Error } & 1494 & 152.1083386 & 0.1018128 & \\ \text { Corrected Total } & 1498 & 155.6762796 & & & \end{array}$

R-Square Coeff Var Root MSE Phagocytosis_Efficiency_U937 Mean
$0.022919 \quad 44.90089$
0.319081
0.710635

$\begin{array}{lrrrrrr}\text { Source } & \text { DF } & \text { Type I SS } & \text { Mean Square } & \text { F Value } & \operatorname{Pr}>\text { F } \\ \text { Treatment } & 4 & 3.56794101 & 0.89198525 & 8.76 & <.0001\end{array}$


Source DF Type III SS Mean Square F Value Pr $>$ F

$\begin{array}{llllll}\text { Treatment } & 4 & 3.56794101 & 0.89198525 & 8.76 & <.0001\end{array}$

The GLM Procedure

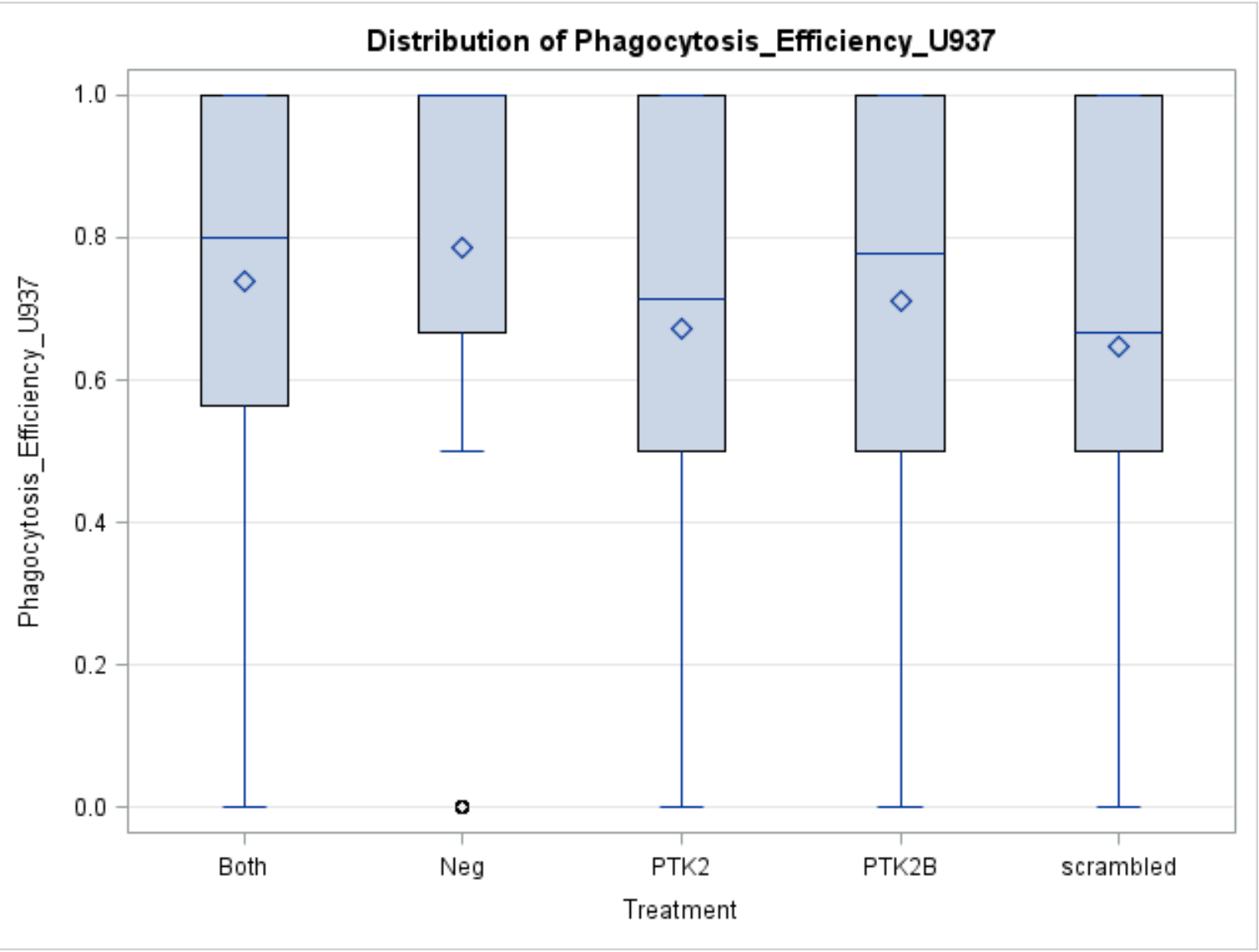

\begin{tabular}{|lrrr}
$\begin{array}{l}\text { Level of } \\
\text { Treatment }\end{array}$ & N & Phagocytosis_Efficiency_U937 \\
Both & $\mathbf{3 0 0}$ & 0.73760239 & 0.29193054 \\
Neg & $\mathbf{3 0 0}$ & 0.78579524 & 0.33460577 \\
PTK2 & $\mathbf{3 0 0}$ & 0.67251665 & 0.31805029 \\
PTK2B & $\mathbf{3 0 0}$ & 0.71026410 & 0.31687063 \\
& & & Std Dev \\
scrambled & $\mathbf{2 9 9}$ & 0.64678142 & 0.33218240
\end{tabular}


The GLM Procedure

Least Squares Means

Adjustment for Multiple Comparisons: Tukey-Kramer

\begin{tabular}{|lrr}
\hline Treatment Phagocytosis_Efficiency_U937 & LSMEAN Number \\
& LSMEAN & \\
Both & 0.73760239 & 1 \\
Neg & 0.78579524 & 2 \\
PTK2 & 0.67251665 & 3 \\
PTK2B & 0.71026410 & 4 \\
scrambled & 0.64678142 & 5
\end{tabular}

\begin{tabular}{|lrrrrrr}
\hline \multicolumn{5}{|c|}{$\begin{array}{r}\text { Least Squares Means for effect Treatment } \\
\text { Pr > }|\mathbf{t}| \text { for H0: LSMean(i)=LSMean(j) }\end{array}$} \\
Dependent Variable: Phagocytosis_Efficiency_U937 \\
i/j & $\mathbf{1}$ & $\mathbf{2}$ & $\mathbf{3}$ & $\mathbf{4}$ & $\mathbf{5}$ \\
$\mathbf{1}$ & & 0.3453 & 0.0915 & 0.8322 & 0.0046 \\
$\mathbf{2}$ & 0.3453 & & 0.0001 & 0.0311 & $<.0001$ \\
$\mathbf{3}$ & 0.0915 & 0.0001 & & 0.5960 & 0.8613 \\
$\mathbf{4}$ & 0.8322 & 0.0311 & 0.5960 & & 0.1067 \\
$\mathbf{5}$ & 0.0046 & $<.0001$ & 0.8613 & 0.1067 & \\
\hline
\end{tabular}




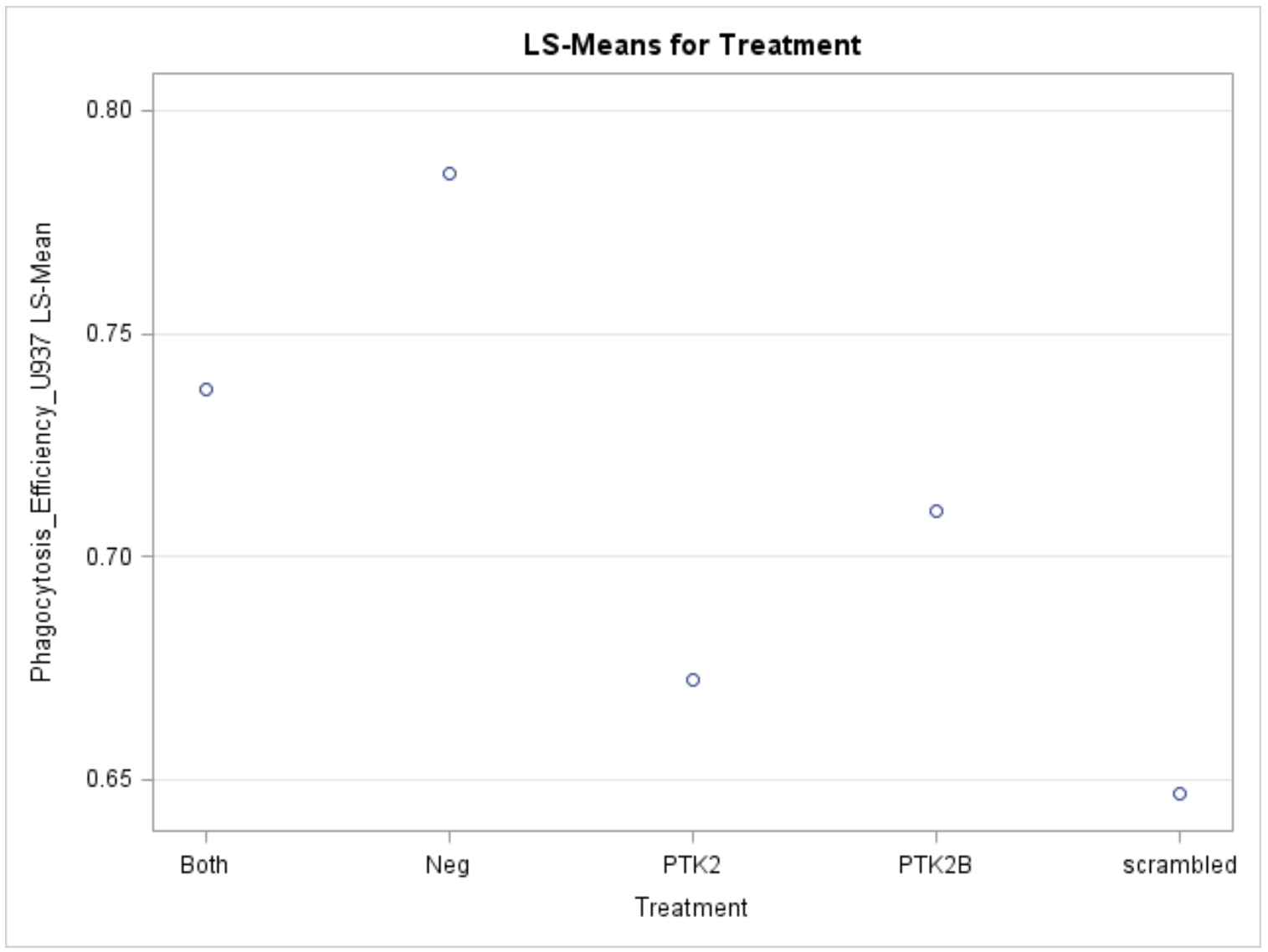




\section{Appendix E. SAS 9.3 program ANOVA analysis of the phagocytosis efficiency for IgG beads second replicate in RPMI 10\%FBS media.}

The SAS System

The GLM Procedure

\section{Class Level Information}

Class Levels Values

Treatment 5 Both Neg PTK2 PTK2B scrambled

Number of Observations Read 750

Number of Observations Used 750

The GLM Procedure

Dependent Variable: Phagocytosis_Efficiency_U937

\begin{tabular}{|lrrrrr}
\hline Source & DF & Sum of Squares & Mean Square & F Value & Pr $>$ F \\
Model & 4 & 1.95639445 & 0.48909861 & 5.04 & 0.0005 \\
Error & 745 & 72.34641802 & 0.09710929 & & \\
Corrected Total & 749 & 74.30281247 & & & \\
\end{tabular}

R-Square Coeff Var Root MSE Phagocytosis_Efficiency_U937 Mean
$0.026330 \quad 48.33596$
0.311624
0.644704

$\begin{array}{lrrrrrr}\text { Source } & \text { DF } & \text { Type I SS } & \text { Mean Square } & \text { F Value } & \text { Pr }>\text { F } \\ \text { Treatment } & 4 & 1.95639445 & 0.48909861 & 5.04 & 0.0005\end{array}$


Source DF Type III SS Mean Square F Value $\operatorname{Pr}>$ F

$\begin{array}{llllll}\text { Treatment } \quad 4 & 1.95639445 & 0.48909861 & 5.04 & 0.0005\end{array}$

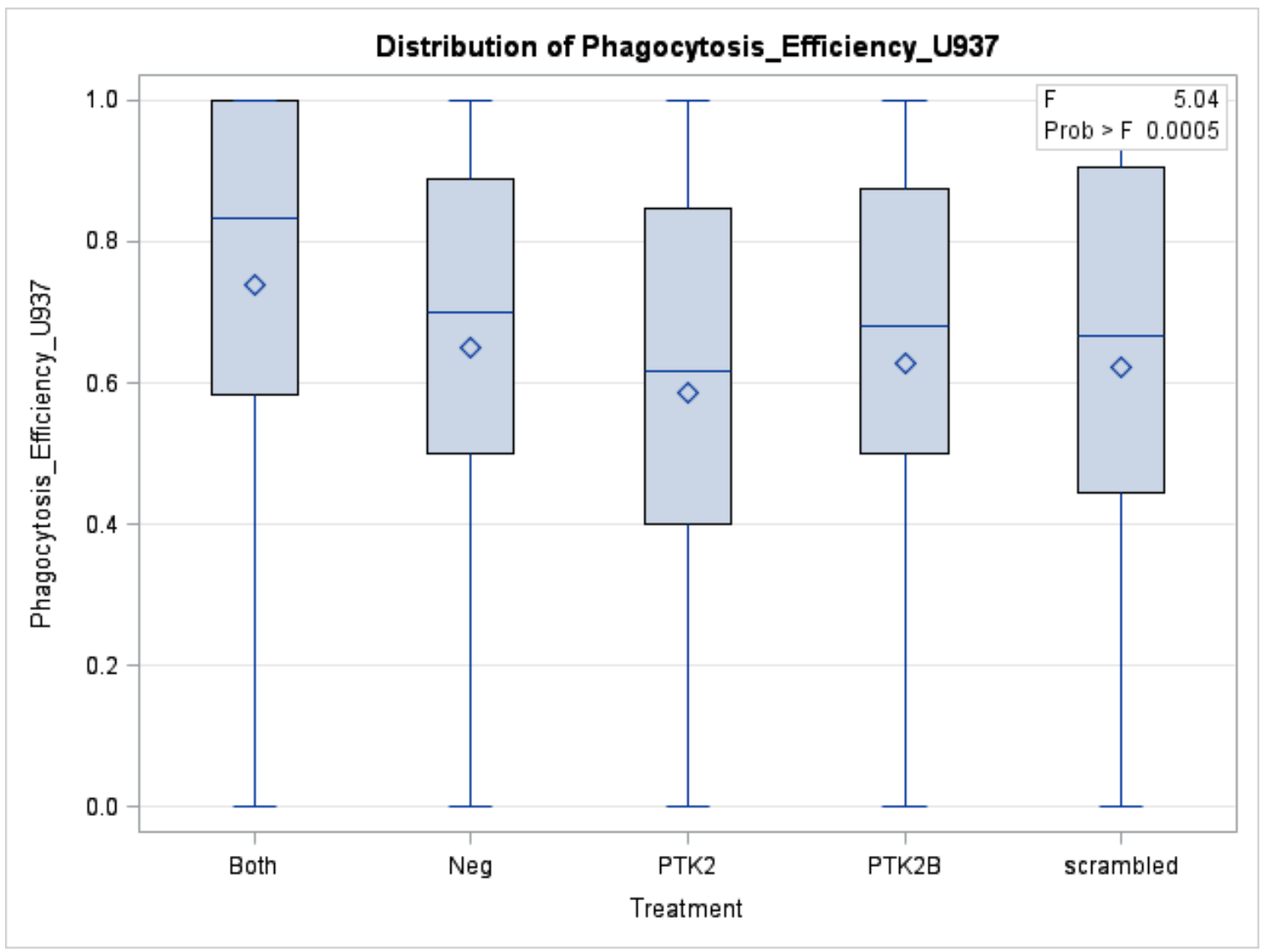

The GLM Procedure

Least Squares Means

Adjustment for Multiple Comparisons: Tukey

$\begin{array}{lrr}\text { Treatment } & \begin{array}{r}\text { Phagocytosis_Efficiency_U937 } \\ \text { LSMEAN }\end{array} \\ & 0.73846721 & 1 \\ \text { Both } & 0.64877324 & 2 \\ \text { Neg } & 0.58613186 & 3 \\ \text { PTK2 } & & 4 \\ \text { PTK2B } & 0.62913847 & 4\end{array}$




\section{Treatment Phagocytosis_Efficiency_U937 LSMEAN Number LSMEAN \\ $\begin{array}{lll}\text { scrambled } & 0.62100695 & 5\end{array}$}

\begin{tabular}{|c|c|c|c|c|c|}
\hline & $\begin{array}{r}\text { Least Sq } \\
\operatorname{Pr}>|t| \\
\text { ndent } V\end{array}$ & $\begin{array}{l}\text { ares Me } \\
\text { or H0: L } \\
\text { iable: Pl }\end{array}$ & $\begin{array}{l}\text { Is for ef } \\
\text { Mean(i) } \\
\text { gocytos }\end{array}$ & $\begin{array}{l}\text { t Treatr } \\
\text { LSMean } \\
\text { Efficier }\end{array}$ & $\begin{array}{l}\text { ent } \\
\text { y937 }\end{array}$ \\
\hline $\mathbf{i} / \mathbf{j}$ & 1 & 2 & 3 & 4 & 5 \\
\hline 1 & & 0.0933 & 0.0003 & 0.0207 & 0.0101 \\
\hline 2 & 0.0933 & & 0.4095 & 0.9825 & 0.9387 \\
\hline 3 & 0.0003 & 0.4095 & & 0.7542 & 0.8690 \\
\hline 4 & 0.0207 & 0.9825 & 0.7542 & & 0.9994 \\
\hline 5 & 0.0101 & 0.9387 & 0.8690 & 0.9994 & \\
\hline
\end{tabular}




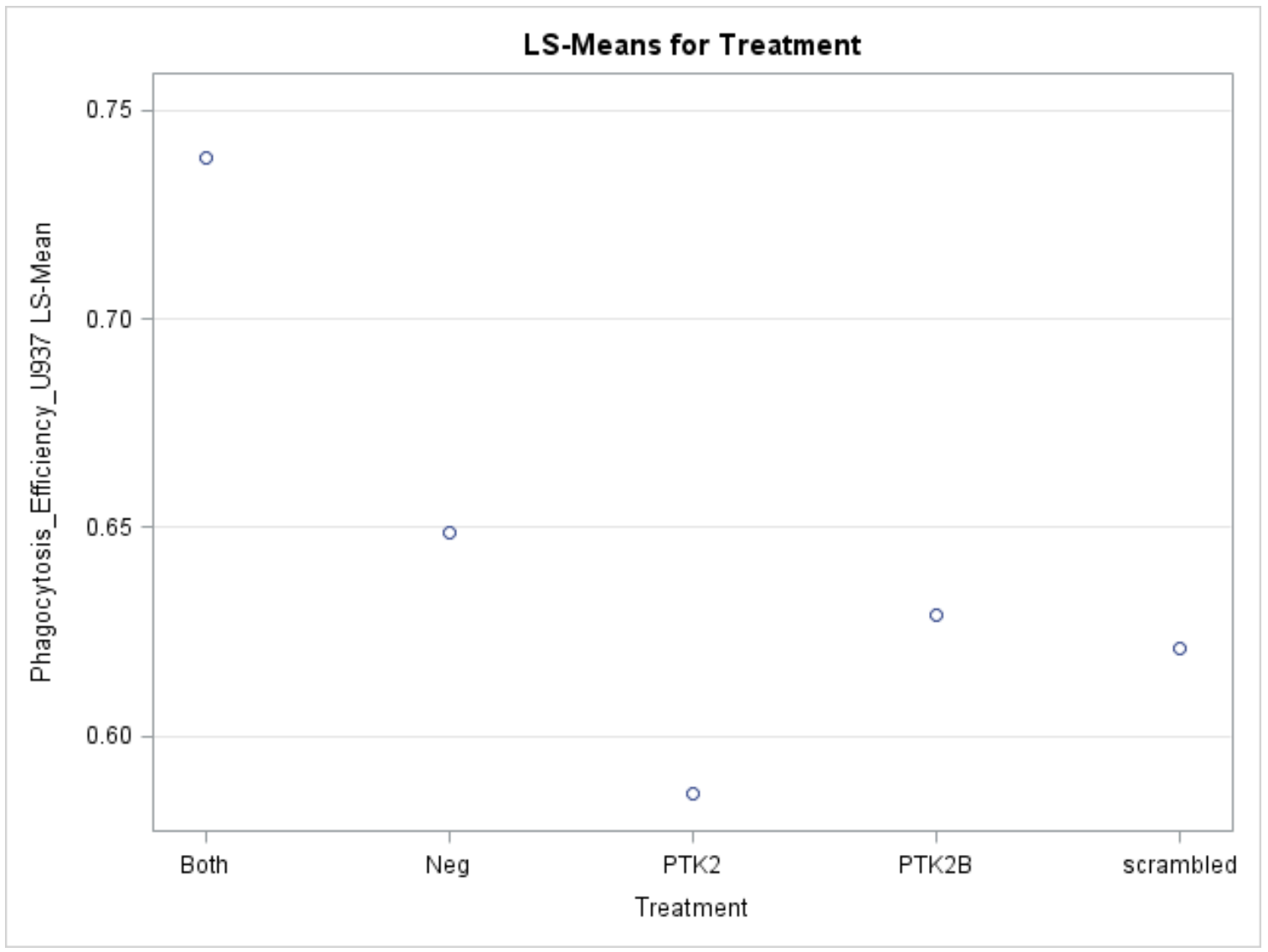




\section{Appendix F. SAS 9.3 program ANOVA analysis of the phagocytosis efficiency for IgG beads third replicate in RPMI 10\%FBS media.}

The SAS System

The GLM Procedure

\section{Class Level Information}

Class Levels Values

Treatment 5 Both Neg PTK2 PTK2B scrambled

Number of Observations Read 750

Number of Observations Used 750

The GLM Procedure

Dependent Variable: Phagocytosis_Efficiency_U937

$\begin{array}{lrrrrr}\text { Source } & \text { DF } & \text { Sum of Squares } & \text { Mean Square } & \text { F Value } & \text { Pr }>\text { F } \\ \text { Model } & 4 & 0.39960449 & 0.09990112 & 1.05 & 0.3828 \\ \text { Error } & 745 & 71.20277195 & 0.09557419 & & \\ \text { Corrected Total } & 749 & 71.60237644 & & & \\ \end{array}$

R-Square Coeff Var Root MSE Phagocytosis_Efficiency_U937 Mean
$0.005581 \quad 44.56140$
0.309151
0.693764

$\begin{array}{lrrrrrr}\text { Source } & \text { DF } & \text { Type I SS } & \text { Mean Square } & \text { F Value } & \operatorname{Pr}>\text { F } \\ \text { Treatment } & 4 & 0.39960449 & 0.09990112 & 1.05 & 0.3828\end{array}$




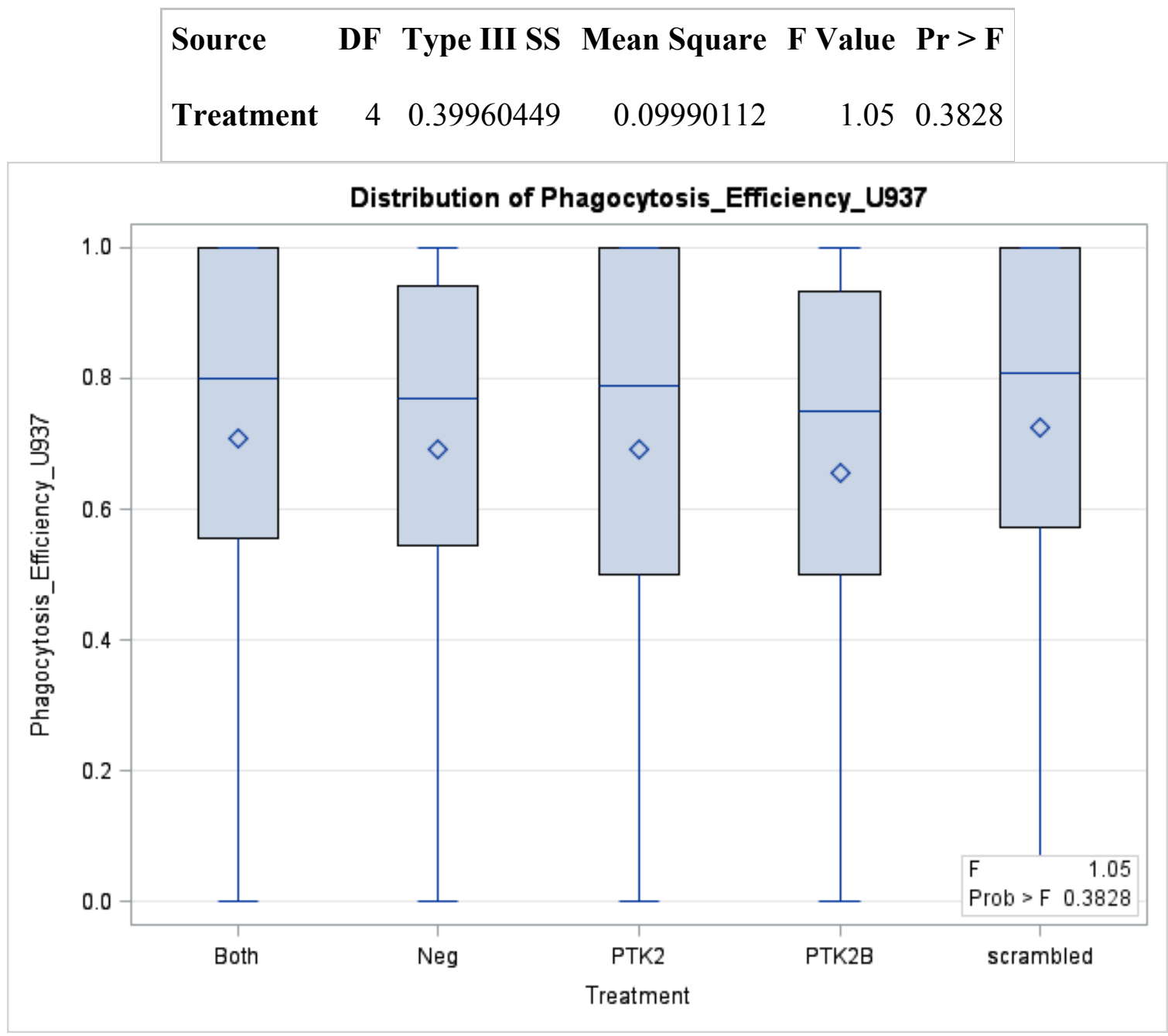

The GLM Procedure

Least Squares Means

Adjustment for Multiple Comparisons: Tukey

Treatment Phagocytosis_Efficiency_U937 LSMEAN Number LSMEAN

Both

0.70756272

1

Neg

0.69080917

2

PTK2

0.69085914

3

PTK2B

0.65497304

4

scrambled

0.72461391

5 


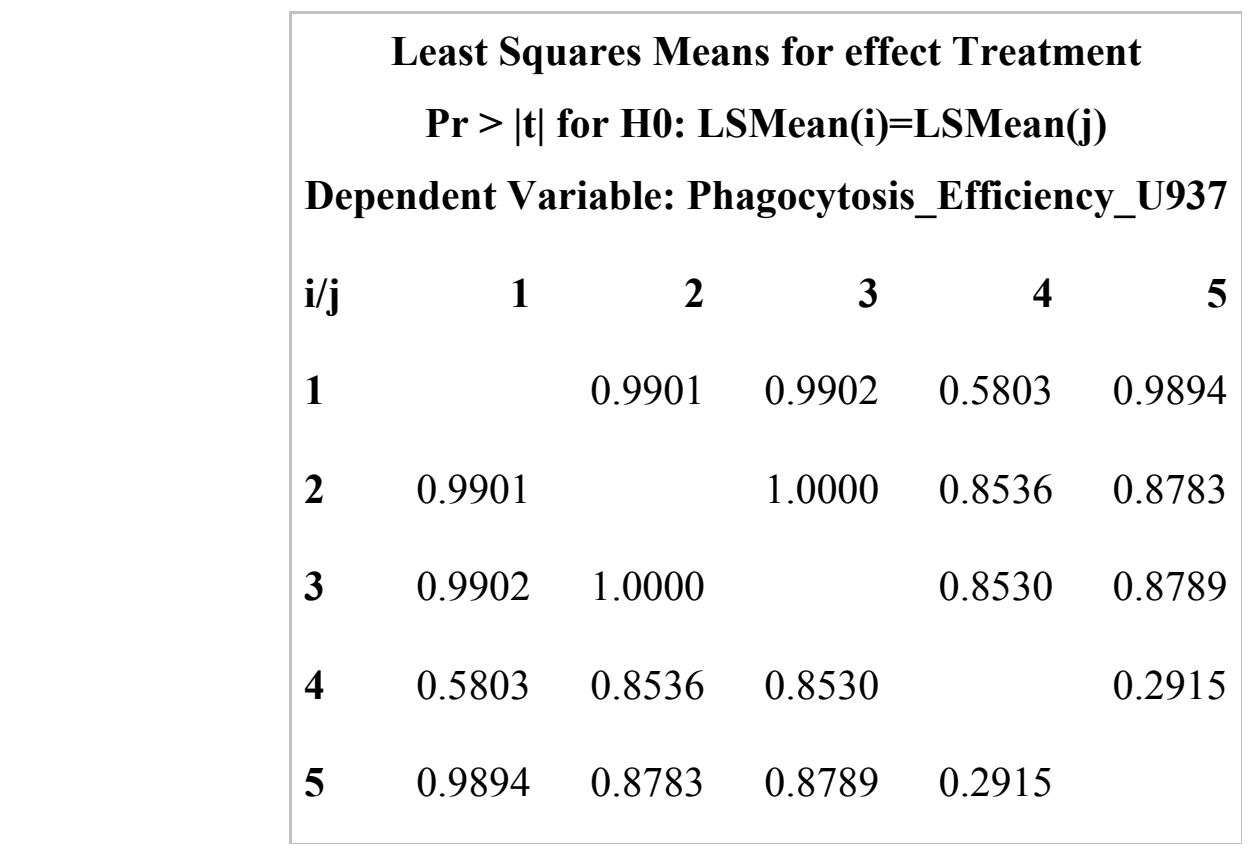

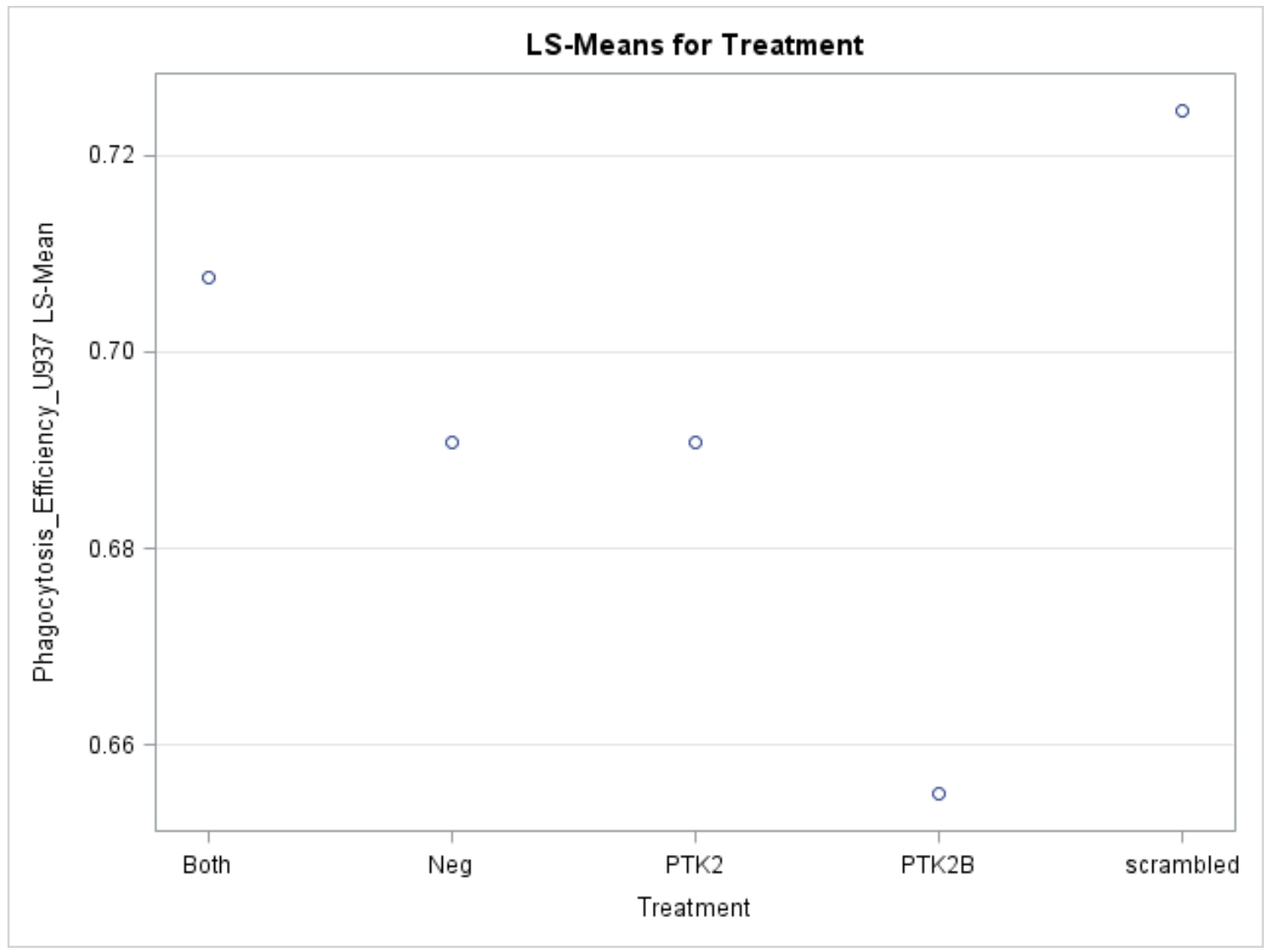




\section{Appendix G. SAS 9.3 program ANOVA analysis of the phagocytosis efficiency for oxLDL beads first replicate in RPMI 10\% FBS media.}

The SAS System

The GLM Procedure

\section{Class Level Information}

Class Levels Values

Treatment 5 Both Neg PTK2 PTK2B Scrambled

Number of Observations Read 751

Number of Observations Used 750

The GLM Procedure

Dependent Variable: Phagocytosis_Efficiency_U937

\begin{tabular}{|lrrrrr}
\hline Source & DF & Sum of Squares & Mean Square & F Value & Pr $>$ F \\
Model & 4 & 5.03713781 & 1.25928445 & $18.07<.0001$ \\
Error & 745 & 51.91163763 & 0.06968005 & & \\
Corrected Total & 749 & 56.94877544 & & & \\
\end{tabular}

R-Square Coeff Var Root MSE Phagocytosis_Efficiency_U937 Mean
0.088450
49.60082
0.263970
0.532188

Source DF Type I SS Mean Square F Value $\operatorname{Pr}>$ F

$\begin{array}{llllll}\text { Treatment } \quad 4 & 5.03713781 & 1.25928445 & 18.07 & <.0001\end{array}$ 
Source DF Type III SS Mean Square F Value Pr $>$ F

$\begin{array}{llllll}\text { Treatment } & 4 & 5.03713781 & 1.25928445 & 18.07 & <.0001\end{array}$

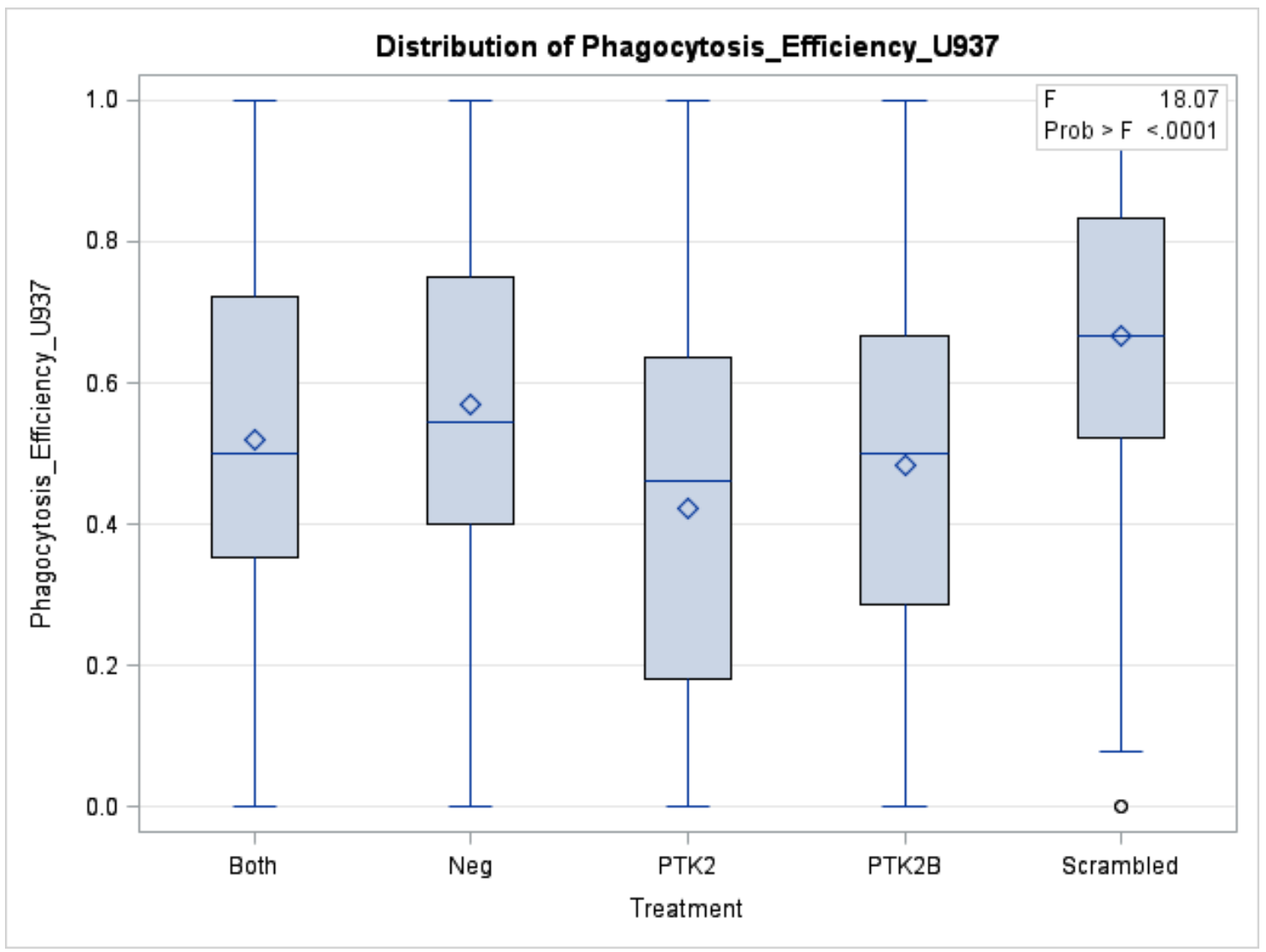

The GLM Procedure

Least Squares Means

Adjustment for Multiple Comparisons: Tukey

Treatment Phagocytosis_Efficiency_U937 LSMEAN Number

LSMEAN

Both

0.52055179

1

Neg

0.56828830

2

PTK2

0.42318821

3

PTK2B

0.48311119

4 
Treatment Phagocytosis_Efficiency_U937 LSMEAN Number LSMEAN

$\begin{array}{lll}\text { Scrambled } & 0.66580236 & 5\end{array}$

\begin{tabular}{|c|c|c|c|c|c|}
\hline & $\begin{array}{r}\text { Least Sq } \\
\qquad \mathbf{P r}>|\mathbf{t}|\end{array}$ & $\begin{array}{l}\text { ares Mea } \\
\text { or H0: L }\end{array}$ & $\begin{array}{l}\text { Is for eff } \\
\text { Mean(i) }\end{array}$ & $\begin{array}{l}\text { et Treatn } \\
\text { LSMean }\end{array}$ & ent \\
\hline & ndent $\mathrm{V}$ & iable: Pl & gocytosi & Effficien & y_U937 \\
\hline $\mathbf{i} / \mathbf{j}$ & 1 & 2 & 3 & 4 & 5 \\
\hline 1 & & 0.5197 & 0.0127 & 0.7348 & $<.0001$ \\
\hline 2 & 0.5197 & & $<.0001$ & 0.0424 & 0.0125 \\
\hline 3 & 0.0127 & $<.0001$ & & 0.2838 & $<.0001$ \\
\hline 4 & 0.7348 & 0.0424 & 0.2838 & & $<.0001$ \\
\hline 5 & $<.0001$ & 0.0125 & $<.0001$ & $<.0001$ & \\
\hline
\end{tabular}




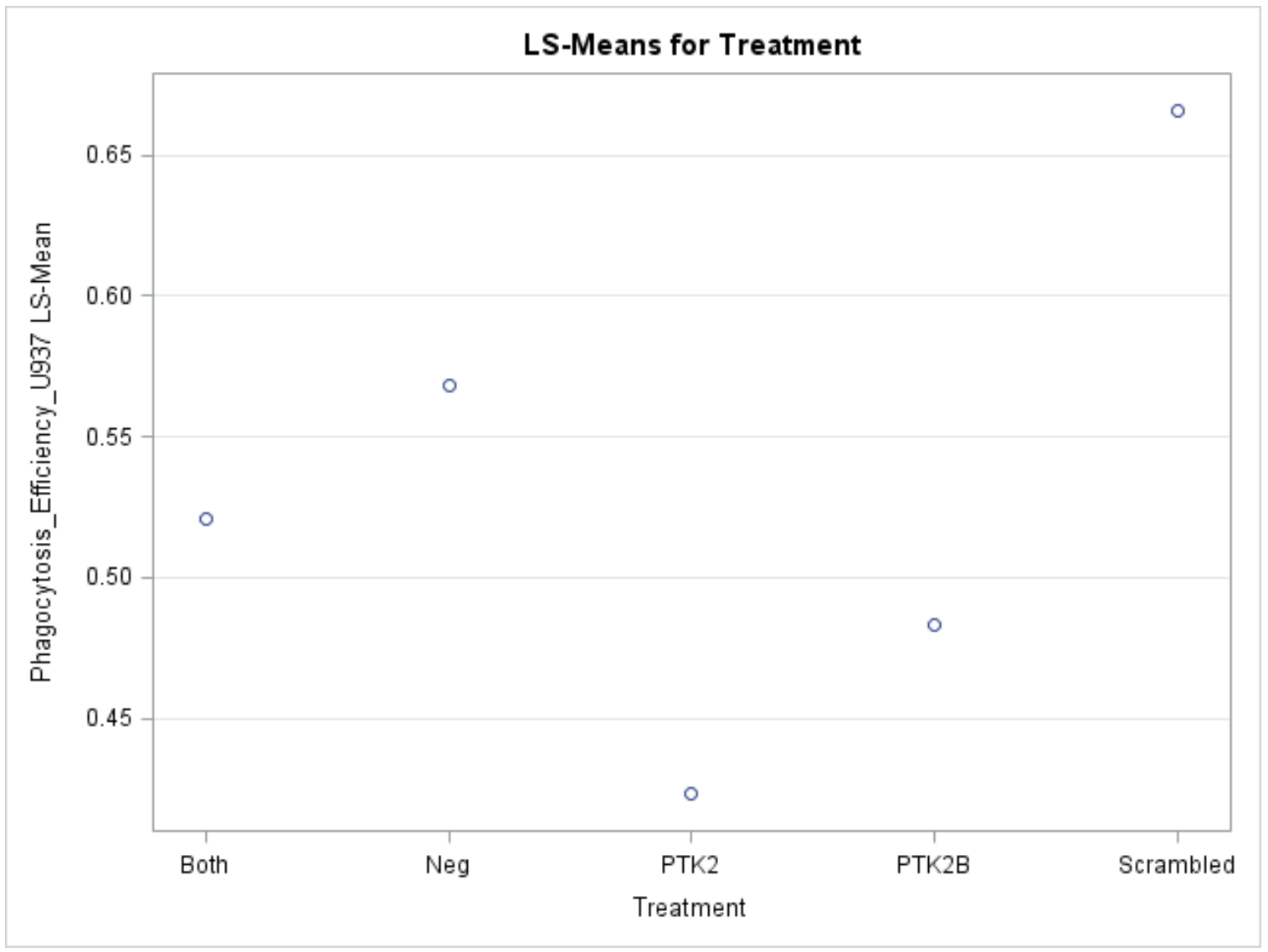




\section{Appendix H. SAS 9.3 program ANOVA analysis of the phagocytosis efficiency for oxLDL beads second replicate in RPMI 10\%FBS media.}

The SAS System

The GLM Procedure

\section{Class Level Information}

Class Levels Values

Treatment 5 Both Neg PTK2 PTK2B Scrambled

Number of Observations Read 751

Number of Observations Used 750

The GLM Procedure

Dependent Variable: Phagocytosis_Efficiency_U937

\begin{tabular}{lrrrrr} 
Source & DF & Sum of Squares & Mean Square & F Value & Pr $>$ F \\
Model & 4 & 1.94895904 & 0.48723976 & 5.04 & 0.0005 \\
Error & 745 & 71.97441392 & 0.09660995 & & \\
Corrected Total & 749 & 73.92337296 & & & \\
\hline
\end{tabular}

R-Square Coeff Var Root MSE Phagocytosis_Efficiency_U937 Mean

$\begin{array}{llll}0.026365 & 64.20310 & 0.310821 & 0.484122\end{array}$

Source DF Type I SS Mean Square F Value $\operatorname{Pr}>$ F

$\begin{array}{llllll}\text { Treatment } & 4 & 1.94895904 & 0.48723976 & 5.04 & 0.0005\end{array}$ 
Source DF Type III SS Mean Square F Value $\operatorname{Pr}>$ F

$\begin{array}{llllll}\text { Treatment } \quad 4 & 1.94895904 & 0.48723976 & 5.04 & 0.0005\end{array}$

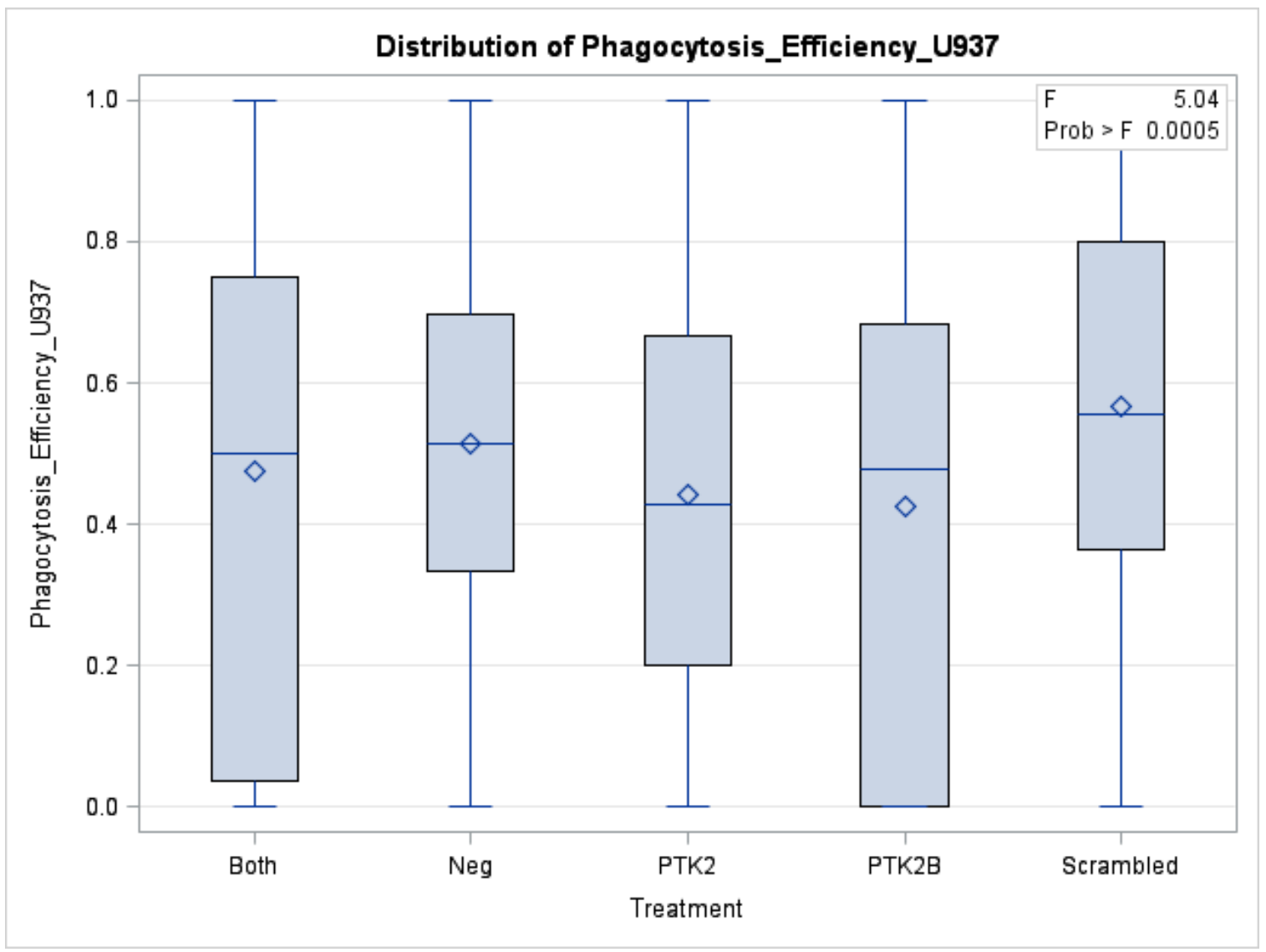

The GLM Procedure

Least Squares Means

Adjustment for Multiple Comparisons: Tukey

Treatment Phagocytosis_Efficiency_U937 LSMEAN Number

LSMEAN

Both $\quad 0.47519254$

$\begin{array}{lll}\text { Neg } & 0.51387415 & 2\end{array}$

$\begin{array}{lll}\text { PTK2 } & 0.44113982 & 3\end{array}$

$\begin{array}{lll}\text { PTK2B } & 0.42472118\end{array}$ 
Treatment Phagocytosis_Efficiency_U937 LSMEAN Number LSMEAN

$\begin{array}{lll}\text { Scrambled } & 0.56568308 & 5\end{array}$

\begin{tabular}{|c|c|c|c|c|c|}
\hline & $\begin{array}{r}\text { Least Sq } \\
\operatorname{Pr}>|t| \\
\text { ndent } V\end{array}$ & $\begin{array}{l}\text { ares Me } \\
\text { or H0: L } \\
\text { iable: Pl }\end{array}$ & $\begin{array}{l}\text { s for eff } \\
\text { Mean(i) } \\
\text { gocytos }\end{array}$ & $\begin{array}{l}\text { t Treatr } \\
\text { LSMean } \\
\text { Efficier }\end{array}$ & $\begin{array}{l}\text { ent } \\
\text { y937 }\end{array}$ \\
\hline $\mathbf{i} / \mathbf{j}$ & 1 & 2 & 3 & 4 & 5 \\
\hline 1 & & 0.8180 & 0.8776 & 0.6238 & 0.0870 \\
\hline 2 & 0.8180 & & 0.2542 & 0.0953 & 0.5996 \\
\hline 3 & 0.8776 & 0.2542 & & 0.9910 & 0.0050 \\
\hline 4 & 0.6238 & 0.0953 & 0.9910 & & 0.0009 \\
\hline 5 & 0.0870 & 0.5996 & 0.0050 & 0.0009 & \\
\hline
\end{tabular}




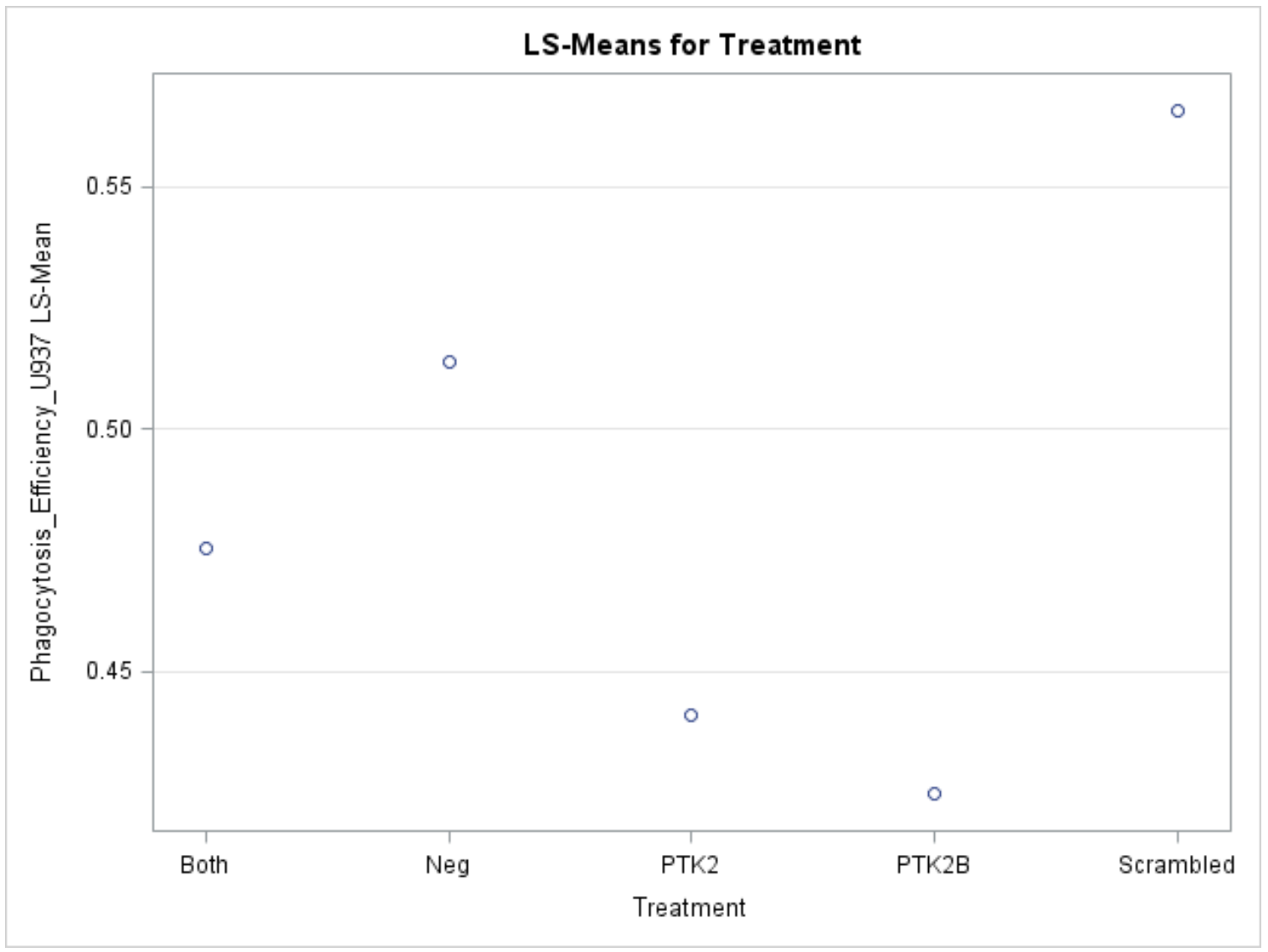




\section{Appendix I. SAS 9.3 program ANOVA analysis of the phagocytosis efficiency for oxLDL beads third replicate in RPMI 10\%FBS media.}

The SAS System

The GLM Procedure

\section{Class Level Information}

Class Levels Values

Treatment 5 Both Neg PTK2 PTK2B Scrambled

Number of Observations Read 751

Number of Observations Used 750

The GLM Procedure

Dependent Variable: Phagocytosis_Efficiency_U937

\begin{tabular}{lrrrrr} 
Source & DF & Sum of Squares & Mean Square & F Value & Pr $>$ F \\
Model & 4 & 0.70842389 & 0.17710597 & 2.44 & 0.0456 \\
Error & 745 & 54.07326895 & 0.07258157 & & \\
Corrected Total & 749 & 54.78169284 & & & \\
\hline
\end{tabular}

R-Square Coeff Var Root MSE Phagocytosis_Efficiency_U937 Mean
$0.012932 \quad 46.13563 \quad 0.269410$
0.583951

Source DF Type I SS Mean Square F Value $\operatorname{Pr}>$ F

$\begin{array}{llllll}\text { Treatment } & 4 & 0.70842389 & 0.17710597 & 2.44 & 0.0456\end{array}$ 
Source DF Type III SS Mean Square F Value $\operatorname{Pr}>$ F
Treatment
$4 \quad 0.70842389$
0.17710597
$2.44 \quad 0.0456$

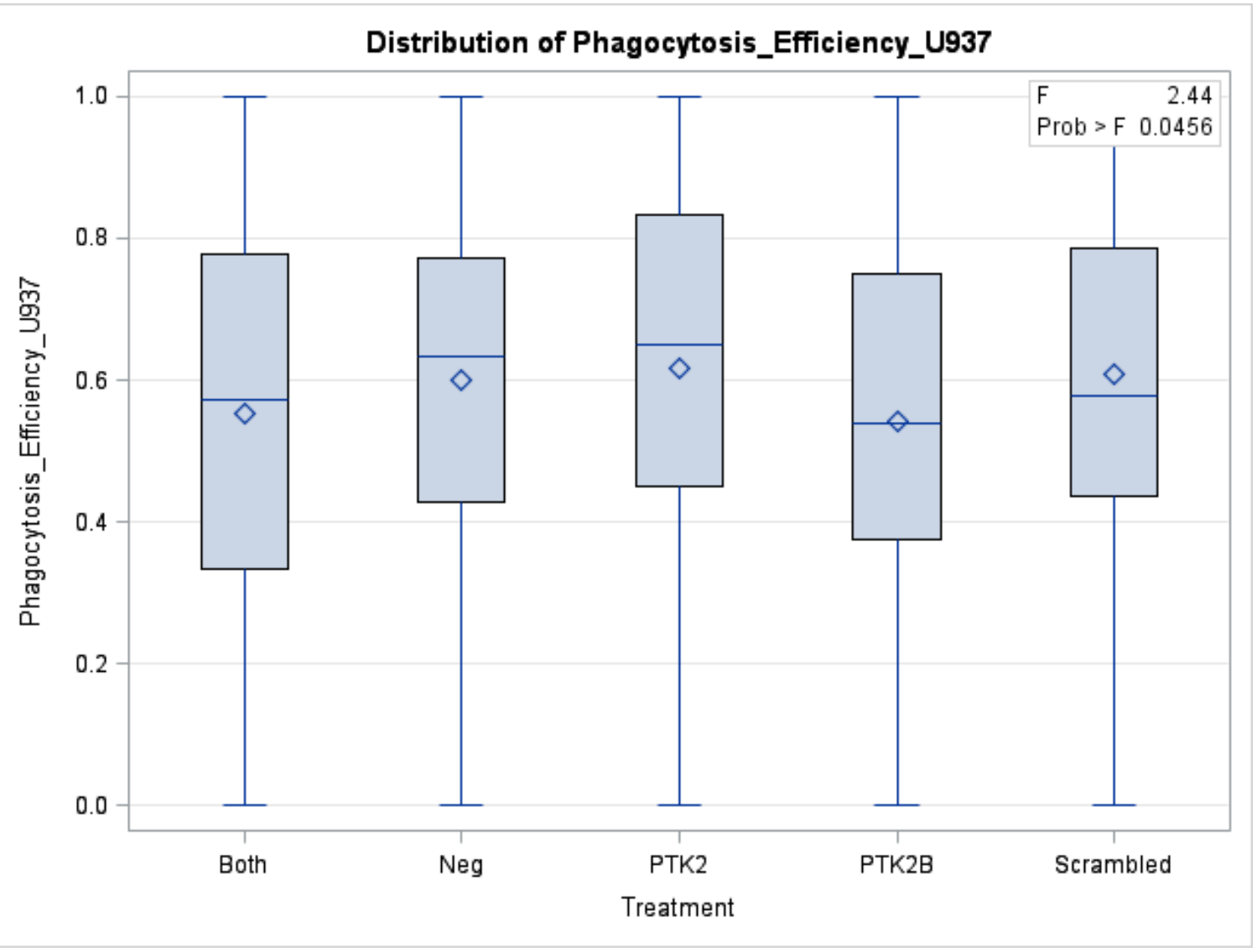

The GLM Procedure

Least Squares Means

Adjustment for Multiple Comparisons: Tukey

Treatment Phagocytosis_Efficiency_U937 LSMEAN Number

\section{LSMEAN}

Both

0.55373581

1

Neg

0.59867855

2

PTK2

0.61783175

3

PTK2B

0.54102166

4 
Treatment Phagocytosis_Efficiency_U937 LSMEAN Number LSMEAN

$\begin{array}{lll}\text { Scrambled } & 0.60848942 & 5\end{array}$

\begin{tabular}{|lrrrrr|}
\hline \multicolumn{5}{|c|}{$\begin{array}{l}\text { Least Squares Means for effect Treatment } \\
\text { Pr }>|\mathbf{t}| \text { for H0: LSMean(i)=LSMean(j) }\end{array}$} \\
Dependent Variable: Phagocytosis_Efficiency_U937 \\
i/j & $\mathbf{1}$ & $\mathbf{2}$ & $\mathbf{3}$ & $\mathbf{4}$ & $\mathbf{5}$ \\
$\mathbf{1}$ & & 0.5989 & 0.2386 & 0.9941 & 0.3979 \\
$\mathbf{2}$ & 0.5989 & & 0.9726 & 0.3437 & 0.9979 \\
$\mathbf{3}$ & 0.2386 & 0.9726 & & 0.0988 & 0.9982 \\
$\mathbf{4}$ & 0.9941 & 0.3437 & 0.0988 & & 0.1928 \\
$\mathbf{5}$ & 0.3979 & 0.9979 & 0.9982 & 0.1928 & \\
\hline
\end{tabular}




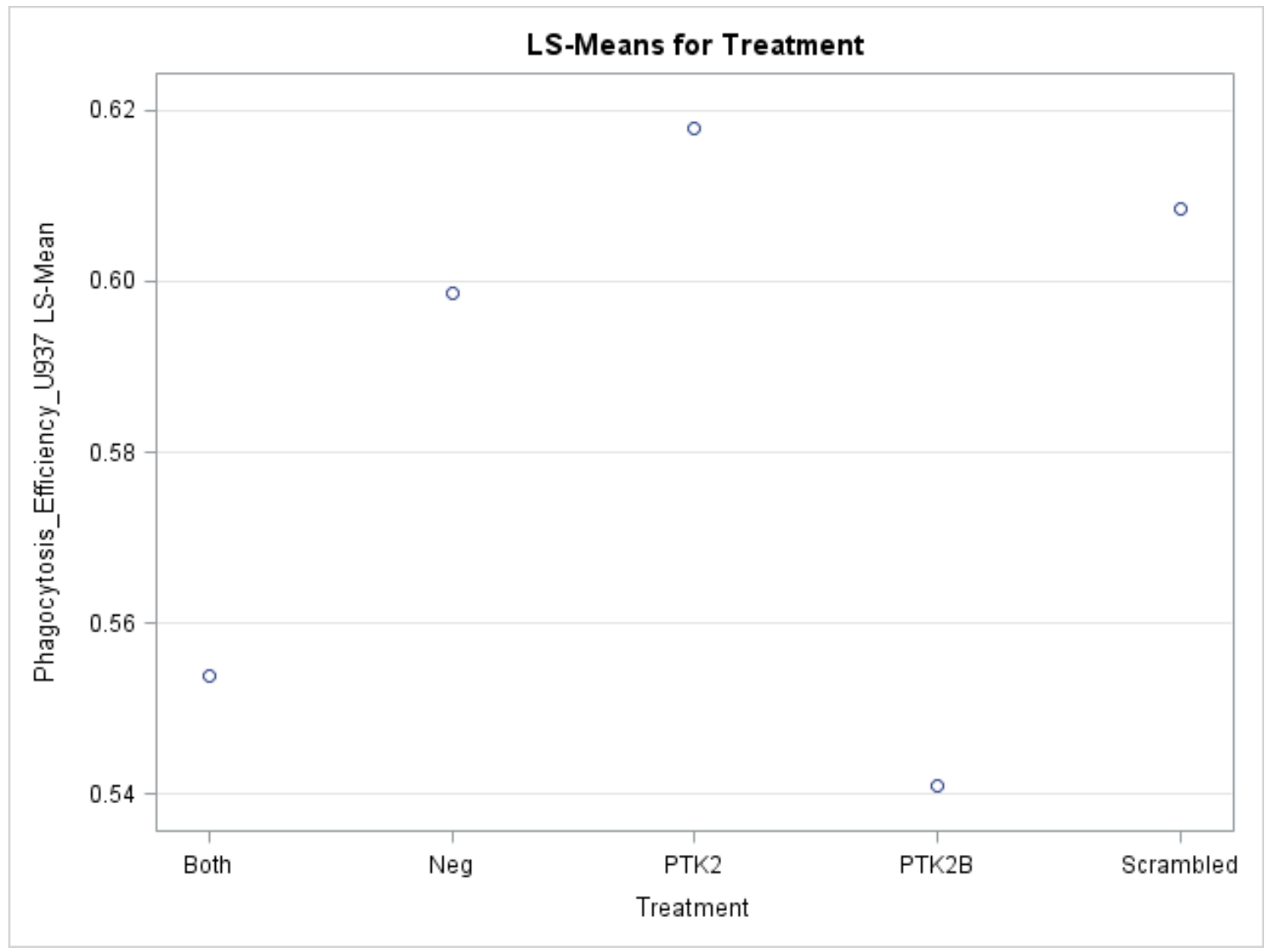




\section{Appendix J. SAS 9.3 program ANOVA analysis of the phagocytosis efficiency for oxLDL beads first replicate in RPMI serum free media.}

The SAS System

The GLM Procedure

\section{Class Level Information}

Class Levels Values

Treatment 5 Both Neg PTK2 PTK2B Scrambled

Number of Observations Read 751

Number of Observations Used 750

The GLM Procedure

Dependent Variable: Phagocytosis_Efficiency_U937

\begin{tabular}{|lrrrrr}
\hline Source & DF & Sum of Squares & Mean Square & F Value & Pr $>$ F \\
Model & 4 & 5.40849638 & 1.35212410 & $19.58<.0001$ \\
Error & 745 & 51.45497512 & 0.06906708 & & \\
Corrected Total & 749 & 56.86347150 & & & \\
\end{tabular}

R-Square Coeff Var Root MSE Phagocytosis_Efficiency_U937 Mean
$0.095114 \quad 45.31684 \quad 0.262806$
0.579931

$\begin{array}{lrrrrrr}\text { Source } & \text { DF } & \text { Type I SS } & \text { Mean Square } & \text { F Value } & \operatorname{Pr}>\text { F } \\ \text { Treatment } & 4 & 5.40849638 & 1.35212410 & 19.58 & <.0001\end{array}$




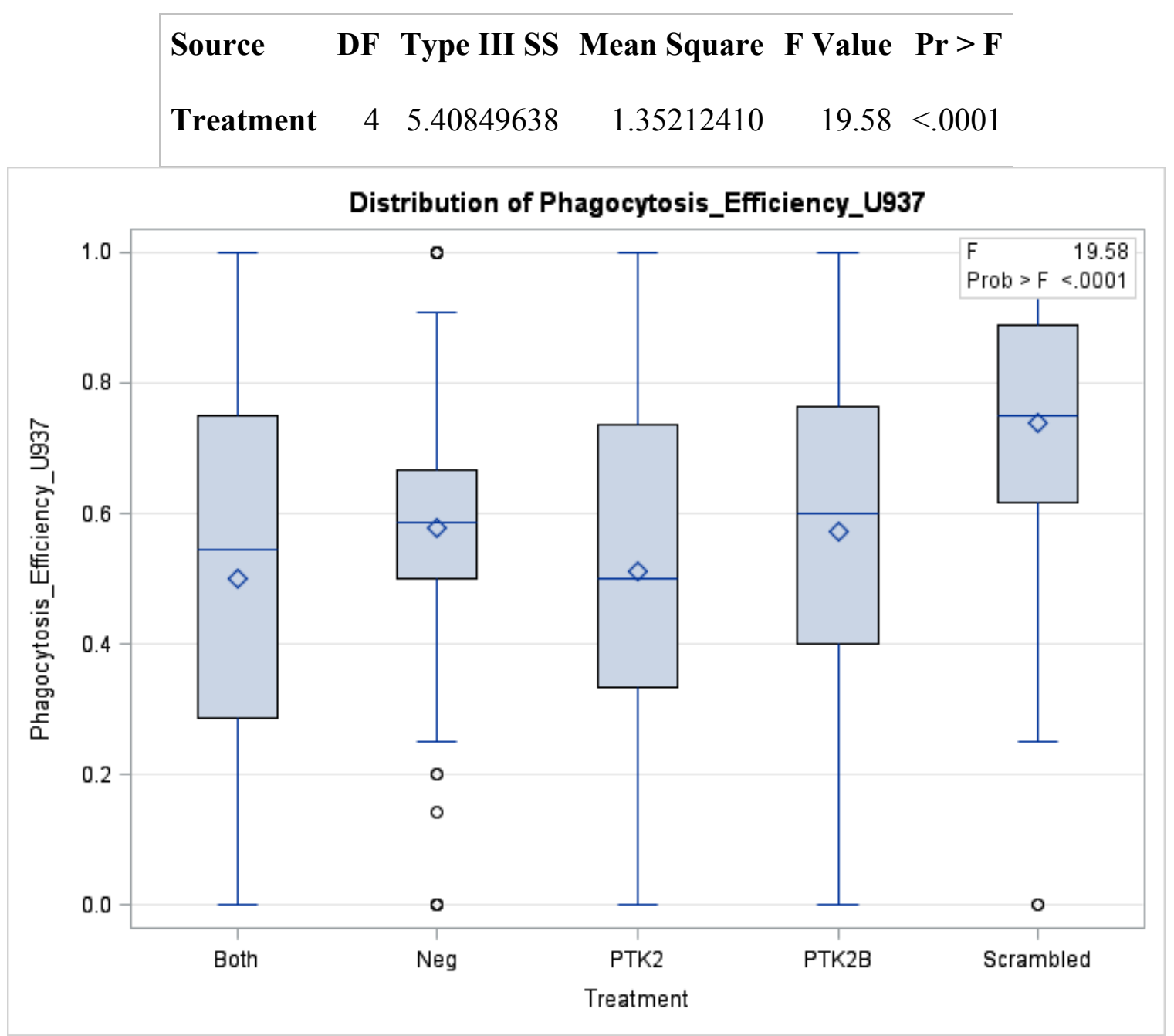

The GLM Procedure

Least Squares Means

Adjustment for Multiple Comparisons: Tukey

Treatment Phagocytosis_Efficiency_U937 LSMEAN Number LSMEAN

Both

0.50117624

1

Neg

0.57792495

2

PTK2

0.51004200

3

PTK2B

0.57273652

4 
Treatment Phagocytosis_Efficiency_U937 LSMEAN Number LSMEAN

Scrambled

0.73777293

5

\begin{tabular}{|c|c|c|c|c|c|}
\hline & $\begin{array}{l}\text { Least } S c \\
\operatorname{Pr}>\mid\end{array}$ & $\begin{array}{l}\text { ares Me } \\
\text { or H0: I }\end{array}$ & $\begin{array}{l}\text { Is for eff } \\
\text { Mean(i) }\end{array}$ & $\begin{array}{l}\text { t Treatr } \\
\text { LSMean }\end{array}$ & \\
\hline De & ndent $V$ & iable: $\mathbf{P}$ & gocytos & Efficien & y_U937 \\
\hline $\mathbf{i} / \mathbf{j}$ & 1 & 2 & 3 & 4 & 5 \\
\hline 1 & & 0.0853 & 0.9984 & 0.1282 & $<.0001$ \\
\hline 2 & 0.0853 & & 0.1673 & 0.9998 & $<.0001$ \\
\hline 3 & 0.9984 & 0.1673 & & 0.2361 & $<.0001$ \\
\hline 4 & 0.1282 & 0.9998 & 0.2361 & & $<.0001$ \\
\hline 5 & $<.0001$ & $<.0001$ & $<.0001$ & $<.0001$ & \\
\hline
\end{tabular}




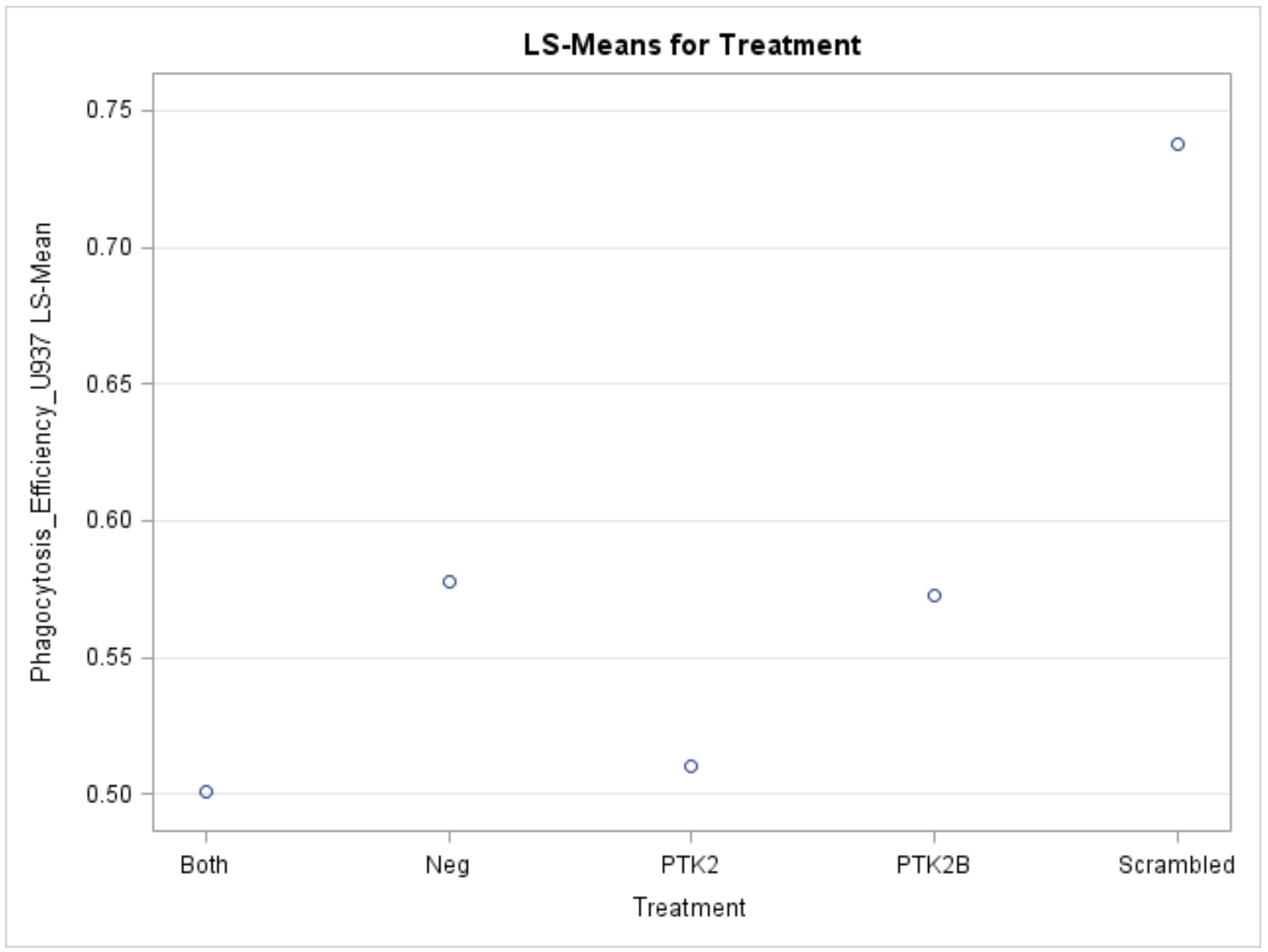


Appendix K. SAS 9.3 program ANOVA analysis of the phagocytosis efficiency for oxLDL beads second replicate in RPMI serum free media.

The SAS System

The GLM Procedure

\section{Class Level Information}

Class Levels Values

Treatment 5 Both Neg PTK2 PTK2B Scrambled

Number of Observations Read 751

Number of Observations Used 750

The GLM Procedure

Dependent Variable: Phagocytosis_Efficiency_U937

\begin{tabular}{|lrrrrr}
\hline Source & DF & Sum of Squares & Mean Square & F Value & Pr $>$ F \\
Model & 4 & 10.61429192 & 2.65357298 & $34.56<.0001$ \\
Error & 745 & 57.20446909 & 0.07678452 & & \\
Corrected Total & 749 & 67.81876101 & & & \\
\end{tabular}

R-Square Coeff Var Root MSE Phagocytosis_Efficiency_U937 Mean
$0.156510 \quad 53.08715$
0.277100
0.521972

Source DF Type I SS Mean Square F Value $\operatorname{Pr}>$ F

Treatment $\quad 4 \quad 10.61429192 \quad 2.65357298 \quad 34.56<.0001$ 
Source DF Type III SS Mean Square F Value $\operatorname{Pr}>$ F

$\begin{array}{llllll}\text { Treatment } & 4 & 10.61429192 & 2.65357298 & 34.56 & <.0001\end{array}$

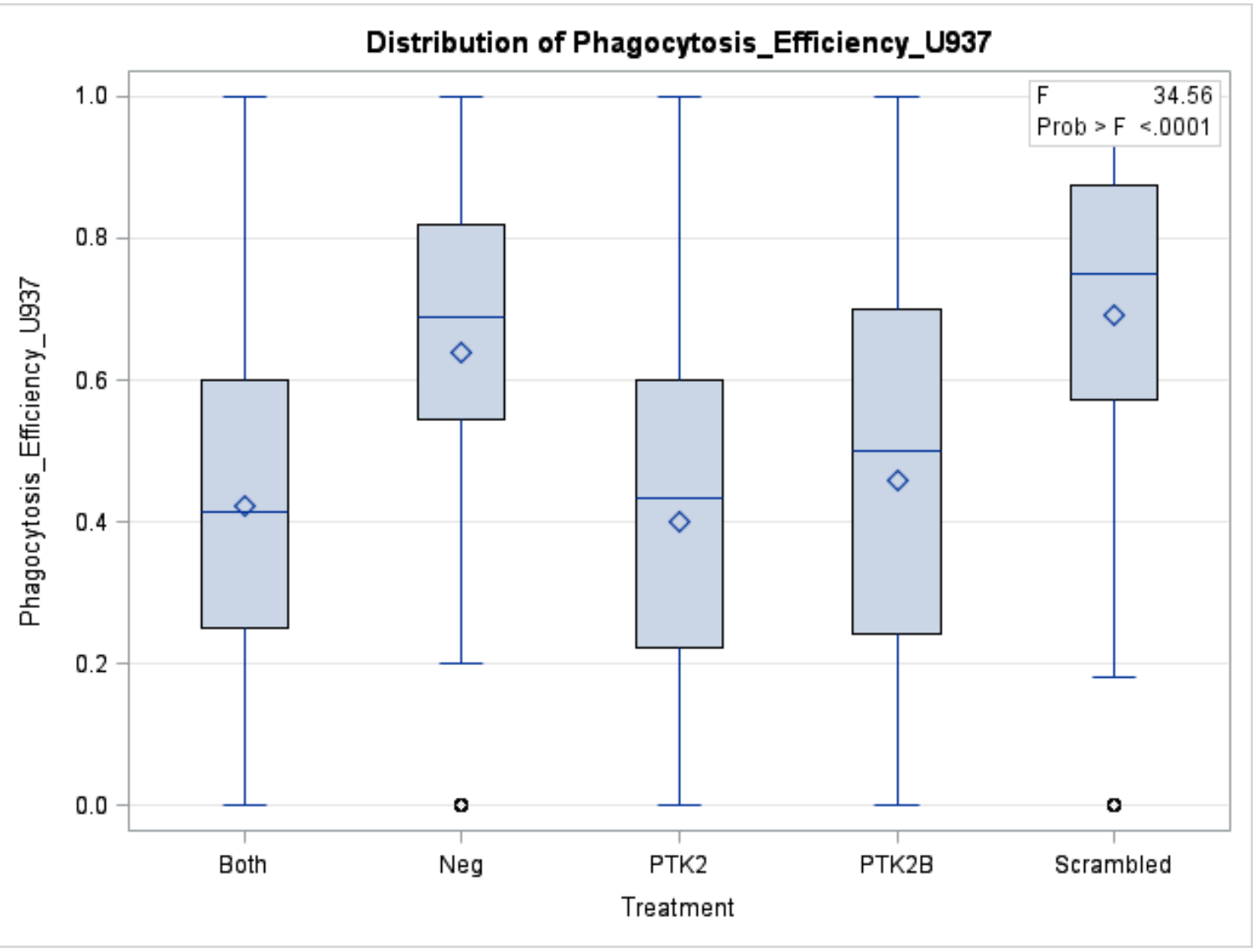

The GLM Procedure

Least Squares Means

Adjustment for Multiple Comparisons: Tukey

Treatment Phagocytosis_Efficiency_U937 LSMEAN Number

LSMEAN

$\begin{array}{llr}\text { Both } & 0.42233558 & 1 \\ \text { Neg } & 0.63760382 & 2 \\ \text { PTK2 } & 0.40028681 & 3 \\ \text { PTK2B } & 0.45847507 & 4\end{array}$


Treatment Phagocytosis_Efficiency_U937 LSMEAN Number LSMEAN

Scrambled $\quad 0.69116026$

\begin{tabular}{|c|c|c|c|c|c|}
\hline & $\begin{array}{l}\text { Least Sq } \\
\qquad \operatorname{Pr}>\mid t\end{array}$ & $\begin{array}{l}\text { ares Me } \\
\text { or H0: I }\end{array}$ & $\begin{array}{l}\text { Is for ef } \\
\text { Mean(i) }\end{array}$ & $\begin{array}{l}\text { t Treatr } \\
\text { LSMean }\end{array}$ & \\
\hline & ndent V & ciable: P & agocytos & Efficien & y_U937 \\
\hline $\mathbf{i} / \mathbf{j}$ & 1 & 2 & 3 & 4 & 5 \\
\hline 1 & & $<.0001$ & 0.9588 & 0.7909 & $<.0001$ \\
\hline 2 & $<.0001$ & & $<.0001$ & $<.0001$ & 0.4509 \\
\hline 3 & 0.9588 & $<.0001$ & & 0.3635 & $<.0001$ \\
\hline 4 & 0.7909 & $<.0001$ & 0.3635 & & $<.0001$ \\
\hline 5 & $<.0001$ & 0.4509 & $<.0001$ & $<.0001$ & \\
\hline
\end{tabular}




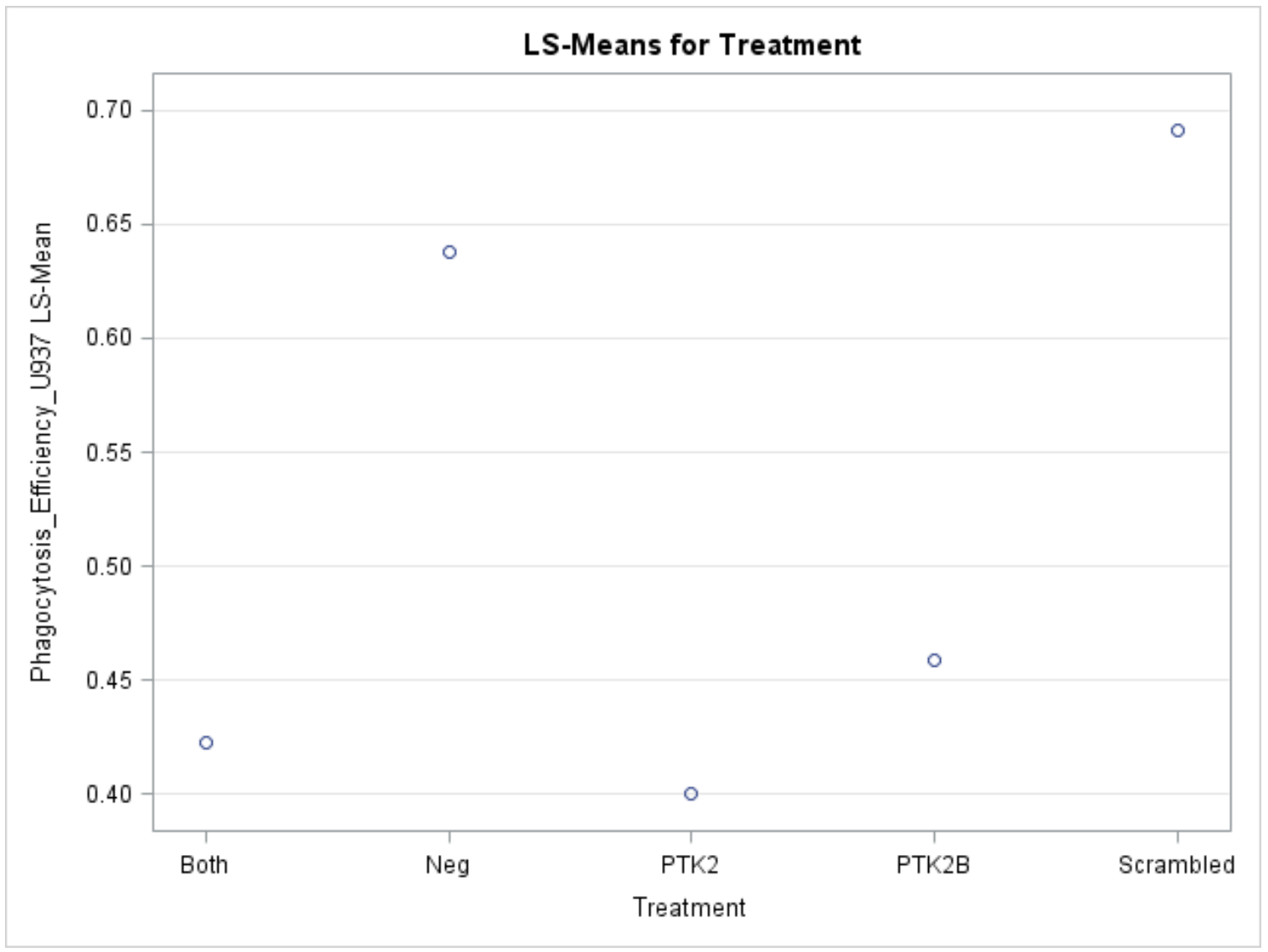




\section{Appendix L. SAS 9.3 program ANOVA analysis of the phagocytosis efficiency for oxLDL beads third replicate in RPMI serum free media.}

The SAS System

The GLM Procedure

\section{Class Level Information}

Class Levels Values

Treatment 5 Both Neg PTK2 PTK2B Scrambled

Number of Observations Read 750

Number of Observations Used 750

The GLM Procedure

Dependent Variable: Phagocytosis_Efficiency_U937

\begin{tabular}{|lrrrrr}
\hline Source & DF & Sum of Squares & Mean Square & F Value & Pr $>$ F \\
Model & 4 & 13.70126724 & 3.42531681 & $49.00<.0001$ \\
Error & 745 & 52.07400440 & 0.06989799 & & \\
Corrected Total & 749 & 65.77527164 & & & \\
\end{tabular}

R-Square Coeff Var Root MSE Phagocytosis_Efficiency_U937 Mean
$0.208304 \quad 49.45151$
0.264382
0.534629

Source DF Type I SS Mean Square F Value $\operatorname{Pr}>$ F

$\begin{array}{lllll}\text { Treatment } \quad 4 & 13.70126724 & 3.42531681 & 49.00 & <.0001\end{array}$ 
Source DF Type III SS Mean Square F Value $\operatorname{Pr}>$ F

$\begin{array}{llllll}\text { Treatment } & 4 & 13.70126724 & 3.42531681 & 49.00 & <.0001\end{array}$

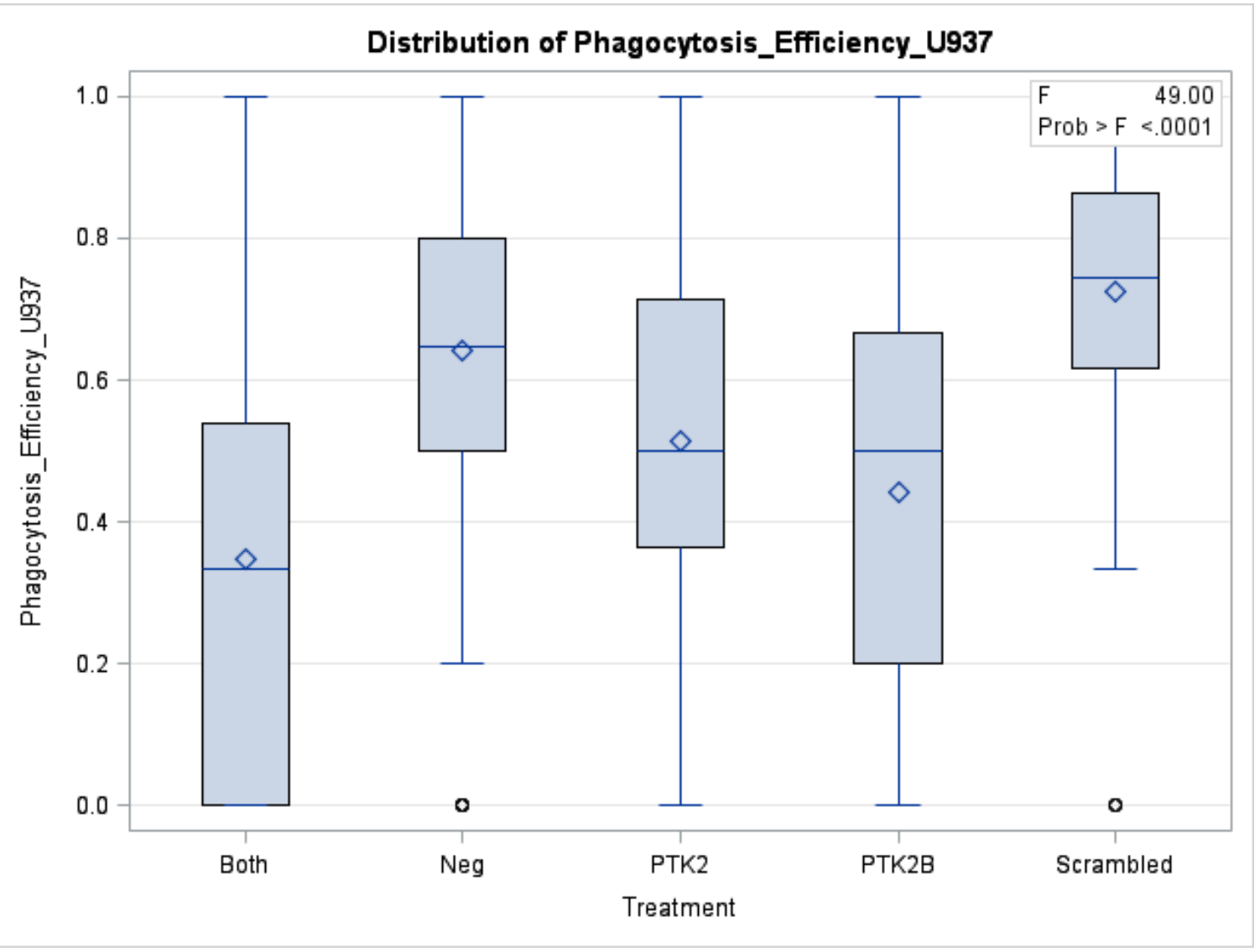

The GLM Procedure

Least Squares Means

Adjustment for Multiple Comparisons: Tukey

Treatment Phagocytosis_Efficiency_U937 LSMEAN Number

\section{LSMEAN}

$\begin{array}{lrr}\text { Both } & 0.34796950 & 1 \\ \text { Neg } & 0.64288543 & 2 \\ \text { PTK2 } & 0.51499135 & 3 \\ \text { PTK2B } & 0.44295767 & 4\end{array}$


Treatment Phagocytosis_Efficiency_U937 LSMEAN Number LSMEAN

Scrambled

0.72434270

5

\begin{tabular}{|c|c|c|c|c|c|}
\hline & $\begin{array}{l}\text { Least Sq } \\
\qquad \operatorname{Pr}>|\mathbf{t}|\end{array}$ & $\begin{array}{l}\text { ares Me } \\
\text { or H0: I }\end{array}$ & $\begin{array}{l}\text { Is for eff } \\
\text { Mean(i) }\end{array}$ & $\begin{array}{l}\text { t Treatn } \\
\text { SMean }\end{array}$ & \\
\hline De & ndent $\mathrm{V}$ & iable: $\mathbf{P}$ & Igocytos & Efficien & y_U937 \\
\hline $\mathbf{i} / \mathbf{j}$ & 1 & 2 & 3 & 4 & 5 \\
\hline 1 & & $<.0001$ & $<.0001$ & 0.0165 & $<.0001$ \\
\hline 2 & $<.0001$ & & 0.0003 & $<.0001$ & 0.0597 \\
\hline 3 & $<.0001$ & 0.0003 & & 0.1277 & $<.0001$ \\
\hline 4 & 0.0165 & $<.0001$ & 0.1277 & & $<.0001$ \\
\hline 5 & $<.0001$ & 0.0597 & $<.0001$ & $<.0001$ & \\
\hline
\end{tabular}




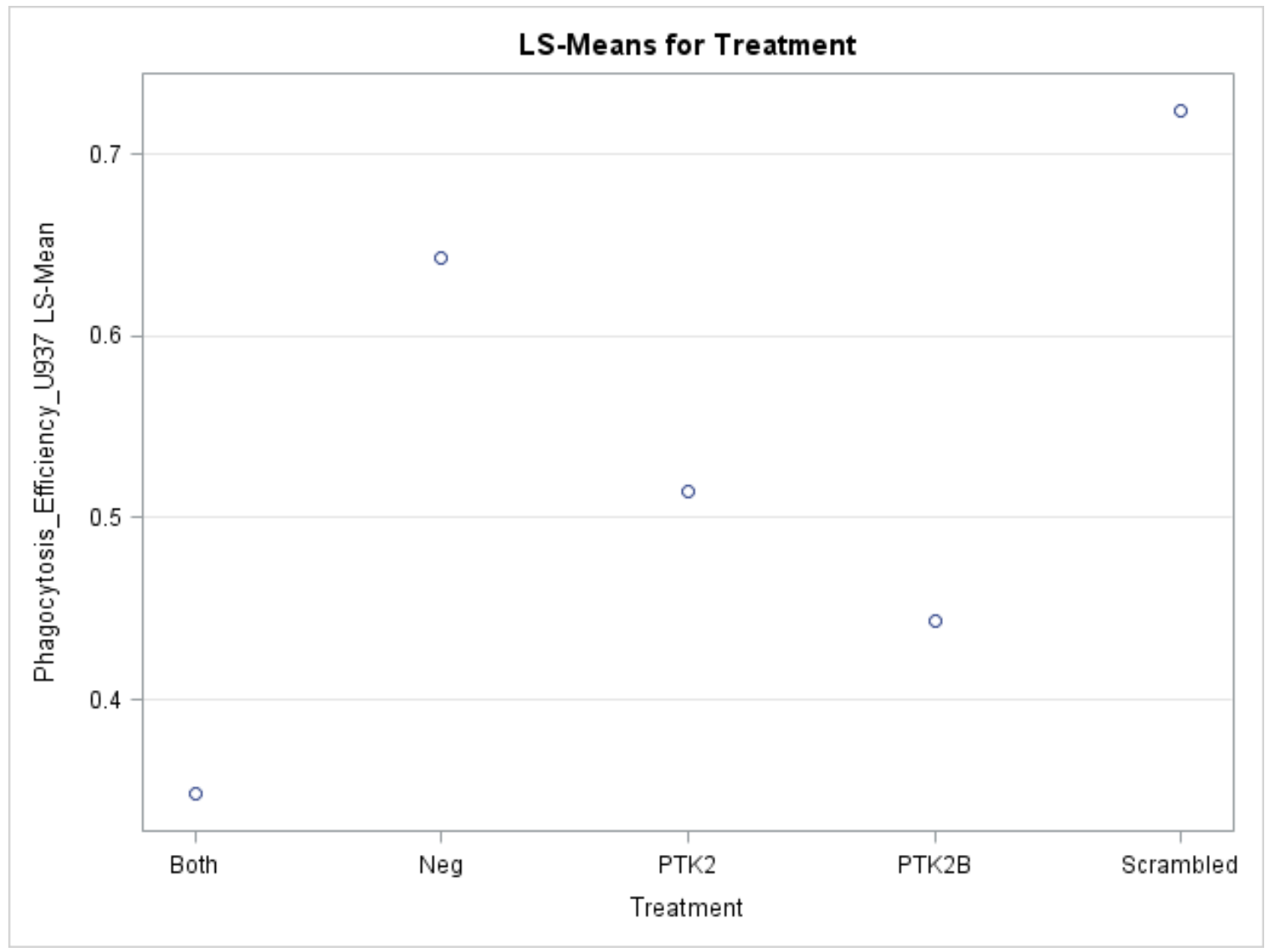




\section{Appendix M. SAS 9.3 program ANOVA analysis of the phagocytosis efficiency for oxLDL beads first replicate in HEPES buffer.}

The SAS System

The GLM Procedure

\section{Class Level Information}

Class Levels Values

Treatment 5 Both Neg PTK2 PTK2B Scrambled

Number of Observations Read 750

Number of Observations Used 750

The GLM Procedure

Dependent Variable: Phagocytosis_Efficiency_U937

\begin{tabular}{|lrrrrr}
\hline Source & DF & Sum of Squares & Mean Square & F Value & Pr $>$ F \\
Model & 4 & 12.27865804 & 3.06966451 & $77.62<.0001$ \\
Error & 745 & 29.46256544 & 0.03954707 & & \\
Corrected Total & 749 & 41.74122347 & & & \\
\end{tabular}

R-Square Coeff Var Root MSE Phagocytosis_Efficiency_U937 Mean
$0.294161 \quad 61.92866$
0.198864
0.321119

Source DF Type I SS Mean Square F Value $\operatorname{Pr}>$ F

$\begin{array}{llllll}\text { Treatment } \quad 4 & 12.27865804 & 3.06966451 & 77.62<.0001\end{array}$ 
Source DF Type III SS Mean Square F Value $\operatorname{Pr}>$ F

$\begin{array}{llllll}\text { Treatment } & 4 & 12.27865804 & 3.06966451 & 77.62<.0001\end{array}$

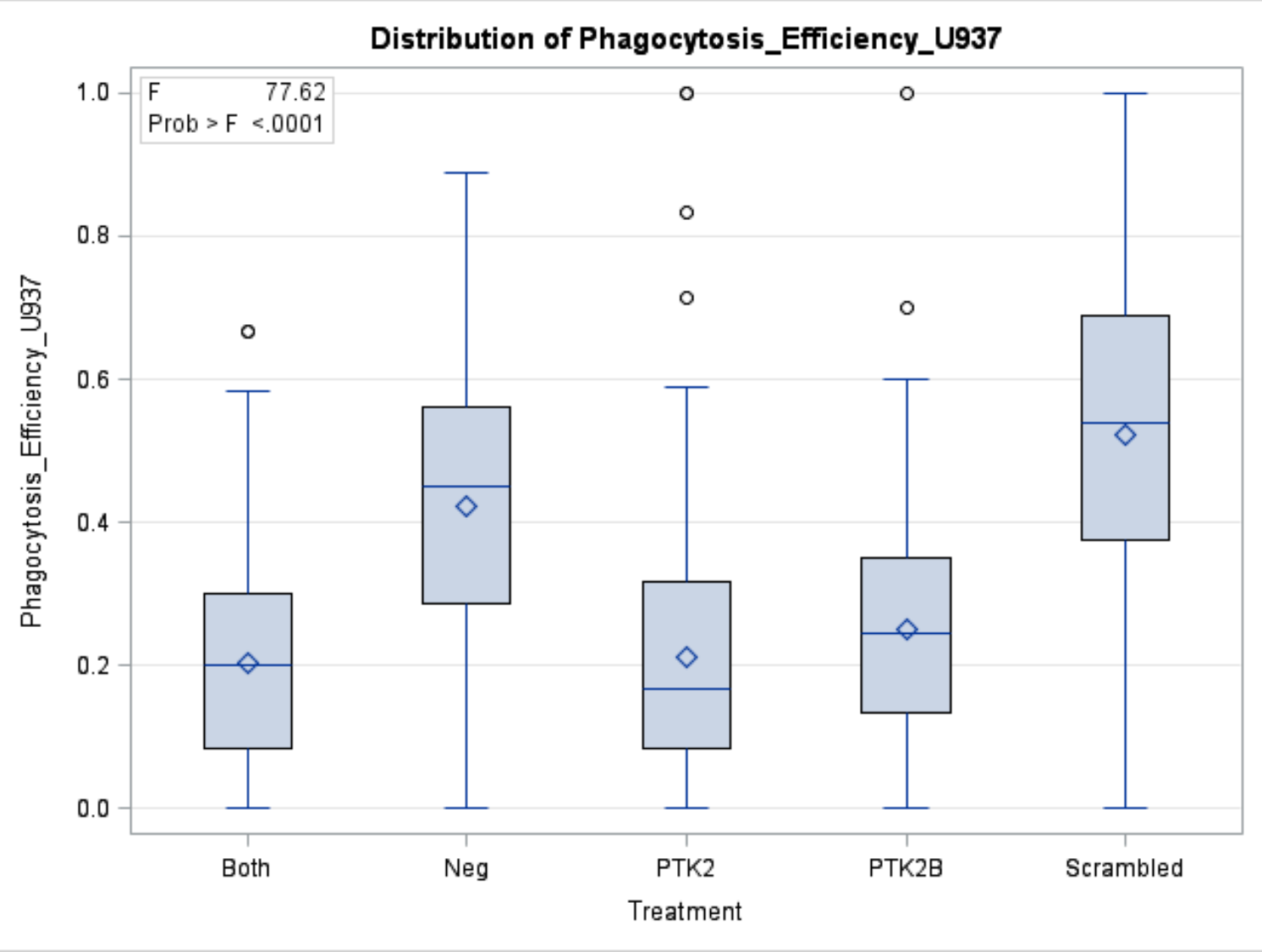

The GLM Procedure

Least Squares Means

Adjustment for Multiple Comparisons: Tukey

Treatment Phagocytosis_Efficiency_U937 LSMEAN Number

LSMEAN

$\begin{array}{lll}\text { Both } & 0.20206001 & 1\end{array}$

$\begin{array}{lll}\text { Neg } & 0.42149867 & 2\end{array}$

$\begin{array}{lll}\text { PTK2 } & 0.21050956\end{array}$

$\begin{array}{lll}\text { PTK2B } & 0.24972072 & 4\end{array}$ 
Treatment Phagocytosis_Efficiency_U937 LSMEAN Number LSMEAN

Scrambled $\quad 0.52180392$

\begin{tabular}{|c|c|c|c|c|c|}
\hline & $\begin{array}{r}\text { Least Sq } \\
\qquad \operatorname{Pr}>|\mathbf{t}|\end{array}$ & $\begin{array}{l}\text { ares Mea } \\
\text { or H0: L }\end{array}$ & $\begin{array}{l}\text { Is for eff } \\
\text { Mean(i) }\end{array}$ & $\begin{array}{l}\text { ct Treatn } \\
\text { LSMean }\end{array}$ & ent \\
\hline & endent $\mathrm{V}$ & iable: Pl & gocytosi & _Efficien & y_U937 \\
\hline $\mathbf{i} / \mathbf{j}$ & 1 & 2 & 3 & 4 & 5 \\
\hline 1 & & $<.0001$ & 0.9961 & 0.2318 & $<.0001$ \\
\hline 2 & $<.0001$ & & $<.0001$ & $<.0001$ & 0.0001 \\
\hline 3 & 0.9961 & $<.0001$ & & 0.4298 & $<.0001$ \\
\hline 4 & 0.2318 & $<.0001$ & 0.4298 & & $<.0001$ \\
\hline 5 & $<.0001$ & 0.0001 & $<.0001$ & $<.0001$ & \\
\hline
\end{tabular}




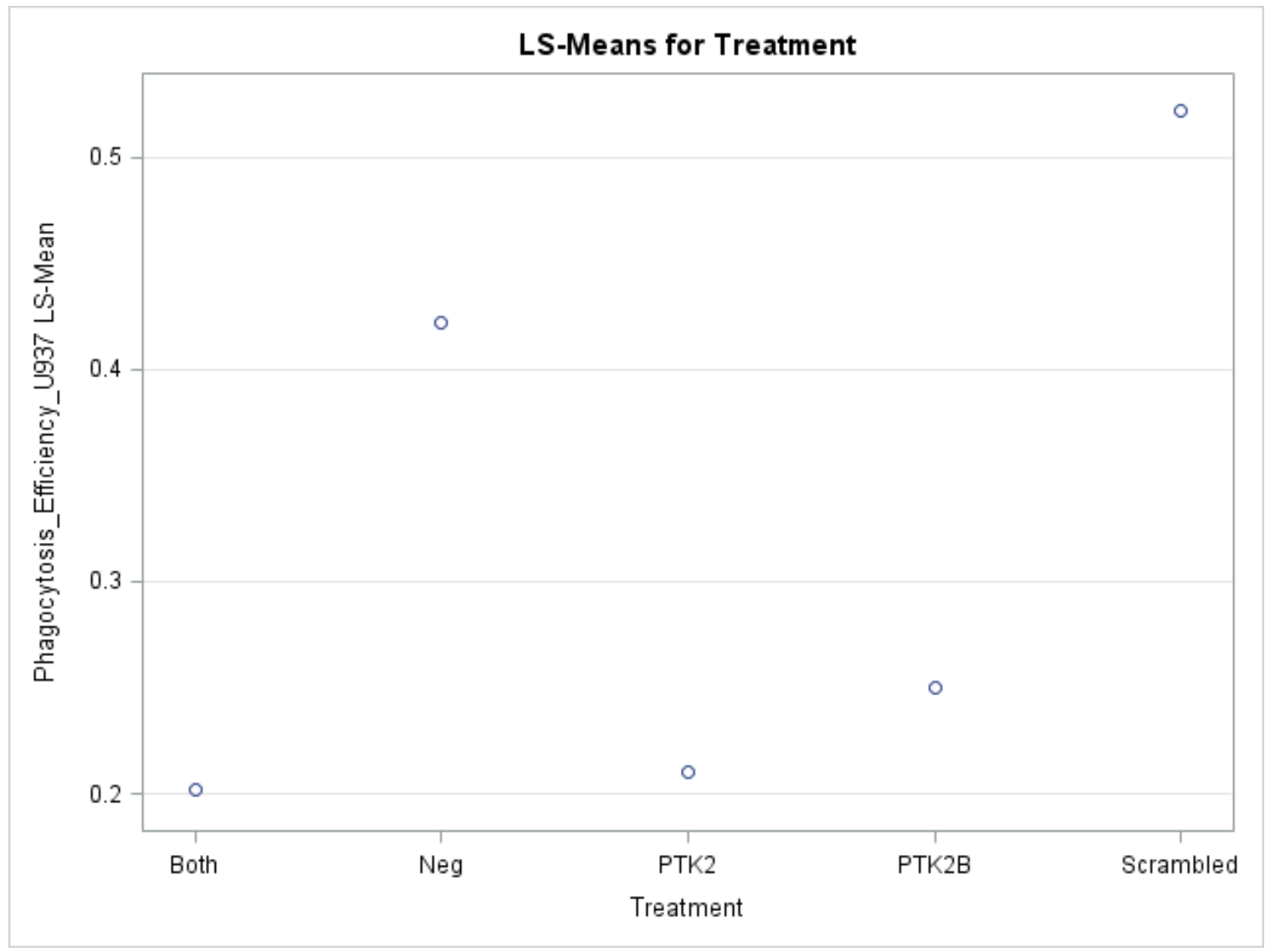




\section{Appendix N. SAS 9.3 program ANOVA analysis of the phagocytosis efficiency for oxLDL beads second replicate in HEPES buffer.}

The SAS System

The GLM Procedure

\section{Class Level Information}

Class Levels Values

Treatment 5 Both Neg PTK2 PTK2B Scrambled

Number of Observations Read 750

Number of Observations Used 750

The GLM Procedure

Dependent Variable: Phagocytosis_Efficiency_U937

\begin{tabular}{|lrrrrr|}
\hline Source & DF & Sum of Squares & Mean Square & F Value & Pr $>$ F \\
Model & 4 & 19.96579798 & 4.99144950 & $102.54<.0001$ \\
Error & 745 & 36.26354546 & 0.04867590 & \\
Corrected Total & 749 & 56.22934345 & & \\
\hline & & & & & \\
\hline R-Square & Coeff Var & Root MSE & Phagocytosis_Efficiency_U937 Mean \\
\hline 0.355078 & 70.15909 & 0.220626 & &
\end{tabular}

$\begin{array}{lrrrrrr}\text { Source } & \text { DF } & \text { Type I SS } & \text { Mean Square } & \text { F Value } & \operatorname{Pr}>\text { F } \\ \text { Treatment } & 4 & 19.96579798 & 4.99144950 & 102.54 & <.0001\end{array}$

Source DF Type III SS Mean Square F Value Pr $>$ F 
Source DF Type III SS Mean Square F Value $\operatorname{Pr}>$ F

$\begin{array}{llllll}\text { Treatment } \quad 4 & 19.96579798 & 4.99144950 & 102.54 & <.0001\end{array}$

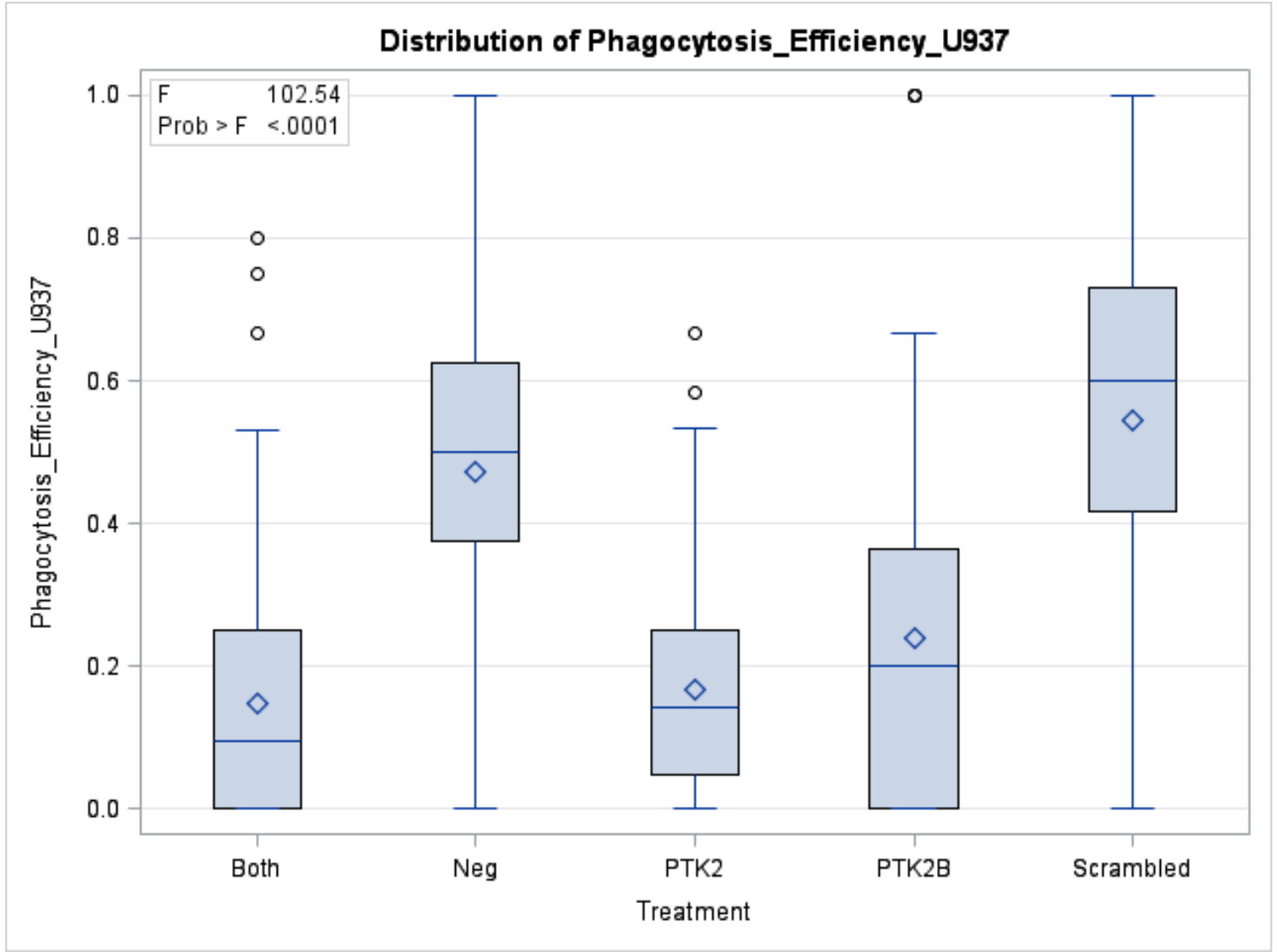

The GLM Procedure

Least Squares Means

Adjustment for Multiple Comparisons: Tukey

Treatment Phagocytosis_Efficiency_U937 LSMEAN Number

LSMEAN

$\begin{array}{lll}\text { Both } & 0.14792905 & 1\end{array}$

$\begin{array}{lll}\text { Neg } & 0.47172842 & 2\end{array}$

$\begin{array}{lll}\text { PTK2 } & 0.16832626 & 3\end{array}$ 
Treatment Phagocytosis_Efficiency_U937 LSMEAN Number LSMEAN

PTK2B

0.23853926

4

Scrambled

0.54580471

5

\begin{tabular}{|c|c|c|c|c|c|}
\hline & $\begin{array}{r}\text { Least Sq } \\
\qquad \operatorname{Pr}>\mid t \\
\text { ndent V }\end{array}$ & $\begin{array}{l}\text { ares Me } \\
\text { or H0: I } \\
\text { iable: P }\end{array}$ & $\begin{array}{l}\text { s for efi } \\
\text { Mean(i) } \\
\text { gocytos }\end{array}$ & $\begin{array}{l}\text { t Treatn } \\
\text { SMean } \\
\text { Efficien }\end{array}$ & $\begin{array}{l}\text { tht } \\
\text { U937 }\end{array}$ \\
\hline $\mathbf{i} / \mathbf{j}$ & 1 & 2 & 3 & 4 & 5 \\
\hline 1 & & $<.0001$ & 0.9304 & 0.0037 & $<.0001$ \\
\hline 2 & $<.0001$ & & $<.0001$ & $<.0001$ & 0.0307 \\
\hline 3 & 0.9304 & $<.0001$ & & 0.0471 & $<.0001$ \\
\hline 4 & 0.0037 & $<.0001$ & 0.0471 & & $<.0001$ \\
\hline 5 & $<.0001$ & 0.0307 & $<.0001$ & $<.0001$ & \\
\hline
\end{tabular}




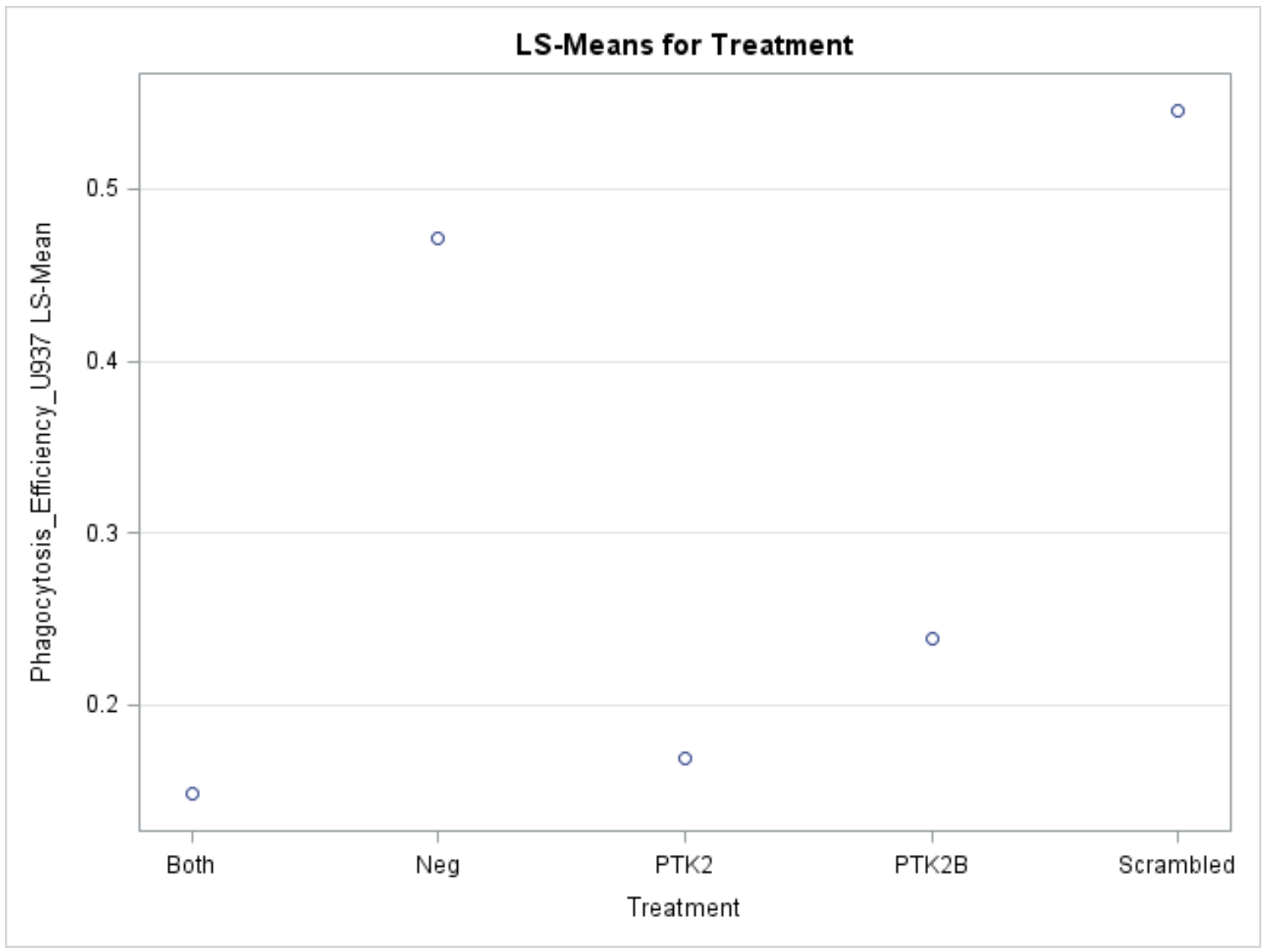




\section{Appendix O. SAS 9.3 program ANOVA analysis of the phagocytosis efficiency for oxLDL beads third replicate in HEPES buffer. \\ The SAS System}

The GLM Procedure

\section{Class Level Information}

Class Levels Values

Treatment $\quad 5$ Both Neg PTK2 PTK2B Scrambled

Number of Observations Read 750

Number of Observations Used 750

The GLM Procedure

Dependent Variable: Phagocytosis_Efficiency_U937

$\begin{array}{lrrrrr}\text { Source } & \text { DF } & \text { Sum of Squares } & \text { Mean Square } & \text { F Value } & \text { Pr }>\text { F } \\ \text { Model } & 4 & 19.51958958 & 4.87989740 & 124.87<.0001 \\ \text { Error } & 745 & 29.11441469 & 0.03907975 & & \\ \text { Corrected Total } & 749 & 48.63400427 & & & \end{array}$

R-Square Coeff Var Root MSE Phagocytosis_Efficiency_U937 Mean
$0.401357 \quad 64.20988$
0.197686
0.307875

\begin{tabular}{|lrrrrrr|}
\hline Source & DF & Type I SS & Mean Square & F Value & $\operatorname{Pr}>$ F \\
Treatment & 4 & 19.51958958 & 4.87989740 & 124.87 & $<.0001$ \\
\hline Source & DF & Type III SS & Mean Square & F Value & $\operatorname{Pr}>$ F
\end{tabular}


Source DF Type III SS Mean Square F Value $\operatorname{Pr}>$ F

$\begin{array}{llllll}\text { Treatment } \quad 4 & 19.51958958 & 4.87989740 & 124.87 & <.0001\end{array}$

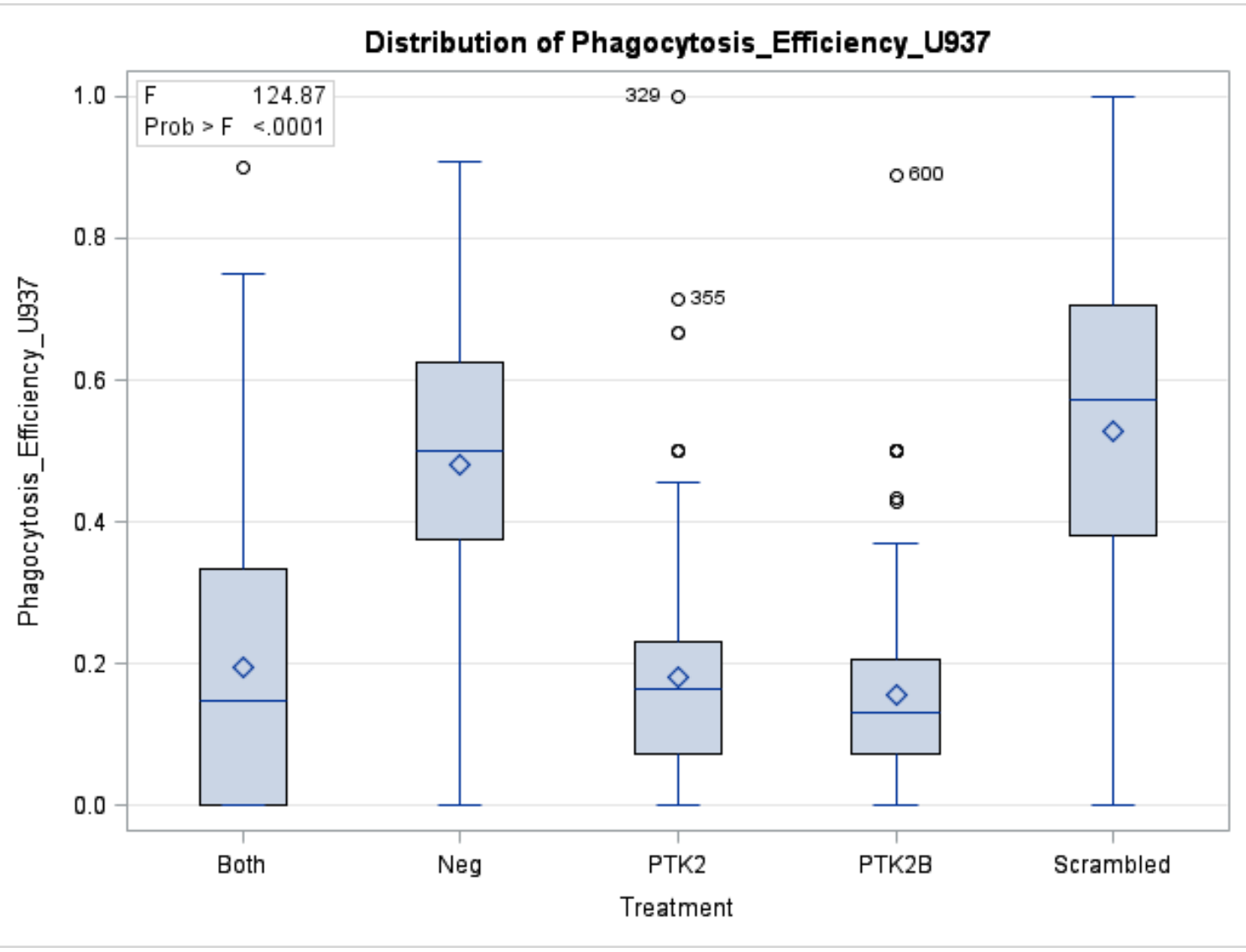

The GLM Procedure

Least Squares Means

Adjustment for Multiple Comparisons: Tukey

Treatment Phagocytosis_Efficiency_U937 LSMEAN Number

LSMEAN

Both

0.19524048

1

Neg

0.48139317

2

PTK2

0.17972365

3

PTK2B

0.15623765

4 
Treatment Phagocytosis_Efficiency_U937 LSMEAN Number LSMEAN

$\begin{array}{lll}\text { Scrambled } & 0.52677875 & 5\end{array}$

\begin{tabular}{|c|c|c|c|c|c|}
\hline & $\begin{array}{r}\text { Least Sq } \\
\qquad \operatorname{Pr}>|\mathbf{t}|\end{array}$ & $\begin{array}{l}\text { ares Mea } \\
\text { or H0: L }\end{array}$ & $\begin{array}{l}\text { Is for eff } \\
\text { Mean(i) }\end{array}$ & $\begin{array}{l}\text { ct Treatn } \\
\text { LSMean }\end{array}$ & ent \\
\hline & endent $\mathrm{V}$ & iable: Pl & gocytosi & _Efficien & y_U937 \\
\hline $\mathbf{i} / \mathbf{j}$ & 1 & 2 & 3 & 4 & 5 \\
\hline 1 & & $<.0001$ & 0.9608 & 0.4292 & $<.0001$ \\
\hline 2 & $<.0001$ & & $<.0001$ & $<.0001$ & 0.2727 \\
\hline 3 & 0.9608 & $<.0001$ & & 0.8420 & $<.0001$ \\
\hline 4 & 0.4292 & $<.0001$ & 0.8420 & & $<.0001$ \\
\hline 5 & $<.0001$ & 0.2727 & $<.0001$ & $<.0001$ & \\
\hline
\end{tabular}




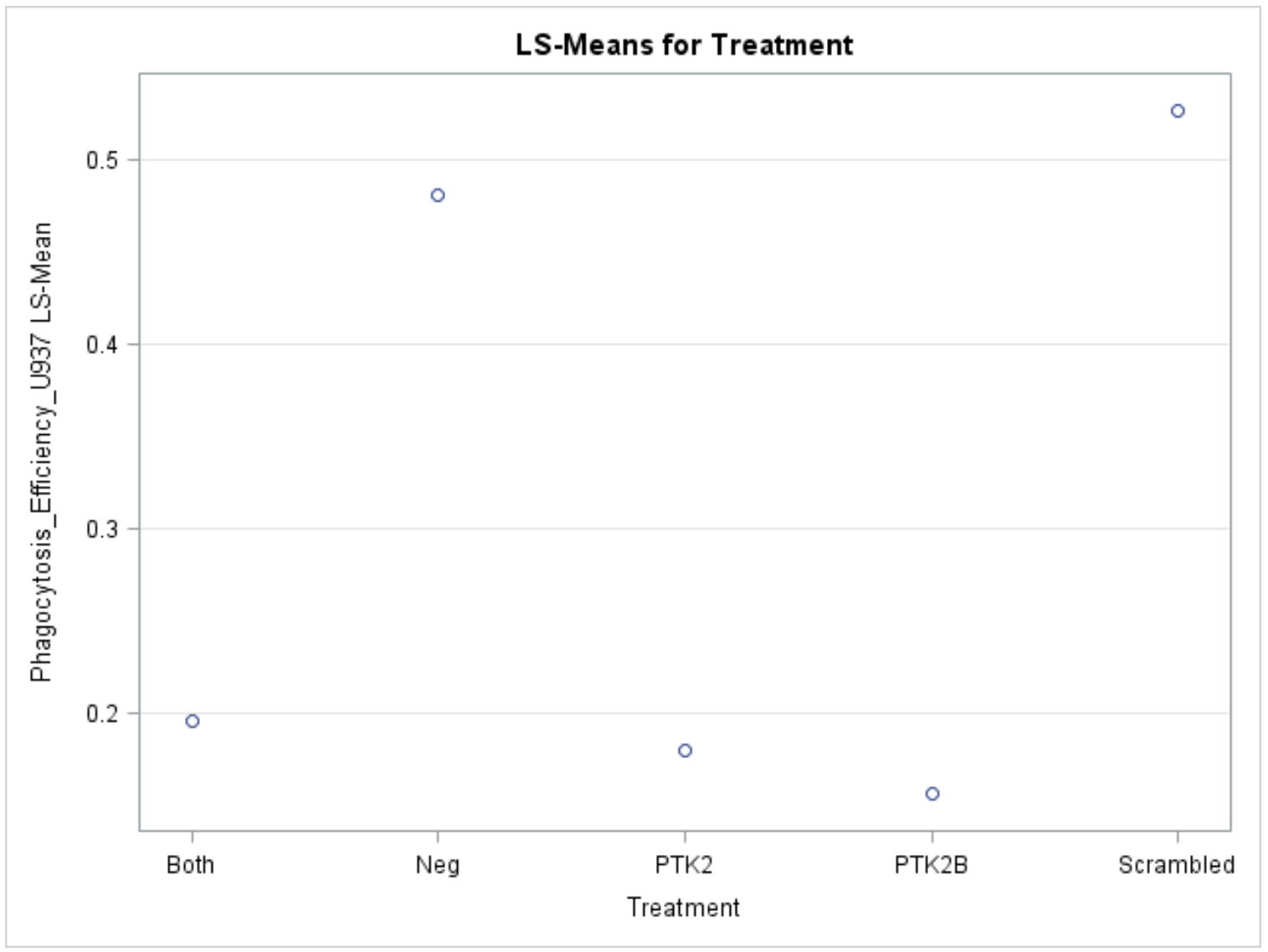




\section{Appendix P. SAS 9.3 program ANOVA analysis of PF 573228 treated cell by the phagocytosis efficiency for oxLDL beads first replicate in HEPES buffer.}

The SAS System

The GLM Procedure

\section{Class Level Information}

Class Levels Values

Treatment $\quad 7 \quad 0.1 \mathrm{microM} 0.5 \mathrm{microM} 10 \mathrm{microMo} 1 \mathrm{microMol} 5 \mathrm{microMol} \mathrm{Neg}$ Neg. DMSO

Number of Observations Read 175

Number of Observations Used 175

The GLM Procedure

Dependent Variable: Phagocytosis_Efficiency_U937_ox

Source DF Sum of Squares Mean Square F Value $\operatorname{Pr}>$ F

$\begin{array}{llllll}\text { Model } & 6 & 3.12349473 & 0.52058246 & 6.42<.0001\end{array}$

$\begin{array}{llll}\text { Error } & 168 & 13.62661424 & 0.08111080\end{array}$

Corrected Total $174 \quad 16.75010897$

R-Square Coeff Var Root MSE Phagocytosis_Efficiency_U937_ox Mean
0.186476
44.78946
0.284800
0.635863

Source DF Type I SS Mean Square F Value $\operatorname{Pr}>$ F 
Source DF Type I SS Mean Square F Value $\operatorname{Pr}>$ F

$\begin{array}{llllll}\text { Treatment } & 6 & 3.12349473 & 0.52058246 & 6.42<.0001\end{array}$

Source DF Type III SS Mean Square F Value $\operatorname{Pr}>$ F

$\begin{array}{llllll}\text { Treatment } & 6 & 3.12349473 & 0.52058246 & 6.42<.0001\end{array}$

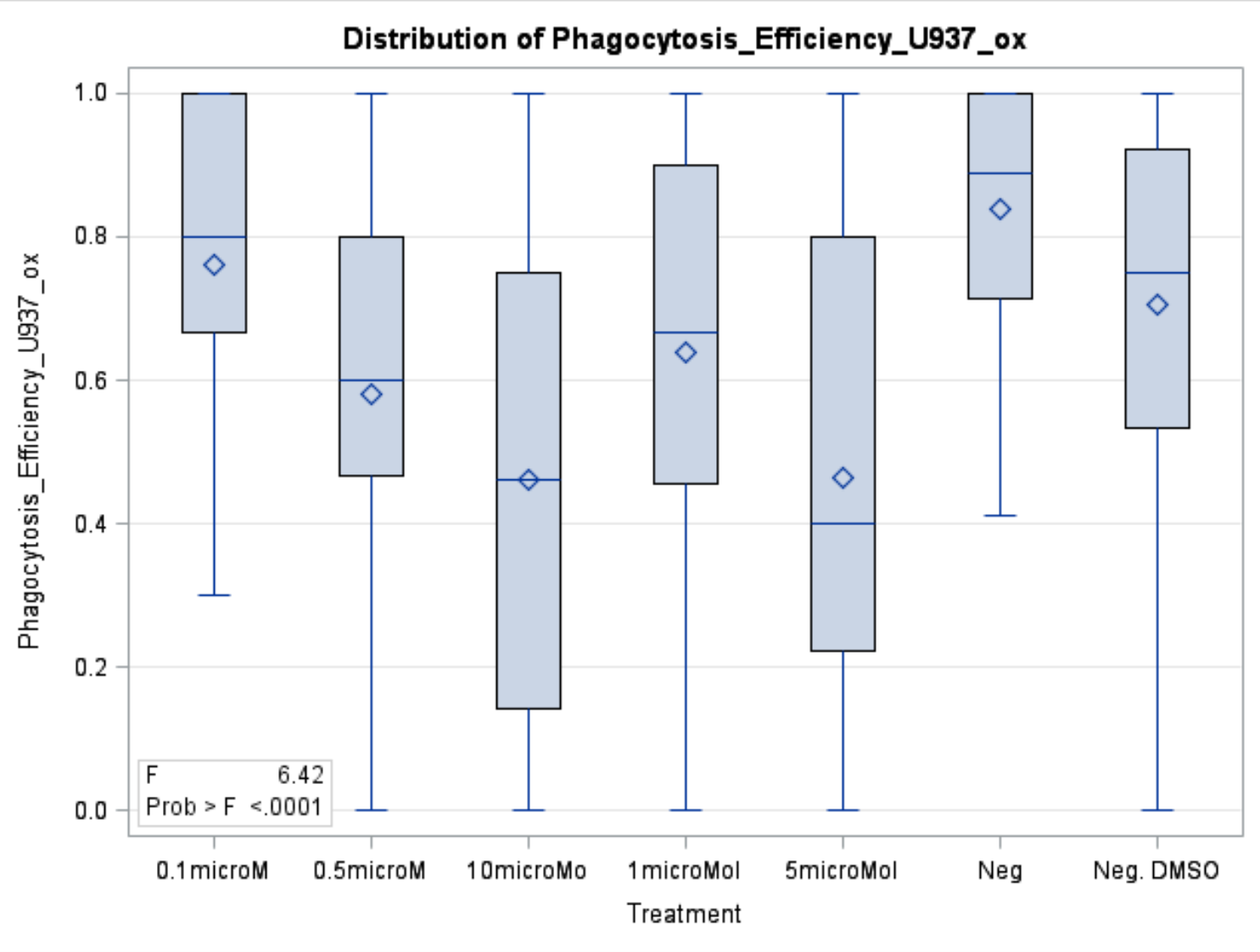

The GLM Procedure

Least Squares Means

Adjustment for Multiple Comparisons: Tukey

Treatment Phagocytosis_Efficiency_U937_ox LSMEAN Number LSMEAN

0.1microM

0.75977156

0.5microM

0.57967801 


\begin{tabular}{|lrr|}
\hline Treatment & $\begin{array}{r}\text { Phagocytosis_Efficiency_U937_ox } \\
\text { LSMEAN }\end{array}$ & \\
& LSMEAN Number \\
10microMo & 0.46146427 & 3 \\
1microMol & 0.64017196 & 4 \\
5microMol & 0.46426055 & 5 \\
Neg & 0.84000190 & 6 \\
Neg. DMSO & 0.70569229 & 7
\end{tabular}

\begin{tabular}{|c|c|c|c|c|c|c|c|}
\hline \multicolumn{8}{|c|}{$\begin{array}{c}\text { Least Squares Means for effect Treatment } \\
\qquad \operatorname{Pr}>|\mathbf{t}| \text { for H0: LSMean(i)=LSMean(j) }\end{array}$} \\
\hline $\mathbf{i} / \mathbf{j}$ & 1 & 2 & 3 & 4 & 5 & 6 & 7 \\
\hline 1 & & 0.2823 & 0.0053 & 0.7536 & 0.0059 & 0.9543 & 0.9940 \\
\hline 2 & 0.2823 & & 0.7636 & 0.9890 & 0.7833 & 0.0245 & 0.7051 \\
\hline 3 & 0.0053 & 0.7636 & & 0.2913 & 1.0000 & 0.0001 & 0.0438 \\
\hline 4 & 0.7536 & 0.9890 & 0.2913 & & 0.3099 & 0.1730 & 0.9833 \\
\hline 5 & 0.0059 & 0.7833 & 1.0000 & 0.3099 & & 0.0001 & 0.0483 \\
\hline 6 & 0.9543 & 0.0245 & 0.0001 & 0.1730 & 0.0001 & & 0.6387 \\
\hline 7 & 0.9940 & 0.7051 & 0.0438 & 0.9833 & 0.0483 & 0.6387 & \\
\hline
\end{tabular}




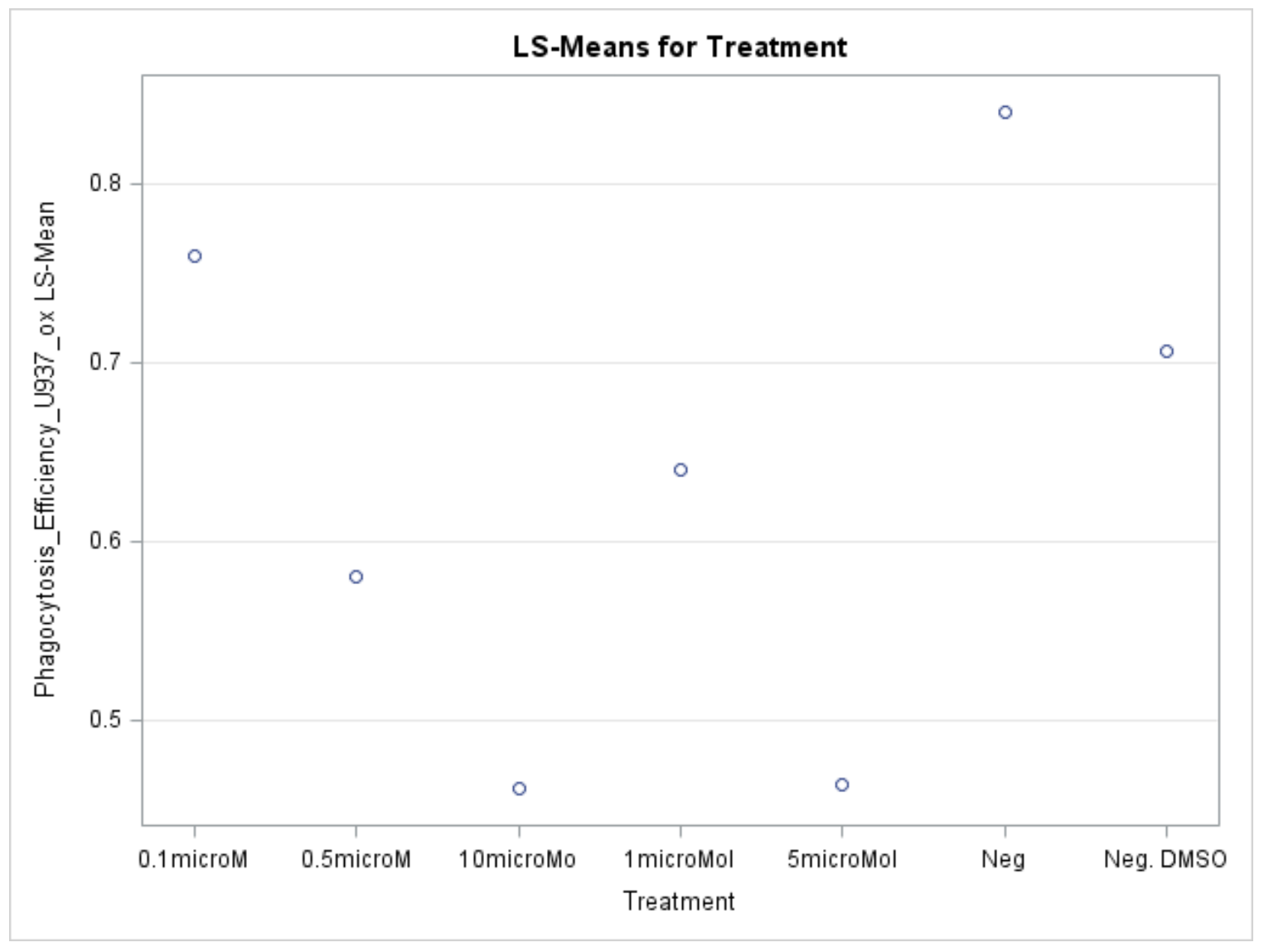




\section{Appendix Q. SAS 9.3 program ANOVA analysis of PF 573228 treated cell by the phagocytosis efficiency for oxLDL beads second replicate in HEPES buffer.}

The SAS System

The GLM Procedure

\section{Class Level Information}

Class Levels Values

Treatment $\quad 7 \quad 0.1$ microM 0.5 microM 10 microMo 1 microMol 5 microMol Neg Neg. DMSO

Number of Observations Read 175

Number of Observations Used 175

The GLM Procedure

Dependent Variable: Phagocytosis_Efficiency_U937_ox

Source DF Sum of Squares Mean Square F Value $\operatorname{Pr}>$ F

$\begin{array}{llllll}\text { Model } & 6 & 5.75703242 & 0.95950540 & 13.41<.0001\end{array}$

$\begin{array}{llll}\text { Error } & 168 & 12.01661681 & 0.07152748\end{array}$

Corrected Total $174 \quad 17.77364923$

R-Square Coeff Var Root MSE Phagocytosis_Efficiency_U937_ox Mean
$0.323908 \quad 40.26662 \quad 0.267446$
0.664188

Source DF Type I SS Mean Square F Value $\operatorname{Pr}>$ F 
Source DF Type I SS Mean Square F Value $\operatorname{Pr}>$ F

$\begin{array}{llllll}\text { Treatment } & 6 & 5.75703242 & 0.95950540 & 13.41<.0001\end{array}$

Source DF Type III SS Mean Square F Value Pr $>$ F

$\begin{array}{llllll}\text { Treatment } & 6 & 5.75703242 & 0.95950540 & 13.41<.0001\end{array}$

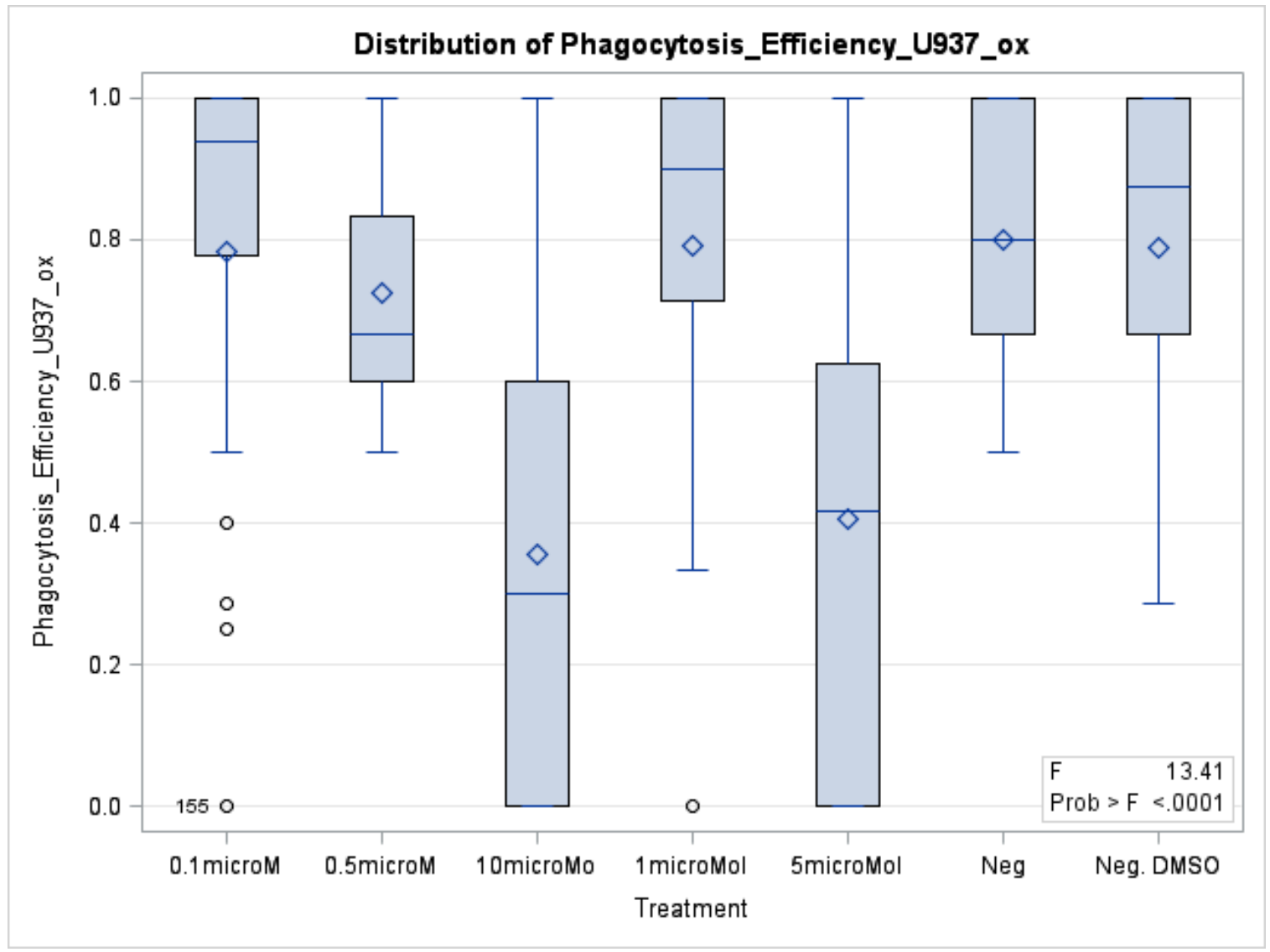

The GLM Procedure

Least Squares Means

Adjustment for Multiple Comparisons: Tukey

Treatment Phagocytosis_Efficiency_U937_ox LSMEAN Number LSMEAN

0.1microM

0.78320665

1 


\begin{tabular}{|lrr|}
\hline Treatment & $\begin{array}{r}\text { Phagocytosis_Efficiency_U937_ox } \\
\text { LSMEAN }\end{array}$ & \\
& 0.72606272 & 2 \\
0.5microM & 0.35602750 & 3 \\
10microMo & 0.79129804 & 4 \\
1microMol & 0.40463272 & 5 \\
5microMol & 0.80007263 & 6 \\
Neg & 0.78801832 & 7 \\
Neg. DMSO &
\end{tabular}

\begin{tabular}{|c|c|c|c|c|c|c|c|}
\hline \multicolumn{8}{|c|}{$\begin{array}{c}\text { Least Squares Means for effect Treatment } \\
\operatorname{Pr}>|\mathbf{t}| \text { for H0: LSMean(i)=LSMean(j) }\end{array}$} \\
\hline $\mathbf{i} / \vec{s}$ & 1 & 2 & 3 & 4 & 5 & 6 & 7 \\
\hline 1 & & 0.9887 & $<.0001$ & 1.0000 & $<.0001$ & 1.0000 & 1.0000 \\
\hline 2 & 0.9887 & & $<.0001$ & 0.9775 & 0.0007 & 0.9580 & 0.9827 \\
\hline 3 & $<.0001$ & $<.0001$ & & $<.0001$ & 0.9953 & $<.0001$ & $<.0001$ \\
\hline 4 & 1.0000 & 0.9775 & $<.0001$ & & $<.0001$ & 1.0000 & 1.0000 \\
\hline 5 & $<.0001$ & 0.0007 & 0.9953 & $<.0001$ & & $<.0001$ & $<.0001$ \\
\hline 6 & 1.0000 & 0.9580 & $<.0001$ & 1.0000 & $<.0001$ & & 1.0000 \\
\hline 7 & 1.0000 & 0.9827 & $<.0001$ & 1.0000 & $<.0001$ & 1.0000 & \\
\hline
\end{tabular}




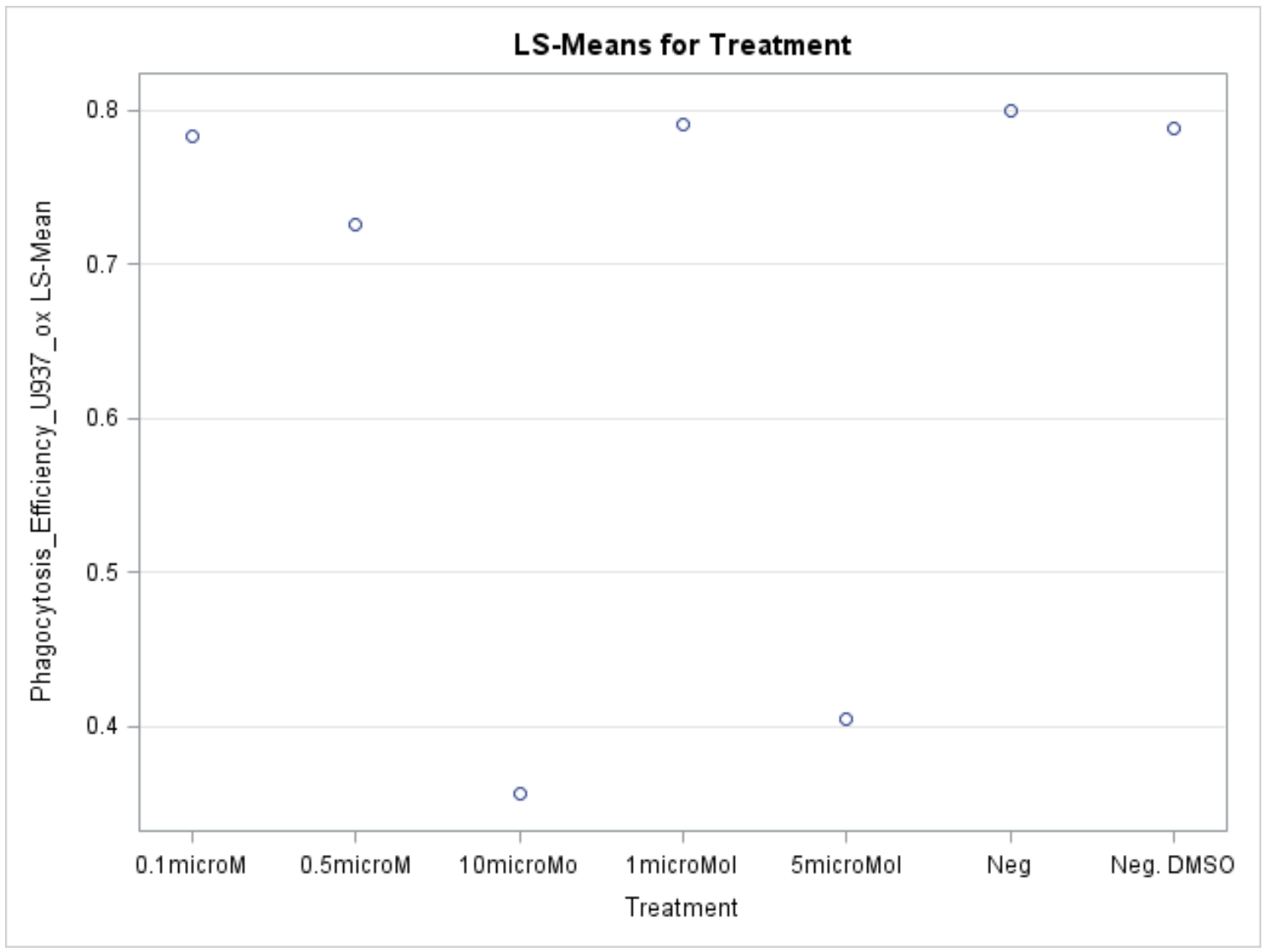




\section{Appendix R. SAS 9.3 program ANOVA analysis of PF 573228 treated cell by the phagocytosis efficiency for oxLDL beads third replicate in HEPES buffer.}

The SAS System

The GLM Procedure

\section{Class Level Information}

Class Levels Values

Treatment $\quad 7 \quad 0.1$ microM 0.5 microM 10microMo 1 microMol 5microMol Neg Neg. DMSO

Number of Observations Read 175

Number of Observations Used 175

The GLM Procedure

Dependent Variable: Phagocytosis_Efficiency_U937_ox

$\begin{array}{lrrrrr}\text { Source } & \text { DF } & \text { Sum of Squares } & \text { Mean Square } & \text { F Value } & \text { Pr }>\text { F } \\ \text { Model } & 6 & 17.85302301 & 2.97550384 & 14.85<.0001 \\ \text { Error } & 168 & 33.66223011 & 0.20037042 & & \\ \text { Corrected Total } & 174 & 51.51525312 & & & \\ \end{array}$

R-Square Coeff Var Root MSE Phagocytosis_Efficiency_U937_ox Mean
$0.346558 \quad 56.40500 \quad 0.447628$
0.793595

Source DF Type I SS Mean Square F Value Pr $>$ F

$\begin{array}{llllll}\text { Treatment } & 6 & 17.85302301 & 2.97550384 & 14.85 & <.0001\end{array}$ 


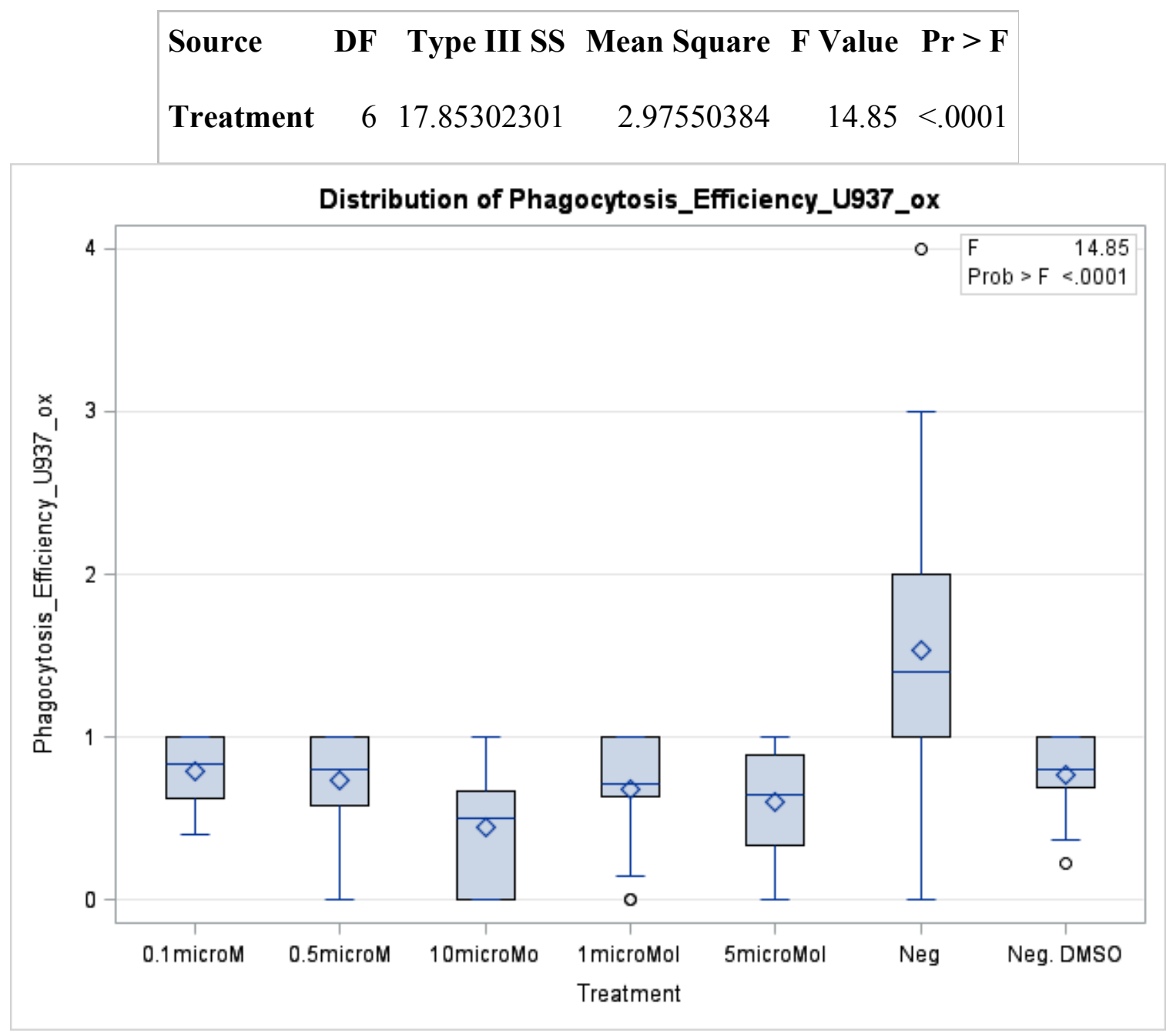

The GLM Procedure

Least Squares Means

Adjustment for Multiple Comparisons: Tukey

Treatment Phagocytosis_Efficiency_U937_ox LSMEAN Number

LSMEAN

0.1microM

0.79293506

1

0.5 microM

0.73686580

2

10microMo

0.44675824

3

1microMol

0.68014330

4

5microMol

0.60367692

5 


$\begin{array}{|lrr|}\text { Treatment } & \text { Phagocytosis_Efficiency_U937_ox } & \text { LSMEAN Number } \\ & \text { LSMEAN } & \\ \text { Neg } & 1.52904762 & 6 \\ \text { Neg. DMSO } & 0.76574137 & 7\end{array}$

\begin{tabular}{|c|c|c|c|c|c|c|c|}
\hline \multicolumn{8}{|c|}{$\begin{array}{l}\text { Least Squares Means for effect Treatment } \\
\operatorname{Pr}>|\mathbf{t}| \text { for H0: } \operatorname{LSMean}(\mathbf{i})=\operatorname{LSMean}(\mathbf{j})\end{array}$} \\
\hline $\mathbf{i} / \mathbf{j}$ & 1 & 2 & 3 & 4 & 5 & 6 & 7 \\
\hline 1 & & 0.9994 & 0.0962 & 0.9735 & 0.7476 & $<.0001$ & 1.0000 \\
\hline 2 & 0.9994 & & 0.2543 & 0.9994 & 0.9408 & $<.0001$ & 1.0000 \\
\hline 3 & 0.0962 & 0.2543 & & 0.5209 & 0.8777 & $<.0001$ & 0.1590 \\
\hline 4 & 0.9735 & 0.9994 & 0.5209 & & 0.9966 & $<.0001$ & 0.9937 \\
\hline 5 & 0.7476 & 0.9408 & 0.8777 & 0.9966 & & $<.0001$ & 0.8602 \\
\hline 6 & $<.0001$ & $<.0001$ & $<.0001$ & $<.0001$ & $<.0001$ & & $<.0001$ \\
\hline 7 & 1.0000 & 1.0000 & 0.1590 & 0.9937 & 0.8602 & $<.0001$ & \\
\hline
\end{tabular}




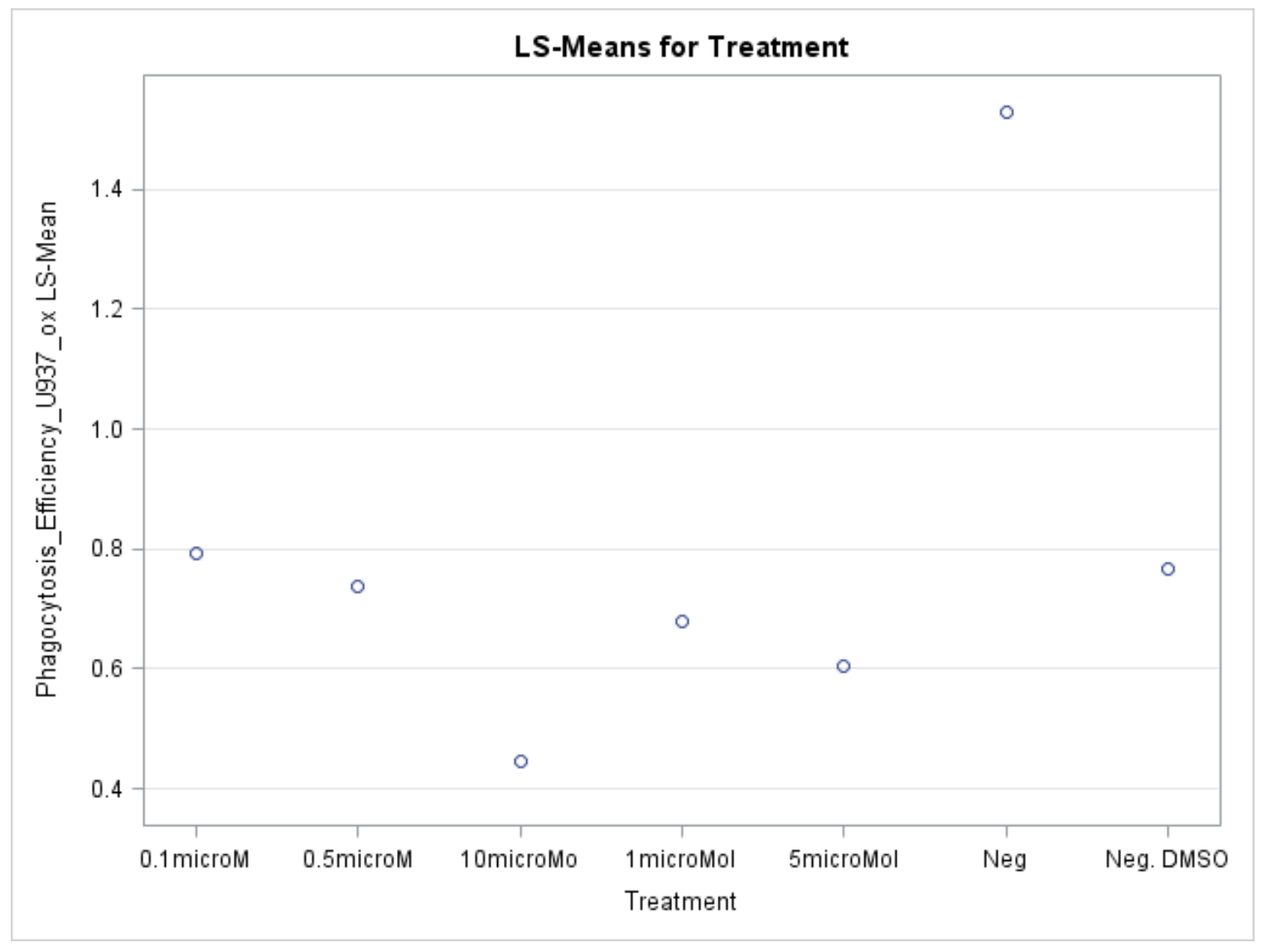




\section{Appendix S. SAS 9.3 program ANOVA analysis of PF 573228 treated cell by the phagocytosis efficiency for IgG beads first replicate in RPMI $10 \%$ FBS media.}

The SAS System

The GLM Procedure

\section{Class Level Information}

Class Levels Values

Treatment $\quad 7 \quad 0.1$ microM 0.5 microM 10 microMo 1 microMol 5 microMol Neg Neg. DMSO

Number of Observations Read 175

Number of Observations Used 175

The GLM Procedure

Dependent Variable: Phagocytosis_Efficiency_U937_IgG

$\begin{array}{lrrrrr}\text { Source } & \text { DF } & \text { Sum of Squares } & \text { Mean Square } & \text { F Value } & \text { Pr }>\text { F } \\ \text { Model } & 6 & 0.39204902 & 0.06534150 & 2.32 & 0.0356 \\ \text { Error } & 168 & 4.73768970 & 0.02820053 & & \\ \text { Corrected Total } & 174 & 5.12973872 & & & \end{array}$

R-Square Coeff Var Root MSE Phagocytosis_Efficiency_U937_IgG Mean
$0.076427 \quad 20.40052$
0.167930
0.823166 
Source DF Type I SS Mean Square F Value $\operatorname{Pr}>$ F
Treatment
$\begin{array}{ll}6 & 0.39204902\end{array}$
0.06534150
2.320 .0356

Source DF Type III SS Mean Square F Value $\operatorname{Pr}>$ F

$\begin{array}{llllll}\text { Treatment } & 6 & 0.39204902 & 0.06534150 & 2.32 & 0.0356\end{array}$

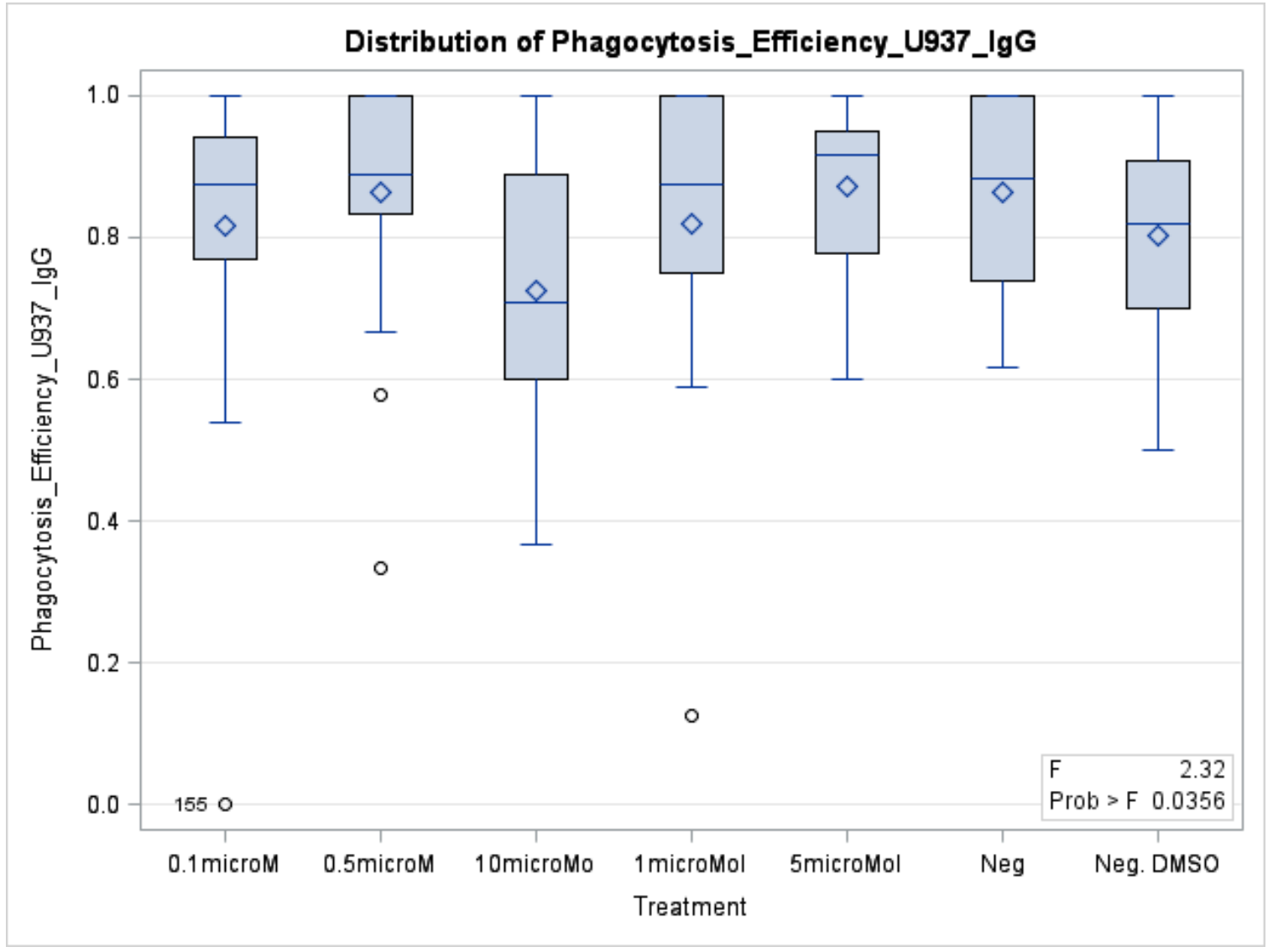

The GLM Procedure

Least Squares Means

Adjustment for Multiple Comparisons: Tukey

Treatment Phagocytosis_Efficiency_U937_IgG LSMEAN Number

LSMEAN

0.1microM

0.81577581

1

0.5microM

0.86323959 


\begin{tabular}{|lrr|}
\hline Treatment & $\begin{array}{r}\text { Phagocytosis_Efficiency_U937_IgG } \\
\text { LSMEAN }\end{array}$ & \\
10microMo & 0.72499615 & 3 \\
1 microMol & 0.81882353 & 4 \\
5microMol & 0.87223598 & 5 \\
Neg & 0.86305804 & 6 \\
Neg. DMSO & 0.80403383 & 7
\end{tabular}

\begin{tabular}{|c|c|c|c|c|c|c|c|}
\hline & $\begin{array}{r}\text { Le } \\
\mathbf{F}\end{array}$ & $\begin{array}{l}\text { ist Squa } \\
r>|t| \text { fo }\end{array}$ & $\begin{array}{l}\text { res Me } \\
\text { r H0: I }\end{array}$ & $\begin{array}{l}\text { ns for } e \\
\text { SMean( }\end{array}$ & $\begin{array}{l}\text { ffect Tre } \\
\text { i) }=\mathbf{L S M}\end{array}$ & $\begin{array}{l}\text { atment } \\
\text { ean(j) }\end{array}$ & \\
\hline & penden & Variab & le: Pha & ocytosis & _Efficie & ncy_U93 & 77_IgG \\
\hline $\mathbf{i} / \mathbf{j}$ & 1 & 2 & 3 & 4 & 5 & 6 & 7 \\
\hline 1 & & 0.9536 & 0.4758 & 1.0000 & 0.8976 & 0.9544 & 1.0000 \\
\hline 2 & 0.9536 & & 0.0611 & 0.9663 & 1.0000 & 1.0000 & 0.8747 \\
\hline 3 & 0.4758 & 0.0611 & & 0.4342 & 0.0361 & 0.0617 & 0.6409 \\
\hline 4 & 1.0000 & 0.9663 & 0.4342 & & 0.9198 & 0.9670 & 0.9999 \\
\hline 5 & 0.8976 & 1.0000 & 0.0361 & 0.9198 & & 1.0000 & 0.7816 \\
\hline 6 & 0.9544 & 1.0000 & 0.0617 & 0.9670 & 1.0000 & & 0.8763 \\
\hline 7 & 1.0000 & 0.8747 & 0.6409 & 0.9999 & 0.7816 & 0.8763 & \\
\hline
\end{tabular}




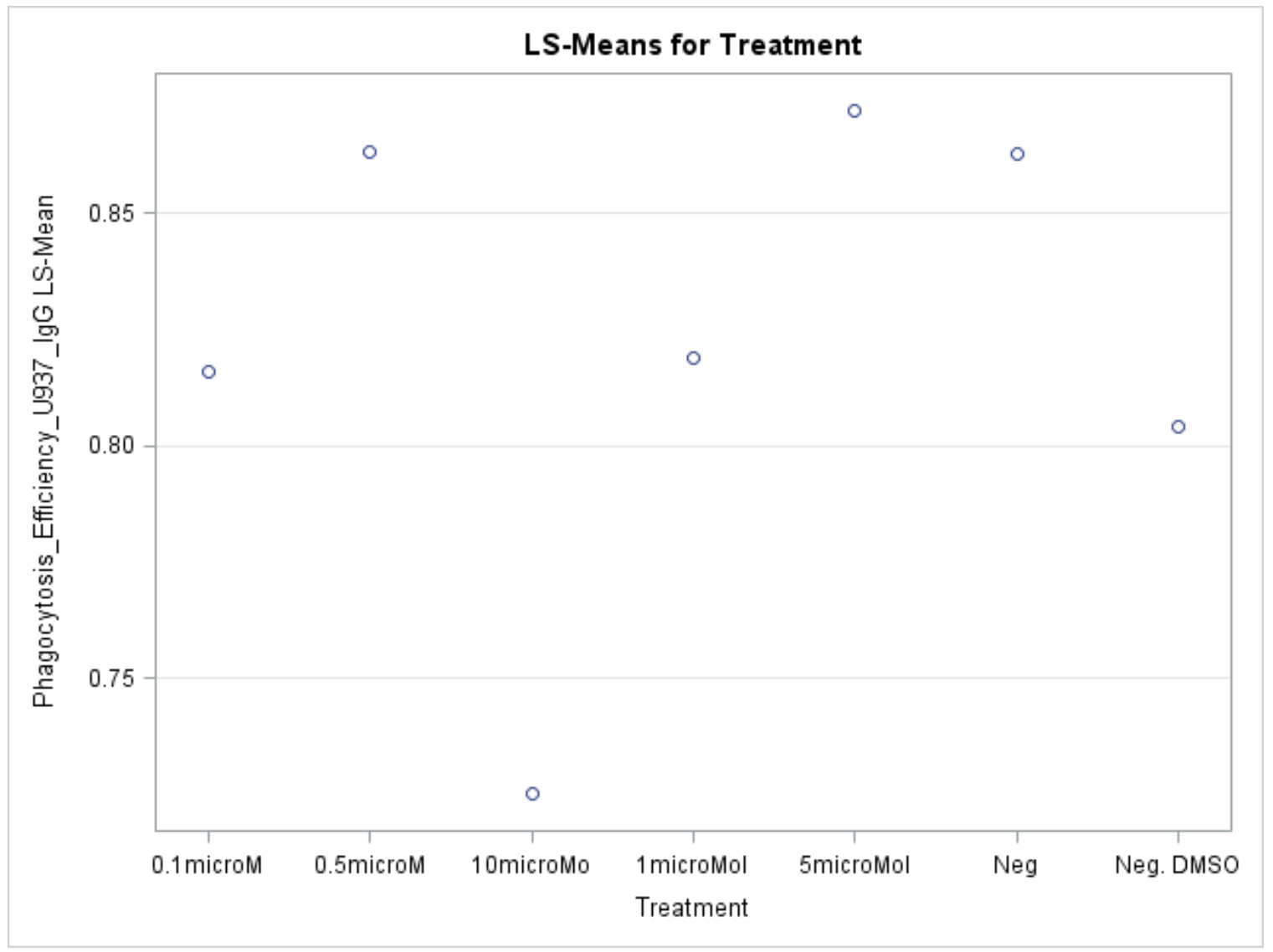




\title{
Appendix T. SAS 9.3 program ANOVA analysis of PF 573228 treated cell by the phagocytosis efficiency for IgG beads second replicate in RPMI 10\% FBS media.
}

The SAS System

The GLM Procedure

\section{Class Level Information}

Class Levels Values

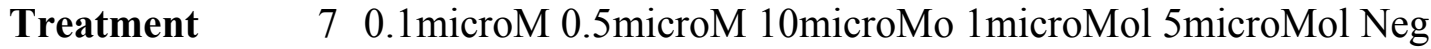
Neg. DMSO

\author{
Number of Observations Read 175 \\ Number of Observations Used 175
}

The GLM Procedure

Dependent Variable: Phagocytosis_Efficiency_U937_IgG

$\begin{array}{lrrrrr}\text { Source } & \text { DF } & \text { Sum of Squares } & \text { Mean Square } & \text { F Value } & \text { Pr }>\text { F } \\ \text { Model } & 6 & 1.26468192 & 0.21078032 & 6.91<.0001 \\ \text { Error } & 168 & 5.12606970 & 0.03051232 & & \\ \text { Corrected Total } & 174 & 6.39075161 & & & \end{array}$

R-Square Coeff Var Root MSE Phagocytosis_Efficiency_U937_IgG Mean
0.197893
22.14207
0.174678
0.788895

$\begin{array}{lrrrrrr}\text { Source } & \text { DF } & \text { Type I SS } & \text { Mean Square } & \text { F Value } & \text { Pr }>\text { F } \\ \text { Treatment } & 6 & 1.26468192 & 0.21078032 & 6.91 & <.0001\end{array}$


Source DF Type III SS Mean Square F Value Pr $>$ F

$\begin{array}{llllll}\text { Treatment } & 6 & 1.26468192 & 0.21078032 & 6.91<.0001\end{array}$

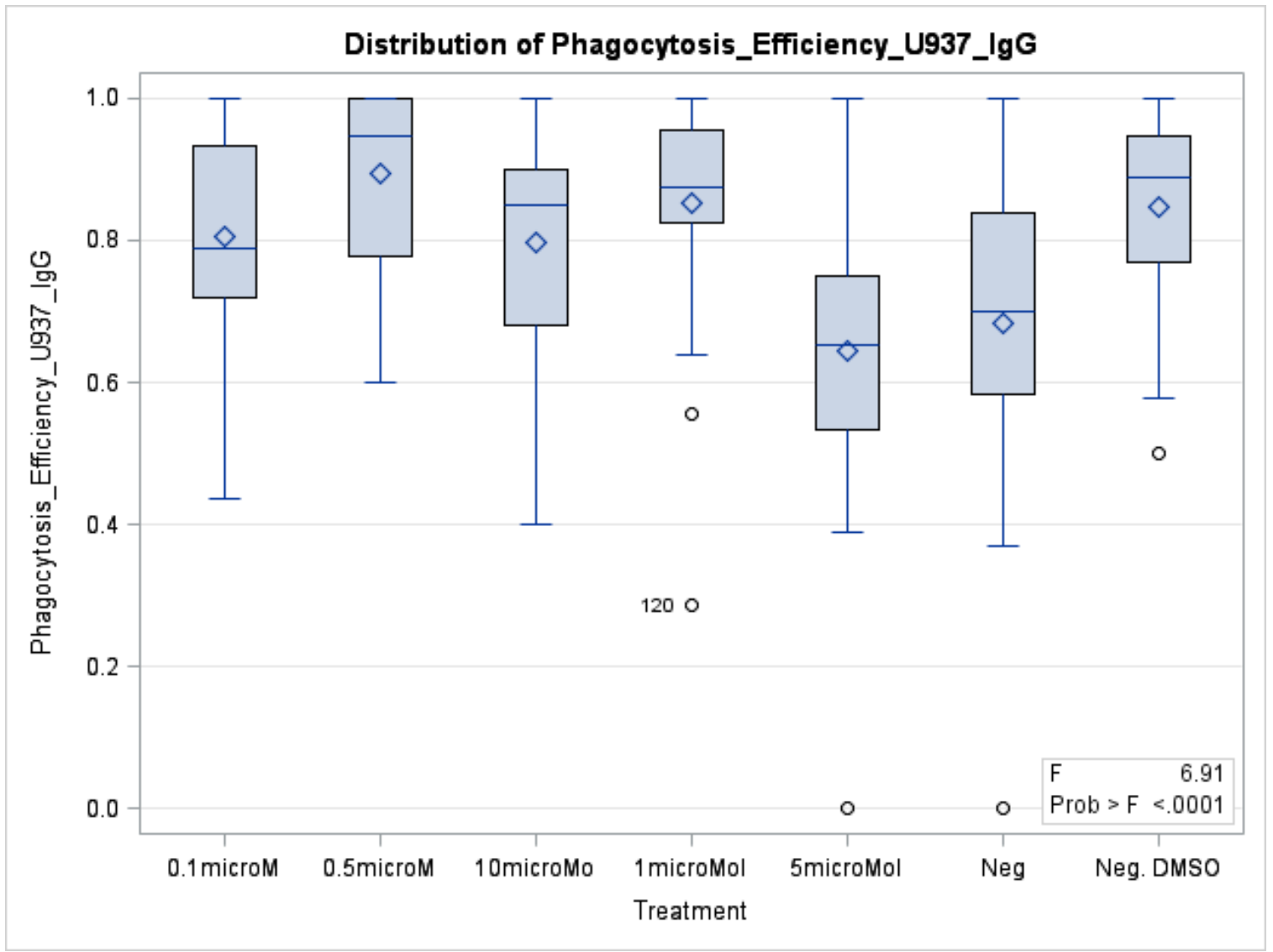

The GLM Procedure

Least Squares Means

Adjustment for Multiple Comparisons: Tukey

$\begin{array}{lcr}\text { Treatment } & \begin{array}{r}\text { Phagocytosis_Efficiency_U937_IgG } \\ \text { LSMEAN }\end{array} & 1 \\ \text { 0.1microM } & 0.80587755 & 2 \\ \text { 0.5microM } & 0.89305012 & 3 \\ \text { 10microMo } & 0.79587302 & 4 \\ \text { 1microMol } & 0.85274129 & \end{array}$




\begin{tabular}{|lrr|}
\hline Treatment & $\begin{array}{r}\text { Phagocytosis_Efficiency_U937_IgG } \\
\text { LSMEAN }\end{array}$ & \\
& & 5 \\
5microMol & 0.64441637 & 6 \\
Neg & 0.68353291 & 7 \\
Neg. DMSO & 0.84677672 & 7
\end{tabular}

\begin{tabular}{|c|c|c|c|c|c|c|c|}
\hline \multicolumn{8}{|c|}{$\begin{array}{c}\text { Least Squares Means for effect Treatment } \\
\operatorname{Pr}>|\mathbf{t}| \text { for H0: LSMean(i)=LSMean(j) }\end{array}$} \\
\hline $\mathbf{i} / \mathrm{s}$ & 1 & 2 & 3 & 4 & 5 & 6 & 7 \\
\hline 1 & & 0.5739 & 1.0000 & 0.9639 & 0.0219 & 0.1747 & 0.9818 \\
\hline 2 & 0.5739 & & 0.4396 & 0.9831 & $<.0001$ & 0.0007 & 0.9661 \\
\hline 3 & 1.0000 & 0.4396 & & 0.9110 & 0.0398 & 0.2630 & 0.9463 \\
\hline 4 & 0.9639 & 0.9831 & 0.9110 & & 0.0008 & 0.0134 & 1.0000 \\
\hline 5 & 0.0219 & $<.0001$ & 0.0398 & 0.0008 & & 0.9855 & 0.0013 \\
\hline 6 & 0.1747 & 0.0007 & 0.2630 & 0.0134 & 0.9855 & & 0.0196 \\
\hline 7 & 0.9818 & 0.9661 & 0.9463 & 1.0000 & 0.0013 & 0.0196 & \\
\hline
\end{tabular}




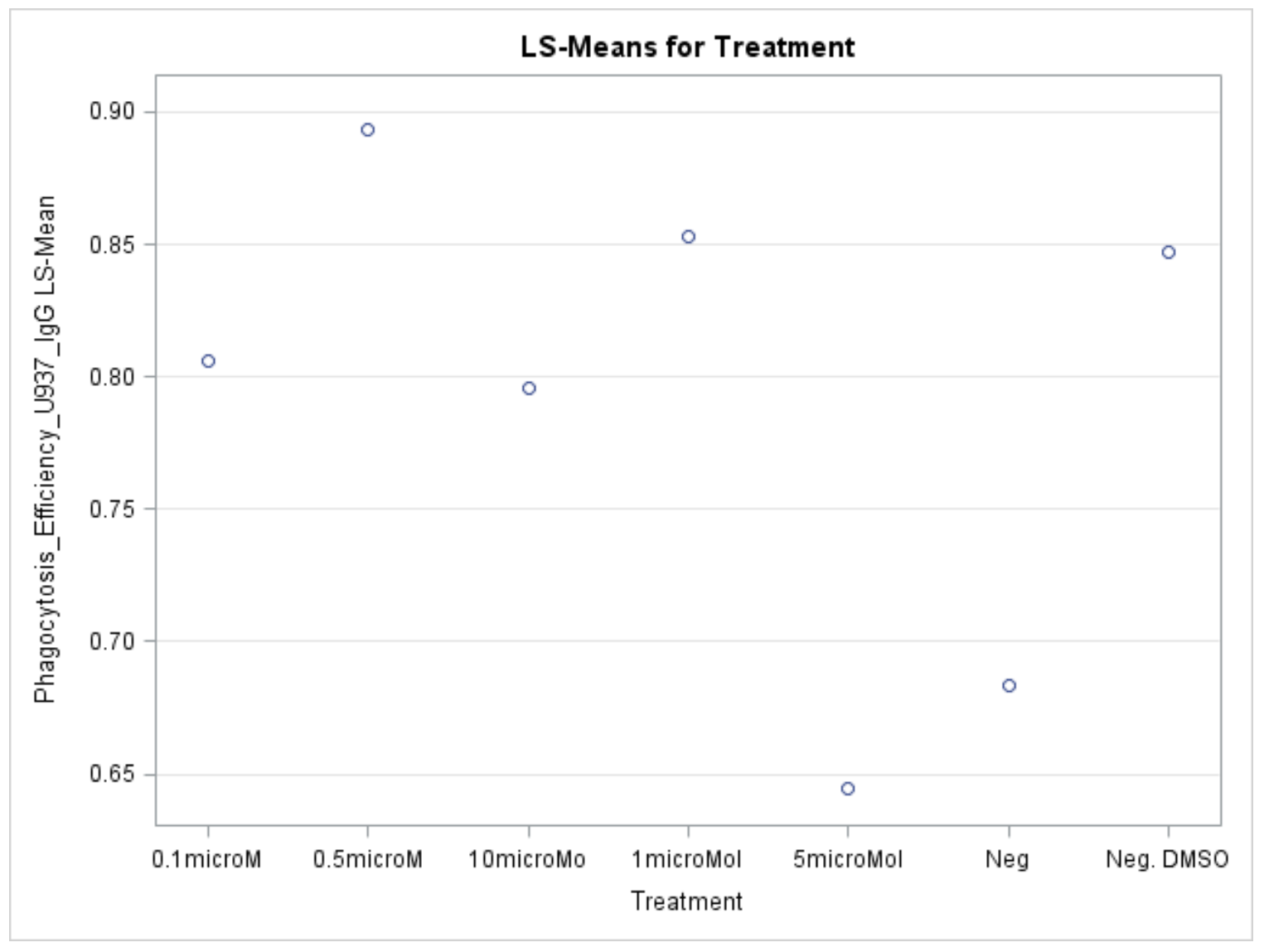




\section{Appendix U. SAS 9.3 program ANOVA analysis of PTK2 immunofluorescence Cy5 intensity of cells treated with oxLDL beads in HEPES buffer.}

The SAS System

The GLM Procedure

Class Level Information

Class Levels Values

Treatment 2 Neg. SiRN

Number of Observations Read 200

Number of Observations Used 200

The GLM Procedure

Dependent Variable: Intensity_PTK2

\begin{tabular}{|lrrrrr|}
\hline Source & DF & Sum of Squares & Mean Square & F Value & Pr $>$ F \\
Model & 1 & 171787.101 & 171787.101 & $26.46<.0001$ \\
Error & 198 & 1285685.288 & 6493.360 & \\
Corrected Total & 199 & 1457472.389 & & & \\
\end{tabular}

R-Square Coeff Var Root MSE Intensity_PTK2 Mean

$\begin{array}{llll}0.117866 & 29.06720 & 80.58139 & 277.2245\end{array}$

Source DF Type I SS Mean Square F Value $\operatorname{Pr}>$ F 
Source DF Type I SS Mean Square F Value Pr $>$ F

$\begin{array}{llllll}\text { Treatment } & 1 & 171787.1011 & 171787.1011 & 26.46 & <.0001\end{array}$

Source DF Type III SS Mean Square F Value $\operatorname{Pr}>$ F

$\begin{array}{llllll}\text { Treatment } & 1 & 171787.1011 & 171787.1011 & 26.46 & <.0001\end{array}$

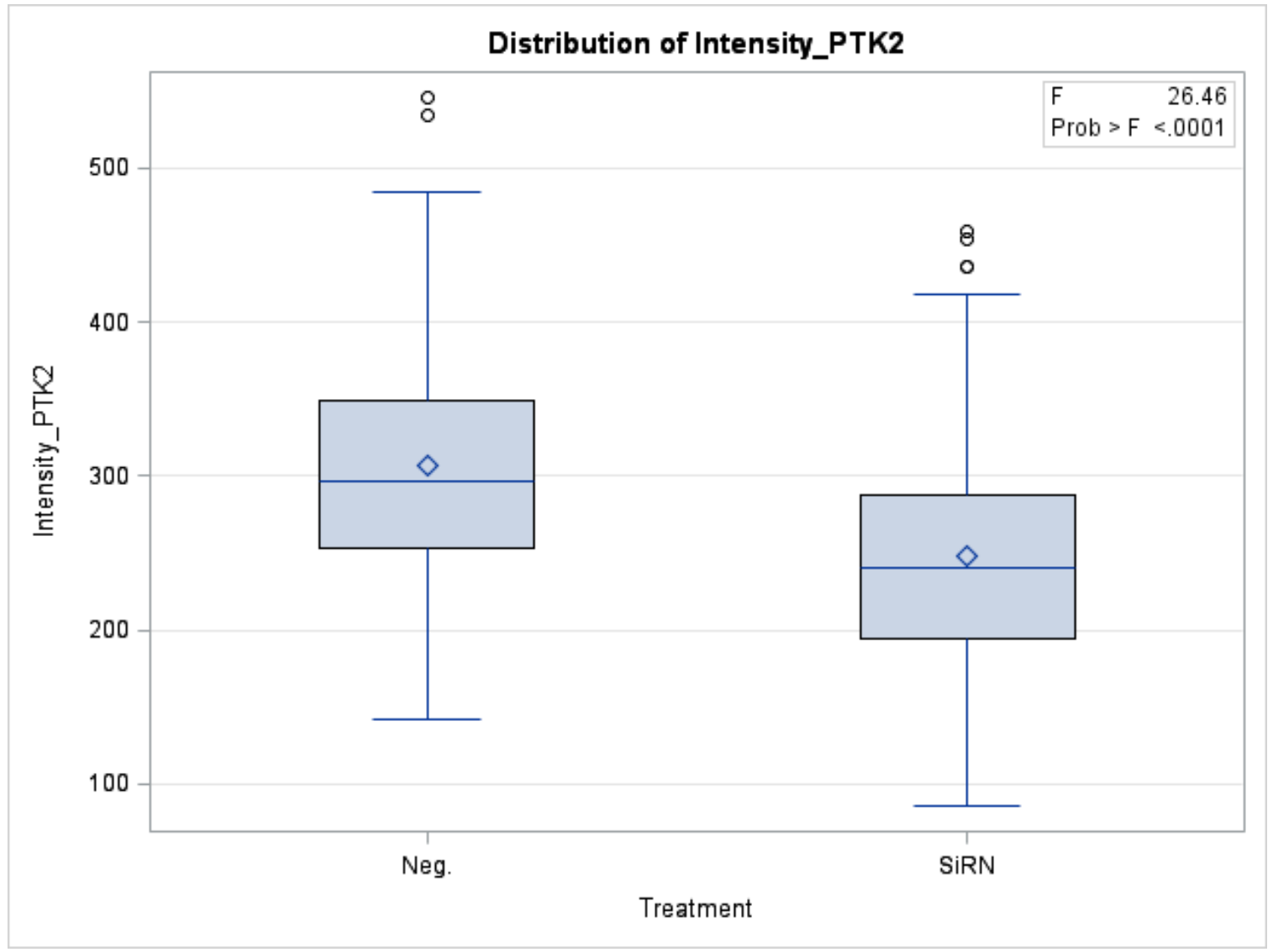


The GLM Procedure

Least Squares Means

Adjustment for Multiple Comparisons: Tukey

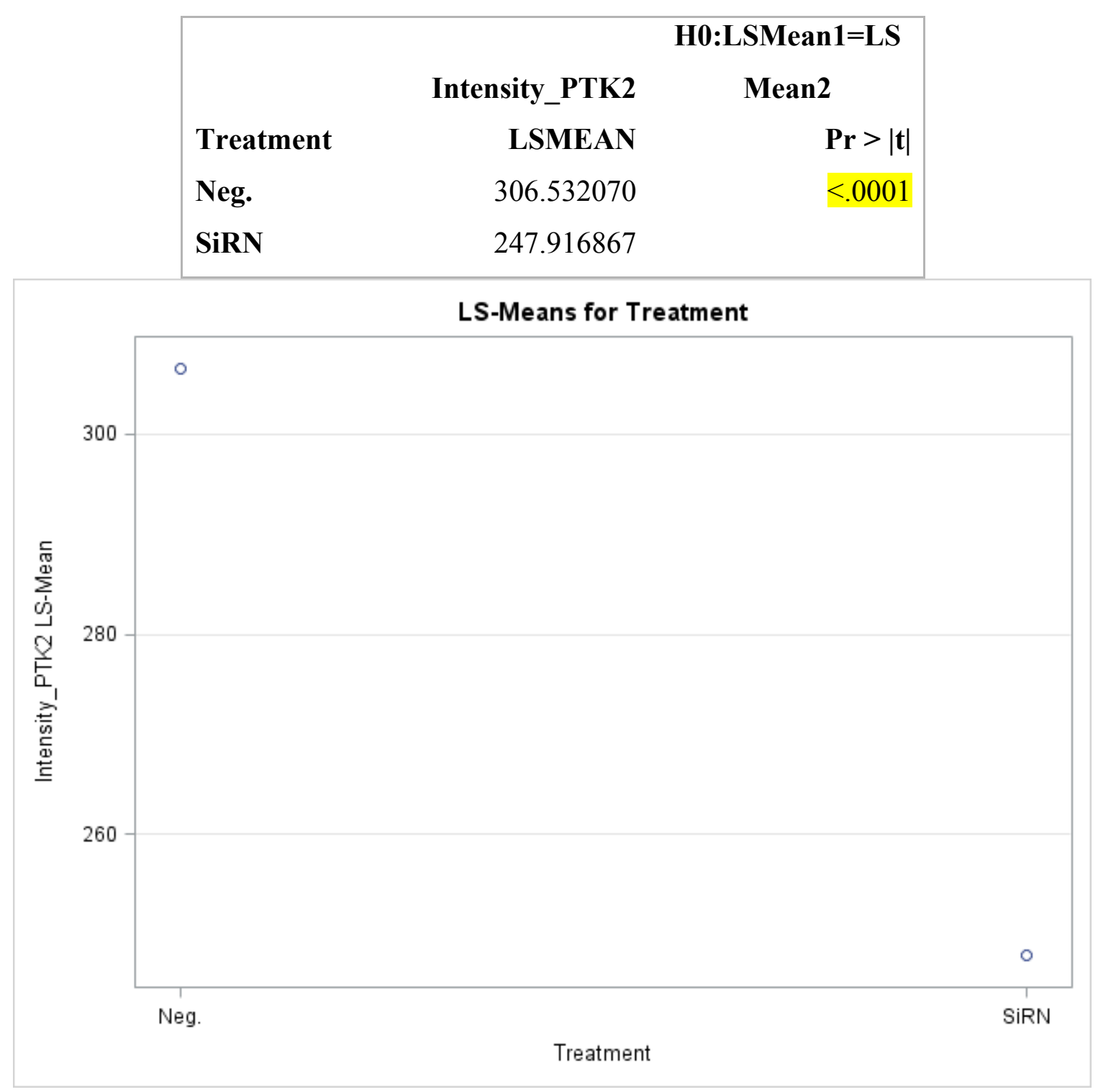




\section{Appendix V. SAS 9.3 program regression analysis of PTK2 immunofluorescence $\mathrm{Cy} 5$ intensity verses $\mathrm{Cy} 3$ intensity.}

Scatter Plot of Cy3 Intensity by Cy5 intensity

The REG Procedure

Model: MODEL1

Dependent Variable: Cy5_Intensity

Number of Observations Read 100

Number of Observations Used 100

Note: No intercept in model. R-Square is redefined.

\begin{tabular}{|lrrrrr}
\hline \multicolumn{4}{c}{ Analysis of Variance } & & \\
Source & DF & Sum of & Mean & F Value & Pr $>$ F \\
& & Squares & Square & & \\
& 1 & 3492200 & 3492200 & $103.38<.0001$ \\
Model & 99 & 3344235 & 33780 & \\
Error & & & & & \\
Uncorrected Total & 100 & 6836436 & &
\end{tabular}

\begin{tabular}{|lccc|}
\hline Root MSE & 183.79379 & R-Square & 0.5108 \\
Dependent Mean & 247.91687 & Adj R-Sq & 0.5059 \\
Coeff Var & 74.13525 &
\end{tabular}

Parameter Estimates 
Variable DF Parameter Standard t Value $\operatorname{Pr}>|t|$

Estimate Error

$\begin{array}{llllll}\text { Cy3_Intensity } & 1 & 0.10352 & 0.01018 & 10.17 & <.0001\end{array}$

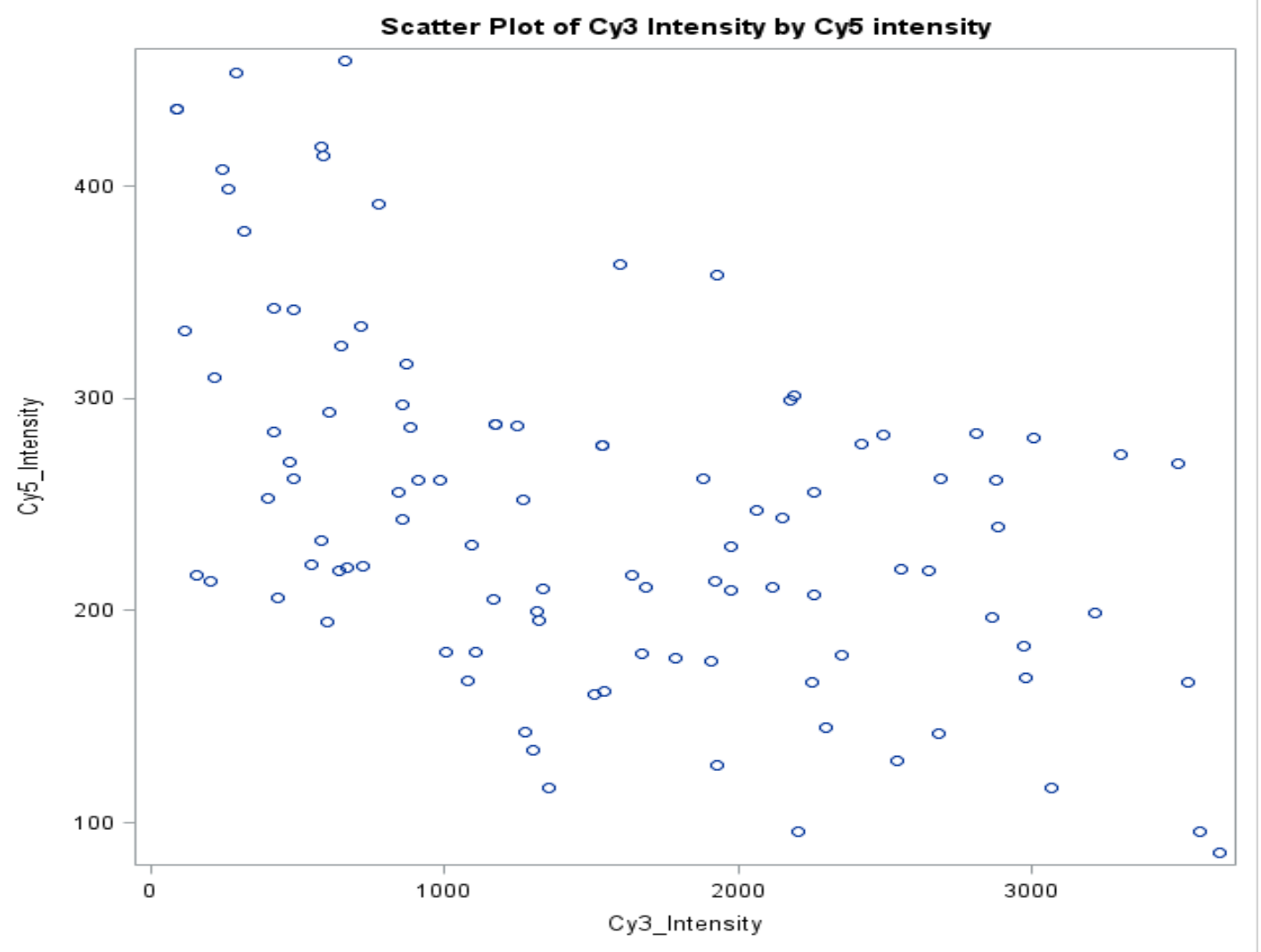




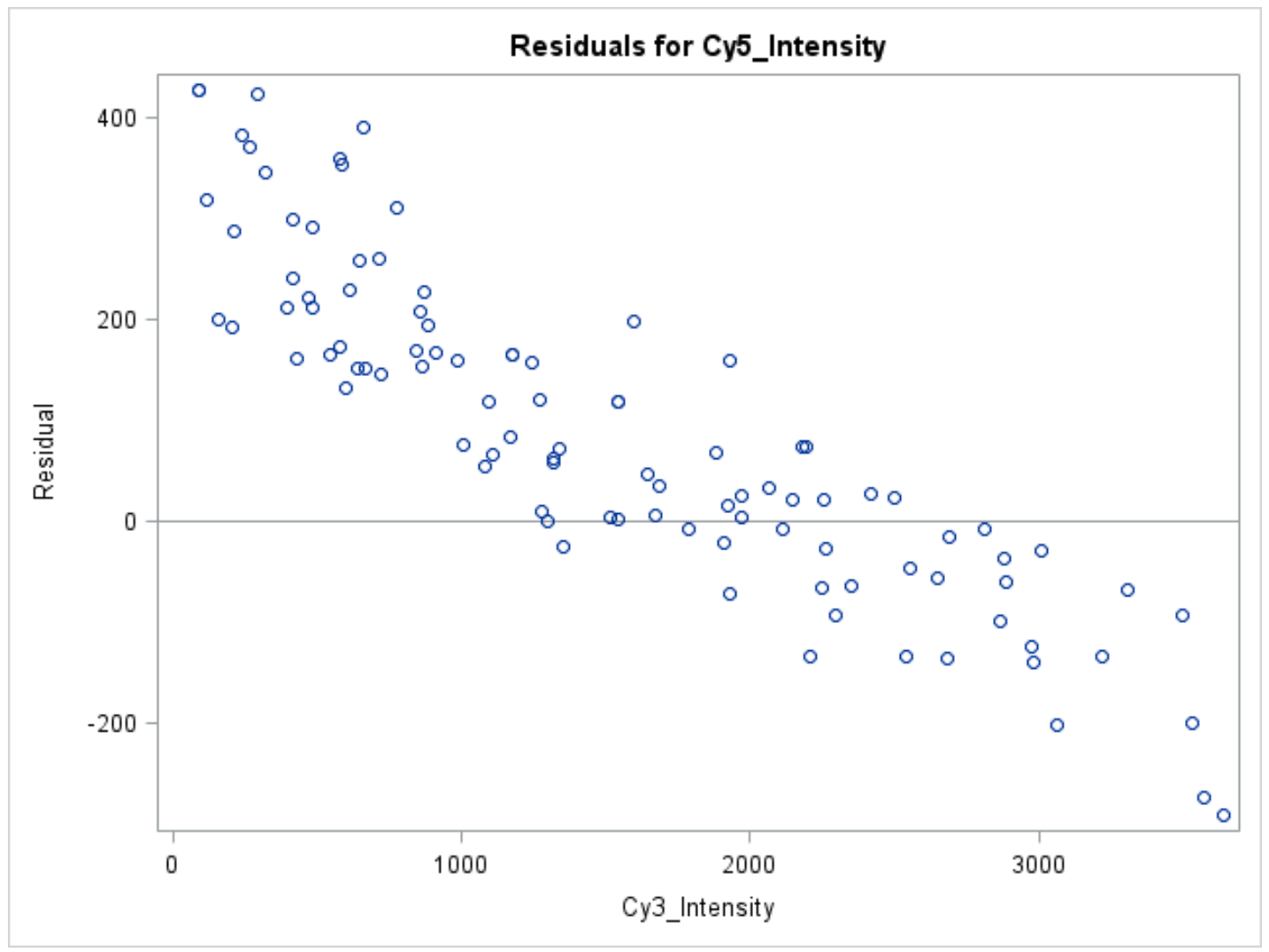




\section{Appendix W. SAS 9.3 program ANOVA analysis of PTK2B immunofluorescence Cy5 intensity of cells treated with oxLDL in HEPES buffer.}

The SAS System

The GLM Procedure

Class Level Information

Class Levels Values

Treatment 2 Neg. SiRN

Number of Observations Read 340

Number of Observations Used 340

The GLM Procedure

Dependent Variable: Intensity_PTK2B

\begin{tabular}{|lrrrrr} 
Source & DF & Sum of Squares & Mean Square & F Value & Pr $>$ F \\
Model & 1 & 413597.242 & 413597.242 & $44.98<.0001$ \\
Error & 338 & 3108239.105 & 9195.974 & & \\
Corrected Total & 339 & 3521836.348 & & &
\end{tabular}

R-Square Coeff Var Root MSE Intensity_PTK2B Mean
$0.117438 \quad 35.13989 \quad 95.89564$
272.8968

Source DF Type I SS Mean Square F Value $\operatorname{Pr}>$ F

$\begin{array}{llllll}\text { Treatment } & 1 & 413597.2422 & 413597.2422 & 44.98 & <.0001\end{array}$ 


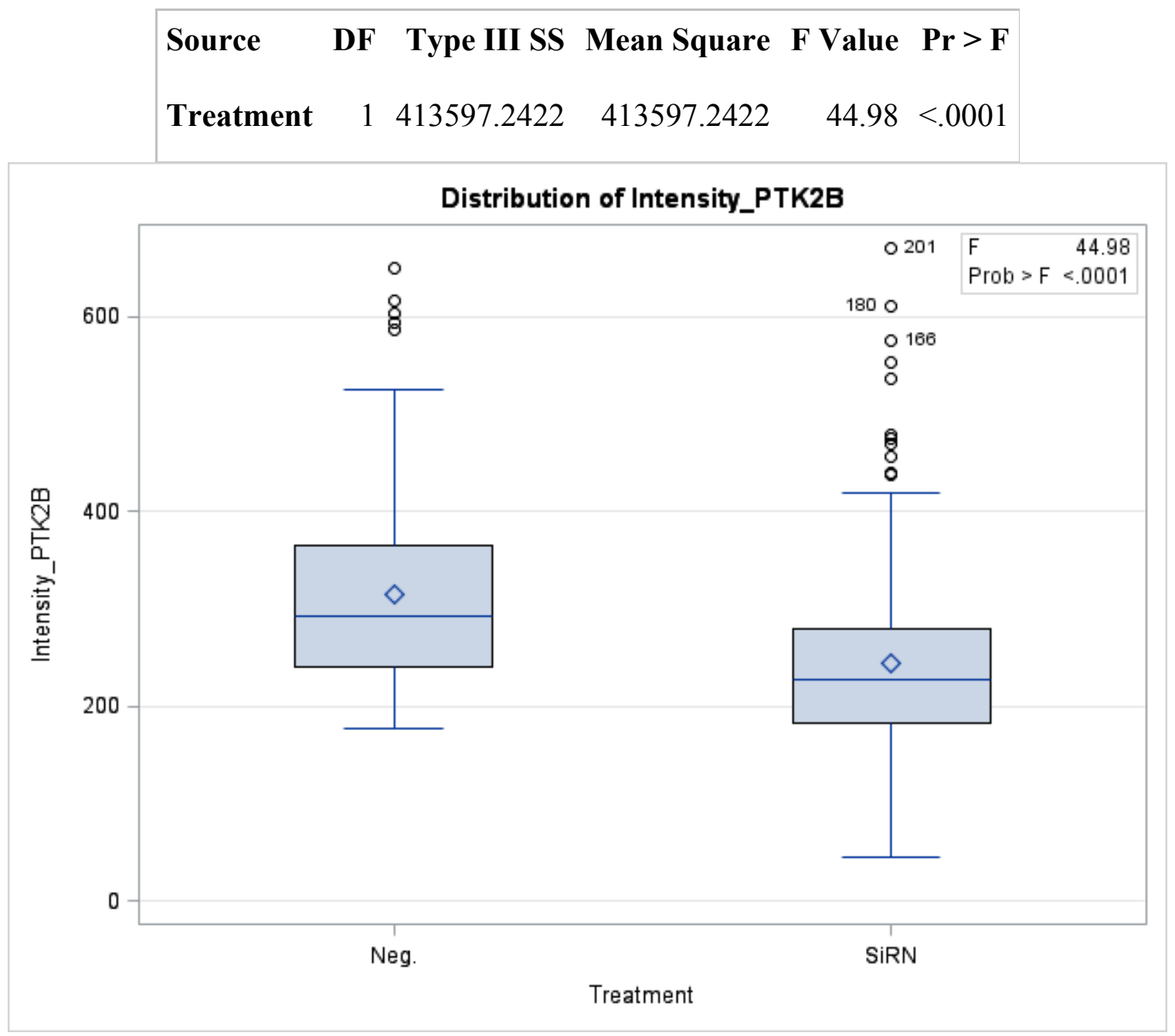

The GLM Procedure

Least Squares Means

Adjustment for Multiple Comparisons: Tukey-Kramer

Treatment Intensity_PTK2B LSMEAN H0:LSMean1=LSMean2

$\operatorname{Pr}>|\mathbf{t}|$

Neg.

314.583757

$<.0001$

SiRN

243.715907 


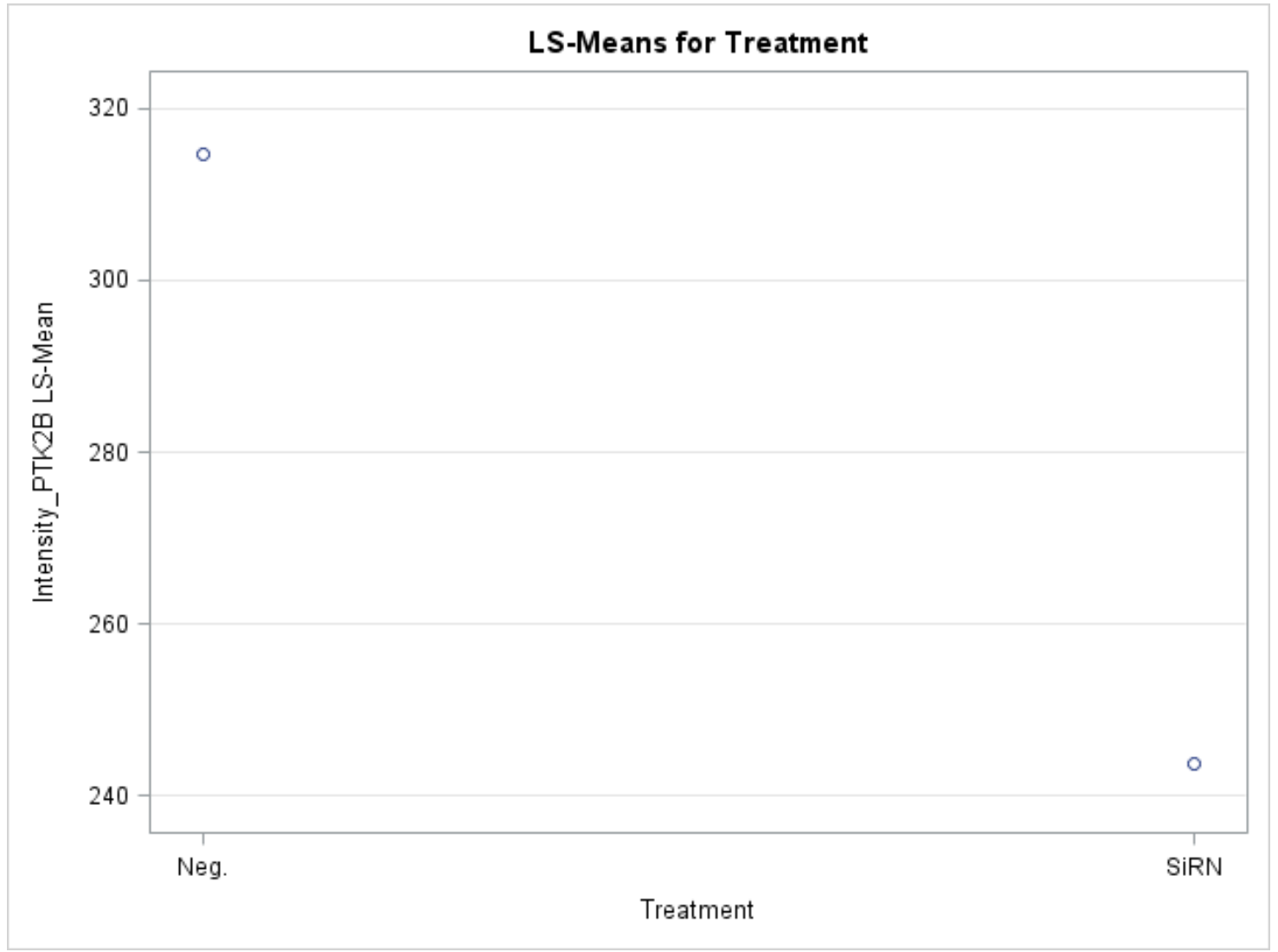




\section{Appendix X. SAS 9.3 program regression analysis of PTK2B immunofluorescence $\mathrm{Cy} 5$ intensity verses $\mathrm{Cy} 3$ intensity.}

Scatter Plot of Cy3 Intensity by Cy5 intensity

The REG Procedure

Model: MODEL1

Dependent Variable: Cy5_Intensity

Number of Observations Read 200

Number of Observations Used 200

Note: No intercept in model. R-Square is redefined.

\begin{tabular}{|c|c|c|c|c|c|}
\hline \multicolumn{6}{|c|}{ Analysis of Variance } \\
\hline Source & DF & $\begin{array}{c}\text { Sum of } \\
\text { Squares }\end{array}$ & $\begin{array}{r}\text { Mean } \\
\text { Square }\end{array}$ & F Value & $\operatorname{Pr}>\mathbf{F}$ \\
\hline Model & 1 & 3742341 & 3742341 & 74.88 & $<.0001$ \\
\hline Error & 199 & 9945150 & 49976 & & \\
\hline Uncorrected Total & 200 & 13687491 & & & \\
\hline
\end{tabular}

\begin{tabular}{|lrrr} 
Root MSE & 223.55230 & R-Square & 0.2734 \\
Dependent Mean & 243.71591 & Adj R-Sq & 0.2698 \\
Coeff Var & 91.72659 & &
\end{tabular}

\section{Parameter Estimates}




\begin{tabular}{|lrrrrr}
\hline Variable & DF & $\begin{array}{r}\text { Parameter } \\
\text { Estimate }\end{array}$ & $\begin{array}{c}\text { Standard } \\
\text { Error }\end{array}$ \\
& & & & & \\
Cy3_Intensity & $\mathbf{1}$ & 0.38427 & 0.04441 & 8.65 & $<.0001$
\end{tabular}

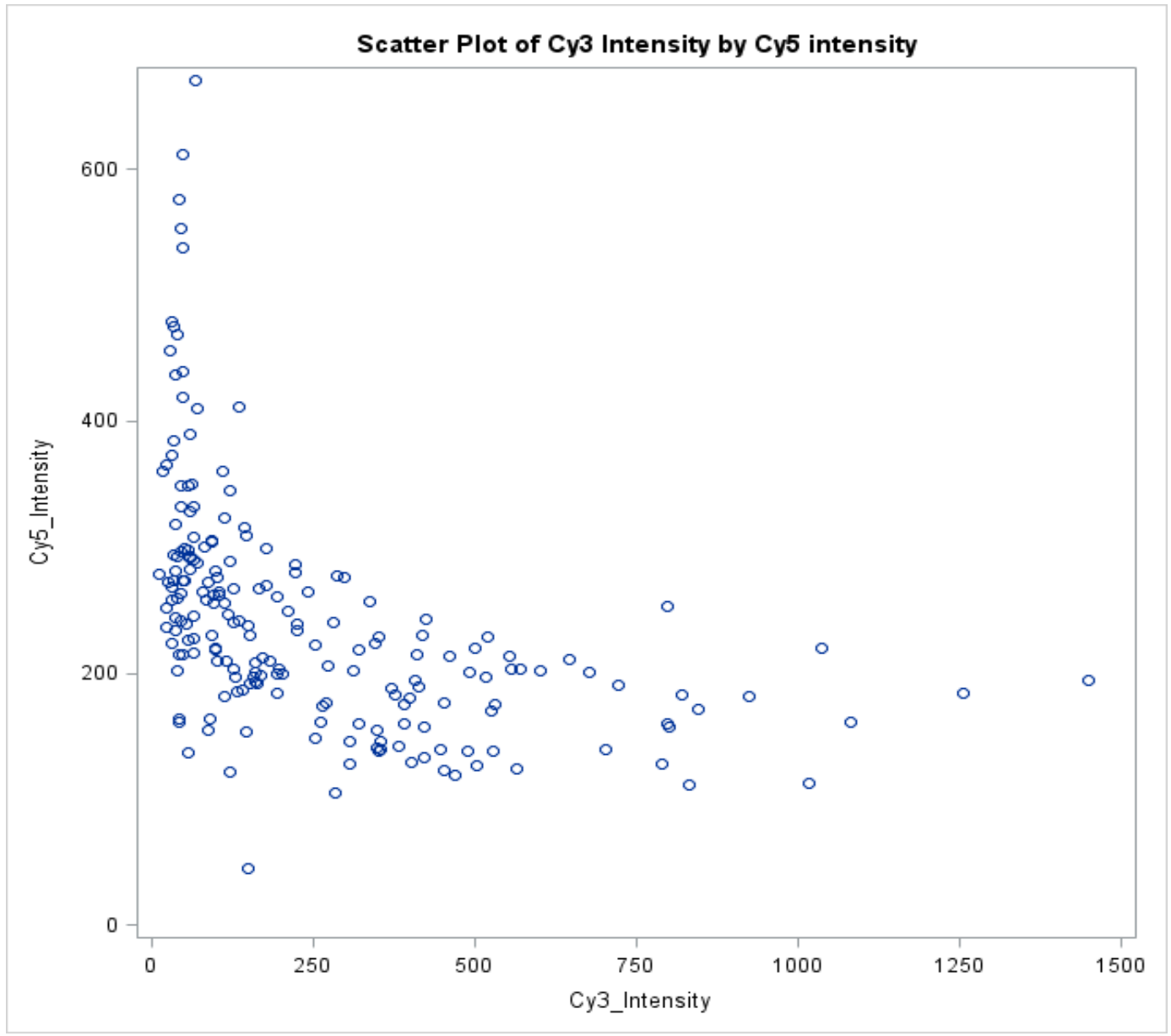




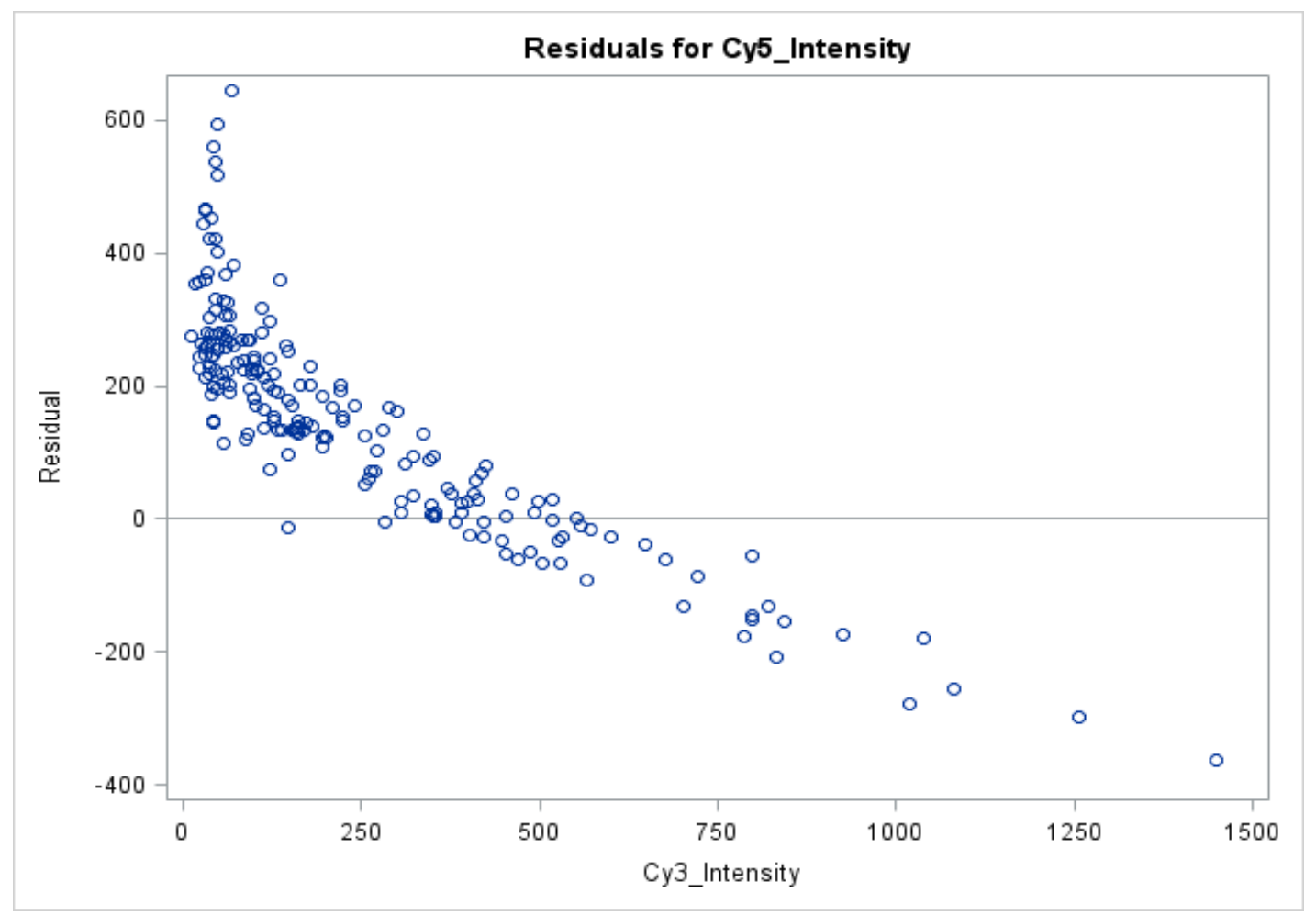




\section{REFERENCES}

Abbi, S., Ueda, H., Zheng, C., Cooper, L. A., Zhao, J., Christopher, R., et al. (2002).

Regulation of focal adhesion kinase by a novel protein inhibitor FIP200. Molecular Biology of the Cell, 13(9), 3178-3191.

Aderem, A., \& Underhill, D. M. (1999). Mechanisms of phagocytosis in macrophages. Annual Review of Immunology, 17(1), 593-623.

Aebersold, R., \& Goodlett, D. R. (2001). Mass spectrometry in proteomics. Chemical Reviews, 101(2), 269-295.

Agochiya, M., Brunton, V. G., Owens, D. W., Parkinson, E. K., Paraskeva, C., Keith, W. N., et al. (1999). Increased dosage and amplification of the focal adhesion kinase gene in human cancer cells. Oncogene, 18(41), 5646-5653.

Aiken, M. L., Ginsberg, M. H., Byers-Ward, V., \& Plow, E. F. (1990). Effects of OKM5, a monoclonal antibody to glycoprotein IV, on platelet aggregation and thrombospondin surface expression. Blood, 76(12), 2501-2509.

Alvarez-Llamas, G., de la Cuesta, F., Barderas, M. E. G., Darde, V., Padial, L. R., \& Vivanco, F. (2008). Recent advances in atherosclerosis-based proteomics: New biomarkers and a future perspective. Expert Review of Proteomics, 5(5), 679-691.

Araki, N., Johnson, M. T., \& Swanson, J. A. (1996). A role for phosphoinositide 3-kinase in the completion of macropinocytosis and phagocytosis by macrophages. The Journal of Cell Biology, 135(5), 1249-1260.

Arold, S. T., Hoellerer, M. K., \& Noble, M. E. (2002). The structural basis of localization and signaling by the focal adhesion targeting domain. Structure (London, England : 1993), 10(3), 319-327.

Arold, S. T., Ulmer, T. S., Mulhern, T. D., Werner, J. M., Ladbury, J. E., Campbell, I. D., et al. (2001). The role of the src homology 3-src homology 2 interface in the 
regulation of src kinases. The Journal of Biological Chemistry, 276(20), 1719917205.

Avraham, H., Park, S. Y., Schinkmann, K., \& Avraham, S. (2000). RAFTK/Pyk2mediated cellular signalling. Cellular Signalling, 12(3), 123-133.

Avraham, S., London, R., Fu, Y., Ota, S., Hiregowdara, D., Li, J., et al. (1995). Identification and characterization of a novel related adhesion focal tyrosine kinase (RAFTK) from megakaryocytes and brain. The Journal of Biological Chemistry, 270(46), 27742-27751.

Badimon, L., Vilahur, G., \& Padro, T. (2009). Lipoproteins, platelets and atherothrombosis. Revista Espanola De Cardiologia, 62(10), 1161-1178.

Benbernou, N., Muegge, K., \& Durum, S. K. (2000). Interleukin (IL)-7 induces rapid activation of Pyk2, which is bound to janus kinase 1 and IL-7Ralpha. The Journal of Biological Chemistry, 275(10), 7060-7065.

Bianchi, M., De Lucchini, S., Marin, O., Turner, D. L., Hanks, S. K., \& Villa-Moruzzi, E. (2005). Regulation of FAK ser-722 phosphorylation and kinase activity by GSK3 and PP1 during cell spreading and migration. Biochemical Journal, 391(Pt 2), 359.

Bobryshev, Y. V. (2006). Monocyte recruitment and foam cell ation in atherosclerosis. Micron, 37(3), 208-222.

Bochem, A. E., van Wijk, D. F., Holleboom, A. G., Duivenvoorden, R., Motazacker, M. M., Dallinga-Thie, G. M., et al. (2013). ABCA1 mutation carriers with low highdensity lipoprotein cholesterol are characterized by a larger atherosclerotic burden. European Heart Journal, 34(4), 286-291.

Botelho, R. J., Teruel, M., Dierckman, R., Anderson, R., Wells, A., York, J. D., et al. (2000). Localized biphasic changes in phosphatidylinositol-4,5-bisphosphate at sites of phagocytosis. The Journal of Cell Biology, 151(7), 1353-1368.

Boullier, A., Bird, D. A., Chang, M. K., Dennis, E. A., Friedman, P., Gillotre-Taylor, K., 
et al. (2001). Scavenger receptors, oxidized LDL, and atherosclerosis. Annals of the New York Academy of Sciences, 947, 214-22; discussion 222-3.

Bowden, P., Beavis, R., \& Marshall, J. (2009). Tandem mass spectrometry of human tryptic blood peptides calculated by a statistical algorithm and captured by a relational database with exploration by a general statistical analysis system. Journal of Proteomics, 73(1), 103-111.

Braren, R., Hu, H., Kim, Y. H., Beggs, H. E., Reichardt, L. F., \& Wang, R. (2006). Endothelial FAK is essential for vascular network stability, cell survival, and lamellipodial formation. The Journal of Cell Biology, 172(1), 151-162.

Cai, X., Lietha, D., Ceccarelli, D. F., Karginov, A. V., Rajfur, Z., Jacobson, K., et al. (2008). Spatial and temporal regulation of focal adhesion kinase activity in living cells. Molecular and Cellular Biology, 28(1), 201-214.

Calalb, M. B., Polte, T. R., \& Hanks, S. K. (1995). Tyrosine phosphorylation of focal adhesion kinase at sites in the catalytic domain regulates kinase activity: A role for src family kinases. Molecular and Cellular Biology, 15(2), 954-963.

Castellano, F., Montcourrier, P., \& Chavrier, P. (2000). Membrane recruitment of Rac1 triggers phagocytosis. Journal of Cell Science, 113 ( Pt 17)(Pt 17), 2955-2961.

Ceccarelli, D. F., Song, H. K., Poy, F., Schaller, M. D., \& Eck, M. J. (2006). Crystal structure of the FERM domain of focal adhesion kinase. The Journal of Biological Chemistry, 281(1), 252-259.

Cheeseman, K. L., Ueyama, T., Michaud, T. M., Kashiwagi, K., Wang, D., Flax, L. A., et al. (2006). Targeting of protein kinase C-epsilon during fcgamma receptordependent phagocytosis requires the epsilonC1B domain and phospholipase Cgamma1. Molecular Biology of the Cell, 17(2), 799-813.

Chen, R., Kim, O., Li, M., Xiong, X., Guan, J. L., Kung, H. J., et al. (2001). Regulation of the PH-domain-containing tyrosine kinase etk by focal adhesion kinase through 
the FERM domain. Nature Cell Biology, 3(5), 439-444.

Chen, S. Y., \& Chen, H. C. (2006). Direct interaction of focal adhesion kinase (FAK) with met is required for FAK to promote hepatocyte growth factor-induced cell invasion. Molecular and Cellular Biology, 26(13), 5155-5167.

Chiurchiu, V., Izzi, V., D'Aquilio, F., Vismara, D., Carotenuto, F., Catanzaro, G., et al. (2011). Endomorphin-1 prevents lipid accumulation via CD36 down-regulation and modulates cytokines release from human lipid-laden macrophages. Peptides, $32(1), 80-85$.

Chu, E. M., Tai, D. C., Beer, J. L., \& Hill, J. S. (2013). Macrophage heterogeneity and cholesterol homeostasis: Classically-activated macrophages are associated with reduced cholesterol accumulation following treatment with oxidized LDL. Biochimica Et Biophysica Acta, 1831(2), 378-386.

Costa, P., Scales, T. M., Ivaska, J., \& Parsons, M. (2013). Integrin-specific control of focal adhesion kinase and RhoA regulates membrane protrusion and invasion. PloS One, 8(9), e74659.

Cox, D., Chang, P., Zhang, Q., Reddy, P. G., Bokoch, G. M., \& Greenberg, S. (1997). Requirements for both Rac1 and Cdc42 in membrane ruffling and phagocytosis in leukocytes. The Journal of Experimental Medicine, 186(9), 1487-1494.

Demetz, E., Tancevski, I., Duwensee, K., Stanzl, U., Huber, E., Heim, C., et al. (2012). Inhibition of hepatic scavenger receptor-class B type I by RNA interference decreases atherosclerosis in rabbits. Atherosclerosis, 222(2), 360-366.

Dhodapkar, K. M., Banerjee, D., Connolly, J., Kukreja, A., Matayeva, E., Veri, M. C., et al. (2007). Selective blockade of the inhibitory fcgamma receptor (FcgammaRIIB) in human dendritic cells and monocytes induces a type I interferon response program. The Journal of Experimental Medicine, 204(6), 1359-1369. 
DiMichele, L. A., Hakim, Z. S., Sayers, R. L., Rojas, M., Schwartz, R. J., Mack, C. P., \& Taylor, J. M. (2009). Transient expression of FRNK reveals stage-specific requirement for focal adhesion kinase activity in cardiac growth. Circulation Research, 104(10), 1201-1208.

DiNitto, J. P., \& Lambright, D. G. (2006). Membrane and juxtamembrane targeting by PH and PTB domains. Biochimica Et Biophysica Acta (BBA)-Molecular and Cell Biology of Lipids, 1761(8), 850-867.

Doherty, J. T., Conlon, F. L., Mack, C. P., \& Taylor, J. M. (2010). Focal adhesion kinase is essential for cardiac looping and multichamber heart formation. Genesis, 48(8), 492-504.

Draczynska-Lusiak, B., Doung, A., \& Sun, A. Y. (1998). Oxidized lipoproteins may play a role in neuronal cell death in alzheimer disease. Molecular and Chemical Neuropathology / Sponsored by the International Society for Neurochemistry and the World Federation of Neurology and Research Groups on Neurochemistry and Cerebrospinal Fluid, 33(2), 139-148.

Dunty, J. M., Gabarra-Niecko, V., King, M. L., Ceccarelli, D. F., Eck, M. J., \& Schaller, M. D. (2004). FERM domain interaction promotes FAK signaling. Molecular and Cellular Biology, 24(12), 5353-5368.

Endemann, G., Stanton, L. W., Madden, K. S., Bryant, C. M., White, R. T., \& Protter, A. A. (1993). CD36 is a receptor for oxidized low density lipoprotein. The Journal of Biological Chemistry, 268(16), 11811-11816.

Epstein, F. H., \& Ross, R. (1999). Atherosclerosis - an inflammatory disease. New England Journal of Medicine, 340(2), 115-126.

Etienne-Manneville, S., \& Hall, A. (2002). Rho GTPases in cell biology. Nature, 420(6916), 629-635. doi: 10.1038/nature01148 
Ezratty, E. J., Partridge, M. A., \& Gundersen, G. G. (2005). Microtubule-induced focal adhesion disassembly is mediated by dynamin and focal adhesion kinase. Nature Cell Biology, 7(6), 581-590.

Febbraio, M., Abumrad, N. A., Hajjar, D. P., Sharma, K., Cheng, W., Pearce, S. F., et al. (1999). A null mutation in murine CD36 reveals an important role in fatty acid and lipoprotein metabolism. The Journal of Biological Chemistry, 274(27), 1905519062.

Febbraio, M., Podrez, E. A., Smith, J. D., Hajjar, D. P., Hazen, S. L., Hoff, H. F., et al. (2000). Targeted disruption of the class B scavenger receptor CD36 protects against atherosclerotic lesion development in mice. The Journal of Clinical Investigation, 105(8), 1049-1056.

Fiedorek, F. T.,Jr, \& Kay, E. S. (1995). Mapping of the focal adhesion kinase (fadk) gene to mouse chromosome 15 and human chromosome 8. Mammalian Genome : Official Journal of the International Mammalian Genome Society, 6(2), 123-126.

Florentinus, A. K., Jankowski, A., Petrenko, V., Bowden, P., \& Marshall, J. G. (2011). The fc receptor-cytoskeleton complex from human neutrophils. Journal of Proteomics, 75(2), 450-468.

Forrest, A. D., Beggs, H. E., Reichardt, L. F., Dupree, J. L., Colello, R. J., \& Fuss, B. (2009). Focal adhesion kinase (FAK): A regulator of CNS myelination. Journal of Neuroscience Research, 87(15), 3456-3464.

Fox, G. L., Rebay, I., \& Hynes, R. O. (1999). Expression of DFak56, a drosophila homolog of vertebrate focal adhesion kinase, supports a role in cell migration in vivo. Proceedings of the National Academy of Sciences of the United States of America, 96(26), 14978-14983.

Fryer, B. H., Wang, C., Vedantam, S., Zhou, G. L., Jin, S., Fletcher, L., et al. (2006). cGMP-dependent protein kinase phosphorylates p21-activated kinase (pak) 1, inhibiting Pak/Nck binding and stimulating Pak/vasodilator-stimulated 
phosphoprotein association. The Journal of Biological Chemistry, 281(17), 1148711495.

Fuster, V., Fayad, Z. A., \& Badimon, J. J. (1999). Acute coronary syndromes: Biology. The Lancet, 353, s5-s9.

Gao, D., Pararasa, C., Dunston, C. R., Bailey, C. J., \& Griffiths, H. R. (2012). Palmitate promotes monocyte atherogenicity via de novo ceramide synthesis. Free Radical Biology \& Medicine, 53(4), 796-806.

Garcia-Garcia, E., \& Rosales, C. (2002). Signal transduction during fc receptor-mediated phagocytosis. Journal of Leukocyte Biology, 72(6), 1092-1108.

Geloen, A., Helin, L., Geeraert, B., Malaud, E., Holvoet, P., \& Marguerie, G. (2012). CD36 inhibitors reduce postprandial hypertriglyceridemia and protect against diabetic dyslipidemia and atherosclerosis. PloS One, 7(5), e37633.

Ghosh, S., Gepstein, S., Heikkila, J. J., \& Dumbroff, E. B. (1988). Use of a scanning densitometer or an ELISA plate reader for measurement of nanogram amounts of protein in crude extracts from biological tissues. Analytical Biochemistry, 169(2), 227-233.

Gilmore, A., \& Romer, L. (1996). Inhibition of focal adhesion kinase (FAK) signaling in focal adhesions decreases cell motility and proliferation. Molecular Biology of the Cell, 7(8), 1209.

Giodini, A., Rahner, C., \& Cresswell, P. (2009). Receptor-mediated phagocytosis elicits cross-presentation in nonprofessional antigen-presenting cells. Proceedings of the National Academy of Sciences of the United States of America, 106(9), 3324-3329.

Girault, J. A., Labesse, G., Mornon, J. P., \& Callebaut, I. (1999). The N-termini of FAK and JAKs contain divergent band 4.1 domains. Trends in Biochemical Sciences, 24(2), 54-57. 
Glass, C. K., \& Witztum, J. L. (2001). Atherosclerosis: The road ahead review. Cell, 104, 503-516.

Golubovskaya, V., Finch, R., Zheng, M., Kurenova, E., \& Cance, W. (2008). The 7amino-acid site in the proline-rich region of the $\mathrm{N}$-terminal domain of $\mathrm{p} 53$ is involved in the interaction with FAK and is critical for p53 functioning. Biochem.J, $411,151-160$.

Golubovskaya, V. M., Kweh, F. A., \& Cance, W. G. (2009). Focal adhesion kinase and cancer. Histology and Histopathology, 24(4), 503-510.

Gough, P. J., Greaves, D. R., Suzuki, H., Hakkinen, T., Hiltunen, M. O., Turunen, M., et al. (1999). Analysis of macrophage scavenger receptor (SR-A) expression in human aortic atherosclerotic lesions. Arteriosclerosis, Thrombosis, and Vascular Biology, 19(3), 461-471.

Gousset, K., Tsvetkova, N. M., Crowe, J. H., \& Tablin, F. (2004). Important role of raft aggregation in the signaling events of cold-induced platelet activation. Biochimica Et Biophysica Acta (BBA)-Biomembranes, 1660(1), 7-15.

Granados-Principal, S., Quiles, J. L., Ramirez-Tortosa, C. L., Ochoa-Herrera, J., PerezLopez, P., Pulido-Moran, M., et al. (2012). Squalene ameliorates atherosclerotic lesions through the reduction of CD36 scavenger receptor expression in macrophages. Molecular Nutrition \& Food Research, 56(5), 733-740.

Greenberg, S., Chang, P., \& Silverstein, S. C. (1994). Tyrosine phosphorylation of the gamma subunit of fc gamma receptors, p72syk, and paxillin during fc receptormediated phagocytosis in macrophages. Journal of Biological Chemistry, 269(5), 3897-3902.

Greenberg, S., \& Grinstein, S. (2002). Phagocytosis and innate immunity. Current Opinion in Immunology, 14(1), 136-145. 
Guan, J. L. (2010). Integrin signaling through FAK in the regulation of mammary stem cells and breast cancer. IUBMB Life, 62(4), 268-276.

Guinamard, R., Okigaki, M., Schlessinger, J., \& Ravetch, J. V. (2000). Absence of marginal zone B cells in pyk-2-deficient mice defines their role in the humoral response. Nature Immunology, 1(1), 31-36.

Hakim, Z. S., DiMichele, L. A., Doherty, J. T., Homeister, J. W., Beggs, H. E., Reichardt, L. F., . . Mack, C. P. (2007). Conditional deletion of focal adhesion kinase leads to defects in ventricular septation and outflow tract alignment. Molecular and Cellular Biology, 27(15), 5352-5364.

Hall, J. E., Fu, W., \& Schaller, M. D. (2011). Focal adhesion kinase: Exploring fak structure to gain insight into function. International Review of Cell and Molecular Biology, 288, 185-225.

Han, J., Hajjar, D. P., Tauras, J. M., Feng, J., Gotto, A. M.,Jr, \& Nicholson, A. C. (2000). Transforming growth factor-beta1 (TGF-beta1) and TGF-beta2 decrease expression of CD36, the type B scavenger receptor, through mitogen-activated protein kinase phosphorylation of peroxisome proliferator-activated receptorgamma. The Journal of Biological Chemistry, 275(2), 1241-1246.

Han, S., Mistry, A., Chang, J. S., Cunningham, D., Griffor, M., Bonnette, P. C., et al. (2009). Structural characterization of proline-rich tyrosine kinase 2 (PYK2) reveals a unique (DFG-out) conformation and enables inhibitor design. The Journal of Biological Chemistry, 284(19), 13193-13201.

Handberg, A., Hojlund, K., Gastaldelli, A., Flyvbjerg, A., Dekker, J. M., Petrie, J., et al. (2012). Plasma sCD36 is associated with markers of atherosclerosis, insulin resistance and fatty liver in a nondiabetic healthy population. Journal of Internal Medicine, 271(3), 294-304. 
Hanks, S. K., Calalb, M. B., Harper, M. C., \& Patel, S. K. (1992). Focal adhesion proteintyrosine kinase phosphorylated in response to cell attachment to fibronectin. Proceedings of the National Academy of Sciences, 89(18), 8487-8491.

Hanks, S. K., Ryzhova, L., Shin, N. Y., \& Brabek, J. (2003). Focal adhesion kinase signaling activities and their implications in the control of cell survival and motility. Front Biosci, 8(1-3), d982-d996.

Hansson, G. K. (1997). Cell-mediated immunity in atherosclerosis. Current Opinion in Lipidology, 8(5), 301-311.

Hansson, G. K., \& Hermansson, A. (2011). The immune system in atherosclerosis. Nature Immunology, 12(3), 204-212.

Hansson, G. K., Robertson, A. K., \& Soderberg-Naucler, C. (2006). Inflammation and atherosclerosis. Annual Review of Pathology, 1, 297-329.

Hashizume, M., \& Mihara, M. (2012). Atherogenic effects of TNF-alpha and IL-6 via upregulation of scavenger receptors. Cytokine, 58(3), 424-430.

Hayashi, I., Vuori, K., \& Liddington, R. C. (2002). The focal adhesion targeting (FAT) region of focal adhesion kinase is a four-helix bundle that binds paxillin. Nature Structural Biology, 9(2), 101-106.

Hazen, S. L., \& Heinecke, J. W. (1997). 3-chlorotyrosine, a specific marker of myeloperoxidase-catalyzed oxidation, is markedly elevated in low density lipoprotein isolated from human atherosclerotic intima. Journal of Clinical Investigation, 99(9), 2075.

Heit, B., Kim, H., Cosio, G., Castano, D., Collins, R., Lowell, C. A., et al. (2013). Multimolecular signaling complexes enable syk-mediated signaling of CD36 internalization. Developmental Cell, 24(4), 372-383. 
Herzog, H., Nicholl, J., Hort, Y. J., Sutherland, G. R., \& Shine, J. (1996). Molecular cloning and assignment of FAK2, a novel human focal adhesion kinase, to 8p11.2p22 by nonisotopic in situ hybridization. Genomics, 32(3), 484-486.

Hogarth, P. M. (2002). Fc receptors are major mediators of antibody based inflammation in autoimmunity. Current Opinion in Immunology, 14(6), 798-802.

Huang, M. M., Bolen, J. B., Barnwell, J. W., Shattil, S. J., \& Brugge, J. S. (1991). Membrane glycoprotein IV (CD36) is physically associated with the fyn, lyn, and yes protein-tyrosine kinases in human platelets. Proceedings of the National Academy of Sciences of the United States of America, 88(17), 7844-7848.

Inazawa, J., Sasaki, H., Nagura, K., Kakazu, N., Abe, T., \& Sasaki, T. (1996). Precise localization of the human gene encoding cell adhesion kinase beta (CAK beta/PYK2) to chromosome 8 at p21.1 by fluorescence in situ hybridization. Human Genetics, 98(4), 508-510.

Ivashkiv, L. B. (2009). Cross-regulation of signaling by ITAM-associated receptors. Nature Immunology, 10(4), 340-347.

Jankowski, A., Zhu, P., \& Marshall, J. G. (2008). Capture of an activated receptor complex from the surface of live cells by affinity receptor chromatography. Analytical Biochemistry, 380(2), 235-248.

Jones, M. L., Shawe-Taylor, A. J., Williams, C. M., \& Poole, A. W. (2009). Characterization of a novel focal adhesion kinase inhibitor in human platelets. Biochemical and Biophysical Research Communications, 389(1), 198-203.

Karimi, K., \& Lennartz, M. R. (1998). Mitogen-activated protein kinase is activated during IgG-mediated phagocytosis, but is not required for target ingestion. Inflammation, 22(1), 67-82.

Kataoka, H., Kume, N., Miyamoto, S., Minami, M., Moriwaki, H., Murase, T., et al. (1999). Expression of lectinlike oxidized low-density lipoprotein receptor-1 in 
human atherosclerotic lesions. Circulation, 99(24), 3110-3117.

Katz, B. Z., Romer, L., Miyamoto, S., Volberg, T., Matsumoto, K., Cukierman, E., et al. (2003). Targeting membrane-localized focal adhesion kinase to focal adhesions: Roles of tyrosine phosphorylation and SRC family kinases. The Journal of Biological Chemistry, 278(31), 29115-29120.

Klingbeil, C. K., Hauck, C. R., Hsia, D. A., Jones, K. C., Reider, S. R., \& Schlaepfer, D. D. (2001). Targeting Pyk2 to beta 1-integrin-containing focal contacts rescues fibronectin-stimulated signaling and haptotactic motility defects of focal adhesion kinase-null cells. The Journal of Cell Biology, 152(1), 97-110.

Kodama, A., Lechler, T., \& Fuchs, E. (2004). Coordinating cytoskeletal tracks to polarize cellular movements. The Journal of Cell Biology, 167(2), 203-207.

Krieger, M. (1997). The other side of scavenger receptors: Pattern recognition for host defense. Current Opinion in Lipidology, 8(5), 275-280.

Kusner, D. J., Hall, C. F., \& Schlesinger, L. S. (1996). Activation of phospholipase D is tightly coupled to the phagocytosis of mycobacterium tuberculosis or opsonized zymosan by human macrophages. The Journal of Experimental Medicine, 184(2), 585-595.

Kusner, D. J., Hall, C. F., \& Jackson, S. (1999). Fc gamma receptor-mediated activation of phospholipase D regulates macrophage phagocytosis of IgG-opsonized particles. Journal of Immunology (Baltimore, Md.: 1950), 162(4), 2266-2274.

Lafrenaye, A. D., \& Fuss, B. (2010). Focal adhesion kinase can play unique and opposing roles in regulating the morphology of differentiating oligodendrocytes. Journal of Neurochemistry, 115(1), 269-282.

Lakkakorpi, P. T., Bett, A. J., Lipfert, L., Rodan, G. A., \& Duong le, T. (2003). PYK2 autophosphorylation, but not kinase activity, is necessary for adhesion-induced association with c-src, osteoclast spreading, and bone resorption. The Journal of 
Biological Chemistry, 278(13), 11502-11512.

Larsen, E. C., DiGennaro, J. A., Saito, N., Mehta, S., Loegering, D. J., Mazurkiewicz, J. E., et al. (2000). Differential requirement for classic and novel PKC isoforms in respiratory burst and phagocytosis in RAW 264.7 cells. Journal of Immunology (Baltimore, Md.: 1950), 165(5), 2809-2817.

Larsen, E. C., Ueyama, T., Brannock, P. M., Shirai, Y., Saito, N., Larsson, C., et al. (2002). A role for PKC-epsilon in fc gammaR-mediated phagocytosis by RAW 264.7 cells. The Journal of Cell Biology, 159(6), 939-944.

Lee, W. L., Cosio, G., Ireton, K., \& Grinstein, S. (2007). Role of CrkII in fcgamma receptor-mediated phagocytosis. The Journal of Biological Chemistry, 282(15), 11135-11143.

Leeuwenburgh, C., Hardy, M. M., Hazen, S. L., Wagner, P., Oh-ishi, S., Steinbrecher, U. P., \& Heinecke, J. W. (1997). Reactive nitrogen intermediates promote low density lipoprotein oxidation in human atherosclerotic intima. Journal of Biological Chemistry, 272(3), 1433-1436.

Lennartz, M. R., Yuen, A. F., Masi, S. M., Russell, D. G., Buttle, K. F., \& Smith, J. J. (1997). Phospholipase A2 inhibition results in sequestration of plasma membrane into electronlucent vesicles during IgG-mediated phagocytosis. Journal of Cell Science, 110 ( Pt 17)(Pt 17), 2041-2052.

Lev, S., Hernandez, J., Martinez, R., Chen, A., Plowman, G., \& Schlessinger, J. (1999). Identification of a novel family of targets of PYK2 related to drosophila retinal degeneration B (rdgB) protein. Molecular and Cellular Biology, 19(3), 2278-2288.

Lev, S., Moreno, H., Martinez, R., Canoll, P., Peles, E., Musacchio, J. M., et al. (1995). Protein tyrosine kinase PYK2 involved in ca(2+)-induced regulation of ion channel and MAP kinase functions. Nature, 376(6543), 737-745.

Li, K., Yao, W., Zheng, X., \& Liao, K. (2009). Berberine promotes the development of 
atherosclerosis and foam cell formation by inducing scavenger receptor A expression in macrophage. Cell Research, 19(8), 1006-1017.

Li, X. Y., Kong, L. X., Li, J., He, H. X., \& Zhou, Y. D. (2013). Kaempferol suppresses lipid accumulation in macrophages through the downregulation of cluster of differentiation 36 and the upregulation of scavenger receptor class B type I and ATP-binding cassette transporters A1 and G1. International Journal of Molecular Medicine, 31(2), 331-338.

Liao, J. K., Shin, W. S., Lee, W. Y., \& Clark, S. L. (1995). Oxidized low-density lipoprotein decreases the expression of endothelial nitric oxide synthase. The Journal of Biological Chemistry, 270(1), 319-324.

Lietha, D., Cai, X., Ceccarelli, D. F., Li, Y., Schaller, M. D., \& Eck, M. J. (2007). Structural basis for the autoinhibition of focal adhesion kinase. Cell, 129(6), 11771187.

Lim, S. T., Chen, X. L., Lim, Y., Hanson, D. A., Vo, T. T., Howerton, K., et al. (2008). Nuclear FAK promotes cell proliferation and survival through FERM-enhanced p53 degradation. Molecular Cell, 29(1), 9-22.

Lipsky, R. H., Eckert, D. M., Tang, Y., \& Ockenhouse, C. F. (1997). The carboxylterminal cytoplasmic domain of CD36 is required for oxidized low-density lipoprotein modulation of NF-kappaB activity by tumor necrosis factor-alpha. Receptors \& Signal Transduction, 7(1), 1-11.

Llorente-Cortes, V., Martinez-Gonzalez, J., \& Badimon, L. (2000). LDL receptor-related protein mediates uptake of aggregated LDL in human vascular smooth muscle cells. Arteriosclerosis, Thrombosis, and Vascular Biology, 20(6), 1572-1579.

López-Ferrer, D., Martínez-Bartolomé, S., Villar, M., Campillos, M., Martín-Maroto, F., \& Vázquez, J. (2004). Statistical model for large-scale peptide identification in databases from tandem mass spectra using SEQUEST. Analytical Chemistry, 76(23), 6853-6860. 
Lougheed, M., Lum, C. M., Ling, W., Suzuki, H., Kodama, T., \& Steinbrecher, U. (1997). High affinity saturable uptake of oxidized low density lipoprotein by macrophages from mice lacking the scavenger receptor class A type I/II. The Journal of Biological Chemistry, 272(20), 12938-12944.

Lundberg, A. M., \& Hansson, G. K. (2010). Innate immune signals in atherosclerosis. Clinical Immunology (Orlando, Fla.), 134(1), 5-24.

Mancuso, P., Nana-Sinkam, P., \& Peters-Golden, M. (2001). Leukotriene B4 augments neutrophil phagocytosis of klebsiella pneumoniae. Infection and Immunity, 69(4), 2011-2016.

Mansfield, P. J., Shayman, J. A., \& Boxer, L. A. (2000). Regulation of polymorphonuclear leukocyte phagocytosis by myosin light chain kinase after activation of mitogen-activated protein kinase. Blood, 95(7), 2407-2412.

Marshall, J. G., Booth, J. W., Stambolic, V., Mak, T., Balla, T., Schreiber, A. D., et al. (2001). Restricted accumulation of phosphatidylinositol 3-kinase products in a plasmalemmal subdomain during fc gamma receptor-mediated phagocytosis. The Journal of Cell Biology, 153(7), 1369-1380.

Maskrey, B. H., Megson, I. L., Whitfield, P. D., \& Rossi, A. G. (2011). Mechanisms of resolution of inflammation: A focus on cardiovascular disease. Arteriosclerosis, Thrombosis, and Vascular Biology, 31(5), 1001-1006.

Massol, P., Montcourrier, P., Guillemot, J. C., \& Chavrier, P. (1998). Fc receptormediated phagocytosis requires CDC42 and Rac1. The EMBO Journal, 17(21), 6219-6229.

Matsuura, E., Hughes, G. R. V., \& Khamashta, M. A. (2008). Oxidation of LDL and its clinical implication. Autoimmunity Reviews, 7(7), 558-566.

Maxeiner, H., Husemann, J., Thomas, C. A., Loike, J. D., El Khoury, J., \& Silverstein, S. C. (1998). Complementary roles for scavenger receptor A and CD36 of human 
monocyte-derived macrophages in adhesion to surfaces coated with oxidized lowdensity lipoproteins and in secretion of $\mathrm{H} 2 \mathrm{O} 2$. The Journal of Experimental Medicine, 188(12), 2257-2265.

Melendez, A. J., Harnett, M. M., \& Allen, J. M. (1999). FcgammaRI activation of phospholipase Cgamma1 and protein kinase $\mathrm{C}$ in dibutyryl cAMP-differentiated U937 cells is dependent solely on the tyrosine-kinase activated form of phosphatidylinositol-3-kinase. Immunology, 98(1), 1-8.

Miao, W. M., Vasile, E., Lane, W. S., \& Lawler, J. (2001). CD36 associates with CD9 and integrins on human blood platelets. Blood, 97(6), 1689-1696.

Milligan, G., Parenti, M., \& Magee, A. I. (1995). The dynamic role of palmitoylation in signal transduction. Trends in Biochemical Sciences, 20(5), 181-186.

Mitra, S. K., Hanson, D. A., \& Schlaepfer, D. D. (2005). Focal adhesion kinase: In command and control of cell motility. Nature Reviews.Molecular Cell Biology, 6(1), $56-68$.

Mlinaric-Rascan, I., \& Yamamoto, T. (2001). B cell receptor signaling involves physical and functional association of FAK with lyn and IgM. FEBS Letters, 498(1), 26-31.

Moore, K. J., Kunjathoor, V. V., Koehn, S. L., Manning, J. J., Tseng, A. A., Silver, J. M., et al. (2005). Loss of receptor-mediated lipid uptake via scavenger receptor A or CD36 pathways does not ameliorate atherosclerosis in hyperlipidemic mice. The Journal of Clinical Investigation, 115(8), 2192-2201.

Nakata, A., Nakagawa, Y., Nishida, M., Nozaki, S., Miyagawa, J., Nakagawa, T., et al. (1999). CD36, a novel receptor for oxidized low-density lipoproteins, is highly expressed on lipid-laden macrophages in human atherosclerotic aorta. Arteriosclerosis, Thrombosis, and Vascular Biology, 19(5), 1333-1339.

Navab, M., Berliner, J. A., Watson, A. D., Hama, S. Y., Territo, M. C., Lusis, A. J., . . . Demer, L. L. (1996). The yin and yang of oxidation in the development of the fatty 
streak: A review based on the 1994 george lyman duff memorial lecture. Arteriosclerosis, Thrombosis, and Vascular Biology, 16(7), 831-842.

Nergiz-Unal, R., Kuijpers, M. J., de Witt, S. M., Heeneman, S., Feijge, M. A., Garcia Caraballo, S. C., et al. (2013). Atheroprotective effect of dietary walnut intake in ApoE-deficient mice: Involvement of lipids and coagulation factors. Thrombosis Research, 131(5), 411-417.

Nimmerjahn, F., \& Ravetch, J. V. (2006). Fcgamma receptors: Old friends and new family members. Immunity, 24(1), 19-28.

Nowakowski, J., Cronin, C. N., McRee, D. E., Knuth, M. W., Nelson, C. G., Pavletich, N. P., et al. (2002). Structures of the cancer-related aurora-A, FAK, and EphA2 protein kinases from nanovolume crystallography. Structure (London, England: 1993), 10(12), 1659-1667.

Okazaki, H., Igarashi, M., Nishi, M., Sekiya, M., Tajima, M., Takase, S., et al. (2008). Identification of neutral cholesterol ester hydrolase, a key enzyme removing cholesterol from macrophages. The Journal of Biological Chemistry, 283(48), 33357-33364.

Okigaki, M., Davis, C., Falasca, M., Harroch, S., Felsenfeld, D. P., Sheetz, M. P., et al. (2003). Pyk2 regulates multiple signaling events crucial for macrophage morphology and migration. Proceedings of the National Academy of Sciences of the United States of America, 100(19), 10740-10745.

Oorni, K., Pentikainen, M. O., Ala-Korpela, M., \& Kovanen, P. T. (2000). Aggregation, fusion, and vesicle formation of modified low density lipoprotein particles: Molecular mechanisms and effects on matrix interactions. Journal of Lipid Research, 41(11), 1703-1714.

Orr, A. W., Stockton, R., Simmers, M. B., Sanders, J. M., Sarembock, I. J., Blackman, B. R., et al. (2007). Matrix-specific p21-activated kinase activation regulates vascular permeability in atherogenesis. The Journal of Cell Biology, 176(5), 719-727. 
Palmer, R. H., Fessler, L. I., Edeen, P. T., Madigan, S. J., McKeown, M., \& Hunter, T. (1999). DFak56 is a novel drosophila melanogaster focal adhesion kinase. The Journal of Biological Chemistry, 274(50), 35621-35629.

Pan, X. Q., Darby, C., Indik, Z. K., \& Schreiber, A. D. (1999). Activation of three classes of nonreceptor tyrosine kinases following fc $\gamma$ receptor crosslinking in human monocytes. Clinical Immunology, 90(1), 55-64.

Papusheva, E., Mello de Queiroz, F., Dalous, J., Han, Y., Esposito, A., Jares-Erijmanxa, E. A., et al. (2009). Dynamic conformational changes in the FERM domain of FAK are involved in focal-adhesion behavior during cell spreading and motility. Journal of Cell Science, 122(Pt 5), 656-666.

Park, Y. M., Febbraio, M., \& Silverstein, R. L. (2009). CD36 modulates migration of mouse and human macrophages in response to oxidized LDL and may contribute to macrophage trapping in the arterial intima. The Journal of Clinical Investigation, $119(1), 136$.

Parsons, J. T. (2003). Focal adhesion kinase: The first ten years. Journal of Cell Science, $116(\mathrm{Pt} 8), 1409-1416$.

Patel, J. C., Hall, A., \& Caron, E. (2002). Vav regulates activation of rac but not Cdc42 during FcgammaR-mediated phagocytosis. Molecular Biology of the Cell, 13(4), 1215-1226.

Piechota, M., Banaszewska, A., Dudziak, J., Slomczynski, M., \& Plewa, R. (2012). Highly upregulated expression of CD36 and MSR1 in circulating monocytes of patients with acute coronary syndromes. The Protein Journal, 31(6), 511-518.

Platt, N., da Silva, R. P., \& Gordon, S. (1998). Recognizing death: The phagocytosis of apoptotic cells. Trends in Cell Biology, 8(9), 365-372.

Podrez, E. A., Febbraio, M., Sheibani, N., Schmitt, D., Silverstein, R. L., Hajjar, D. P., et al. (2000). Macrophage scavenger receptor CD36 is the major receptor for LDL 
modified by monocyte-generated reactive nitrogen species. The Journal of Clinical Investigation, 105(8), 1095-1108.

Poullet, P., Gautreau, A., Kadare, G., Girault, J. A., Louvard, D., \& Arpin, M. (2001). Ezrin interacts with focal adhesion kinase and induces its activation independently of cell-matrix adhesion. The Journal of Biological Chemistry, 276(40), 3768637691.

Prieto, J., Eklund, A., \& Patarroyo, M. (1994). Regulated expression of integrins and other adhesion molecules during differentiation of monocytes into macrophages. Cellular Immunology, 156(1), 191-211.

Pritchard, K. A.,Jr, Groszek, L., Smalley, D. M., Sessa, W. C., Wu, M., Villalon, P., et al. (1995). Native low-density lipoprotein increases endothelial cell nitric oxide synthase generation of superoxide anion. Circulation Research, 77(3), 510-518.

Rac, M. E., Safranow, K., Rac, M., Kurzawski, G., Krzystolik, A., Sagasz-Tysiewicz, D., et al. (2012). CD36 gene is associated with thickness of atheromatous plaque and ankle-brachial index in patients with early coronary artery disease. Kardiologia Polska, 70(9), 918-923.

Rahaman, S. O., Lennon, D. J., Febbraio, M., Podrez, E. A., Hazen, S. L., \& Silverstein, R. L. (2006). A CD36-dependent signaling cascade is necessary for macrophage foam cell formation. Cell Metabolism, 4(3), 211-221.

Ramprasad, M. P., Fischer, W., Witztum, J. L., Sambrano, G. R., Quehenberger, O., \& Steinberg, D. (1995). The 94- to 97-kDa mouse macrophage membrane protein that recognizes oxidized low density lipoprotein and phosphatidylserine-rich liposomes is identical to macrosialin, the mouse homologue of human CD68. Proceedings of the National Academy of Sciences of the United States of America, 92(21), 95809584.

Ravetch, J. V., \& Bolland, S. (2001). IgG fc receptors. Annual Review of Immunology, 19, 275-290. 
Ren, X. D., Kiosses, W. B., Sieg, D. J., Otey, C. A., Schlaepfer, D. D., \& Schwartz, M. A. (2000). Focal adhesion kinase suppresses rho activity to promote focal adhesion turnover. Journal of Cell Science, 113 ( Pt 20)(Pt 20), 3673-3678.

Ricciarelli, R., Zingg, J. M., \& Azzi, A. (2000). Vitamin E reduces the uptake of oxidized LDL by inhibiting CD36 scavenger receptor expression in cultured aortic smooth muscle cells. Circulation, 102(1), 82-87.

Richardson, A., \& Parsons, J. T. (1996). A mechanism for regulation of the adhesionassociated protein tyrosine kinase pp125FAK.

Richardson, A., Malik, R. K., Hildebrand, J. D., \& Parsons, J. T. (1997). Inhibition of cell spreading by expression of the C-terminal domain of focal adhesion kinase (FAK) is rescued by coexpression of src or catalytically inactive FAK: A role for paxillin tyrosine phosphorylation. Molecular and Cellular Biology, 17(12), 6906-6914.

Ridley, A. J. (2011). Life at the leading edge. Cell, 145(7), 1012-1022.

Ridley, A. J., \& Hall, A. (1992). The small GTP-binding protein rho regulates the assembly of focal adhesions and actin stress fibers in response to growth factors. Cell, 70(3), 389-399.

Sabri, A., Govindarajan, G., Griffin, T. M., Byron, K. L., Samarel, A. M., \& Lucchesi, P. A. (1998). Calcium-and protein kinase C-Dependent activation of the tyrosine kinase PYK2 by angiotensin II in vascular smooth muscle. Circulation Research, 83(8), 841-851.

Sasaki, H., Nagura, K., Ishino, M., Tobioka, H., Kotani, K., \& Sasaki, T. (1995). Cloning and characterization of cell adhesion kinase beta, a novel protein-tyrosine kinase of the focal adhesion kinase subfamily. The Journal of Biological Chemistry, 270(36), 21206-21219.

Sawamura, T., Kume, N., Aoyama, T., Moriwaki, H., Hoshikawa, H., Aiba, Y., et al. (1997). An endothelial receptor for oxidized low-density lipoprotein. Nature, 
386(6620), 73-77.

Schaller, M. D. (2001). Biochemical signals and biological responses elicited by the focal adhesion kinase. Biochimica Et Biophysica Acta, 1540(1), 1-21.

Schaller, M. D. (2010). Cellular functions of FAK kinases: Insight into molecular mechanisms and novel functions. Journal of Cell Science, 123(Pt 7), 1007-1013.

Schaller, M. D., Borgman, C. A., Cobb, B. S., Vines, R. R., Reynolds, A. B., \& Parsons, J. T. (1992). pp125FAK a structurally distinctive protein-tyrosine kinase associated with focal adhesions. Proceedings of the National Academy of Sciences of the United States of America, 89(11), 5192-5196.

Schaller, M. D., Hildebrand, J. D., Shannon, J. D., Fox, J. W., Vines, R. R., \& Parsons, J. T. (1994). Autophosphorylation of the focal adhesion kinase, pp125FAK, directs SH2-dependent binding of pp60src. Molecular and Cellular Biology, 14(3), 16801688.

Schlaepfer, D. D., Hanks, S. K., Hunter, T., \& van der Geer, P. (1994). Integrin-mediated signal transduction linked to ras pathway by GRB2 binding to focal adhesion kinase.

Schlaepfer, D. D., Mitra, S. K., \& Ilic, D. (2004). Control of motile and invasive cell phenotypes by focal adhesion kinase. Biochimica Et Biophysica Acta, 1692(2-3), $77-102$.

Schlesinger, M., Veit, M., \& Schmidt, M. (1993). Palmitoylation of cellular and viral proteins. Lipid Modifications of Proteins (Schlesinger, MJ, Ed.), 1-19.

Schmidt, T. S., \& Alp, N. J. (2007). Mechanisms for the role of tetrahydrobiopterin in endothelial function and vascular disease. Clinical Science (London, England: 1979), 113(2), 47-63.

Sefton, B. M., \& Buss, J. E. (1987). The covalent modification of eukaryotic proteins with lipid. The Journal of Cell Biology, 104(6), 1449-1453. 
Shen, L. H., Zhou, L., Wang, B. Y., Pu, J., Hu, L. H., Chai, D. J., et al. (2008). Oxidized low-density lipoprotein induces differentiation of RAW264.7 murine macrophage cell line into dendritic-like cells. Atherosclerosis, 199(2), 257-264.

Sieg, D. J., Hauck, C. R., Ilic, D., Klingbeil, C. K., Schaefer, E., Damsky, C. H., et al. (2000). FAK integrates growth-factor and integrin signals to promote cell migration. Nature Cell Biology, 2(5), 249-256.

Sieg, D. J., Hauck, C. R., \& Schlaepfer, D. D. (1999). Required role of focal adhesion kinase (FAK) for integrin-stimulated cell migration. Journal of Cell Science, 112 ( Pt 16)(Pt 16), 2677-2691.

Sieg, D. J., Ilic, D., Jones, K. C., Damsky, C. H., Hunter, T., \& Schlaepfer, D. D. (1998). Pyk2 and src-family protein-tyrosine kinases compensate for the loss of FAK in fibronectin-stimulated signaling events but Pyk2 does not fully function to enhance FAK- cell migration. The EMBO Journal, 17(20), 5933-5947.

Silverstein, R. L., Li, W., Park, Y. M., \& Rahaman, S. O. (2010). Mechanisms of cell signaling by the scavenger receptor CD36: Implications in atherosclerosis and thrombosis. Transactions of the American Clinical and Climatological Association, $121,206-220$.

Steinberg, D., \& Witztum, J. (1999). Lipoproteins, lipoprotein oxidation, and atherogenesis. Molecular Basis of Cardiovascular Disease.KR Chien, Editor.WB Saunders Co.Philadelphia, Pennsylvania, USA, 458-475.

Stuart, L. M., Bell, S. A., Stewart, C. R., Silver, J. M., Richard, J., Goss, J. L., . . Moore, K. J. (2007). CD36 signals to the actin cytoskeleton and regulates microglial migration via a p130Cas complex. Journal of Biological Chemistry, 282(37), 2739227401.

Su, Y. R., Dove, D. E., Major, A. S., Hasty, A. H., Boone, B., Linton, M. F., et al. (2005). 
Reduced ABCA1-mediated cholesterol efflux and accelerated atherosclerosis in apolipoprotein E-deficient mice lacking macrophage-derived ACAT1. Circulation, 111(18), 2373-2381.

Sugawa, M., Ikeda, S., Kushima, Y., Takashima, Y., \& Cynshi, O. (1997). Oxidized low density lipoprotein caused CNS neuron cell death. Brain Research, 761(1), $165-$ 172.

Sun, C. X., Robb, V. A., \& Gutmann, D. H. (2002). Protein 4.1 tumor suppressors: Getting a FERM grip on growth regulation. Journal of Cell Science, 115(Pt 21), 3991-4000.

Swanson, J. A., \& Hoppe, A. D. (2004). The coordination of signaling during fc receptormediated phagocytosis. Journal of Leukocyte Biology, 76(6), 1093-1103.

Szklarczyk, D., Franceschini, A., Kuhn, M., Simonovic, M., Roth, A., Minguez, P., et al. (2011). The STRING database in 2011: Functional interaction networks of proteins, globally integrated and scored. Nucleic Acids Research, 39(Database issue), D561-8.

Takai, T. (2002). Roles of fc receptors in autoimmunity. Nature Reviews.Immunology, 2(8), 580-592.

Tao, N., Wagner, S. J., \& Lublin, D. M. (1996). CD36 is palmitoylated on both N-and Cterminal cytoplasmic tails. Journal of Biological Chemistry, 271(37), 22315-22320.

Taylor, J. M., Mack, C. P., Nolan, K., Regan, C. P., Owens, G. K., \& Parsons, J. T. (2001). Selective expression of an endogenous inhibitor of FAK regulates proliferation and migration of vascular smooth muscle cells. Molecular and Cellular Biology, 21(5), 1565-1572.

Terpstra, V., Bird, D. A., \& Steinberg, D. (1998). Evidence that the lipid moiety of oxidized low density lipoprotein plays a role in its interaction with macrophage receptors. Proceedings of the National Academy of Sciences of the United States of 
America, 95(4), 1806-1811.

Thomas, J. W., Ellis, B., Boerner, R. J., Knight, W. B., White, G. C.,2nd, \& Schaller, M. D. (1998). SH2- and SH3-mediated interactions between focal adhesion kinase and src. The Journal of Biological Chemistry, 273(1), 577-583.

Thorne, R. F., Marshall, J. F., Shafren, D. R., Gibson, P. G., Hart, I. R., \& Burns, G. F. (2000). The integrins $\alpha 3 \beta 1$ and $\alpha 6 \beta 1$ physically and functionally associate with CD36 in human melanoma cells. Journal of Biological Chemistry, 275(45), 3526435275 .

Tsuboi, N., Asano, K., Lauterbach, M., \& Mayadas, T. N. (2008). Human neutrophil fcgamma receptors initiate and play specialized nonredundant roles in antibodymediated inflammatory diseases. Immunity, 28(6), 833-846.

Underhill, D. M., \& Goodridge, H. S. (2007). The many faces of ITAMs. Trends in Immunology, 28(2), 66-73.

Vadali, K., Cai, X., \& Schaller, M. D. (2007). Focal adhesion kinase: An essential kinase in the regulation of cardiovascular functions. IUBMB Life, 59(11), 709-716.

van Lent, P. L., Nabbe, K., Blom, A. B., Holthuysen, A. E., Sloetjes, A., van de Putte, L. B., et al. (2001). Role of activatory fc gamma RI and fc gamma RIII and inhibitory fc gamma RII in inflammation and cartilage destruction during experimental antigen-induced arthritis. The American Journal of Pathology, 159(6), 2309-2320.

Vidal, F., Colome, C., Martinez-Gonzalez, J., \& Badimon, L. (1998). Atherogenic concentrations of native low-density lipoproteins down-regulate nitric-oxidesynthase mRNA and protein levels in endothelial cells. European Journal of Biochemistry / FEBS, 252(3), 378-384.

Wang, Q., Xie, Y., Du, Q. S., Wu, X. J., Feng, X., Mei, L., et al. (2003). Regulation of the formation of osteoclastic actin rings by proline-rich tyrosine kinase 2 interacting with gelsolin. The Journal of Cell Biology, 160(4), 565-575. 
Ward, D., Williams, W. A., Schapiro, N. E., Christy, S. R., Weber, G. L., Salt, M., . . . Plopper, G. E. (2007). Focal adhesion kinase signaling controls cyclic tensile strain enhanced collagen I-induced osteogenic differentiation of human mesenchymal stem cells. MOLECULAR AND CELLULAR BIOMECHANICS, 4(4), 177.

Watson, J. M., Harding, T. W., Golubovskaya, V., Morris, J. S., Hunter, D., Li, X., et al. (2001). Inhibition of the calcium-dependent tyrosine kinase (CADTK) blocks monocyte spreading and motility. The Journal of Biological Chemistry, 276(5), 3536-3542.

Wei, W. C., Kopec, A. K., \& Tang, M. J. (2009). Requirement of focal adhesion kinase in branching tubulogenesis. J.Biomed.Sci, 16(5)

Weiner, T. M., Liu, E. T., Craven, R. J., \& Cance, W. G. (1993). Expression of focal adhesion kinase gene and invasive cancer. Lancet, 342(8878), 1024-1025.

Wiesner, P., Choi, S. H., Almazan, F., Benner, C., Huang, W., Diehl, C. J., et al. (2010). Low doses of lipopolysaccharide and minimally oxidized low-density lipoprotein cooperatively activate macrophages via nuclear factor kappa B and activator protein-1: Possible mechanism for acceleration of atherosclerosis by subclinical endotoxemia. Circulation Research, 107(1), 56-65.

Witztum, J.L., and Steinberg, D. (1995). The hyperlipoproteinemias. In Cecil Textbook of Medicine, L. Goldman and J.C. Bennett, Eds. (Philadelphia: W.B. Saunders), pp. 1090-1100.

Xie, Z., \& Tsai, L. H. (2004). Cdk5 phosphorylation of FAK regulates centrosomeassociated microtubules and neuronal migration. Cell Cycle, 3(2), 105-108.

Xiong, W. C., Macklem, M., \& Parsons, J. T. (1998). Expression and characterization of splice variants of PYK2, a focal adhesion kinase-related protein. Journal of Cell Science, 111(14), 1981-1991.

Yamada, Y., Doi, T., Hamakubo, T., \& Kodama, T. (1998). Scavenger receptor family 
proteins: Roles for atherosclerosis, host defence and disorders of the central nervous system. Cellular and Molecular Life Sciences : CMLS, 54(7), 628-640.

Yang, M. Y., Huang, C. N., Chan, K. C., Yang, Y. S., Peng, C. H., \& Wang, C. J. (2011). Mulberry leaf polyphenols possess antiatherogenesis effect via inhibiting LDL oxidation and foam cell formation. Journal of Agricultural and Food Chemistry, 59(5), 1985-1995.

Yesner, L. M., Huh, H. Y., Pearce, S. F., \& Silverstein, R. L. (1996). Regulation of monocyte CD36 and thrombospondin-1 expression by soluble mediators. Arteriosclerosis, Thrombosis, and Vascular Biology, 16(8), 1019-1025.

Yoshida, H., Quehenberger, O., Kondratenko, N., Green, S., \& Steinberg, D. (1998). Minimally oxidized low-density lipoprotein increases expression of scavenger receptor A, CD36, and macrosialin in resident mouse peritoneal macrophages. Arteriosclerosis, Thrombosis, and Vascular Biology, 18(5), 794-802.

Yu, X. H., Fu, Y. C., Zhang, D. W., Yin, K., \& Tang, C. K. (2013). Foam cells in atherosclerosis. Clinica Chimica Acta; International Journal of Clinical Chemistry, $424,245-252$.

Yu, Y., Ross, S. A., Halseth, A. E., Hollenbach, P. W., Hill, R. J., Gulve, E. A., et al. (2005). Role of PYK2 in the development of obesity and insulin resistance. Biochemical and Biophysical Research Communications, 334(4), 1085-1091.

Yuasa-Kawase, M., Masuda, D., Yamashita, T., Kawase, R., Nakaoka, H., Inagaki, M., et al. (2012). Patients with CD36 deficiency are associated with enhanced atherosclerotic cardiovascular diseases. Journal of Atherosclerosis and Thrombosis, 19(3), 263-275.

Zhang, Y., Hoppe, A. D., \& Swanson, J. A. (2010). Coordination of fc receptor signaling regulates cellular commitment to phagocytosis. Proceedings of the National Academy of Sciences of the United States of America, 107(45), 19332-19337. 
Zhao, J., \& Guan, J. L. (2009). Signal transduction by focal adhesion kinase in cancer. Cancer and Metastasis Reviews, 28(1), 35-49.

Zhao, J. F., Ching, L. C., Huang, Y. C., Chen, C. Y., Chiang, A. N., Kou, Y. R., et al. (2012). Molecular mechanism of curcumin on the suppression of cholesterol accumulation in macrophage foam cells and atherosclerosis. Molecular Nutrition \& Food Research, 56(5), 691-701.

Zhao, Z. Z., Wang, Z., Li, G. H., Wang, R., Tan, J. M., Cao, X., et al. (2011). Hydrogen sulfide inhibits macrophage-derived foam cell formation. Experimental Biology and Medicine (Maywood, N.J.), 236(2), 169-176.

Zheng, C., Xing, Z., Bian, Z. C., Guo, C., Akbay, A., Warner, L., et al. (1998). Differential regulation of Pyk2 and focal adhesion kinase (FAK). the C-terminal domain of FAK confers response to cell adhesion. The Journal of Biological Chemistry, 273(4), 2384-2389.

Zheng, Y., Xia, Y., Hawke, D., Halle, M., Tremblay, M. L., Gao, X., et al. (2009). FAK phosphorylation by ERK primes ras-induced tyrosine dephosphorylation of FAK mediated by PIN1 and PTP-PEST. Molecular Cell, 35(1), 11-25.

Zingg, J. M., Ricciarelli, R., \& Azzi, A. (2000). Scavenger receptors and modified lipoproteins: Fatal attractions? IUBMB Life, 49(5), 397-403. 